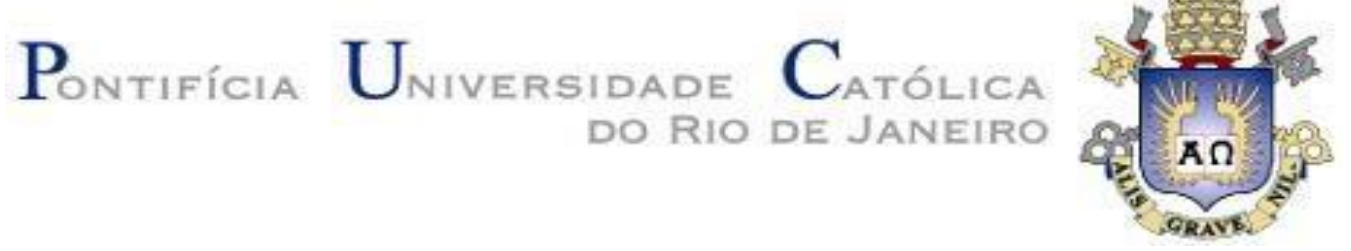

Conceição Santos Fernandes

DESENVOLVIMENTO E EVIDÊNCIAS DE VALIDADE DE UMA NOVA BATERIA INFANTOJUVENIL DE AVALIAÇÃO DE TEORIA DA MENTE

TESE DE DOUTORADO

Tese apresentada ao Programa de Pósgraduação em Psicologia da PUC-Rio como requisito parcial para obtenção do grau de doutor em Psicologia.

Orientadora: Prof ${ }^{\underline{a}}$ Helenice CharchatFichman

Rio de Janeiro

Março de 2019 
Conceição Santos Fernandes

\title{
DESENVOLVIMENTO E EVIDÊNCIAS DE VALIDADE DE UMA NOVA BATERIA INFANTOJUVENIL DE AVALIAÇÃO DE TEORIA DA MENTE
}

\begin{abstract}
Tese apresentada como requisito parcial para obtenção do grau de Doutor pelo Programa de Pós-Graduação em Psicologia (Psicologia Clínica) da PUC-Rio. Aprovada pela Comissão Examinadora.
\end{abstract}

Prof $^{\mathrm{a}}$ Helenice Charchat-Fichman

Orientadora

Departamento de Psicologia PUC-Rio

Profa Patricia de Souza Barros

Co-Orientadora

Universidade do Minho

Prof ${ }^{\text {C Cidiane Vaz Gonçalves }}$

Pontifícia Universidade Católica do Rio de Janeiro PUC-Rio

Profo Carlos Eduardo L. dos Santos Norte

Pontifícia Universidade Católica do Rio de Janeiro PUC-Rio

Profa Cleonice Alves Bosa Universidade Federal do Rio Grande do SulUFRGS

Prof ${ }^{a}$ Rosinda Martins Oliveira Universidade Federal do Rio de Janeiro-UFRJ

Rio de Janeiro, 21 de março de 2019. 
Todos os direitos reservados. É proibida a reprodução total ou parcial do trabalho sem autorização do autor, do orientador e da universidade.

\section{Conceição Santos Fernandes}

Graduação em Psicologia - Universidade do Estado do Rio de Janeiro (UERJ) 08/2002 - 03/2008. Mestrado em Psicologia Social PPGPS/Universidade do Estado do Rio de Janeiro (UERJ) 03/2009 03/2011.

Ficha Catalográfica

Fernandes, Conceição Santos

Desenvolvimento e evidências de validade de uma nova bateria infantojuvenil de avaliação de teoria da mente / Conceição Santos Fernandes ; orientadora: Helenice Charchat-Fichman ; co-orientadora: Patricia de Souza Barros. - 2019.

186 f. : il. color. ; $30 \mathrm{~cm}$

Tese (doutorado)-Pontifícia Universidade Católica do Rio de Janeiro, Departamento de Psicologia, 2019.

Inclui bibliografia

1. Psicologia - Teses. 2. Teoria da mente. 3. ToM. 4. Validação. 5. BToM. 6. TEA. I. Charchat-Fichman, Helenice. II. Barros, Patricia de Souza. III. Pontifícia Universidade Católica do Rio de Janeiro. Departamento de Psicologia. IV. Título. 


\title{
Agradecimentos
}

"O presente trabalho foi realizado com o apoio da Coordenação de Aperfeiçoamento de Pessoal de Nível Superior - Brasil (CAPES) - Código de Financiamento 001".

\author{
À PUC-Rio.
}

À Organização Governamental-Instituto Reação do Rio de Janeiro, pela parceria no desenvolvimento do trabalho.

À minha coorientadora, Patrícia Barros, por suas colaborações clínicas pertinentes e de grande relevância para a construção do instrumento.

A Bruno Biolchini, que produziu as imagens utilizadas no instrumento.

Às alunas que trabalharam com comprometimento, competência, cooperando significativamente com a coleta de minha pesquisa: Antonia Sigrist, Bábara França, Jana Garcia, Juliana Cozzolino, Laryssa Couto, Paola Alvarenga, Paulo Quérette, Sarah Araújo.

Aos professores que participaram da Comissão Examinadora.

Á minha família e amigos que confiam no meu crescimento profissional.

Rio de Janeiro, março de 2019. 


\section{Resumo}

Fernandes, Conceição Santos; Fichman, Helenice Charchat (Orientadora); Barros, Patricia de Souza (Coorientadora). Desenvolvimento e evidências de validade de uma nova bateria infanto-juvenil de avaliação de Teoria da Mente. Rio de Janeiro, 2019. Tese de Doutorado Departamento de Psicologia, Pontifícia Universidade Católica do Rio de Janeiro.

A teoria da mente (ToM) é definida como a habilidade de inferir estados mentais internos de outras pessoas. Há consenso na literatura de que ToM é um marcador sociocognitivo do Transtorno do Espectro autista-TEA. A testagem é realizada, em grande parte, a partir de um paradigma denominado falsa crença. Contudo, verifica-se a necessidade de instrumentos de avaliação mais apurados, que compreendam: a complexidade do constructo, a relação com outros domínios cognitivos como funções executivas. O objetivo deste trabalho foi desenvolver e verificar evidências de validade de um novo instrumento que avalie os diferentes domínios de ToM para auxílio de diagnóstico em crianças com TEA. Este estudo foi registrado no Comitê de Ética em Pesquisa da Pontifícia Universidade Católica-PUC-Rio. O projeto foi dividido em quatro estudos, que englobavam desde uma revisão bibliográfica sobre as tarefas de ToM utilizadas em avaliações de crianças com diagnóstico de TEA, até mostrar evidências de validade do instrumento de nominado Bateria de avaliação em Teoria da Mente-BToM. Os resultados mostraram que BToM possui evidências de validade de conteúdo e de constructo, bem como de precisão. Além disso, identifica tarefas de "Estados Mentais" e "Verbalizações", como possíveis marcadores sociocognitivos no diagnóstico de fenótipos mais leves do TEA.

\section{Palavras-Chave}

Teoria da Mente; BToM; funções executivas; TEA; marcador sociocognitivo. 


\begin{abstract}
Fernandes, Conceição Santos; Fichman, Helenice Charchat (Advisor); Barros, Patricia de Souza (Co-advisor). Development and validity evidence of a new theory of mind battery for children. Rio de Janeiro, 2019. Tese de Doutorado - Departamento de Psicologia, Pontifícia Universidade Católica do Rio de Janeiro.
\end{abstract}

Theory of Mind (ToM) is defined as the ability to infer other's internal mental states. There is a consensus in the literature that ToM is a sociocognitive marker of Autism Spectrum Disorder-ASD. Performance is assessed in majority from false belief paradigm. However, there is a need for more accurate assessment tools, which include: complexity of the construct, interface with other cognitive domains as executive functions. The purpose of this work was to develop and verify validity's evidences of a new instrument who evaluates differents ToM domains for diagnostic support in children with ASD. This study was registered in the Research Ethics Committee of Pontifical Catholical University of Rio de Janeiro-PUC-Rio. The project was divided into five studies, ranging from a literature review of ToM tasks used in assessments of ASD children, to show validity evidences of the instrument nominated Battery of Theory of Mind-BToM. The results showed BToM has evidence of content and construct validity as well as accuracy. In addition, it identifies "Mental States" and "Verbalizations" tasks as possible sociocognitive markers on diagnoses of lighter ASD phenotypes.

\title{
Keywords
}

Theory of mind; BToM; Executive Functions; ASD; sociocognitive markes. 


\section{Sumário}

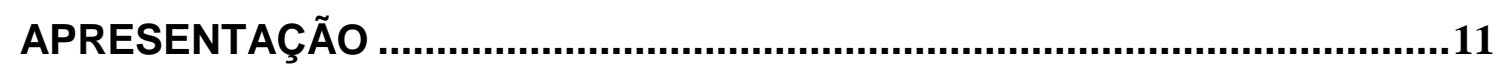

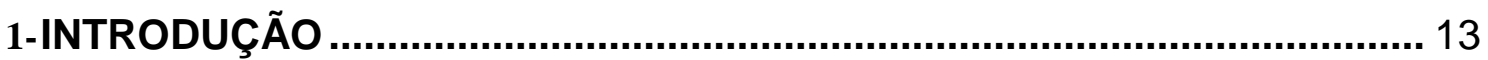

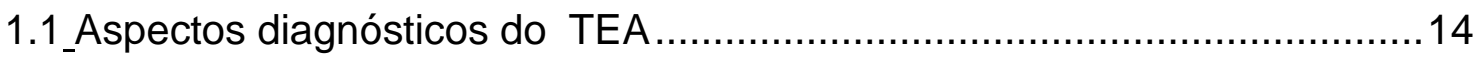

1.2- As relações entre funções executivas e ToM no perfil neuropsicológico do

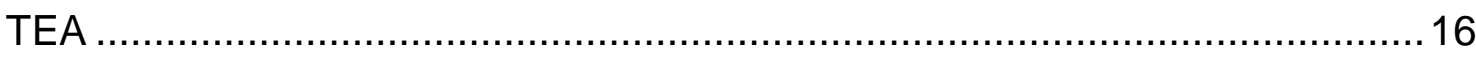

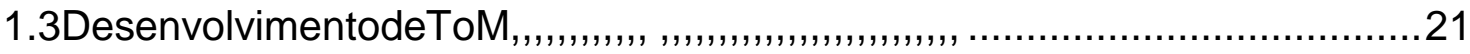

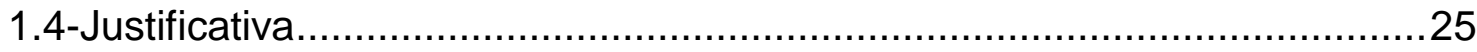

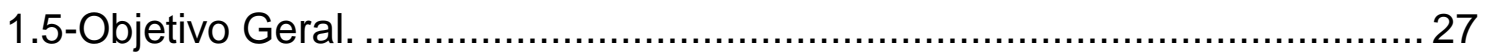

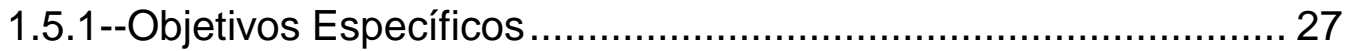

2- CATEGORIZAÇÃO DE DOMÍNIOS EM TAREFAS DE TEORIA DA MENTE-

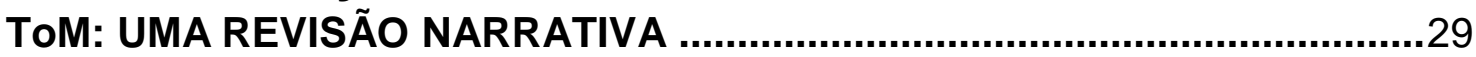

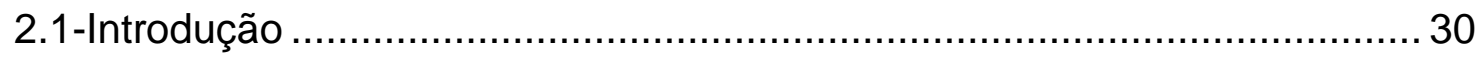

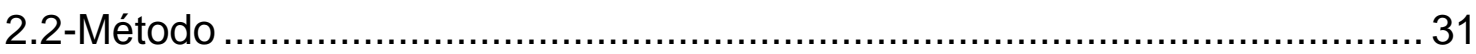

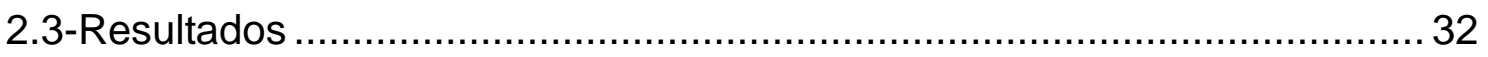

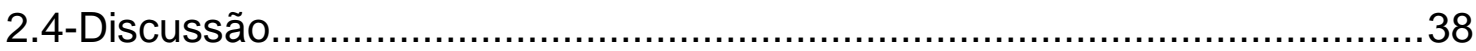

3- EVIDÊNCIAS DE DIAGNÓSTICO DIFERENCIAL ENTRE TRANSTORNO DO ESPECTRO AUTISTA (TEA) E TRANSTORNO DO DESENVOLVIMENTO INTELECTUAL (TDI): ANÁLISE DE CASOS .................................................. 41

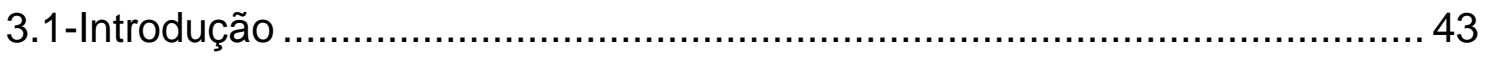

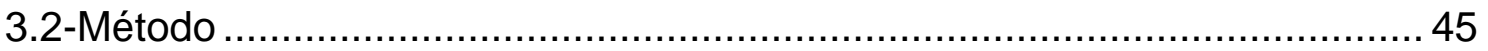

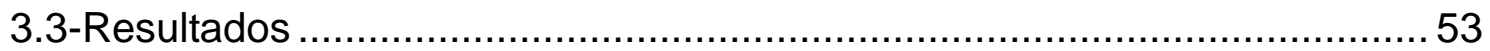

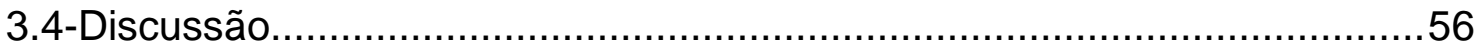

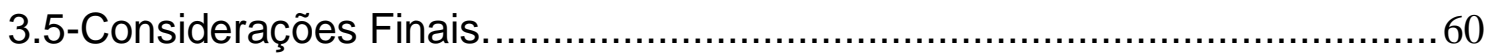


4- DESENVOLIVIMENTO DE UMA BATERIA DE TEORIA DA MENTE (BTOM)

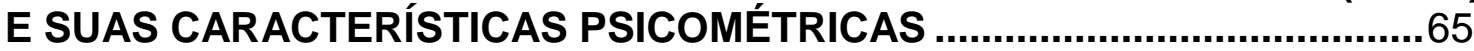

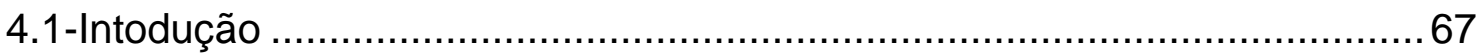

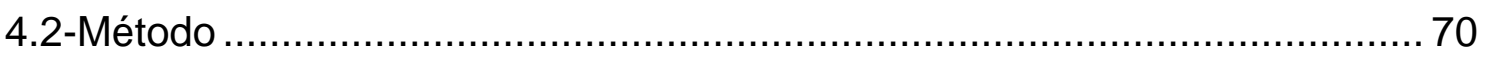

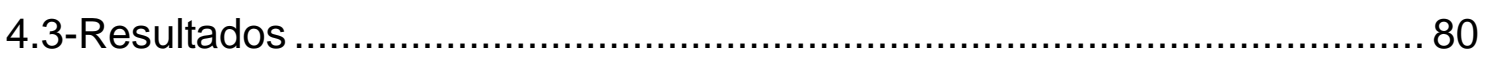

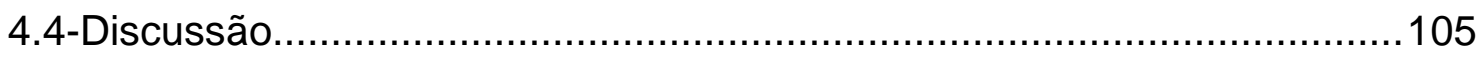

4.5-Considerações Finais......................................................................113

5- MARCADORES SOCIOCOGNITIVOS NO DIAGNÓSTICO DO TEA DE ALTA HABILIDADE: UM ESTUDO DE VALIDADE DE CRITÉRIO DA BToM 115

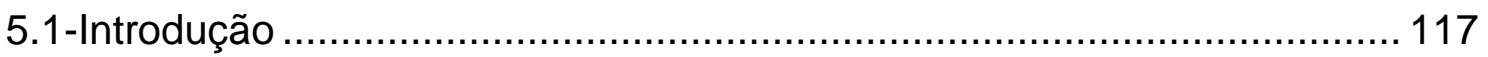

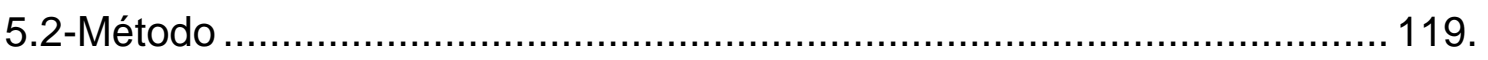

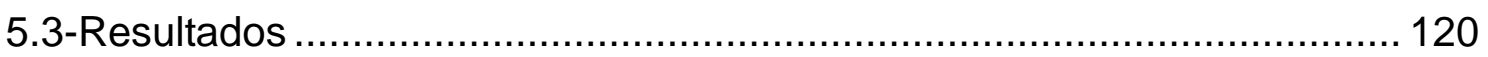

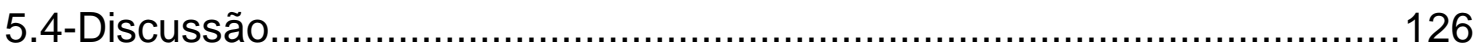

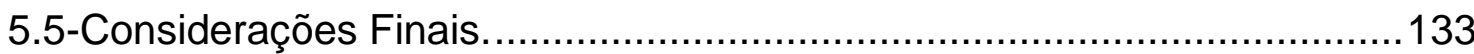

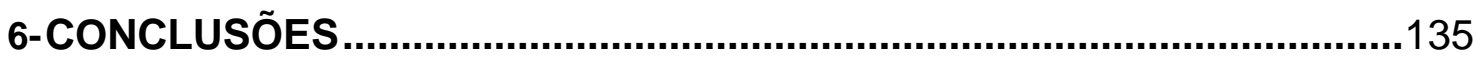

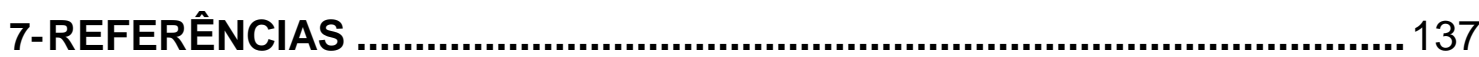

APÊNDICE A: Aula para treinamento dos juízes que validaram o conteúdo

APÊNDICE B: Questionário sóciodemográfico e

clínico.

APÊNDICE C: Termos de Consentimento Livre e

Esclarecido.

APÊNDICE D: Aula para treinamento dos juízes de precisão do instrumento BToM.

APÊNDICE E: Folha de Registro e apuração de BToM. 
ANEXO A: Texto explicativo sobre Teoria da Mente e categorizações... 


\section{APRESENTAÇÃO}

O interesse neste tema surgiu pela aproximação, como psicóloga clínica, de transtornos do neurodesenvolvimento, em especial Transtorno do Espectro Autista (TEA). Diante disso, dois aspectos se destacaram: (1) Teoria da Mente (ToM) como um marcador clínico do TEA; (2) observação de prejuízos em ToM em outros diagnósticos do desenvolvimento infantojuvenil.

Com o debruçar sobre a teoria, constatou-se que ToM é um constructo mais complexo do que sua definição conceitual, além de ser extremamente relevante no desenvolvimento cognitivo infantil. E é neste cenário que ele atravessa e é atravessado por outras funções cognitivas complexas, dentre elas: as funções executivas.

Em seguida, buscou-se entender o constructo de ToM em uma perspectiva modular, que entende que a aquisição de habilidades depende de maturação, e, portanto, as habilidades vão se sucedendo; bem como a conversa teórica estabelecida com outros componentes de funções executivas: memória de trabalho, controle inibitório e flexibilidade cognitiva. Ressalta-se aqui que estes componentes, além de se destacarem na literatura de ToM, são caracterizadores cognitivos do TEA e de outros diagnósticos do neurodesenvolvimento, constituindo um provável endofenótipo dessas patologias.

No processo de compreensão de ToM e seu impacto diagnóstico, evidenciaram-se pontos críticos nos modelos de avaliação utilizados. Grande parte desses modelos são tarefas testadas em grupos clínicos, com reduzido controle cognitivo e metodológico; geralmente são escolhidas tarefas de falsas crenças, por serem o padrão-ouro. Todavia, este modelo não abrange todo o constructo de ToM. Outra tendência observada é o uso de múltiplas tarefas, sendo o padrão mais visto a realização de tarefas repetidas do mesmo modelo ou paradigma (falsa crença), ou uma compilação de tarefas, com diferentes modelos, mas com pouca sistematização teórica entre as mesmas.

Diante do exposto, o olhar clínico sobre ToM como um marcador clínico do TEA estreitou-se ao interesse acadêmico quanto ao constructo sociocognitivo e aos modelos de avaliação utilizados. Ambos convergiram para a construção de um instrumento de avaliação de ToM, que abrange múltiplos aspectos do constructo, 
baseados na teoria de desenvolvimento. O instrumento construído compreende aspectos do constructo em níveis diferentes de dificuldade, com controle de possíveis variáveis intervenientes.

A presente tese contempla cinco artigos desenvolvidos no doutorado. Inicia-se com uma introdução, contemplando os principais aspectos da fundamentação teórica recrutada ao longo dos capítulos. A seguir, o primeiro capítulo traz uma revisão narrativa de tarefas de avaliação de ToM em crianças com TEA. O segundo capítulo apresenta o modelo piloto do instrumento apartir de casos clínicos, comparando padrões de desempenho de ToM e funções executivas em dois diagnósticos do neurodesenvolvimento: TEA e transtorno do déficit intelectual (TDI). O terceiro capítulo apresenta a validade de conteúdo, considerando a construção do instrumento, análise de juízes e de cluster hierárquico entre os itens do instrumento; evidências de precisão do instrumento, a partir de análises de correlação entre correções de diferentes avaliadores; além de validade de constructo, a partir de análise de associação com padrão-ouro verificado na literatura (tarefa Sally-Anne). O quinto artigo traz um estudo de validade de critério do instrumento, a partir da comparação entre um grupo saudável (sem diagnóstico) e um grupo com TEA. Por fim, há uma conclusão geral, com considerações acerca dos resultados obtidos, as limitações do trabalho e perspectivas de estudos futuros. 


\section{1-INTRODUÇÃO}

A teoria da mente (ToM) (Baron-Cohen, Leslie \& Frith,1985; Premack \& Woodruff, 1978) conceitualmente é definida como a habilidade de inferir estados mentais internos de outras pessoas, como intenções, pensamentos, crenças e desejos (O’Connor \& Evans, 2019; Sanvicente-Vieira, Brietzke \& GrassiOliveira, 2012). Em outras palavras, significa ter acesso aos pensamentos, desejos e emoções próprios e os de outras pessoas (Miller, 2009).

Apesar desta definição, ToM vai se desdobrando em múltiplas facetas (Flavell, Miller \& Miller, 1999). Elas variam em termos de complexidade durante todo o processo de desenvolvimento infantil. Com isto, o constructo de ToM se mostra bem mais intrincado do que sua definição conceitual.

Os déficits em ToM frequentemente são descritos na literatura do Transtorno do Espectro Autista (TEA). Esses prejuízos são relacionados a déficits na interação social (Scheeren, Rosnay, Koot \& Begeer, 2013; Silliman et al., 2003; Hutchins, Prelock \& Chace, 2008), como aqueles pertinentes à habilidade de empatia: compartilhamento de emoções e comportamentos altruístas (Brown, Thibodeau, Pierucci \& Gilpin, 2017); ou mesmo à comunicação verbal (Astington, 1998) e integração com pares (Smogorzewska, Szumski \& Grygiel, 2018).

Já o modelo de testagem de ToM, no âmbito de pesquisas com TEA, são realizados, em grande parte, a partir de um paradigma denominado falsa crença. Nele, o sujeito avaliado deve identificar diferentes crenças ou perspectivas, a partir de ações entre personagens. Um dos exemplos clássicos é a tarefa SallyAnne, onde há 2 personagens (Sally e Anne). Sally deixa a bola em sua cesta, coloca uma tampa e sai. Anne muda a posição da bola de Sally e a transfere para sua caixa com tampa. Sally retorna à sala. $\mathrm{O}$ sujeito deve identificar onde ela vai procurar a sua bola. Neste caso, há perspectivas diferentes, pois, uma das personagens não estava assistindo à mudança de localização. Logo, ela não deve saber onde o objeto realmente está; ela ainda acredita que ele está no lugar onde deixou antes de sair da sala (Baron-Cohen, Leslie \& Frith, 1985). 
Entretanto, há discussões quanto ao uso deste paradigma. As críticas incluem desde o aspecto multifacetado de ToM (Muris et al., 1999), até diferentes formas de administração, como a existência de diferentes apresentações da mesma tarefa (Van Buijsen, Hendriks, ketelaars \& Verhoeven, 2011). Klin (2000), por exemplo, discutiu em seu artigo que sujeitos com TEA, de alto funcionamento, usariam recursos de linguagem para resolver problemas propostos pelas tarefas de ToM, especialmente os de falsa crença, questionando a circunscrição excessiva que as tarefas de falsa crença dão aos problemas sociais. Com isso, os autores estão mais propensos ao uso de tarefas múltiplas, que acessem diferentes aspectos de ToM e com diferentes modelos de apresentação (Hale \& Tager - Flusberg, 2005; Muris et al., 1999; Schaller \& Rauh, 2017).

A pluralidade do constructo e as críticas aos paradigmas se evidenciam quando compreendidos no contexto do TEA, dada a diversidade intrínseca ao próprio diagnóstico. Por um lado, a literatura aponta consistentemente para prejuízos em ToM e descreve amplamente o paradigma de falsa crença em avaliações de TEA (Baron-Cohen et al., 1985; Buitelaar, Wees, Swaab-Barneveld \& van der Gaag, 1999). Por outro lado, autores mostram que o desempenho de ToM neste diagnóstico também é influenciado por outras variáveis, como: (1) outros aspectos da cognição (Durrleman \& Franck, 2015; Yang, Zhou, Yao, Su \& McWhinnie, 2009); (2) pouca variabilidade, com maior frequência de paradigmas de falsas crenças, como a tarefa Sally \& Anne, tida como padrão-ouro por alguns autores em contextos de pesquisa (Korkiakangas, Dindar, Laitila \& Kärnä, 2016).

Discussões importantes surgem na esfera do constructo de ToM, assim como quando o constructo está associado ao diagnóstico de TEA. Nesse contexto, devem-se considerar as multifacetas do constructo; a complexidade do diagnóstico de TEA; além da contextualização de ToM no desenvolvimento cognitivo infantil.

\section{1-Aspectos diagnósticos do TEA}

Segundo o Manual Diagnóstico para Transtornos Mentais - DSM 5 (2013), o diagnóstico de TEA é sustentado por dois eixos: 1) os déficits sociais e de comunicação e 2) comportamentos repetitivos e restritivos. Além disso, o DSM 5 (2013) define que a gravidade é determinada pela variação de sintomas. São 
descritos três níveis: Nível 1- Requer suporte; Nível 2- Requer suporte substancial; Nível 3- Requer extremo suporte.

Nível I - Na ausência de apoio, há prejuízo social notável; dificuldades para iniciar interações, por vezes parecem apresentar um interesse reduzido por estas; há tentativas malsucedidas no contato social, além da dificuldade de organização, planejamento e certa inflexibilidade de comportamentos.

Nível II - Exige apoio substancial, havendo prejuízos sociais aparentes, limitações para iniciar e manter interações, inflexibilidade de comportamento e dificuldade para lidar com mudanças.

Nível III - Exige muito apoio substancial, havendo déficits graves nas habilidades de comunicação social, inflexibilidade de comportamento e extrema dificuldade com mudanças. Assim, quanto menor o grau de comprometimento do nível, melhor tende a ser o prognóstico do paciente.

Houve algumas mudanças no diagnóstico de TEA ao longo dos anos. No DSM IV-TR, por exemplo, as características comuns eram agrupadas em subgrupos diagnósticos. Os subtipos diagnósticos não se enquadram mais, e os critérios são associados a padrões sociais inadequados, que envolvem comunicação e padrões repetitivos e estereotipados do comportamento. O manual também destaca influências de variáveis cognitivas como déficit intelectual e linguagem (Constantino \& Charman, 2016), que poderiam apresentar-se como comorbidades ao diagnóstico.

Dentre essas variáveis cognitivas, encontram-se o perfil sociocognitivo e neuropsicológico como: (1) alterações em Teoria da Mente - ToM (Baron-Cohen et al., 1985), (2) inadequação de comunicação e interação social (Simms, 2017) e (3) funções executivas, em especial déficits em flexibilidade cognitiva (Leung \& Zakzanis, 2014), memória de trabalho (Faja \& Dawson, 2014) e controle inibitório (Schmitt, White, Cook, Sweeney \& Mosconi, 2018). Mas, apesar da consistência, esses perfis de prejuízos psicológicos e neuropsicológicos também são encontrados em outros diagnósticos (Alloway, Seed \& Tewolde, 2016).

Essas nuances cognitivas e funcionais mostram que, apesar da retirada dos subtipos, mantém-se a variabilidade na apresentação do fenótipo no TEA. Permanecem os diferentes níveis de gravidade em função de suas características, que podem estar associados a padrões cognitivos de rebaixamento intelectual e/ou 
ao atraso de linguagem, bem como a padrões de funções executivas. Além da variabilidade, esses padrões insinuam a convergência com outros diagnósticos de neurodesenvolvimento infantojuvenil (Pedersen et al., 2016; Yates \& Le Couter, 2016).

\section{2- As relações entre funções executivas e ToM no perfil neuropsicológico do} $\underline{\text { TEA }}$

Cognitivamente, além do déficit intelectual e da linguagem, têm se destacado na literatura perfis neuropsicológicos, que discutem ToM (Baron-Cohen et al., 1985), mas também funções executivas (Demetriou et al., 2017). O constructo de funções executivas compreende diversas habilidades de gerenciamento do pensamento e da ação (Diamond, 2013), tais como: planejamento, monitorização, memória de trabalho, controle inibitório e flexibilidade cognitiva.

No modelo de funções executivas, salientam-se os componentes de memória de trabalho, controle inibitório e flexibilidade, visto que estes são recrutados em diversos processos/operações ou funções executivas (Martin \& Failows, 2010; Myake et al. 2000). A literatura neuropsicológica mais recente do TEA também tem convergido para o estudo destes mesmos componentes: memória de trabalho (Barendse, Schreuder, Thoonen, Hendriks, Kessels, Backes, Aldenkamp \& Jansen, 2018; Miller et al., 2015), controle inibitório (Schmitt, et al., 2018) e flexibilidade cognitiva (Leung e Zakzanis, 2014).

O modelo de memória de trabalho utilizado atualmente é o proposto por Baddeley (2012). Neste modelo, a memória de trabalho tem um papel de armazenador e gerenciador de informações para uso on-line. Há um executivo central (gerencia as demandas e o recrutamento da atenção para tais), a alça de trabalho fonológica (armazenador de informações fonológicas), a alça visuoespacial (armazenador de informações visuoespaciais, e, por fim, o buffer episódico (armazenador e integrador de informações manipuladas na memória de trabalho). A memória de trabalho é de extrema relevância para o raciocínio fluido, que significa o gerenciamento de múltiplas demandas de resolução de problemas novos e que, portanto, exige a regulação de necessidades internas (próprio sujeito) 
e externas (do outro/ambiente). E é justamente neste cenário onde se encontra o raciocínio ou a cognição social (Barendsen et al., 2013).

Já o controle inibitório é considerado amplamente como a capacidade de inibir respostas automáticas em favor de novas respostas. Entretanto, ele também se abre como um constructo guarda-chuva, envolvendo: controle de interferências, inibição cognitiva, comportamental e motivacional. O controle de interferências seria a inibição de uma resposta preponderante motora ou cognitiva (ex.: como visto no paradigma stroop e stop-signal); a inibição cognitiva seria a supressão de pensamentos para proteger a memória de trabalho e a atenção, isto é, suprimir ideias na realização de outras tarefas (p.ex., resistência a distratores, que aparecem junto com o estímulo-alvo ou resistência a interferências de uma outra aprendizagem); a inibição comportamental seria a inibição de respostas socialmente inadequadas, como na tarefa go no go; a inibição motivacional envolve a regulação de respostas à novidade e aos reforçadores (Diamond, 2013; Nigg, 2000).

A flexibilidade cognitiva envolve mudança de perspectiva espacial, mudança de perspectiva mental e mudança da perspectiva mental em relação ao outro (Diamond, 2013), ou seja, envolve a capacidade em se deslocar cognitivamente frente a diferentes tarefas e demandas. Alguns autores consideram que esta função depende de outros processos, que seriam: memória de trabalho e controle inibitório (Diamond, 2013).

Em princípio, a flexibilidade cognitiva talvez seja o componente executivo que mais se relacione com os critérios nosológicos do TEA (DSM 5, 2013; Simms, 2017). Ela remete à ideia de comportamentos repetitivos, estereotipados e mesmo à inadequação social, descritos no DSM 5 (2013). Leung e Zakzanis (2014), em uma revisão sistemática, avaliaram testes neuropsicológicos e o subteste de flexibilidade de uma escala comportamental (Brief). Na escala, a flexibilidade se apresenta como marcador clínico para o espectro. Porém, os autores discutem que nem sempre a rigidez é detectada como um marcador uniforme quando testada em paradigmas mais formais (testes neuropsicológicos) e menos comportamentais. Uma das hipóteses seriam os diferentes modelos de tarefas utilizados, em que alguns podem recrutar mais ou menos aspectos de memória de trabalho e controle inibitório. 
Miller et al., (2015), por exemplo, discutem que a dificuldade observada em tarefas de set shifting, ou flexibilidade, estaria associada a prejuízos na sustentação de uma nova regra que redirecione o comportamento. Neste caso, sujeitos com TEA tenderiam a voltar para comportamentos de preferência, por não conseguir manipular uma nova regra e, com isso, redirecionar sua ação. Este estudo também constata a inconsistência da inflexibilidade cognitiva e comportamental do TEA, pertinentes ao estilo de tarefa de set shifting, que podem envolver maior ou menor demanda da memória de trabalho.

Alguns estudos também apontam para dificuldade de memória de trabalho visuoespacial no TEA, essencial para o processamento de informações afetivas e do mundo social (Barendse et al., 2018). Logo, sujeitos com TEA perceberiam as cenas visuais por detalhes e não como um todo integrado (Mammarella, Giofrè, Caviola, Cornoldi \& Hamilton, 2014). Em seu estudo, Mammarella et al. (2014) verificaram que crianças com TEA têm processamento visual baseado no detalhe. Entretanto, haveria uma assimetria em função de diferentes conteúdos, pois esta fragmentação não se daria com manipulação de objetos, como construção de blocos, mas sim quando envolve a semântica ou a compreensão de significados em contextos visuais.

Quanto ao controle inibitório, existem diferenças de resultados na literatura. Alguns autores encontram prejuízos de controle inibitório em TEA, já outros não encontram diferenças significativas entre grupos. Christ, Holt, White e Green (2007) usaram múltiplas tarefas de controle inibitório e obtiveram resultados diferentes. Eles observaram o desempenho intacto de TEA em tarefas que avaliam respostas preponderantes, como o paradigma STROOP. Por outro lado, avaliaram maior dificuldade de TEA quando se trata de resistência a distratores visuais (flanker interference task) e tarefas go no go, onde os pacientes cometem mais erros na tentativa go do que os controles. Christ, Bodner e Miles (2011) também oferecem dados para um modelo múltiplo de controle inibitório. Eles encontraram desempenho intacto na inibição de resposta preponderante e na resistência proativa (capacidade de resistir a intrusões da memória), mas não na resistência a distratores visuais (não conseguiriam suprimir respostas visuais irrelevantes, quando eles aparecem juntos). 
Schmitt et al. (2018) realizaram um estudo com 121 indivíduos com TEA e 76 controles. A idade variava de 5 a 28 anos, e foi utilizado um paradigma stopsignal. Os autores encontram os seguintes resultados: (1) o grupo com TEA apresentou maior prejuízo em atrasar respostas comportamentais em situações de incerteza, porém eles não apresentam a mesma dificuldade em parar diante de um sinal de stop; (2) a capacidade de atrasar respostas em situação de incerteza diminui com o aumento da demanda da tarefa, ou seja, quanto mais longo o período da incerteza (escolha de respostas), menor a capacidade de controle inibitório; (3) na adolescência haveria maior dificuldade em controle inibitório.

Os resultados desses estudos convergem para a ideia do controle inibitório como um constructo guarda-chuva. Sendo assim, alguns aspectos do controle inibitório podem estar comprometidos em TEA, enquanto outros não estariam. No caso, estaria preservada a inibição de resposta preponderante que, no modelo de Nigg (2000), seria o controle de interferências. Por outro lado, haveria prejuízos em aspectos da inibição cognitiva (supressão de distratores que aparecem ao mesmo tempo) e na inibição comportamental (atraso de respostas em situações de incerteza). Pode haver também impacto da memória de trabalho, já que se verifica, em um dos artigos, redução da capacidade em função de aumento de demanda e quando há mais de um estímulo a ser escolhido.

Além disso, a literatura tem apontado relações diretas entre ToM e funções executivas. A direção em que ocorrem ainda é bastante discutida. Em alguns momentos, hipotetiza-se sobre a importância para a gravidade de sintomas de TEA (Joseph \& Tager-Flusberg, 2004). Kouklaria, Tsermentseli e Auyeungb (2018) encontram relações diferentes nos subcomponentes de funções executivas e ToM. Os autores verificam em seus resultados associações entre memória de trabalho e ToM. Já os aspectos de controle inibitório e flexibilidade estariam ligados à comunicação social, considerada por eles como fluência verbal, coerência, contexto, conversação estereotipada, iniciação inapropriada e rapport.

Kimhi, Shoam-Kugelmas, Bem-Artzi, Bem-Moshe e Bauminger-Zviely (2014), em um estudo com 59 crianças pré-escolares com QI Médio (29 TEA e 30 típicos), avaliaram os seguintes aspectos de funções executivas: planejamento, flexibilidade, bem como tarefas de falsa crença de ToM, localização inesperada e conteúdo inesperado com predição de emoção (há troca de conteúdo e deve-se 
identificar a emoção antes de e após ver o conteúdo). As análises mostraram melhor desempenho de crianças típicas em FE e ToM.

Austin, Groppe \& Elsner, (2014) realizaram um estudo longitudinal com crianças de 6-12 anos por um ano. Quando avaliaram ToM e funções executivas nesse período, verificaram relações entre ToM para dois subcomponentes de funções executivas: deslocamento atencional e memória de trabalho. Contudo, não encontraram o mesmo para inibição. Constataram também diferenças deste componente em idade escolar e pré-escolar, onde haveria mais impacto da inibição na idade pré-escolar do que escolar. Para os autores, isso poderia ocorrer devido aos pré-escolares ainda estarem desenvolvendo habilidades inibitórias e ao fato de as tarefas de falsa crença de $1^{a}$ ordem demandarem mais de controle inibitório do que tarefas de falsa crença de $2^{\mathrm{a}}$ ordem, usadas no estudo longitudinal.

Por outro lado, Yang et al. (2009) compararam grupos de TEA, crianças típicas e Transtorno do Déficit de Atenção e Hiperatividade-TDAH, quanto a ToM e funções executivas, com idade variando de 3 a 15 anos. Utilizou paradigma stroop, paradigma de flexibilidade, de memória visuoespacial e avaliação de funcionamento global. Para avaliar ToM utilizaram tarefas de distinção entre aparência e realidade, de localização inesperada (baseada em Sally-Anne) e conteúdo inesperado. Encontraram correlação apenas do controle inibitório com as tarefas de ToM.

Com a análise destes estudos, deve-se ter em conta a qualidade das tarefas de ToM e a variação da idade. Os autores avaliam pré-escolares e escolares ao mesmo tempo, além disso as tarefas de ToM variam pouco e são referentes a domínios iniciais (distinção entre aparência e realidade) ou de falsa crença de $1^{\text {a }}$ ordem, que demandam de fato mais recursos de controle de interferência para uma resposta adequada. Logo, o impacto da função inibitória pode ser explicado pelas características do desenvolvimento cognitivo dos pré-escolares; e/ou quais recursos cognitivos são recrutados, dependendo do modelo das tarefas ou do estágio de ToM avaliado. Já o impacto de memória de trabalho e do deslocamento (flexibilidade) parece ser mais consistente em ToM. De qualquer forma, a 
avaliação de ToM deve considerar outros aspectos cognitivos em seu desempenho, bem como no seu desenvolvimento.

\section{3- Desenvolvimento de ToM}

Quando descrita em termos modulares, ToM consiste de diferentes níveis. Para Flavell et al., (1999) existem cinco postulados de desenvolvimento ToM. Os três primeiros estágios seriam: $1^{\circ}$ Adotar o conceito de mente; $2^{\circ}$ A mente tem conexões com o mundo físico, e $3^{\circ} \mathrm{A}$ mente separada do mundo físico. O quarto seria a teoria da mente propriamente dita (falsas crenças), e o quinto estágio seria a teoria da mente mais madura, representada pelas crenças falsas de segunda ordem (Muris et al., 1999).

Dentro destes domínios de ToM, encontram-se habilidades como intencionalidade, distinção entre aparência e realidade; reconhecimento de emoções; tomada de perspectiva visual de nível 1 e 2; uso de linguagem emocional descritiva; compreensão e capacidade de identificar desejos e intenções (Flavell, 1999; Flavell, Everett, Croft \& Flavell, 1981; Flavell, Flavell, Green \& Wilcox, 1980; Flavell, Flavell \& Green, 1987).

Essas habilidades têm relações entre si, mas, na descrição do desenvolvimento de cada uma, nem sempre são linearmente dependentes. Algumas ocorrem de forma simultânea e, ainda assim, não são dependentes. Outras, se desenvolvem em momentos etários diferentes, mas dependem de uma ou mais habilidades anteriores.

Um exemplo é a capacidade de entender um paradigma de falsa crença. Flavell (1999) mostra uma relação da falsa crença com a mudança de perspectiva visual e a habilidade de entender perspectivas visuais diferentes. Mas em nenhum momento remete à necessidade de reconhecer emoções. Em outra palavras, o autor discute que pode haver conexões entre a distinção de aparência x realidade e tomada de perspectiva do nível 2 , na origem da habilidade de falsa crença, (perceber que o mesmo objeto pode ser entendido de formas diferentes por pessoas diferentes), apesar de não conseguir explicitar como essas conexões, de fato, se dariam (Flavell et al., 1987). Outros exemplos são a habilidade de fingir, 
derivada da distinção de aparência e realidade; a tomada de perspectiva nível 2, derivada da tomada de perspectiva nível 1 (Flavell, 1999; Flavell et al., 1987). Cronologicamente, essas habilidades podem ser pensadas da seguinte forma:

\begin{tabular}{|c|c|c|}
\hline $\begin{array}{c}\text { Idade } \\
\text { aproximada }\end{array}$ & Habilidade & Definição \\
\hline 12 meses & Intencionalidade & $\begin{array}{l}\text { Pessoas se diferem de objetos; como as } \\
\text { pessoas se relacionam com objetos. }\end{array}$ \\
\hline 18-24 meses & $\begin{array}{l}\text { distinção entre aparência } \mathrm{e} \\
\text { realidade de objetos }\end{array}$ & $\begin{array}{l}\text { Ato de conseguir dar função a objetos } \\
\text { próximos em semelhança e depois } \\
\text { distantes em aspectos perceptuais. }\end{array}$ \\
\hline 18-24 meses & $\begin{array}{l}\text { Tomada de perspectiva visual } \\
\text { simples (Nível 1) }\end{array}$ & $\begin{array}{l}\text { Identificação de que uma pessoa é } \\
\text { capaz de ver algo ou não, dependendo } \\
\text { se algo está bloqueando ou não sua } \\
\text { visão. }\end{array}$ \\
\hline$<24$ meses & Reconhecimento de emoções & $\begin{array}{l}\text { Discriminação de expressões } \\
\text { emocionais faciais. }\end{array}$ \\
\hline $\begin{array}{l}24 \text { meses-36 } \\
\text { meses }\end{array}$ & Linguagem emocional descritiva & $\begin{array}{l}\text { Nomeação das expressões emocionais } \\
\text { identificadas. }\end{array}$ \\
\hline $\begin{array}{ll}3,6 & \text { meses-4 } \\
\text { anos } & \end{array}$ & $\begin{array}{l}\text { Distinção entre intenções e } \\
\text { desejos }\end{array}$ & $\begin{array}{l}\text { Percepção de que as pessoas não só } \\
\text { agem por desejos, mas que elas } \\
\text { planejam uma ação (antecipação). }\end{array}$ \\
\hline $3-5$ anos & $\begin{array}{l}\text { Tomada de perspectiva visual } \\
\text { complexa (Nível 2) }\end{array}$ & $\begin{array}{l}\text { A criança identifica que o mesmo } \\
\text { objeto pode ser percebido de formas } \\
\text { diferentes por diferentes pessoas, } \\
\text { dependendo das circunstâncias de } \\
\text { visualização (diferentes posições). }\end{array}$ \\
\hline 4-5 anos & Falsas crenças & $\begin{array}{l}\text { Identificação das crenças de outro, a } \\
\text { partir de situações incongruentes, ou } \\
\text { seja, a partir de perspectivas visuais } \\
\text { diferentes. Definição se aproxima de } \\
\text { tomada de perspectiva visual e } \\
\text { distinção entre aparência e realidade. }\end{array}$ \\
\hline 4-5 anos & $\begin{array}{l}\text { Aprimoramento da habilidade de } \\
\text { fingir }\end{array}$ & $\begin{array}{l}\text { Capacidade de faz de conta expandida, } \\
\text { com uso de objetos ambíguos e } \\
\text { invisíveis e consciência desse uso. }\end{array}$ \\
\hline
\end{tabular}

O desenvolvimento destas habilidades também interage com outras funções cognitivas, como aspectos de linguagem (Tomasello, 2003), atenção compartilhada e o constructo de funções executivas (Tonietto, Wagner, Trentini, Sperb \& Parente, 2011). Tomasello (2003) agrega o conceito de intencionalidade, ou seja, a capacidade de diferenciar pessoas de objetos e relacioná-las a eles. $\mathrm{Na}$ proposta de Tomasello (2006), isto se daria em contextos de atenção compartilhada, isto é, no compartilhamento da atenção entre a criança, o objeto e 
outra pessoa, que envolve olhar na direção do olhar do outro; observar a face do outro, quando estão em uma situação ambígua; mostrar e compartilhar objetos com outros (Machado \& Bello, 2015). Flavell (1999) cita esse mesmo conceito como um componente que permeia ToM.

Outros autores propõem a divisão de ToM em um sistema implícito e explícito. Esta divisão pode deixar mais claro em que ponto há interface com os demais domínios da cognição. O sistema implícito seria aquele mais automático, mais independente de outros recursos cognitivos. Ele seria responsável por perceber e registrar as relações existentes entre agentes e objetos, em termos de perspectiva. Já o sistema explícito estaria envolvido com as atribuições e a formação das crenças (Oktay-Gür, Schulz \& Rakoczy, 2018). Conversando com as teorias de desenvolvimento, o sistema implícito se assemelha aos conceitos de intencionalidade, atenção compartilhada e tomada de perspectivas de nível 1. Já o sistema explícito utiliza mais recursos de linguagem e memória de trabalho, como linguagem emocional descritiva e atribuição de pensamentos a personagens em paradigmas de falsas crenças, por exemplo. Em resumo, aspectos conceituais do constructo de ToM cruzam com aspectos conceituais da cognição de domínio mais geral.

Ainda neste contexto de interface do desenvolvimento de ToM com outras áreas do desenvolvimento infantil, encontram-se as diferenças na capacidade da criança com TEA em estabelecer relações entre o mundo físico e mental. Segundo Baron-Cohen, Leslie e Frith (1986), crianças com TEA seriam preservadas quanto às relações de causalidade e o conceito de objeto, mas não nas relações de causalidade do mundo mental. Ou seja, elas teriam dificuldades em construir relações que envolvem inferências de estados mentais (ToM), mas conseguiriam construir relações lógicas, como ordenação de objetos ou de sequências visuais. Pruett, Kandala, Petersen e Povinelli (2015) verificaram essas dissociações em seus resultados, onde observaram que uma criança com TEA, por exemplo, poderia estabelecer algumas relações entre variáveis e ainda assim não ter um bom desempenho em ToM.

Singman e Ungerer (1981) testaram 6 estágios sensório-motores como exploração do objeto: capacidade de integrar e unir partes de objeto (fazer rotações ou abrir e fechar; procurar por objetos escondidos (consciência da 
existência de um objeto quando coberto); uso de intermediários (ver a relação entre dois objetos, usar um instrumento para pegar um outro objeto); combinação de objetos (resolução de problemas). Eles não encontraram diferenças significativas para controles normais. Eles também não identificaram relações com a linguagem mais ou menos preservada. Sendo assim, as crianças com TEA seriam mais hábeis em identificar objetos e relações causais que envolvem objetos do mundo físico.

O déficit intelectual também seria um fator de interferência no desempenho da falsa crença. Scheeren et al. (2013) associaram o melhor desempenho em falsa crença com um melhor desempenho em habilidade verbal. Nesta perspectiva, Lind e Bowler (2010) enfatizam a ideia de tarefas de controle cognitivo em tarefas de ToM. No modelo utilizado por esses autores, essas tarefas seriam perguntas realizadas um momento antes da tarefa experimental de ToM. Os autores criaram perguntas controle do experimento, que envolviam lembrança de uma ação, relação causal entre as ações das personagens e uma inferência final, com base na ação, porém nenhuma delas envolvia estados mentais (ToM), como na tarefa experimental. Ou seja, perguntas que recrutavam outros domínios cognitivos, que não de ToM propriamente, mas que poderiam estar associadas ao desempenho de ToM. Eles chegaram a esta conclusão, pois a tarefa experimental, além de ToM, também demandava lembrança de uma ação, relações causais entre as personagens e inferências.

Estes estudos exemplificam como outros domínios cognitivos coexistem em um modelo de desenvolvimento de ToM, e mesmo no desempenho de tarefas experimentais. Neste caso, encontram-se tarefas de ToM, que também recrutam outros componentes cognitivos, tais como: memória de trabalho (como em uso excessivo de histórias verbais ou muitas informações); flexibilidade cognitiva e controle inibitório (para análise da informação a ser compreendida, antes de realizar a inferência do estado mental); identificação de nexo causal lógico (necessárias para a compreensão de uma situação social) e acesso semântico (uso de verbos mentais e linguagem emocional). 


\section{4- Justificativa:}

ToM pode ser considerada um marcador de destaque para diagnóstico de TEA (Baron-Cohen et al., 1985), além de ser um dos eixos cognitivos do desenvolvimento infantil (Flavell, 1999). Boa parte desta literatura sobre avaliação de ToM utiliza o paradigma de falsa crença e suas variações (Altschuler et al., 2018; Durrleman \& Franck, 2015; Miller, 2009).

Ao se fazer um levantamento do uso de tarefas de avaliação, verifica-se grande quantidade de tarefas. Entretanto, ao olhar com mais cuidado suas descrições, elas apresentam formatos de personagens, de apresentação e de histórias diferentes, porém fazem parte de um mesmo paradigma: falsa crença. Podem ser citadas as seguintes tarefas como exemplos: Sally Anne tas; M\&M's (Smarties); Location-change false belief task; Unexpected-contents False belief test; Verbal false belief tasks; Bears post-test; Ist-order Deception tasks; Fact belief-juice; Value-belief-smell; value belief-taste; Candy box; Sandbox tax; Cream Van Story; Second-Order Belief Attribution; Second-order false belief task; Cuddle Toys Second-Order; Traces Second-Order False Belief (Buitelaar, Van der Wees, Swaab-Barneveld, \& Van der Gaag; 1999; Durrleman \& Franck, 2015; Fisher \& Happé, 2005; Hale \& Tager-Flusberg, 2005; Happé,1994; Kaland, Callesen, Møller-Nielsen, Mortensen \& Smith, 2008; Klin, 2000; Muris, et al., 1999; Perner, Leslie \& Leekam, 1989; Pilowsky, Yirmiya, Arbelle \& Mozes, 2000; Peterson, 2012; Prior et al., 1998; Wellman, et al., 2002; Tager-Flusberg \& Sullivan, 1994).

Todas as tarefas são baseadas em paradigma de falsa crença, de primeira ou segunda ordem, ou seja, onde se faz a interação entre personagens, em seguida a mudança de localização ou de conteúdo, onde um personagem não assiste a esta mudança de cenário, e, por fim, deve-se identificar qual a sua perspectiva ( ${ }^{\mathrm{a}}$ ordem) ou de outros personagens sobre ele ( $2^{\mathrm{a}}$ ordem).

Alguns autores prezam pela variabilidade e inserem em seus modelos de avaliação tarefas de identificação de emoções, conceitos iniciais de brincadeira simbólica, como os teste de aparência e realidade, ou mesmo tarefas mais complexas que envolvem traços de personalidade, integração de informações visuoespaciais para organizações lógicas ou sequências visuoespaciais, como: Traits task; Children's "Reading the Mind in the Eyes"; Picture Sequence 
Measure (Baron-Cohen, 1989; Fisher \& Happé, 2005; Hale \& Tager- Flusberg, 2005). Entretanto, elas encontram-se em menor quantidade e ainda com referencial teórico pouco sistematizado.

A reduzida variedade de paradigmas chama atenção, visto que existem diversos domínios não priorizados. A literatura mais recente tem discutido a ideia de um modelo de ToM mais abrangente. Alguns autores chamam de Teoria da Mente Avançada (Pedreño Pousa, Navarro, Pàmias \& Obiols, 2017). Mas o termo teoria da mente avançada muitas vezes é usado para descrever testes mais complexos, que envolvem muita linguagem pragmática, como gafes sociais e descrição de emoções complexas com identificação do olhar, dentre elas: The Strange Stories Test (Happé, 1994); Reading the Mind in the Eyes Test (BaronCohen et al. 1997; Baron-Cohen, 2001); The Faux Pas Test (Stone et al., 1998).

Em um artigo de 2018 (Altschuler et al., 2018), também foi encontrado o termo ToM avançado, originado da ideia de ToM ser um constructo que envolve múltiplas habilidades. Estes autores definem o modelo, como: entendimento de falsas crenças, reconhecimento de emoções e compreensão social. Eles utilizam as seguintes tarefas: Tarefas de falsa crença de primeira ordem; ToM test (Muris et al., 1999), composto de histórias para verificar falsa crença de $1^{\mathrm{a}}$ e $2^{\mathrm{a}}$ ordem e identificação de estados emocionais e o SAT (Klin, 2000), onde as crianças assistem a figuras geométricas animadas e identificam significados de suas ações com e sem pistas verbais.

Há, portanto, uma tendência em se pensar em modelos mais amplos e complexos de instrumentos de avaliação, que envolvem tarefas de domínios diferentes, como reconhecimento de emoções e de estados mentais, compreensão social em cenas dinâmicas, como vídeos e com maior variação de emoções, numa tentativa de se aproximar das demandas de cenas sociais reais (Schaller \& Rauh, 2017). Mas ainda não há um condutor teórico, baseado em modelos de desenvolvimento.

Outro ponto crítico das tarefas de ToM é a clara relação com outras demandas cognitivas. Discute-se o impacto desses domínios cognitivos no desempenho e no próprio desenvolvimento de ToM. O reduzido controle cognitivo das tarefas dificulta ter certeza do quanto o desempenho em ToM pode 
estar de fato isolado de comprometimentos em outros domínios cognitivos (Pedreño et al., 2017, Scheeren et al., 2013, Lind \& Bowler, 2010)

Considerando a complexidade do constructo de ToM, o uso de tarefas mais circunscritas ou tarefas onde há dificuldade de discriminar prejuízos em ToM de outros prejuízos cognitivos, como flexibilidade cognitiva, memória de trabalho, controle inibitório, linguagem, funcionamento global, tem um impacto especial, principalmente quando se pensa em um diagnóstico que apresenta grande variabilidade como TEA, com prejuízos em diferentes aspectos do desenvolvimento.

Com isto, revela-se a importância em se desenvolver novos modelos de avaliação a partir das características observadas atualmente: grande frequência de tarefas de teoria da mente avaliando um único domínio, em especial falsas crenças; poucas tarefas considerando em seus modelos o impacto de componentes de funções executivas, além de relações lógicas do mundo social.

Neste contexto, mostra-se relevante o desenvolvimento de um novo instrumento de ToM para diagnóstico de TEA, que compreenda diferentes domínios deste constructo e compreenda a relação com outros domínios cognitivos.

\section{5-Objetivo geral:}

Desenvolver e verificar evidências de validade de um novo instrumento que avalie os diferentes domínios do constructo de ToM para auxílio de diagnóstico em crianças com TEA.

\subsection{1--Objetivos Específicos:}

A- Realizar a revisão narrativa acerca de tarefas de avaliação do constructo Teoria da Mente, a fim de entender os modelos de tarefa, a frequência de uso de tarefas e a abordagem teórica utilizada. 
B- Desenvolver um modelo de instrumento de ToM, baseado em estórias em quadrinhos, e identificar diferenças de desempenho em ToM em dois diagnósticos diferentes do neurodesenvolvimento: TEA e TDI . Este estudo foi considerado um piloto para o desenvolvimento da BToM.

C- Verificar a validade de conteúdo: elaboração do instrumento e avaliação de juízes. Busca-se identificar o quanto o instrumento compreende as características do constructo ToM e consegue definir controles cognitivos válidos escolhidos a partir da literatura.

D-Verificar a confiabilidade do instrumento, a partir de concordância de escores pontuados entre avaliadores, em uma amostra de controles.

E-Verificar a validade de constructo, a partir de associação das tarefas do instrumento com padrão-ouro em avaliação de desempenho em ToM.

E-Investigar evidências de validade de critério, onde são verificadas as diferenças no desempenho do instrumento, usando como critério a presença ou não do diagnóstico de TEA. 


\title{
2- CATEGORIZAÇÃO DE DOMÍNIOS EM TAREFAS DE TEORIA DA MENTE-TOM: UMA REVISÃO NARRATIVA
}

Resumo

Teoria da mente (ToM) tem como definição a capacidade do indivíduo em atribuir estados mentais a si mesmo e aos outros. A literatura aponta para um grande número de tarefas, sendo significativo o paradigma de falsa crença. $\mathrm{O}$ objetivo deste estudo é mapear as tarefas descritas na literatura e utilizadas para avaliar ToM em crianças e adolescentes autistas. Uma revisão narrativa foi realizada utilizando o banco de dados Pubmed. Foram selecionados 27 artigos, a partir de critérios de inclusão. Em função do grande número de tarefas, classificações foram realizadas, e as tarefas foram agrupadas pelos autores em categorias, chamadas de domínios, utilizando uma perspectiva de desenvolvimento. Neste contexto, serão discutidos os seguintes aspectos: (1) diferentes domínios avaliados (2) pouca generalização aos problemas sociais (3) impacto das variáveis cognitivas.

Palavras-chave: Teoria da Mente; TEA; tarefas; ToM

\begin{abstract}
Theory of Mind (ToM) is defined as the individual's ability to infer mental states. The literature highlights many tasks to evaluate ToM. Among these tasks, the paradigm of false belief is frequently used. This study was aimed at mapping tasks described in the literature which were used to evaluate ToM in autistic children and teenagers. A systematic review was carried out using the PubMed database and 27 articles were selected based on the inclusion criteria. Due to the large number of relevant tasks, they were classified and grouped into domains, using a developmental perspective. In this context, the following issues will be dealt with: (1) the different domains evaluated, (2) the lack of generalization for social problems, and (3) the impact of cognitive variables.
\end{abstract}

Keywords: theory of mind; ASD; tasks; ToM 


\section{1-INTRODUÇÃO}

O termo "Teoria da Mente (ToM)" originou-se de um artigo clássico de Premack e Woodruff (1978) e foi definido como a capacidade de inferir estados mentais, tais como: pensamentos, desejos e emoções (Birch et al., 2017; Bosco, Gabattore \& Tirassa, 2014; Durrleman \& Franck, 2015; Miller, 2009). ToM relaciona-se com diversas implicações para a adaptação psicossocial, como integração social, comportamentos empáticos e comunicação (Brown, Thibodeau, Pierucci \& Gilpin, 2017; Smogorzewska et al., 2018). Prejuízos nesta função sociocognitiva têm sido encontrados em diversas psicopatologias. Dentre elas, a que mais se destaca é o Transtorno do Espectro Autista -TEA (Kimhi, ShoamKugelmas, Ben-Artzi, Ben-Moshe \& Bauminger-Zviely, 2014; Scheeren et al., 2013).

A avaliação de ToM em TEA, frequentemente envolve o modelo de falsa crença (Miller, 2009; Roazzi \& Santana, 2008), mesmo que em formatos diferentes do paradigma. No entanto, a perspectiva de desenvolvimento de ToM (Baron-Cohen, 1989; Flavell et al., 1999) considera outros aspectos importantes. Esta concepção conduz para modelos mais amplos e multifacetados de instrumentos de avaliação (Schaller \& Rauh, 2017; Miller, 2009).

Flavell et al. (1999) definem algumas etapas no que diz respeito ao desenvolvimento de ToM. Ele fala de estágios iniciais (1- conceito de mente, 2conexões entre a mente e o mundo físico, 3- mente separada do mundo físico); estágio 4- crenças falsas e estágio 5 - crenças de segunda ordem ou consequências dessas crenças (Muris et al., 1999). Assim como Flavell, outros autores assumem que o ToM envolve múltiplas habilidades e processos (Carlson, Koenig \& Harms, 2013; Grosse Wiesmann, Friederici, Singer e Steinbeis, 2016; Osterhaus, Koerber \& Sodian, 2016). Além disso, estudos indicam possíveis interfaces com outras funções cognitivas. A literatura discute, por exemplo, aspectos de pragmática e intencionalidade (Tomasello, 2003), atenção compartilhada (Baron-Cohen, 1989) e funções executivas (Devine, White, Ensor \& Hughes, 2016; Tonietto et al., 2011; Yeh, Tsai, Tsai, Lo \& Wang, 2016).

Percebe-se uma grande complexidade do constructo ToM e suas relações com outras funções cognitivas, em contraste ao uso de modelos muitos similares e 
restritos de avaliação; além do notório impacto sobre o diagnóstico de TEA. Tendo em vista esses tópicos, o objetivo deste estudo foi realizar uma revisão narrativa das publicações sobre tarefas de ToM utilizadas para avaliar crianças e adolescentes com TEA, a fim de identificar e discutir a avaliação de ToM nesta população.

\section{2- MÉTODO}

Foi realizada uma revisão narrativa da literatura, visando a atualização quanto às tarefas utilizadas na avaliação de ToM em crianças com TEA. Os artigos foram recuperados da base de dados PubMed, utilizando o operador booleano "AND” e os descritores em inglês: "Teoria da Mente", "crianças adolescentes", "tarefas" e "autismo".

Os artigos foram incluídos com base nos seguintes critérios: (1) a amostra foi composta por crianças e adolescentes com TEA e (2) tarefas ToM foram expostas nos resumos. Os artigos que não preencheram os critérios de inclusão e artigos em língua não inglesa foram excluídos. Considerando esses critérios, 56 artigos foram recuperados. Uma segunda análise verificou se as tarefas foram descritas com detalhes nos métodos e procedimentos. Nesta etapa, 15 artigos foram excluídos. A figura 1 apresenta o diagrama de inclusão.

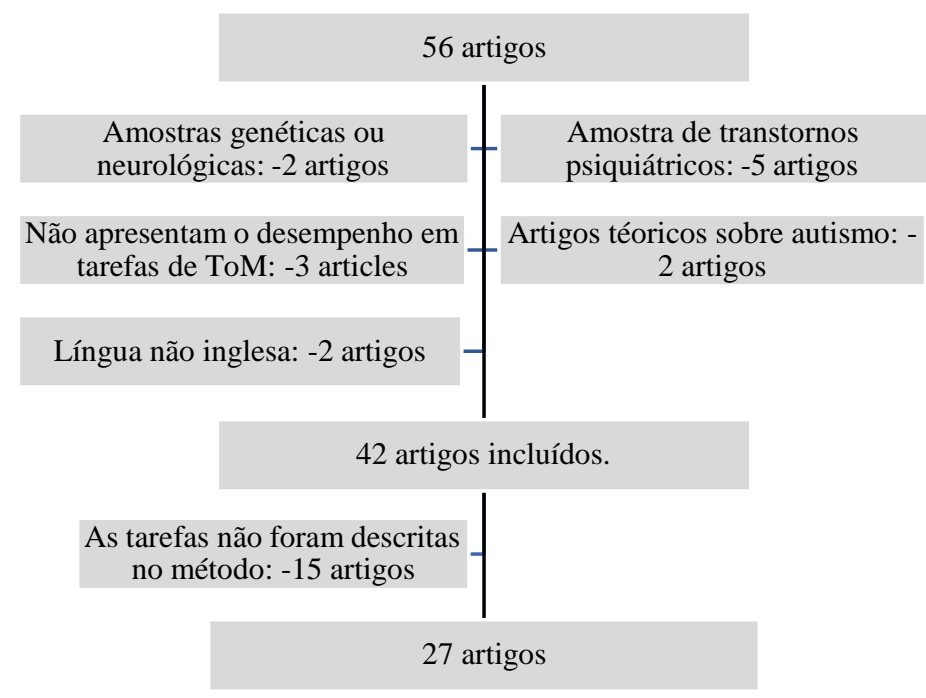

Figura 1: Critérios de exclusão dos artigos 


\section{3-RESULTADOS}

Primeiramente, analisaram-se o número e a descrição das tarefas utilizadas nos 27 artigos, bem como as frequências em que as tarefas apareceram em diferentes artigos. Descrições, frequência e referências são apresentadas nas tabelas a seguir. Tabela 1: Tarefas mais frequentes (utilizadas em 5 ou mais artigos), Tabela 2 (utilizada em 3 ou 4 artigos), Tabela 3 (utilizada em 1 ou 2 artigos). Tarefas originais e similares foram agrupadas. Verifica-se que, nos 27 artigos analisados, 49 tarefas foram expostas e descritas.

Tabela 1: Tarefas ToM com alta frequência (> 5 artigos)

\begin{tabular}{|c|c|c|c|}
\hline Tarefa & Descrição & $\mathrm{N}$ & Artigos \\
\hline 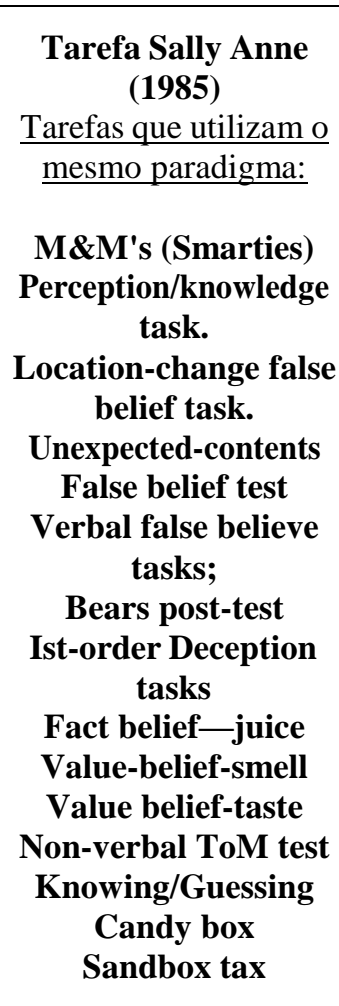 & $\begin{array}{l}\text { São apresentadas duas } \\
\text { bonecas à criança. Uma } \\
\text { delas tem um objeto, que } \\
\text { ela coloca em sua cesta, e } \\
\text { depois sai da sala. A } \\
\text { boneca que permanece na } \\
\text { sala muda o local do objeto } \\
\text { (da cesta para caixa). Os } \\
\text { sujeitos respondem onde a } \\
\text { a boneca que volta para } \\
\text { sala e não viu a troca vai } \\
\text { procurar o objeto. }\end{array}$ & 17 & $\begin{array}{l}\text { 1- } \text { Buitelaar \& Van Der } \\
\text { Wees,(1997); } \\
\text { 2- Buitelaar, et al. (1999); } \\
\text { 3- Buitelaar, Van der Wees, } \\
\text { Swaab-Barneveld, \& Van der Gaag } \\
\text { (1999) } \\
\text { 4- Durrleman \& Franck, (2015); } \\
\text { 5- Fisher, Happé, (2005); } \\
\text { 6- Hale \& Tager-Flusberg. (2005); } \\
\text { 7- Happé (1994); } \\
\text { 8- Kaland, Callesen, Møller- } \\
\text { Nielsen, Mortensen \& Smith. } \\
\text { (2008); } \\
\text { 9- Klin, (2000); } \\
\text { 10- Muris, et al. (1999); } \\
\text { 11- Pilowsky et al (2000); } \\
\text { 12- Perner et al.(1989) } \\
\text { 13- Peterson (2012) } \\
\text { 14- Prior et al. (1998) } \\
\text { 15- Wellman, et al. (2002); } \\
\text { 16- Yirmiya, } \\
\text { Solomonica-levi \& Shulman (1999) } \\
\text { 17- Yirmiya \& Shulman (1996); } \\
\text { 18- Schaller1 \& Rauh, (2017) } \\
\text { 19- Beeger et al. (2017) }\end{array}$ \\
\hline $\begin{array}{c}\text { Strange Stories } \\
\text { (Stories from } \\
\text { Everyday Life-SEL) }\end{array}$ & $\begin{array}{l}12 \text { tipos de histórias com } \\
\text { conteúdo de mentira, } \\
\text { mentirinha, piada, engano, } \\
\text { incompreensão, persuasão, } \\
\text { aparência / realidade, } \\
\text { figura de linguagem, } \\
\text { sarcasmo, esquecimento, } \\
\text { duplo blefe e emoções. }\end{array}$ & 5 & $\begin{array}{ll}\text { • } & \text { Artigos 7; } 8 \\
\text { 20- } & \text { Henderson, Ono, McMahon, } \\
\text { Schwartz, Usher \& Mundy } \\
\text { (2015) } \\
\text { 21- White Frith, Relleck, AL-Noor } \\
\text { \& Gilbert (2014); } \\
\text { 22- } \begin{array}{l}\text { Kaland, Smith \& Mortensen } \\
\text { (2007) }\end{array}\end{array}$ \\
\hline
\end{tabular}


Tabela 2: Frequência de tarefas ToM (3-4 artigos).

\begin{tabular}{|c|c|c|c|}
\hline Tarefa & Descrição & $\mathrm{N}$ & Referências \\
\hline Concept of the Brain & $\begin{array}{l}\text { Investiga a compreensão da função do } \\
\text { cérebro. }\end{array}$ & 4 & $\begin{array}{l}\text { Artigos 1,2,3 } \\
\text { 23-Baron-Cohen } \\
\text { (1989) }\end{array}$ \\
\hline $\begin{array}{l}\text { Appearance-Reality } \\
\text { Task }\end{array}$ & $\begin{array}{l}\text { Investiga a distinção entre aparência e } \\
\text { realidade. }\end{array}$ & 4 & Artigos 1, 2, 3, 23 \\
\hline $\begin{array}{l}\text { Mental-Physical } \\
\text { Distinction }\end{array}$ & $\begin{array}{l}\text { Compara a compreensão do sujeito de } 4 \\
\text { fenômenos mentais com fenômenos físicos. }\end{array}$ & 3 & Artigos $1,2,3$ \\
\hline $\begin{array}{l}\text { Children's "Reading } \\
\text { the Mind in the Eyes" } \\
\text { Based task: MS task }\end{array}$ & $\begin{array}{l}\text { Consiste em escolher uma das quatro } \\
\text { palavras que melhor descrevem a expressão } \\
\text { transmitida na imagem da região dos olhos } \\
\text { de alguém. }\end{array}$ & 4 & $\begin{array}{l}\text { Artigos 5, 8, } 21 \\
\text { 24-Iwanaga, Tanaka, } \\
\text { Nakane, Honda, } \\
\text { Imamura \& Ozawa }\end{array}$ \\
\hline $\begin{array}{l}\text { The Ice Cream Van } \\
\text { Story } \\
\text { Tasks based: } \\
\text { Second-Order Belief } \\
\text { Attribution } \\
\text { Second-order false } \\
\text { belief task } \\
\text { Bowers story }\end{array}$ & $\begin{array}{l}\text { O teste consiste em uma história com dois } \\
\text { personagens (João e Maria). É um local de } \\
\text { transferência inesperado. Verifica-se a } \\
\text { crença da segunda ordem (de um } \\
\text { personagem sobre o outro). }\end{array}$ & 8 & $\begin{array}{l}\text { Artigos } 1,2,3 \\
6,14,10,18,21,22\end{array}$ \\
\hline $\begin{array}{l}\text { Two Second-order } \\
\text { stories }\end{array}$ & $\begin{array}{l}\text { Duas histórias que envolvem mentira e } \\
\text { crenças de segunda ordem. }\end{array}$ & 2 & $\begin{array}{l}\text { Artigos } 8 \\
\text { 25-Tager-Flusberg } \quad \& \\
\text { Sullivan (1994); }\end{array}$ \\
\hline The Picture Story & $\begin{array}{l}\text { A tarefa consiste em duas histórias: } \\
\text { "Birthday" e "Swimming Pool". O } \\
\text { pesquisador lê histórias em voz alta para a } \\
\text { criança, enquanto seis imagens com as } \\
\text { situações da história são apresentadas. Para } \\
\text { cada história, uma questão de crença e } \\
\text { compreensão são realizadas. }\end{array}$ & 3 & Artigos 1, 2, 3 \\
\hline $\begin{array}{l}\text { Cuddle Toys Second- } \\
\text { Order }\end{array}$ & $\begin{array}{l}\text { A tarefa consiste em duas histórias: } \\
\text { "crocodilo" e "coletor de lixo". Fantoches } \\
\text { são usados para demonstração. Para cada } \\
\text { história, uma pergunta sobre crença e } \\
\text { justificação são realizadas. }\end{array}$ & 3 & Artigos 1, 2, 3 \\
\hline $\begin{array}{l}\text { Traces Second-Order } \\
\text { False Belief Task }\end{array}$ & $\begin{array}{l}\text { O material consiste em uma prancheta } \\
\text { mágica com bonecas Playmobil. Perguntas } \\
\text { são feitas sobre crença e justificação são } \\
\text { realizadas. }\end{array}$ & 3 & Artigos 1, 2, 3 \\
\hline $\begin{array}{l}\begin{array}{l}\text { Picture } \\
\text { measure }\end{array} \\
\text { Sequence }\end{array}$ & $\begin{array}{l}\text { Histórias lógicas com quatro imagens fora de } \\
\text { ordem; a primeira imagem é marcada e a } \\
\text { criança organiza as outras imagens. }\end{array}$ & 3 & Artigos 1, 2, 3 \\
\hline
\end{tabular}


Tabela 3: Frequência de tarefas ToM (até dois artigos)

\begin{tabular}{|c|c|c|c|}
\hline Tarefa & Descrição & $\mathrm{N}$ & Referências \\
\hline TOM TEST & $\begin{array}{l}\text { Vinhetas, histórias e desenhos, em que a criança tem que } \\
\text { responder a uma série de perguntas sobre falsa crença e } \\
\text { reconhecimento de estados mentais. }\end{array}$ & 1 & Artigo 10 \\
\hline $\begin{array}{l}\text { A custom- } \\
\text { designed } \\
\text { developmental }\end{array}$ & Tarefa de reconhecimento de emoções - Cinco níveis. & 1 & $\begin{array}{l}\text { 26-Salgueiro } \\
\text { et al. (2012) }\end{array}$ \\
\hline $\begin{array}{l}\text { Social } \\
\text { Attribution Task } \\
\text { (SAT) }\end{array}$ & $\begin{array}{l}\text { Esta tarefa requer a capacidade do participante de extrair } \\
\text { dicas visuais para criar um contexto social com animações } \\
\text { de formas geométricas. }\end{array}$ & 1 & Artigo 9; \\
\hline Desire task & $\begin{array}{l}\text { Duas histórias usando adereços. O personagem não pode } \\
\text { encontrar o objeto desejado. Pergunta-se: "Ele continuará } \\
\text { procurando e por quê?". }\end{array}$ & 1 & Artigo 6 \\
\hline $\begin{array}{l}\text { Seeing Leads to } \\
\text { Knowing }\end{array}$ & $\begin{array}{l}\text { Um dos dois personagens vê um objeto escondido em uma } \\
\text { caixa, enquanto o outro apenas toca o lado de fora da caixa. } \\
\text { A criança é solicitada a dizer quem sabe o que está na caixa. }\end{array}$ & 2 & Artigo 5, 6 \\
\hline $\begin{array}{l}\text { Penny Hiding } \\
\text { Deception Task }\end{array}$ & $\begin{array}{l}\text { A criança deve esconder um pequeno objeto em uma das } \\
\text { mãos atrás das costas e, em seguida, leva as duas mãos para } \\
\text { frente para o pesquisador para adivinhar onde o objeto está } \\
\text { escondido. }\end{array}$ & 1 & Artigo5 \\
\hline $\begin{array}{l}\text { Sticker-hiding } \\
\text { task }\end{array}$ & $\begin{array}{l}\text { Nesta tarefa, é necessário que o participante oculte um } \\
\text { adesivo em uma mão para que o experimentador tenha que } \\
\text { adivinhar sua localização. }\end{array}$ & 2 & Artigo 5, 6 \\
\hline Pretence Task & $\begin{array}{l}\text { Quatro vinhetas envolvendo uma mãe e um bebê. } \\
\text { Participantes usam a boneca mãe para atuar fora da lógica ao } \\
\text { lado do evento. }\end{array}$ & 1 & Artigo 6 \\
\hline $\begin{array}{l}\text { Playmobil John } \\
\text { and Fiona }\end{array}$ & $\begin{array}{l}\text { Fiona e John saem para brincar no parque. São realizadas } \\
\text { perguntas de compreensão e see-know. }\end{array}$ & 1 & $\begin{array}{l}\text { 27-Lind \& } \\
\text { Bowler }\end{array}$ \\
\hline $\begin{array}{l}\text { Lies and jokes } \\
\text { task }\end{array}$ & $\begin{array}{l}\text { Capacidade de distinguir entre mentiras e piadas irônicas (ou } \\
\text { sarcasmo). }\end{array}$ & 1 & Artigo 6 \\
\hline Traits task & $\begin{array}{l}\text { Capacidade dos participantes para julgar intenções com base } \\
\text { em traços de personalidade. }\end{array}$ & 1 & Artigo 6 \\
\hline $\begin{array}{l}\text { Moral judgment } \\
\text { task }\end{array}$ & $\begin{array}{l}\text { Quatro histórias ilustradas em que dois colegas planejam se } \\
\text { encontrar. }\end{array}$ & 1 & Artigo 6 \\
\hline $\begin{array}{l}M A S C \text { (Dziobek } \\
\text { et al. 2006). }\end{array}$ & $\begin{array}{l}\text { Um filme de } 15 \text { minutos sobre um jantar; o vídeo para } 51 \\
\text { vezes, e os participantes respondem a perguntas sobre os } \\
\text { estados mentais, a partir de um paradigma de escolha. O } \\
\text { principal resultado é a taxa de precisão para respostas dadas } \\
\text { corretamente. }\end{array}$ & 1 & Artigo 18 \\
\hline A-tom & $\begin{array}{l}\text { Estímulos dinâmicos baseados em vídeo (por meio da série } \\
\text { de animação de TV "Shaun the Sheep"). Os participantes } \\
\text { são questionados sobre diferentes aspectos, incluindo a } \\
\text { expressão da emoção facial, as intenções, o engano e as } \\
\text { crenças falsas de primeira e segunda ordem. }\end{array}$ & 1 & Artigo 18 \\
\hline $\begin{array}{l}\text { Dynamic } \\
\text { Emotion } \\
\text { Categorization }\end{array}$ & $\begin{array}{l}\text { Faz uso de estímulos faciais dinâmicos de emoção, com } \\
\text { vídeos de atores com expressões de emoções básicas em } \\
\text { diferentes intensidades. }\end{array}$ & 1 & Artigo 18 \\
\hline Hindsight task & $\begin{array}{l}\text { São apresentados objetos comuns borrados, que se tornam } \\
\text { claro em } 10 \mathrm{~s} \text {. Os participantes param a imagem quando } \\
\text { identificam o objeto. Depois disso, eles são solicitados a } \\
\text { indicar em que nível de desfoque eles achavam que uma } \\
\text { pessoa ingênua reconheceria o objeto (Outra condição). }\end{array}$ & 1 & Artigo 19 \\
\hline
\end{tabular}


Em seguida, a apresentação da tarefa foi analisada. Conteúdo visual e verbal foram identificados, assim como os diferentes métodos de apresentação, como narrativa, cenas ou simulações. (Tabela 4).

Tabela 4: Frequência de tarefas por método utilizado

\begin{tabular}{|c|c|c|c|}
\hline $\mathrm{N}$ & Método & \multicolumn{2}{|c|}{ Tarefas } \\
\hline 8 & $\begin{array}{l}\text { Uso de imagens } \\
\text { como fotos ou cenas } \\
\text { em papel ou vídeo }\end{array}$ & $\begin{array}{l}\text { - Concept of the Brain } \\
\text { - MS task } \\
\text { - A custom-designed } \\
\text { developmental protocol } \\
\text { to evaluate the child's } \\
\text { capacity for a "Theory of } \\
\text { Mind' } \\
\text { - Children's "Reading the } \\
\text { Mind in the Eyes" }\end{array}$ & $\begin{array}{l}\text { - Hindsight task } \\
\text { - A-tom } \\
\text { - MASC } \\
\text { - Dynamic Emotion } \\
\text { Categorization Test } \\
\text { - Picture Sequence } \\
\text { measure } \\
\text { Social Attribution Task } \\
\text { (SAT) }\end{array}$ \\
\hline 19 & $\begin{array}{l}\text { Role-play de } \\
\text { personagens (bonecos } \\
\text { ou fantoches), com } \\
\text { manipulação de } \\
\text { posição de objetos } \\
\text { pelo experimentador } \\
\text { ou participante }\end{array}$ & $\begin{array}{l}\text { - M\&M's (Smarties) } \\
\text { - Appearance-Reality } \\
\text { Task } \\
\text { - Candy box } \\
\text { - Pretence task } \\
\text { - Perception/knowledge } \\
\text { task } \\
\text { - Location-change false } \\
\text { belief task. } \\
\text { - Sally Anne task } \\
\text { - Unexpected-contents } \\
\text { false belief task. } \\
\text { - Seeing Leads to } \\
\text { Knowing } \\
\text { - Desire task }\end{array}$ & $\begin{array}{l}\text { - Bears test based on } \\
\text { Sally anne) } \\
\text { - Verbal false believe } \\
\text { tasks } \\
\text { - Cuddle Toys Second- } \\
\text { Order } \\
\text { - Traces Second-Order } \\
\text { False Belief Task } \\
\text { - Playmobil John e } \\
\text { Fiona } \\
\text { - Second-order false } \\
\text { belief attibuittion } \\
\text { task } \\
\text { - The Ice Cream Van } \\
\text { Story } \\
\text { - Bowler's story } \\
\text { - Two Second-order } \\
\text { stories }\end{array}$ \\
\hline 7 & $\begin{array}{l}\text { Experiência } \\
\text { (simulação de } \\
\text { experimentadores, } \\
\text { pode haver } \\
\text { manipulação de } \\
\text { objetos) }\end{array}$ & $\begin{array}{ll}\text { - } & \text { Fact belief-juice } \\
\text { - } & \text { Sticker-hiding task } \\
\text { (the experimenter } \\
\text { asks to hide) } \\
\text { - } \quad \text { Penny Hiding } \\
\text { Deception Task } \\
\text { - Value belief-taste }\end{array}$ & $\begin{array}{ll}\text { - } & \text { Deception Task } \\
\text { - } & \text { Non-verbal ToM } \\
\text { test } \\
\text { - } \\
\text { Dynamic Emotion } \\
\text { Categorization Test } \\
\text { - } \quad \text { Knowing/Guessing } \\
\text { Value belief-smell }\end{array}$ \\
\hline 10 & $\begin{array}{l}\text { Uso de imagens / } \\
\text { histórias de } \\
\text { personagens }\end{array}$ & $\begin{array}{ll}\text { - } & \text { Mental-Physical } \\
\text { - } & \text { Distinction } \\
\text { - } & \text { The Picture Story } \\
\text { - } & \text { Lies and jokes task } \\
\text { - } & \text { Traits task } \\
\text { Strange Stories }\end{array}$ & $\begin{array}{llr}\text { - } & \text { Stories } & \text { from } \\
& \begin{array}{l}\text { Everyday } \\
\text { (SEL) }\end{array} \\
\text { - } & \text { TOM test } \\
\text { - } & \text { Second-order false } \\
& \text { belief task } \\
\text { - } & \text { Traits task } \\
\text { - } & \text { Sandbox task }\end{array}$ \\
\hline
\end{tabular}


A partir da leitura detalhada de cada tarefa, diferentes níveis de complexidade foram identificados. Esses níveis são condizentes com os diferentes estágios desse constructo, relacionados ao desenvolvimento infantil e a outras funções cognitivas. Em outras palavras, as tarefas podem ser direcionadas para diferentes aspectos de ToM. Nessa perspectiva, as tarefas foram divididas em grupos, definidos como domínios.

1-Precursores de ToM (Flavell et al., 1999): Conceitos de estado mental e cerebral, distinção entre estados físico e mental, reconhecimento de emoção.

2-Diversas crenças (primeira e segunda ordem) (Flavell et al., 1999; Wellman e Liu, 2004; Miller, 2009): onde não há conteúdo incongruente, a criança e os personagens não sabem e a criança tem que julgar diferentes perspectivas.

2.1 Crenças de primeira ordem: identificação de desejos, emoções, crenças e o que está acontecendo na situação.

2.2- Segunda ordem: pensamentos inferidos a partir da observação das emoções do outro.

3- Falsas Crenças (primeira e segunda ordem) (Flavell et al., 1999): Há conteúdo incongruente, a criança sabe e os personagens, não. $\mathrm{Na}$ primeira ordem, há uma representação direta de um personagem e, na segunda ordem, uma representação do que o personagem pensa sobre os outros.

4- Consequências do raciocínio de segunda ordem (Miller, 2009): as possibilidades decorrentes do raciocínio de segunda ordem, como mentiras, piadas, gafes e erros. Envolve linguagem pragmática.

5- Identificação do contexto social mais amplo, a partir de pistas visuais (Klin, 2000). As tabelas 5 e 6 mostram as tarefas e classificações em seus respectivos domínios. 
Tabela 5: Domínios das tarefas

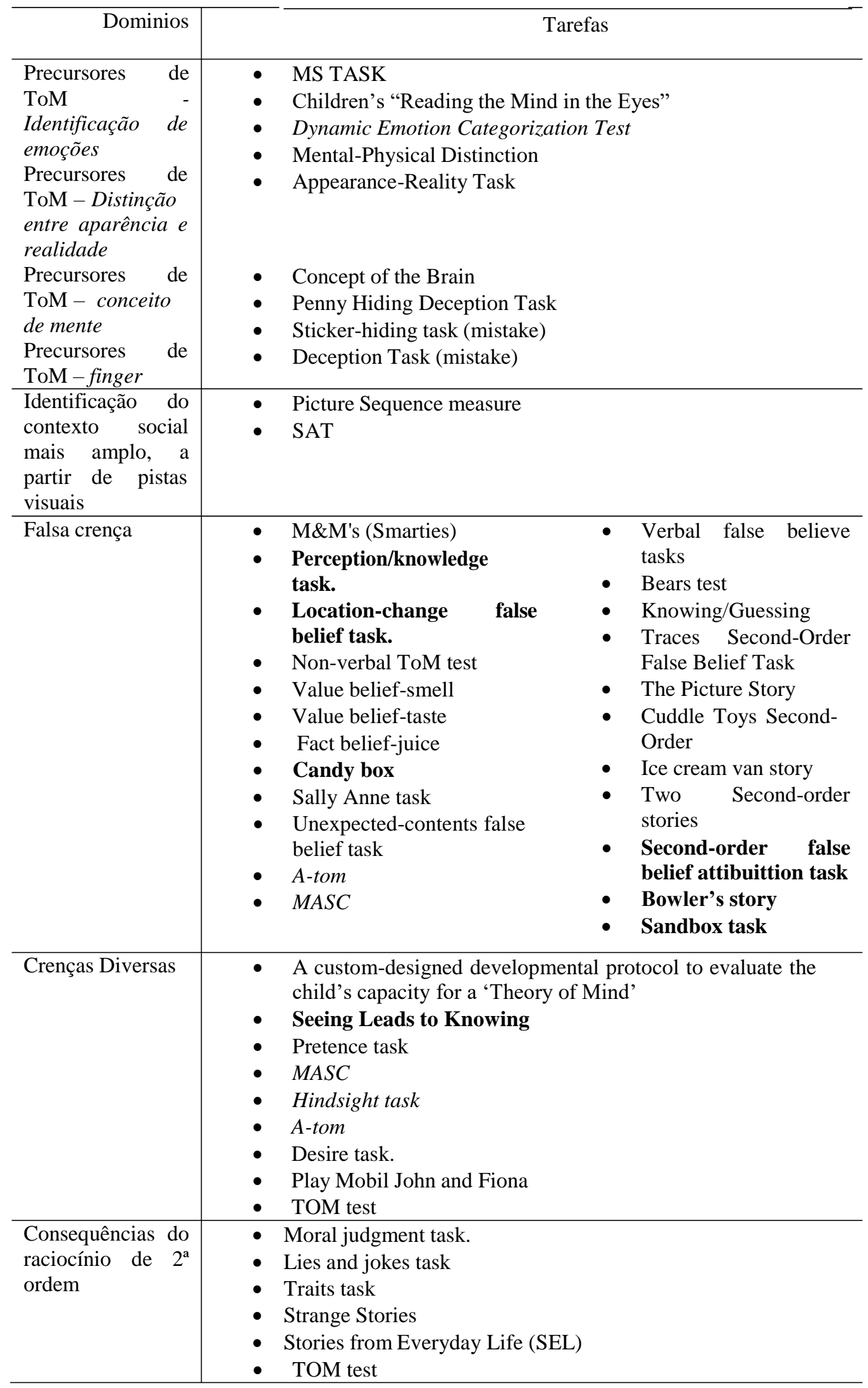




\section{4-DISCUSSÃO}

Os resultados demonstram o grande número de tarefas ToM; contudo, com alta frequência de tarefas falsas de crença. Essas tarefas podem ser encontradas de duas formas: (1) tarefas de falsa crença combinadas com outros modelos, (2) ou diferentes modelos de tarefas derivados do mesmo paradigma no mesmo artigo (Tabela 1). Ou seja, alguns artigos utilizam grande quantidade de tarefas, porém com o mesmo paradigma, mas em modos de apresentação diferentes (narrativas, uso de objetos ou desenhos). Essa variação da apresentação, mas não do paradigma tem sofrido críticas, por reduzir controles metodológicos (Van Buijsen et al., 2008), além de circunscrever o desempenho de ToM a tarefas experimentais, com pouca conexão com as situações do cotidiano (Oktay-Gür et al., 2018).

Outros modelos de tarefas são identificados. Claramente, esses artigos estão em menor quantidade, porém descrevem tarefas de diferentes domínios. No entanto, eles não necessariamente relacionam a tarefa utilizada com um referencial teórico bem definido, como a própria teoria de desenvolvimento de ToM. Os artigos 1, 2 e 3 (Tabela 1), por exemplo, usavam as seguintes tarefas: (a) crenças falsas de primeira e segunda ordem; (b) identificação de contexto social a partir de pistas visuais como a medida de Sequência de Figuras, e (c) precursores de ToM, como o Conceito do Cérebro ou da Realidade x Aparência. Entretanto, os autores não indicaram a contextualização teórica na escolha desses instrumentos. O mesmo pode ser observado nos artigos 5 e 6 (Tabela 1), onde não se discute qualquer base teórica para a escolha das tarefas.

As categorizações de tarefas também revelaram uma baixa frequência de instrumentos multitarefa, ou seja, compostos por diferentes tarefas conectadas entre si, ou com proximidade ecológica, isto é, com seu desempenho em situações do cotidiano. Dentre os poucos descritos, encontram-se: ToM Test, SAT, MASC, Picture Sequence measure, e A-ToM. Muris et al. (1999), seguindo o modelo de Flavell, discutiram a existência de várias outras tarefas, incluindo outras dimensões de ToM. Neste estudo de 1999, os autores testaram a confiabilidade e a validade do teste ToM delineado por Steerneman (1994), que inclui: precursores da ToM (como o reconhecimento da emoção), falsas crenças e crenças de segunda 
ordem. Os resultados indicaram confiabilidade do teste em termos de consistência interna, bem como validade na avaliação de vários aspectos do ToM.

Enfatizando esta limitação em modelos de avaliação, a literatura ressalta que restringir os modelos de tarefas prejudica a avaliação mais realista do desempenho de sujeitos com TEA. O desempenho poderia melhorar, pois o sujeito não está em situação ecológica ou simulando-a (Lind \& Bowler, 2010). Entre estas questões são considerados diferentes perfis cognitivos nos fenótipos de TEA. Klin (2000), por exemplo, destacou que indivíduos com TEA poderiam usar recursos de linguagem para explicar tarefas de falsas crenças. Neste contexto, o desempenho pode ser impactado por diferentes níveis de preservação de linguagem ou funções executivas, por exemplo.

Fisher e Happe (2005) descreveram as relações entre funções executivas e ToM, destacando a flexibilidade cognitiva e o controle inibitório. Lind e Bowler (2010) incluíram uma tarefa para o controle de variáveis cognitivas, a fim de identificar mais precisamente os danos ToM em indivíduos com Síndrome de Asperger. Durrleman e Franck (2015) também discutiram a relação entre ToM, linguagem e funções executivas. Eles entenderam que as tarefas verbais podem afetar o desempenho do ToM, assim como os processos executivos (Kouklaria et al., 2018).

Algumas tarefas diferem na avaliação de ToM, como o teste ToM (Muris et al, 1999), o SAT (Klin, 2000) e a medida de sequência de imagens (Buitelaar, Van der Wess, Swaab-Barneveld e Van der Gaag, 1999). Eles usam conteúdo visual, com integração de dicas visuais, e expandem problemas sociais, embora ainda não forneçam relações teóricas consistentes com outras funções cognitivas.

A presente revisão pontuou: (a) alta frequência de tarefas de ToM que avaliam um único domínio: falsas crenças; (b) impacto de outras funções cognitivas, como funções executivas, linguagem, integração visuoespacial; c) proximidade de situações sociais reais, e (d) uso reduzido de uma base teórica de desenvolvimento para a escolha ou desenvolvimento de ferramentas ToM. Esse panorama sugere a necessidade de considerar os seguintes aspectos ao desenvolver instrumentos de avaliação ToM: (1) o controle de funções cognitivas, como função executiva (processos de autorregulação: memória operacional, 
controle inibitório e flexibilidade cognitiva) e linguagem, e (2) abrangendo diferentes domínios, de acordo com a perspectiva de desenvolvimento do ToM. 


\section{3- EVIDÊNCIAS DE DIAGNÓSTICO DIFERENCIAL ENTRE TRANSTORNO DO ESPECTRO AUTISTA (TEA) E TRANSTORNO DO DESENVOLVIMENTO INTELECTUAL (TDI): ANÁLISE DE CASOS}

\section{Resumo}

O Transtorno do Espectro Autista (TEA) é um diagnóstico prevalente no contexto infanto-juvenil. A prevalência de TEA e a abrangência dos critérios diagnósticos do espectro mostram a necessidade de desenvolvimento de instrumentos para melhorar a precisão na identificação desse diagnóstico. $\mathrm{O}$ objetivo do presente estudo é descrever, a partir de múltiplos casos, as diferenças entre o desempenho nos testes neuropsicológicos de TEA com rebaixamento intelectual e Transtorno do Desenvolvimento Intelectual (TDI). Quatro casos clínicos atendidos no serviço de neuropsicologia da PUC-Rio participaram desse estudo: dois participantes com diagnóstico clínico de TEA (Grau leve), com 11 e 9 anos, no $6^{\circ}$ e $3^{\circ}$ ano do ensino fundamental, respectivamente e dois com diagnóstico de TDI, com 11 e 8 anos, no $5^{\circ}$ e $2^{\circ}$ ano do ensino fundamental, respectivamente. Foram avaliados os seguintes componentes cognitivos: funcionamento cognitivo global, habilidades verbais, aspectos visuo-espaciais e construtivos, processamento de memória de trabalho fonológica, controle inibitório, funções executivas (planejamento e flexibilidade cognitiva), aprendizagem verbal e teoria da mente. Os resultados dos testes neuropsicológicos foram comparados e analisados pelos escores padronizados. Os casos com TEA apresentaram desempenho inferior nas tarefas de Teoria da Mente em comparação aos casos com TDI, sendo esta função cognitiva um possível marcador primário do diagnóstico de TEA. O mesmo efeito não foi observado nas tarefas que avaliaram as demais funções cognitivas, em especial funções executivas. Apesar dos resultados condizentes com a literatura, os dados apontam impasses na caracterização de um perfil sociocognitivo de ambos os diagnósticos e levanta discussões quanto ao diagnóstico diferencial.

Palavras-chave: Transtorno do espectro autista, diagnóstico diferencial, avaliação neuropsicológica, Teoria da Mente, deficiência intelectual.

\section{Abstract:}

Autism spectrum disorder (ASD) is a relevant diagnosis in school-age children context. The prevalence and variability of ASD criteria show the need for the development of instruments to improve accuracy in the identification of this diagnosis. The objective of this study is to describe, from multiple cases, the differences between neuropsychological tests performance of ASD with intellectual disability and pure Intellectual Deficit Disorder (ID); in addition to identifying possible primary and secondary markers of the ASD's cognitive profile. Four clinical cases attended in the Neuropsychology service of PUC-Rio participated in this study: two participants with clinical diagnosis of ASD (level 
1), with 11 and 9 years, in the 6th and 3rd year of elementary School, respectively, and two with diagnosis of ID, 11 and 8 years old, in the 5th and 2nd year of elementary school, respectively. The following cognitive components were evaluated: global cognitive functioning, verbal skills, visuo-spatial and constructive aspects, phonological working memory processing, inhibitory control, executive functions (planning and cognitive flexibility), verbal learning and theory of mind. The cases were discussed, from the results of the comparative neuropsychological evaluation. The cases were discussed, based on the results of the comparative neuropsychological evaluation. Theory of mind tasks showed consistency in ASD cases compared to pure ID cases. The same effect was not observed in the tasks that evaluated other cognitive functions, in particular executive functions. Despite the results consistent with the literature, the data points to the impasses in the characterization of a sociocognitive profile of both diagnoses and raises discussions about the differential diagnosis.

Keywords: Autism spectrum disorder; differential diagnosis, neuropsychological assessment, Theory of mind, intellectual disorder.

2- Artigo aceito para publicação em agosto de 2018 na revista SLAN (Fernandes, CharchatFichman \& Barros, 2018). 


\section{1-INTRODUÇÃO}

O transtorno do espectro autista (TEA) é um diagnóstico prevalente no contexto infantojuvenil. Ele afeta diversos aspectos da cognição e apresenta manifestações comportamentais significativas (Losh, et al., 2009). Dados recentes mostram que atinge 3\% da população, com prevalência de 1 a cada 100 crianças, segundo National Institute for Health and Care Excellence NICE - (Yates \& Couteur, 2016).

Segundo as Diretrizes de Atenção à Reabilitação da pessoa com transtornos do espectro do autismo (TEA), lançada pelo Ministério da Saúde (Brasil, 2013), os estudos no Brasil são escassos. Contudo, eles trazem um estudo onde há uma estimativa de prevalência de 500 mil pessoas com TEA, a partir do Censo realizado em 2000.

Também se mostra relevante, entender os critérios diagnósticos e a variabilidade dentro do fenótipo. Os critérios passaram por mudanças ao longo dos anos. Por algum tempo foram agrupadas características comuns em subgrupos de diagnósticos. Atualmente, o diagnóstico é único, com variabilidade no espectro. Independente destas mudanças, existem perfis diferentes incluídos no mesmo diagnóstico, com influências de variáveis como déficit intelectual (DI) (Constantino \& Charman, 2016). Todos estes aspectos podem causar conflitos no diagnóstico.

Polyak, Kubina e Girirajan (2015), por exemplo, mostram dados de estimativas de prevalência, impactadas por comorbidades no TEA, como síndromes genéticas e TDI. Os autores realizaram um estudo longitudinal ao longo de 11 anos, em diversas escolas de educação especial, nos Estados Unidos. Eles observaram aumento substancial de prevalência de TEA, devido a comorbidades com DI. Os autores descrevem que o aumento de TEA estaria relacionado com a diminuição de diagnóstico de TDI, sendo que há maior tendência de crianças mais velhas com TDI serem recategorizadas como TEA. Logo, houve uma correlação negativa entre prevalências de diagnósticos como TEA e TDI, contudo isto não ocorre em todos os estados, talvez por políticas de saúde, ou devido a categorização utilizada, ou mesmo impacto sociocultural. As 
estimativas sofrem alterações também em função da idade. Picos de maior prevalência para TEA entre 7 e 9 anos e para TDI entre 11 e 18 anos, possivelmente pelas janelas de diagnósticas, pelas comorbidades, ou mesmo pelos critérios utilizados. Este estudo coloca em perspectiva o impacto das comorbidades na prevalência e possíveis confusões diagnósticas, especialmente entre TEA e TDI.

As características diagnósticas clínicas também não são totalmente excludentes entre TEA e TDI. Pedersen et al. (2016), realizaram um estudo com 2816 crianças entre 8 e 14 anos para diferenciar crianças com TDI com alguns sintomas de TEA, daquelas com TEA e TDI. Eles compararam, a partir de análise de registro destas crianças, através de 14 lugares dos Estados Unidos, o poder de discriminação dos critérios diagnósticos do DSM IV-Tr entre os dois diagnósticos. Eles realizaram análise de curva Roc e encontraram: (1) comportamentos motores repetitivos seriam mais discriminantes do que adesão a rotina; e (2) que um conjunto de critérios associados, composto 2 fatores sociais e 4 critérios da classe de comportamentos estereotipados, como interesses restritos, maneirismos motores, adesão a rotina e preocupação com partes e não com todo, teriam melhor poder de discriminação para diferenciar os dois diagnósticos. Logo, individualmente os critérios relacionados a comportamentos estereotipados seriam mais discriminantes, bem como teriam maior impacto quando em conjunto com os critérios de habilidades sociais. Contudo, os autores discutem que estes resultados contrastam com estudos anteriores.

A prevalência do diagnóstico de TEA (Brasil, 2013); bem como na variabilidade do espectro (Trammell, Wilczynski, Dale, \& Mcintoshi, 2013), e as variáveis, como as características comórbidas (Polyack, et al., 2016), mostram a necessidade de precisão diagnóstica, em especial na diferenciação com TDI (Simms, 2017; Polyack, et al., 2016). Alguns perfis psicológicos são encontrados na literatura para contribuir com diagnóstico diferencial. De forma consistente é observado no TEA: (1) alterações em Teoria da Mente- ToM, no que diz respeito a falsa crença (Baron-Cohen et al., 1985), (2) rigidez comportamental (mudanças de rotina, padrões repetitivos e interesses restritos) e (3) inadequação de comunicação e interação social (Simms, 2017). Há, ainda, aspectos de perfil neuropsicológico, como funções executivas, em especial déficits em flexibilidade 
cognitiva (Leung \& Zakzanis, 2014) e processos de autorregulação: memória de trabalho (Faja \& Dawson, 2014) e controle inibitório (Schmitt et al., 2018).

Barendse et al. (2018), identificam menor eficiência em memória de trabalho em TEA de alto funcionamento, comparado com grupo saudável. Já Bühler, Bachmann, Goyert, Heinzel-Gutenbrunner e Kamp-Becker (2011) não encontram diferenças entre TEA e transtorno do déficit de atenção/ hiperatividade em tarefas de ToM, demonstrando que ambos apresentam impacto nesta habilidade. Porém, identificam maior prejuízos de controle inibitório em TEA com comorbidade com déficit de atenção.

Contudo, estes perfis de prejuízos psicológicos e neuropsicológicos também são encontrados em outros diagnósticos (Alloway et al., 2016). Os autores apontam para prejuízos em controle inibitório e memória de trabalho no TDI. Schuchardt, Gebhardt e Mäehler (2010) discutem o aumento do prejuízo de memória de trabalho, quanto maior o prejuízo intelectual em indivíduos com TDI. Bexkens, Ruzzano, Collot Escury-Koenigs, Van der Molen, e Huizenga, (2014), encontram prejuízos inibitórios em alguns aspectos no TDI.

Estes estudos mostram que o perfil psicológico e neuropsicológico encontrado no TEA, pode ser observado em outros diagnósticos, possivelmente com variações clínicas e que comorbidades podem gerar variações neste perfil do TEA. Logo, buscar evidências que auxiliem no diagnóstico diferencial tem um impacto clínico significativo, tornando as intervenções mais consistentes. O interesse do presente estudo centra-se no diagnóstico diferencial de TEA e TDI. O objetivo é descrever, a partir da avaliação neuropsicológica de múltiplos casos, as diferenças entre TEA com rebaixamento intelectual e o TDI puro, com prejuízos sociais; além de discutir possíveis aspectos neuropsicológicos primários e secundários nos casos clínicos observados.

\section{2-MÉTODO}

\subsection{1- PARTICIPANTES}

Quatro casos clínicos atendidos no serviço de neuropsicologia da PUCRio. Participaram desse estudo dois participantes com diagnóstico clínico de TEA 
(Grau leve), com 11 e 9 anos, no $6^{\circ}$ e $3^{\circ}$ ano do ensino fundamental, respectivamente e dois com diagnóstico de TDI, com 11 e 8 anos, no $5^{\circ}$ e $2^{\circ}$ ano do ensino fundamental, respectivamente. Os quatro casos apresentaram queixas de prejuízos sociais, tais como: isolamento social com pares, dificuldades na sustentação de amizades, prejuízos em compreensão de metáforas e prejuízos de aprendizagem, tais como: reprovação escolar, notas abaixo do esperado.

\subsection{2- INSTRUMENTOS}

\subsubsection{1-Avaliação neuropsicológica}

1-Entrevista clínica semi-estruturada, construída pelo serviço de neuropsicologia da PUC-Rio. A entrevista conta com informações sociodemográficas, história de desenvolvimento cognitivo e psicomotor, história da queixa neuropsicológica e aspectos sociocomportamentais. As entrevistas foram realizadas com as mães dos pacientes.

2-Escala Weschsler de Inteligência para Crianças- WISC IV (Wechsler, 2013): Compreende dez subtestes principais e cinco suplementares. Avalia diversos aspectos da inteligência, como compreensão verbal, organização perceptual, memória operacional e velocidade de processamento. Gera os seguintes valores: QI total (Funcionamento cognitivo Global), índice de compreensão Verbal (Habilidades verbais) e índice de organização perceptual (aspectos visuoespaciais e construtivos), índice de memória de trabalho e velocidade de processamento.

2.1-Subteste dígitos- WISC IV (Wechsler, 2013): O subteste consiste de aplicação de sequências de números. Ele é aplicado em duas etapas (ordem direta e ordem inversa). Na ordem direta, o avaliando deve repetir as sequências na ordem que são ditas pelo aplicador. Na sequência inversa, o avaliando deve repetir a sequência na ordem inversa à que o avaliador está repetindo. Cada item do subteste é composto por duas tentativas. A cada item, a quantidade de números na sequência aumenta. As tentativas não podem ser repetidas pelo avaliador. Este subteste avalia memória de trabalho fonológica, atenção sustentada e flexibilidade cognitiva. 
3-Paradigma Stroop-Vitória (Spreen e Strauss,1998): O teste consiste em três condições. Na condição 1 (C1), é feita a nomeação, o mais rápido possível, 24 quadrados pintados com as cores azul, verde, vermelho e amarelo. Na condição 2 (C2), as cores são nomeadas, só que agora em forma de palavras comuns. Na condição 3 (C3)- condição de interferência, o procedimento é semelhante ao das partes anteriores, só que as palavras são os nomes das cores pintadas de cores incongruentes. Avalia controle inibitório (C3). As normas utilizadas para estes casos encontram-se em Oliveira, Mograbi, Gabrig, \& Charchat-Fichman (2016).

4-Rey Auditory Verbal Learning test (RAVLT-versão reduzida para crianças em português) (Oliveira \& Charchat-Fichman, 2008): O teste consiste na leitura pelo examinador de 12 palavras por quatro tentativas consecutivas. Cada tentativa é seguida por uma evocação livre. Uma lista de interferência é apresentada (B1), em seguida, solicita-se evocação após interferência (A5). Após 20 minutos de intervalo, é solicitado a evocação livre (A6). Posteriormente, é realizada uma tarefa de reconhecimento A aprendizagem verbal é avaliada pelo somatório das 4 tentativas (Somatório A1-A4). Controle inibitório é avaliado através do desempenho na lista B1, consolidação da aprendizagem após interferência é avaliada pela lista A5 e a consolidação de aprendizagem após período de tempo é avaliada pela lista A6. As normas utilizadas encontram-se em Oliveira et al. (2016).

5-Paradigma de Fluência verbal (Spreen e Straus, 1998): O procedimento se inicia ao solicitar que o indivíduo produza oralmente o maior número possível de palavras iniciando com as letras "F", “A”, "M", um minuto para cada. Não são consideradas palavras corretas: nomes próprios e derivações de gênero, número e grau. Esta parte é denominada de fluência verbal fonológica-FAM e sugere o desempenho de flexibilidade cognitiva, busca estratégica do léxico, ou seja, aspectos de funções executivas e de linguagem. Além disso, solicita-se que o indivíduo produza oralmente o maior número de nomes de animais, com tempo limite de um minuto. Não são consideradas palavras corretas: derivações de gênero. Esta parte do paradigma é denominado de fluência verbal semânticaanimais e avalia o acesso a memória léxico-semântica. As normas utilizadas encontram-se em Oliveira et al. (2016). 
6-Figura complexa de Rey (Oliveira \& Rigoni, 2010): O procedimento consiste em solicitar cópia da figura complexa de Rey em uma folha de papel em branco (cópia) e após intervalo, de forma incidental, solicitar que a reproduza de memória (recordação). A cópia avalia habilidade visuoespacial/ construtiva (planejamento, organização, estratégias de resolução de problemas- Funções executivas) e a evocação, avalia a memória episódica visual.

\subsubsection{2-Avaliação ToM: Três tarefas foram desenvolvidas:}

Tarefa 1: Nomeação e gradação de emoções simples (NGEs). Nesta tarefa são utilizadas 4 emoções básicas (Felicidade, Tristeza, Medo e Raiva), retiradas de imagens públicas de uma personagem de cartoon. As imagens foram trabalhadas para que todas as faces estivessem na mesma posição. As emoções são nomeadas e graduadas do nível mais sutil para mais explícita, dentro da qualidade da emoção. Por exemplo: pouco feliz, médio feliz e muito feliz. Na gradação de emoções, cada grupo contém 3 faces em níveis diferentes, que variam do mais sutil até o mais intenso da emoção, representado por sinais de expressão não verbal, tais como: sorriso mais sutil (linha da boca menos curva) ou mais intenso (linha da boca mais curva, bochechas levantadas); olhos mais sutis (menos estreitos), ou em nível mais intenso de emoção (pele da pálpebra para cima). Estes sinais foram retirados da descrição feita por Ekman e Friesen (2003). Exemplos podem ser observados Figura 2.

No primeiro momento da tarefa, as imagens são apresentadas, solicitandose aos participantes que as categorizem, ou seja, que agrupem a partir de suas semelhanças. Instrução: “Coloque as emoções parecidas juntas”.

No segundo momento, solicita-se a nomeação. Instrução: "Diga o nome deste grupo de emoção". Na última etapa da tarefa, os participantes graduam, do nível mais sutil para o mais intenso. Instrução: “Coloque em ordem de menos raiva para mais raiva". Quando se verifica dificuldades de nomeação, opções são dadas para que a criança escolha dentre elas. São pontuadas nomeações e a posição da gradação corretas de cada nível em 0-1 ponto. É realizado o percentual do somatório dos acertos. 
Tarefa 2: Identificação de estados mentais (EM). As cenas apresentam apenas um quadro, mas aumentam em complexidade de inferência e metáfora e quantidade de personagens ou elementos significativos envolvidos, como mostra tabela 6 . Exemplo pode ser observado na figura 2.

Tabela 6- Descrição das cenas

\begin{tabular}{|c|c|c|c|}
\hline & $\begin{array}{c}\text { Personagens } \\
\text { e elementos }\end{array}$ & Objetivos da tarefa & $\begin{array}{c}\text { Características } \\
\text { da cena }\end{array}$ \\
\hline Cena 1 & $\begin{array}{l}\text { Um } \\
\text { personagem } \\
\text { masculino } \\
\text { Uma } \\
\text { personagem } \\
\text { feminina } \\
\text { Um elemento } \\
\text { significativo } \\
\text {-objeto: carta }\end{array}$ & $\begin{array}{l}\text { Identificar a emoção da personagem, pela face } \\
\text { ou baseada na situação. } \\
\text { Inferir pensamento da personagem, baseado na } \\
\text { emoção. }\end{array}$ & $\begin{array}{lr}\text { A inferência } \\
\text { principal da } \\
\text { cena estava } \\
\text { explícita } \\
\text { Havia } \\
\text { perspectiva }\end{array}$ \\
\hline Cena 2 & $\begin{array}{l}\text { Uma menina, } \\
\text { dois animais e } \\
\text { um elemento } \\
\text { significativo } \\
-\quad \text { objeto: } \\
\text { cesta de } \\
\text { piquenique }\end{array}$ & $\begin{array}{l}\text { Identificar a emoção das personagens animais } \\
\text { Identificar a emoção da personagem humana, } \\
\text { baseada na situação. } \\
\text { Identificar o conhecimento da personagem } \\
\text { humana sobre a perspectiva dos animais. } \\
\text { Identificar a crença/antecipação baseada no } \\
\text { desejo dos animais. }\end{array}$ & $\begin{array}{l}\text { A inferência } \\
\text { principal da } \\
\text { cena estava } \\
\text { explícita } \\
\text { Havia } \\
\text { representações } \\
\text { em diferentes } \\
\text { perspectivas }\end{array}$ \\
\hline Cena 3 & $\begin{array}{l}\text { Dois } \\
\text { meninos, uma } \\
\text { menina e dois } \\
\text { elementos } \\
\text { significativos- } \\
\text { objeto: } \\
\text { brinquedo da } \\
\text { menina e } \\
\text { estado de um } \\
\text { dos } \\
\text { personagens }\end{array}$ & $\begin{array}{l}\text { Identificar a emoção de } 2 \text { personagens, por faces } \\
\text { ou baseada na situação. } \\
\text { Identificação da perspectiva da personagem } \\
\text { feminina. } \\
\text { Identificar o conhecimento de um personagem } \\
\text { masculino sobre a perspectiva da personagem } \\
\text { feminina. } \\
\text { Identificar a perspectiva do } 2^{\text {a }} \text { personagem } \\
\text { masculino (quer era diferente do } 1^{\circ} \text { ) sobre a } \\
\text { perspectiva da personagem masculino e da } \\
\text { personagem feminina. }\end{array}$ & $\begin{array}{l}\text { A inferência } \\
\text { principal da } \\
\text { cena estava } \\
\text { explícita } \\
\text { Havia } \\
\text { representações } \\
\text { em diferentes } \\
\text { perspectivas } \\
\text { (posições das } \\
\text { personagens e } \\
\text { pensamentos } \\
\text { diferentes) }\end{array}$ \\
\hline
\end{tabular}

Nestas cenas, solicita-se que as crianças narrem a história. Perguntas de níveis de estados mentais são realizadas. Por fim, a criança reconta a história. A pontuação é feita a partir da análise qualitativa de elementos de estados mentais utilizados espontaneamente na construção do reconto das histórias e nas respostas às perguntas realizadas pelo avaliador.

A categorização utilizada para pontuar as verbalizações emitidas, são baseadas na descrição de níveis de estados mentais definidos por Howlin et al (2006). Eles definem que o entendimento de estados mentais pode ser separado 
em três componentes (1-entendimento da emoção; 2-os pensamentos e 3- a identificação do fingimento ou falsa aparência). Para a categorização desta análise, são utilizados os critérios para entendimento da emoção e de pensamentos. Segundo os autores, cada um destes critérios apresenta cinco níveis. Os níveis utilizados foram definidos a partir da demanda da cena. São pontuadas (0-1 ponto) verbalizações esperadas, seguindo os parâmetros descritos na tabela 7 . É realizado o percentual do somatório dos acertos

Tabela 7. Parâmetros de classificação de níveis de estados mentais

\begin{tabular}{|c|c|c|}
\hline Cenas & $\begin{array}{l}\text { Níveis de estados mentais } \\
\text { utilizadas }\end{array}$ & Resposta esperada \\
\hline \multirow{3}{*}{ Cena 1} & Entendimento de emoção-Nível 1 & $\begin{array}{l}\text { Identificação de emoção por reconhecimento } \\
\text { de faces (Vergonha na face da personagem } \\
\text { feminina); }\end{array}$ \\
\hline & Entendimento de emoção- Nível 3 & $\begin{array}{l}\text { Identificação de emoção baseada na situação } \\
\text { (vergonha porque o menino estava } \\
\text { debochando, por causa do objeto); }\end{array}$ \\
\hline & Entendimento de emoção-Nível 5 & $\begin{array}{l}\text { Identificação de pensamento baseado em } \\
\text { emoção (A menina pensa: "O menino } \\
\text { descobriu que eu gosto de alguém"). }\end{array}$ \\
\hline \multirow{4}{*}{ Cena 2} & Entendimento de emoção-Nível 4 & $\begin{array}{l}\text { Identificação de emoção baseada no desejo } \\
\text { (os animais estão desanimados ou tristes } \\
\text { porque querem comer a comida do } \\
\text { piquenique); }\end{array}$ \\
\hline & Entendimento de emoção -Nível 3 & $\begin{array}{l}\text { Identificação de emoção baseada na situação } \\
\text { (A menina está feliz, porque estava } \\
\text { comendo) }\end{array}$ \\
\hline & Entendimento de crença- Nível 3 & $\begin{array}{l}\text { Saber leva ao conhecimento-see-know (A } \\
\text { menina não sabe que eles estão olhando para } \\
\text { ela) }\end{array}$ \\
\hline & Entendimento de crença- Nível 4 & $\begin{array}{l}\text { Crença verdadeira/antecipação de } \\
\text { comportamento (Os animais pensam: "ela } \\
\text { vai comer tudo") }\end{array}$ \\
\hline \multirow{3}{*}{ Cena 3} & Entendimento de emoção- Nível 3 & $\begin{array}{l}\text { Identificação de emoção baseada na situação } \\
\text { (raiva porque o brinquedo estava estragado e } \\
\text { assustado/desconfiado porque viu que a } \\
\text { menina estava nervosa); }\end{array}$ \\
\hline & Entendimento de emoção-Nível 1 & $\begin{array}{l}\text { Identificação de emoção por reconhecimento } \\
\text { de faces (expressão de raiva, expressão de } \\
\text { assustado/desconfiado) }\end{array}$ \\
\hline & Entendimento de crença-Nível 3 & $\begin{array}{l}\text { A experiência leva ao conhecimento (sabe } \\
\text { que foi o menino que mexeu em seu } \\
\text { brinquedo porque viu que estava molhado). } \\
\text { Tomada de perspectiva complexa (O menino }\end{array}$ \\
\hline
\end{tabular}


não sabia que a menina o está vendo molhado)

Crença verdadeira/antecipação de comportamento (1- a menina vai bater no

Entendimento de crença-Nível 4 menino)

Identificação de pensamento baseado em

Entendimento de emoção nível 5 emoção (1- O segundo menino pensa: ela não vai acreditar nele)

Tarefa 3: Organização Lógica $(O L)$. Nesta tarefa é necessário organizar histórias a partir de pistas visuais e inferências sociais. Essas histórias são apresentadas em quadros separados e fora de ordem. É solicitado que a criança organize a história com início, meio e fim, como visto na Figura 2. São apresentadas cinco histórias, aumentando de três para cinco quadros. A pontuação é feita a partir do acerto ou erro da sequência. É realizado o percentual do somatório dos acertos Figura 2: Exemplos do material visual utilizado nas tarefas

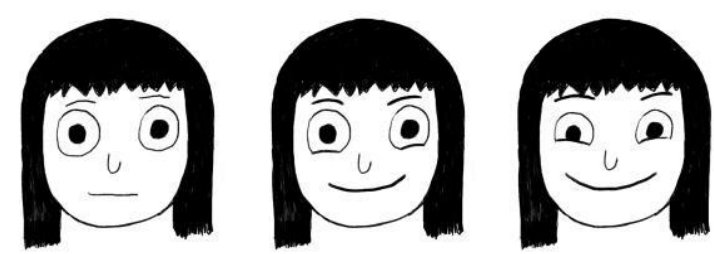

Exemplo de esquema para tarefa NGEs 


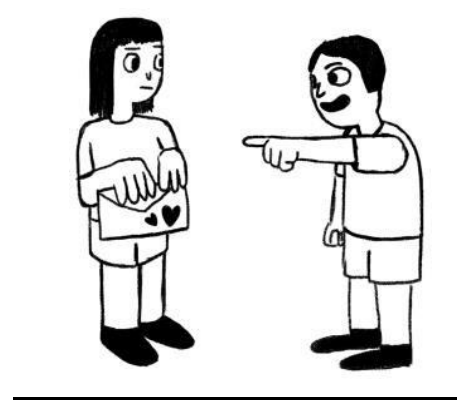

Esquema cena 1

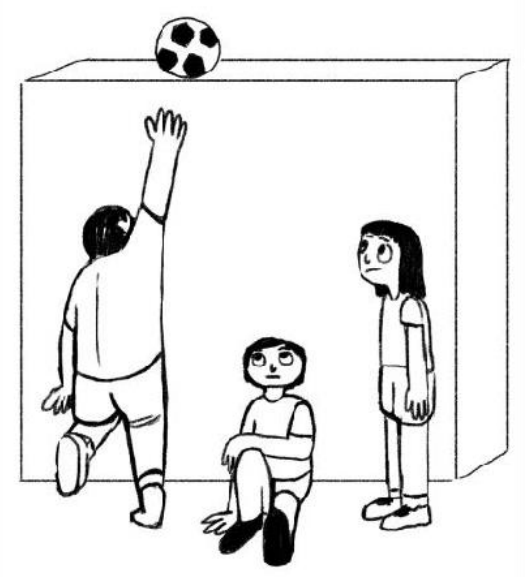

Esquema cena 3

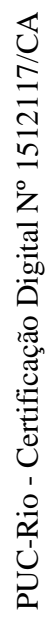

\section{Exemplo de cenas para tarefa EM}

Ordem correta:
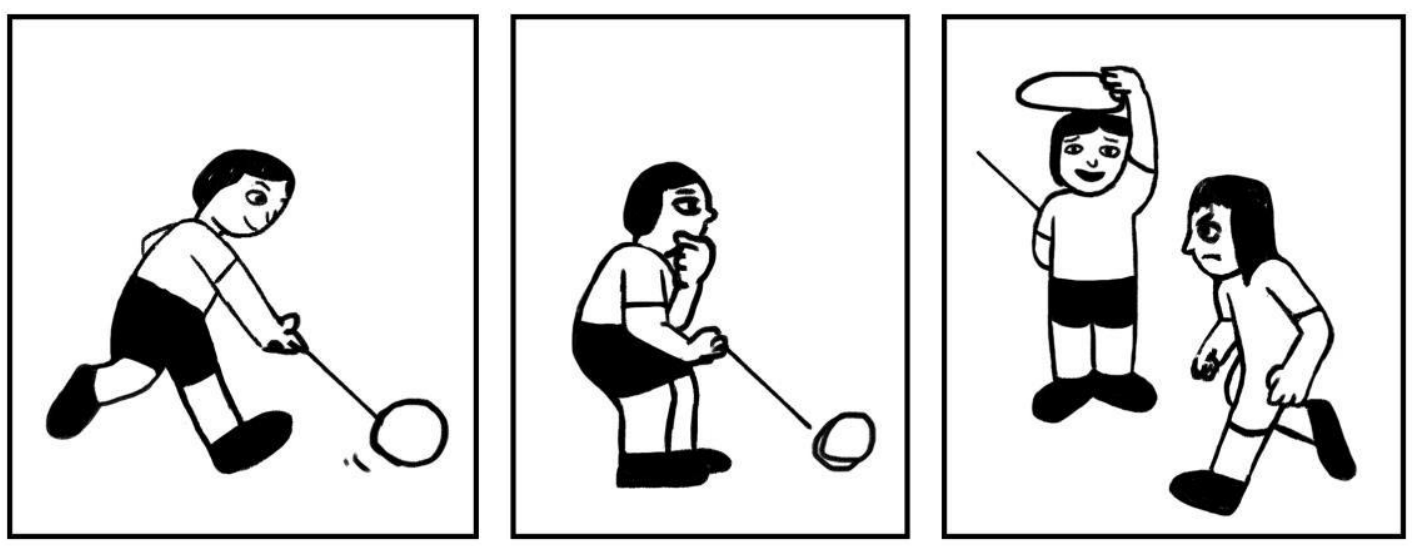

Exemplo de cena para tarefa OL

Na tabela 8 são especificadas as variáveis dos testes e paradigmas utilizados para avaliação das funções cognitivas. 
Tabela 8. Dados sociodemográficos e clínicos

\begin{tabular}{|c|c|}
\hline Variáveis de testes e paradigmas & Funções cognitivas avaliadas \\
\hline Qi Global -WISC IV & Funcionamento cognitivo global \\
\hline Índice de compreensão Verbal- WISC IV & Habilidades verbais \\
\hline $\begin{array}{l}\text { Índice de organização perceptual- WISC } \\
\text { IV }\end{array}$ & Aspectos visuoespaciais e construtivos \\
\hline Score Z da Cópia da Figura de Rey & Planejamento-Funções executivas \\
\hline Score Z-FAM & Flexibilidade cognitiva- Funções executivas \\
\hline $\begin{array}{l}\text { Span da ordem inversa do subteste Dígitos } \\
\text { - WISC IV }\end{array}$ & $\begin{array}{l}\text { Processamento De Memória De Trabalho } \\
\text { fonológica- Funções executivas }\end{array}$ \\
\hline Score Z*-C3 Stroop & Controle inibitório \\
\hline Score Z- BI RAVLT & Controle Inibitório \\
\hline Score Z A1-A4 RAVLT & Aprendizagem verbal \\
\hline Score Z-A6 RAVLT & $\begin{array}{l}\text { Consolidação de aprendizagem após efeito } \\
\text { de interferência }\end{array}$ \\
\hline Score Z -A7 RAVLT & $\begin{array}{l}\text { Consolidação da aprendizagem após período } \\
\text { de tempo }\end{array}$ \\
\hline $\begin{array}{l}\text { Percentual de acertos em NGEs-Nomeação } \\
(N) \text { e gradação }(G)\end{array}$ & Identificação de emoções-ToM \\
\hline Percentual de acertos em EM & $\begin{array}{l}\text { Identificação de estado e conhecimento } \\
\text { interno do outro-ToM }\end{array}$ \\
\hline Percentual em $\underline{\mathrm{OL}}$ & Inferências a partir de pistas visuais-ToM \\
\hline \multicolumn{2}{|c|}{ Nota. Score Z: número de desvios padrão acima ou abaixo da média da população. } \\
\hline \multicolumn{2}{|c|}{$\begin{array}{l}\text { RAVLT: Teste de Aprendizagem Auditivo-verbal de Rey; NGEs: Nomeação e gradação de } \\
\text { emoções simples; EM: Identificação de estados mentais; OL: Organização lógica; ToM: Teoria }\end{array}$} \\
\hline
\end{tabular}

\subsection{3- PROCEDIMENTOS E ASPECTOS ÉTICOS}

Todos os responsáveis pelos pacientes da clínica universitária assinaram termo de consentimento fornecido pelo Serviço de Psicologia Aplicada instituição-PUC-RIO. Após a assinatura, foram realizadas as avaliações neuropsicológicas. Todos passaram pelo mesmo protocolo de avaliação neuropsicológica e avaliação sociocomportamental, com uso de três tarefas, baseadas em domínios de ToM.

\section{3-RESULTADOS}

Os resultados mais detalhados das avaliações dos quatro casos clínicos dessa amostra, anteriormente caracterizados, dois com TEA (casos TEA 1 e 2), dois com TDI puro, com queixas sociais (casos TDI 1 e 2), serão apresentados 
abaixo. Os casos de TEA e TDI foram diagnósticos por psiquiatras e neurologistas previamente. O diagnóstico de déficit intelectual foi realizado através resultados fornecidos pelo WISC IV. Dados sociodemográficos (Tabela 49, caracterização clínica (Tabela 10) e sínteses de resultados (Tabela 11) são apresentados.

Tabela 9- Dados sociodemográficos

\begin{tabular}{cccc}
\hline Casos & Idade & Sexo & Escolaridade \\
\hline TEA 1 & 11 anos & Masculino & $6^{\circ}$ ano \\
TEA 2 & 9 anos & Masculino & $3^{\circ}$ anos \\
TDI 1 & 11 anos & Feminino & $5^{\circ}$ ano \\
TDI 2 & 8 anos & Feminino & $2^{\circ}$ ano \\
\hline
\end{tabular}

Tabela 10-Caracterização clínica

\begin{tabular}{|c|c|c|c|c|}
\hline & Aprendizagem & Socialização & Gestação & Desenvolvimento \\
\hline TEA 1 & $\begin{array}{l}\text { (a) Não } \\
\text { consegue } \\
\text { acompanhar o } \\
\text { conteúdo. } \\
\text { (b) Presença de } \\
\text { mediador. }\end{array}$ & $\begin{array}{l}\text { a)Isolamento em } \\
\text { brincadeiras. } \\
\text { (b)Dificuldade } \\
\text { de compreensão } \\
\text { de metáforas. } \\
\text { (c)Reduzida } \\
\text { aproximação de } \\
\text { pares. }\end{array}$ & $\begin{array}{l}\text { Ausência de } \\
\text { intercorrências }\end{array}$ & $\begin{array}{l}\text { (a) Falou com } 4 \text { anos } \\
\text { (b) Andou com } 1 \\
\text { ano } \\
\text { (c)Hipersensibilidad } \\
\text { e sensorial (luz) }\end{array}$ \\
\hline TEA 2 & $\begin{array}{l}\text { (a)Repetiu o } \\
\text { primeiro ano } \\
\text { (b)Dificuldades } \\
\text { em leitura e } \\
\text { escrita. }\end{array}$ & $\begin{array}{l}\text { (a) Desatenção. } \\
\text { (b)Brinca } \\
\text { sozinho } \\
\text { (c)Fala pouco } \\
\text { com amigos e } \\
\text { professores } \\
\text { (d)Prefere ficar } \\
\text { mais isolado } \\
\text { "assistindo" a } \\
\text { brincadeira } \\
\text { (e) Quando } \\
\text { algum problema } \\
\text { o acontece fica } \\
\text { mais retraído }\end{array}$ & $\begin{array}{l}\text { Nascimento } \\
\text { antes de } 32 \\
\text { semanas } \\
\text { Toxoplasmose } \\
\text { mãe }\end{array}$ & $\begin{array}{l}\text { (a) Falou com } 3 \text { anos } \\
\text { (b) Andou dentro do } \\
\text { esperado }\end{array}$ \\
\hline TDI 1 & $\begin{array}{l}\text { (a) Notas abaixo } \\
\text { do esperado. } \\
\text { (b)Dificuldades } \\
\text { de compreensão } \\
\text { do conteúdo. } \\
\text { (c) Os deveres } \\
\text { são realizados } \\
\text { com auxílio. }\end{array}$ & $\begin{array}{l}\text { (a) Fala sobre } \\
\text { assuntos pouco } \\
\text { pertinentes a } \\
\text { situação; } \\
\text { (b) } \\
\text { Imaturidade- se } \\
\text { interessa por } \\
\text { brincadeiras e }\end{array}$ & $\begin{array}{l}\text { Não há } \\
\text { descrições } \\
\text { precisas, por ter } \\
\text { sido adotada }\end{array}$ & $\begin{array}{l}\text { Não há descrições } \\
\text { precisas, por ter sido } \\
\text { adotada }\end{array}$ \\
\hline
\end{tabular}




\begin{tabular}{l|l|l|l|l}
\hline & & $\begin{array}{l}\text { assuntos } \\
\text { destinados a } \\
\text { crianças mais } \\
\text { novas como, } \\
\text { por exemplo, } \\
\text { Pepa Pig }\end{array}$ & \\
\hline TDI 2 & $\begin{array}{l}\text { (a)Repetiu } \\
\text { segundo ano } \\
\text { (B) Notas } \\
\text { abaixo da média } \\
\text { em todas as } \\
\text { disciplinas }\end{array}$ & Ausente & $\begin{array}{l}\text { (a)Nasceu com } \\
\text { menos de 28 } \\
\text { semanas de } \\
\text { gestação } \\
\text { (b)Internação } \\
\text { hospitalar por } \\
\text { volta de 1 mês e } \\
\text { meio }\end{array}$ & Não houve atrasos \\
\hline
\end{tabular}

Tabela 11. Síntese dos resultados

\begin{tabular}{|c|c|c|c|c|c|}
\hline $\begin{array}{c}\text { Funções } \\
\text { Cognitivas } \\
\end{array}$ & Variáveis & TEA 1 & TEA 2 & TDI 1 & TDI 2 \\
\hline $\begin{array}{l}\text { Funcionamento } \\
\text { cognitivo global }\end{array}$ & QI global & 67 & 75 & 71 & 65 \\
\hline $\begin{array}{l}\text { Habilidades } \\
\text { Verbais }\end{array}$ & $\begin{array}{c}\text { Índice de } \\
\text { compreensão } \\
\text { verbal }\end{array}$ & 80 & 89 & 65 & 65 \\
\hline $\begin{array}{l}\text { Aspectos visuo- } \\
\text { espaciais } \\
\text { construtivos }\end{array}$ & $\begin{array}{c}\text { Índice de } \\
\text { organização } \\
\text { perceptual }\end{array}$ & 69 & 89 & 83 & 71 \\
\hline $\begin{array}{l}\text { Processamento } \\
\text { de memória de } \\
\text { trabalho } \\
\text { fonológica }\end{array}$ & $\begin{array}{l}\text { Span inverso } \\
\text { (Número de } \\
\text { Dígitos) }\end{array}$ & 3 & 2 & 2 & 2 \\
\hline \multirow{2}{*}{$\begin{array}{l}\text { Controle } \\
\text { Inibitório }\end{array}$} & Score z -C3 & $55^{\prime \prime}(-2,71 \mathrm{DP})$ & $34^{\prime \prime}(+0,34 \mathrm{DP})$ & $50 `(-2,10 \mathrm{DP})$ & - \\
\hline & Score z- B1 & $2(-2,4 \mathrm{DP})$ & $2(-2,30 \mathrm{DP})$ & $3(-1,73 \mathrm{DP})$ & $1(-2,69 \mathrm{DP})$ \\
\hline \multirow{2}{*}{$\begin{array}{l}\text { Funções } \\
\text { executivas } \\
\text { (planejamento e } \\
\text { flexibilidade } \\
\text { cognitiva }\end{array}$} & $\begin{array}{c}\text { Score z -Cópia } \\
\text { Da Figura De } \\
\text { Rey }\end{array}$ & $7(-28,48 \mathrm{DP})$ & $17,5(-2,55 \mathrm{DP})$ & $27,5(-1,29 \mathrm{DP})$ & $2(-3,53 \mathrm{DP})$ \\
\hline & Score z- FAM & $\begin{array}{c}\mathrm{F}=4(-1,42 \mathrm{DP}) \\
\mathrm{A}=3(-2,17 \mathrm{DP}) \\
\mathrm{M}=6(-0,86 \mathrm{DP}\end{array}$ & $\begin{array}{c}\mathrm{F}=1(-2,48) \\
\mathrm{A}=2(-1,96 \mathrm{DP}) \\
\mathrm{M}=6(-1,32 \mathrm{DP})\end{array}$ & $\begin{array}{l}F=1(-2,33 D P) \\
A=3(-2,17 D P) \\
M=4(-1,55 D P)\end{array}$ & $\begin{array}{l}F=4(-O, 9 D P) \\
A=4(-O, 54 D P) \\
M=1(-1,6 D P)\end{array}$ \\
\hline $\begin{array}{l}\text { Aprendizagem } \\
\text { verbal }\end{array}$ & $\begin{array}{c}\text { Score z-A1- } \\
\text { A4 }\end{array}$ & $28(-1,61 d p)$ & $33(0,16 \mathrm{DP})$ & $32(-0,70 \mathrm{DP})$ & $20(-1,40 \mathrm{DP})$ \\
\hline $\begin{array}{l}\text { Consolidação de } \\
\text { aprendizagem } \\
\text { após efeito de } \\
\text { interferência }\end{array}$ & Score z-A5 & $7(-1,0 \mathrm{DP})$ & 8 (0DP) & $4(-2,66 \mathrm{DP})$ & $5(-\mathrm{O}, 86 \mathrm{DP})$ \\
\hline $\begin{array}{l}\text { Consolidação de } \\
\text { aprendizagem } \\
\text { após período de } \\
\text { tempo }\end{array}$ & Score z-A6 & 7 (-1,05DP) & 8 (0DP) & $0(-4,94 \mathrm{DP})$ & 7 (-0,13DP) \\
\hline
\end{tabular}




\begin{tabular}{|c|c|c|c|c|c|}
\hline $\begin{array}{l}\text { Identificação de } \\
\text { emoções-ToM }\end{array}$ & $\begin{array}{l}\text { Percentual } \\
\text { NGEs }\end{array}$ & $\begin{array}{l}\mathrm{N}=90 \% \\
\mathrm{G}=60 \%\end{array}$ & $\begin{array}{l}\mathrm{N}=100 \\
\mathrm{G}=83,3 \%\end{array}$ & $\begin{array}{l}\mathrm{N}=100 \% \\
\mathrm{G}=100 \%\end{array}$ & $\begin{array}{l}\mathrm{N}=100 \% \\
\mathrm{G}=100 \%\end{array}$ \\
\hline \begin{tabular}{l}
\multicolumn{2}{l}{ Identificação de } \\
estado \\
conhecimento \\
interno do \\
outro-ToM
\end{tabular} & Percentual EM & $\mathrm{T}=33,3 \%$ & $\mathrm{~T}=40 \%$ & $\mathrm{~T}=80 \%$ & $\mathrm{~T}=60 \% \%$ \\
\hline $\begin{array}{l}\text { Inferências a } \\
\text { partir de pistas } \\
\text { visuais-ToM }\end{array}$ & Percentual OL & $\mathrm{T}=50 \%$ & $\mathrm{~T}=80 \%$ & $\mathrm{~T}=90 \%$ & $\mathrm{~T}=90 \%$ \\
\hline
\end{tabular}

\section{4-DISCUSSÃO}

O primeiro caso de TEA apresentou rebaixamento de funcionamento cognitivo global, com assimetria entre índices de compreensão verbal e de organização perceptual, sendo o primeiro com melhor desempenho. Além disso, há prejuízos significativos de controle inibitório, memória de trabalho e funções executivas. Há déficits sociais relatados, bem como atraso de aquisição de linguagem.

O segundo paciente com TEA, também apresentou rebaixamento cognitivo global, porém não se observa assimetria entre índices de compreensão verbal e de organização perceptual. Há prejuízos significativos de controle inibitório e memória de trabalho. No relato em entrevista clínica, há queixas sociocomportamentais e atraso de aquisição de linguagem.

O caso 1 de TDI apresentou assimetria entre índices de compreensão verbal e de organização perceptual, sendo o verbal mais comprometido, há prejuízos em controle inibitório, funções executivas e imaturidade comportamental importante. Não há relato de atraso de linguagem.

O caso 2 de TDI, também apresentou assimetria entre índices de compreensão verbal e de organização perceptual, sendo o verbal mais comprometido. Há prejuízos atencionais e executivos impactando a 
aprendizagem. Não há relato de prejuízos sociocomportamentais significativos, bem como de atraso de linguagem.

Os testes neuropsicológicos constataram rebaixamento do funcionamento cognitivo global nos quatro pacientes. Aqueles com diagnóstico de TEA apresentaram melhor índice de compreensão verbal em comparação com TDI. A mesma consistência não é observada nos índices de organização perceptual. Além disso, nos casos com diagnóstico de TEA, a aprendizagem verbal, avaliada a partir do Score $\mathrm{Z}$ de consolidação de evocações nas listas do RAVLT, encontra-se dentro da média esperada, ou com reduzido impacto, para suas idades, apesar do rebaixamento, quando comparado com os pacientes com TDI.

Além dessas assimetrias na aprendizagem e nas tarefas verbais, outros resultados foram verificados. $\mathrm{Na}$ análise dos casos, os resultados das tarefas ToM mostraram ser parâmetros para diferenciar TEA de TDI. Os resultados de flexibilidade cognitiva, controle inibitório e memória de trabalho, apontados na literatura como marcadores de funções executivas no TEA, não foram tão consistentes na diferenciação destes diagnósticos (TEA e TDI). Estes serão discutidos a seguir.

\subsection{1-Teoria da Mente}

Nas tarefas de ToM houve maior robustez para distinguir pacientes TEA e TDI. Destaca-se as tarefas que avaliam nomeação e gradação de emoções, esta última com impacto mais relevante; além de organização de histórias lógicas a partir de pistas visuais.

Os aspectos sociocognitivos parecem estar mais bem circunscritos às características do TEA. Os dados mais consistentes aparecem nas tarefas NGEs e OL. Na tarefa NGEs, os resultados mostraram maior prejuízo em pacientes com diagnóstico confirmado de TEA. Houve menor percentual de acertos na identificação de emoções, em especial às variações de valência negativa (raiva e medo).

Dados semelhantes foram encontrados em Losh et al. (2009). Os autores realizaram um estudo de comparação entre TEA e parentes de TEA. Eles 
avaliaram funções executivas (flexibilidade, controle de interferências e planejamento), cognição social e coerência central. Dentre todas as medidas, os resultados mais significativos na distinção do desempenho entre os grupos foram as de cognição social. Foram utilizadas tarefas de reconhecimento de emoção, utilizando faces (Morphed Faces) e cenas com personagens com e sem rosto (Moving Still Cenes).

Diferenças entre TEA e controles neurotípicos foram observadas quanto à avaliação de sentimento de medo e suas variações (Morphed Faces). O mesmo não aconteceu para as emoções feliz e triste. Da mesma forma essa dificuldade é observada em parentes de autistas, só que em variações menos intensas dessa emoção.

Em outra tarefa de cenas com e sem rostos, com emoções coerentes (Moving Still Cenes), os autistas diferiram dos não autistas nas cenas sem rostos. Eles eram menos precisos para identificar cenas de raiva e tristeza sem rosto e muito precisos para identificar cenas de medo. Quando faces eram incorporadas nas cenas, eles continuaram pouco precisos para raiva e dessa vez também para medo, ou seja, a informação facial de emoções de valência negativa não melhorou a precisão de identificação.

Nas tarefas OL, baseadas na identificação e uso de pistas visuais, os participantes TEA, também apresentaram menor percentual de acertos. Qualitativamente, verifica-se que erros na organização de histórias se dão em função de maior foco nos detalhes ou no todo, ou seja, não gerenciam de forma apropriada as relações visuoespaciais entre parte e todo. Em pacientes TDI, verifica-se maior percentual de acertos, sendo os erros ocasionados por trocas atencionais.

Além da dificuldade em fazer uso das pistas visuais para gerenciar sua leitura de cenas sociais, identifica-se um aspecto qualitativo importante na análise da tarefa: erros de parte-todo. Na literatura, essas relações de parte e todo podem ser entendidas como coerência central. Ou, ainda, a capacidade de integrar informação em contexto (Booth \& Happé, 2018), sendo importantes na caracterização do autismo. No TEA, haveria, portanto, déficits nesta percepção mais global, onde há uma lentificação na integração dos elementos, comparados com controles saudáveis (Booth \& Happé, 2018) 
Losh et al. (2009) também encontra, neste estudo, resultados quanto a coerência central. Os autores verificam maior dificuldade de autistas em completar frases, utilizando respostas menos globais e nos aspectos visuais em organizar informações segmentadas. Estes dados estão compatíveis com os prejuízos no gerenciamento das relações entre parte-todo, também observado qualitativamente nas tarefas OL, neste estudo.

Nas análises da tarefa EM, os participantes com TEA obtiveram desempenho abaixo de $60 \%$ em acerto de verbalizações esperadas. Os participantes com TDI apresentaram melhor desempenho entre 60 a $80 \%$ de identificação. Apesar do desempenho de TDI ter sido melhor, ainda há inconsistência entre eles. Estes dados também são condizentes com a literatura sobre 'ToM e TEA. Existem críticas quanto ao desempenho de identificação de estados mentais nem sempre ser consistente, incluindo as falsas crenças (Scheeren et al., 2013), decorrente de diferentes níveis de funcionamento cognitivo e controle de variáveis cognitivas (Durrleman \& Franck, 2015; Lind \& Bowler, 2010).

Lind e Bowler (2010), destacam que tarefas de ToM não são puras e sofrem impacto de múltiplos processos cognitivos. Os autores constróem um modelo de estudo, comparando crianças com autismo, rebaixamento intelectual e desenvolvimento típico. Estes são avaliados em uma de tarefa see-know (onde o conhecimento se dá a partir do acesso a informação visual). Este nível de ToM seria anterior a falsa crença (Baron-cohen, Flavell, Miller \& Miller, 1999). Os autores modificam uma tarefa de Baron Cohen, introduzindo controle de variáveis que envolvem lembrança da ação e inferências a partir da ação, inferência lógica e não mental.

Os resultados mostraram que o grupo de autismo teve pior desempenho na tarefa see-know, mas alguns também tiveram desempenho prejudicado nas tarefas controle. Posteriormente, os sujeitos com desempenho abaixo do esperado nas tarefas controle foram retirados e as diferenças entre os grupos se mantiveram, mas dessa vez se mostraram significativas. Ou seja, aspectos de outros domínios cognitivos podem afetar o desempenho em tarefas de ToM. Com isso, os prejuízos encontrados podem não ser necessariamente originados no déficit de 
representação mental. O não controle destas variáveis pode aproximar estes diagnósticos.

Durrleman e Franck (2015), conduzem estas discussões em outra perspectiva. Segundo os autores, alguns autistas "passam" em tarefas de representação, como as falsas crenças. Os mesmos realizaram um estudo comparando autistas e crianças neurotípicas (DT). Foram aplicadas tarefas de falsa crença, sendo um modelo de tarefa verbal e outra não verbal; além de avaliação de funções executivas (Dimensional Change Card Sorting task), onde eram avaliados a inibição perceptual, a inibição da regra e a flexibilidade da regra.

Nos resultados sobre o modelo de apresentação, verificaram que o grupo de autismo apresentava maior dificuldade em tarefas verbais, sugerindo que o componente verbal influencia este desempenho. Nas correlações realizadas entre as tarefas de funções executivas e falsa crença, em um primeiro momento, não foram encontradas correlações em grupos separados (TEA e DT). Contudo, quando foi feita análise nos dois grupos, houve correlação significativa e positiva entre a flexibilidade da regra e tarefa de falsa crença não-verbal (Durrleman \& Franck, 2015).

Os dois estudos mostram que os níveis de estados mentais informacionais (saber o conhecimento do outro; Baron-Cohen et al., 1999), sofrem impacto de funções executivas, como a flexibilidade. É possível também que o impacto observado do componente verbal tenha uma interface com funções executivas, pois ao tirar a história verbal da tarefa, reduz a sobrecarga de memória de trabalho, processo subjacente ao gerenciamento executivo. Conforme estes componentes executivos são controlados, o prejuízo de representação mental, ou seja, ToM, melhor se define e pode ser um fator mais claro de diagnóstico diferencial.

\subsection{2-Funções executivas e aprendizagem}

As medidas de funções executivas não apresentaram resultados tão claros de diferenciação entre os diferentes diagnósticos no presente artigo, porém se mostram importantes na caracterização dos perfis neuropsicológicos. Há prejuízos em planejamento, processamento de memória de trabalho, controle 
inibitório e flexibilidade cognitiva em todos quatro casos analisados. Isto está condizente com os estudos de perfil neuropsicológico, que apontam para prejuízos em funções executivas e autorregulação, em especial memória de trabalho e controle inibitório, em ambos diagnósticos (Miller et al., 2015; Dekker et al., 2016).

Os prejuízos executivos parecem causar impacto em suas queixas mais predominantes. Contudo, este impacto não se dá da mesma forma em todos os diagnósticos, ou mesmo entre pacientes com TEA. Um exemplo disto é a aprendizagem verbal e sua conexão com os processos controlados da atenção.

No presente estudo, os pacientes com TEA e TDI apresentam variações entre si na curva de aprendizagem. Contudo, os pacientes com TEA têm menor prejuízo da interferência, observados na relação entre B1, na evocação em A5 do RAVLT, sofrendo menor impacto no acesso a informações aprendidas. Por outro lado, nos pacientes TDI há maior impacto do controle inibitório sobre as informações aprendidas e acessadas posteriormente. Além disso, o paciente TEA 2 oscila em seu desempenho em tarefas de controle inibitório (STROOP - melhor desempenho - e interferência do RAVLT) e a recuperação de memória está mais preservada que TEA 1 e os demais pacientes.

A literatura sobre memória mostra que os processos controlados, associados ao lobo frontal podem afetar a codificação e evocação de informações novas, ou seja, a aprendizagem (Stuss \& Alexandre, 2005). Mas neste artigo, os efeitos do controle atencional parecem ser mais robustos em TDI do que TEA. Discutem-se as seguintes hipóteses: (1) existem conflitos de desempenho de memória episódica no autismo, como pode ser verficado em Yat Fan-Siu e Jiaying (2015); (2) TEA seria uma entidade heterogênea. Sendo assim, os sintomas de desatenção e também executivos, observados no TEA, poderiam ter manifestações diferentes de outros diagnósticos (Solomon, McCauley, Iosife, Carter, \& Ragland, 2016).

$\mathrm{Na}$ revisão de Yat Fan-Siu e Jiaying LE (2015), verifica-se que comprometimento de memória episódica encontra-se em modelos de tarefas com menos estrutura interna, como, por exemplo, histórias lógicas. Já em tarefas com estrutura interna, que facilitaria a codificação, como pode ser visto em paradigmas de listas de palavras ou em etapas da tarefa que exigem maior organização 
estratégica. Na revisão realizada por estes autores, o RAVLT é uma tarefa que não apresenta comprometimento. Além disso, observam maiores prejuízos em etapas das tarefas que envolvem evocação livre do que reconhecimento, ou memória de trabalho. Para os autores, as dificuldades de memória no TEA estariam primariamente sendo causadas por prejuízos de organização estratégica.

Solomon et al. (2016), em um estudo que busca descrever a heterogeneidade da memória em adolescentes autistas, ressalta, entre outras discussões, que o autismo não seria uma entidade biológica única e por isso os sintomas de desatenção do autismo seriam diferentes do Transtorno do déficit de atenção e hiperatividade (TDAH), com consequente impacto diferenciado na memória. Eles trazem como fundamento desta proposta um elemento de sua análise, feita a partir do paradigma de lista de palavras California Verbal Learning Test-Children's Version (CVLT-C). Neste estudo, o padrão de déficits nas medidas do CVLT é inconsistente, se intensificam naquelas que exigiam mais memória estratégica. Esta ideia pode estar condizente com as diferenças de padrões de memória no TDI, mais afetado pelo controle atencional, do que o TEA.

A partir destes dados, levanta-se a hipótese que pacientes com TEA sofreriam impacto diferente de funções executivas, dependendo da maior ou menor preservação, em função da própria heterogeneidade do diagnóstico. Isto geraria um padrão de codificação da informação verbal afetado por esta heterogeneidade, associado aos modelos de estrutura das tarefas de memória (com maior ou menor demanda de organização estratégica). O mesmo não ocorreria com TDI, que parece ter um prejuízo atencional mais consistente (DjuricZdravkovic, Japundza-Milisavljevic, \& Macesic-Petrovic, 2010).

Logo, apesar de existirem, nestes casos, queixas de comportamentos sociais impulsivos, não se observa o mesmo impacto em tarefas, onde eles podem automatizar o processo (stroop), ou têm mais estrutura para codificação (RAVLT). E, com isso o impacto do controle inibitório no TEA, apareça mais em tarefas ou situações menos estruturadas, como, por exemplo, as de cunho social, enquanto que para o TDI, que teria um prejuízo atencional mais consistente, e se daria de forma mais clara no processo de aprendizagem formal. 


\section{5-CONSIDERAÇÕES FINAIS}

Observa-se que existe uma consistência de teoria da mente na diferenciação entre TEA e TDI, o que pode ser considerado como um marcador cognitivo primário do TEA. Entretanto, há na literatura dados relevantes sobre o impacto de funções executivas, que não foi observado de forma consistente neste estudo. Ressalta-se que todas as tarefas produzidas eram de origem e método de apresentação visual, que reduz a demanda de memória de trabalho e controle inibitório. Acredita-se que este método permitiu o controle de variáveis cognitivas que poderiam interferir no desempenho, permitindo melhor definição das diferenças em tarefas de ToM.

As funções executivas, mesmo as destacadas na literatura como marcadores, encontram-se como caracterizador do perfil neuropsicológico e possível potencializador das dificuldades de cada diagnóstico. Porém, ressalta-se que este impacto deve ser problematizado, afinal, a literatura aponta correlações importantes, inclusive entre a função de flexibilidade e ToM- marcador mais significativo do TEA (Durrleman \& Franck, 2015). Mas, neste estudo, não foram identificados como marcadores precisos na diferenciação diagnóstica, podendo ser considerado um marcador secundário do TEA.

Apesar dos resultados condizentes com a literatura, os dados apontam que a caracterização de um perfil sociocognitivo de ambos os diagnósticos apresenta impasses, especialmente quando se busca evidências de um diagnóstico diferencial. Contudo, apesar dos entraves observados, foi possível discutir (1) a distinção dos diagnósticos, a partir de tarefas de ToM; (2) a ideia de marcador primário (ToM) e secundário no TEA (funções executivas, como planejamento, memória de trabalho e controle inibitório); (3) controle de variáveis nas tarefas ToM definiram melhor o déficit em representação mental. Estas discussões podem aprimorar a identificação de marcadores primários e secundários destes diagnósticos, considerando, em estudos futuros, modificações em função das seguintes limitações observadas: (a) realização de um estudo com maior número de casos; (b) inclusão de outras tarefas controle, além do método de apresentação visual; (c) análises de correlação entre tarefas de ToM e de funções executivas, o que forneceria dados sobre as relações entre eles, promovendo maior robustez na 
definição de um marcador primário e secundário (d) realização de estudos com faixas etárias pré-escolares, para auxiliar em diagnósticos precoces. 


\section{4- DESENVOLIVIMENTO DE UMA BATERIA DE TEORIA DA MENTE (BTOM) E SUAS CARACTERÍSTICAS PSICOMÉTRICAS}

\section{Resumo}

Teoria da Mente (ToM) é um constructo sociocognitivo pertinente ao perfil de Transtorno do Espectro Autista- TEA. Alguns pontos críticos são observados nos instrumentos de avaliação de ToM. Foi desenvolvido um instrumento de avaliação de ToM, denominado Bateria de avaliação de Teoria da Mente-BToM, que visa a integração, em um modelo de múltiplas tarefas, de diferentes domínios do constructo. O objetivo do presente estudo é apresentar evidências de validade de conteúdo e confiabilidade a partir: (1) elaboração do instrumento, considerando a natureza dinâmica de constructos psicológicos; (2) a verificação da qualidade da representação do conteúdo por avaliação de juízes especialistas; (3) verificar concordância de escores de correção entre avaliadores (4) verificar a validade de constructo de BToM em um procedimento de verificação da proximidade das tarefas e associação com o padrão-ouro SallyAnne. $\mathrm{Na}$ fase 1, etapa de validade de conteúdo, foram identificadas as porcentagens de concordância entre 8 especialistas quanto ao conteúdo de BToM. Em seguida (fase 2), o instrumento foi aplicado em 30 participantes, oriundos Organização Não Governamental - Instituto Reação e de escola do Rio de Janeiro de classe socioeconômica nível c. Também foram aplicadas medidas neuropsicológicas. Os avaliadores de correção foram treinados para correção do instrumento. Foi utilizado porcentagens de concordância entre os juízes de conteúdo e o Coeficiente de Correlação Intraclasses (IC) para avaliar a correlação entre os corretores. Por fim (fase 3), as respostas de 44 participantes, oriundos de Organização Não Governamental - Instituto Reação e de escola do Rio de Janeiro de classe socioeconômica nível c. foram avaliadas. Foi realizada a medida de análise de cluster hierárquico entre as tarefas e análise de qui-quadrado entre as tarefas de BToM e a tarefa Sally-Anne Os resultados sugerem que: (a) instrumento BToM, mostra evidências de validade de contéudo, (b) altos índices de correlação entre ambos os pares de avaliadores de correção, mesmo em tarefas mais subjetivas do instrumento como Verbalizações e (c) identifica-se evidências de validade de constructo. Discute-se algumas alterações no instrumento; bem como ampliação da amostra com padrões socioculturais diferenciados, auxiliando na identificação de respostas alternativas e possível impacto da idade na associação entre as tarefas do instrumento com padrão-ouro.

Palavras-chave: BToM; Validade de conteúdo; validade de constructo; tarefa sally-anne; reconhecimento de emoção; TEA. 


\begin{abstract}
Theory of Mind (ToM) is a sociocognitive construct pertinent to profile of Autism Spectrum Disorder-ASD. Some critical points are observed in the ToM assessment instruments. A ToM evaluation tool was developed- Battery of assessment of Theory of Mind-BToM, which aims to integrate, in a multi-task model, different domains of the construct. The objective is to present evidence of content validity, reliability and construct validity from: (1) elaboration of the instrument, considering the dynamic nature of psychological constructs; (2) verification of the quality of content representation by expert judges; (3) to verify concordance of correction scores between evaluators (4) to verify the construct validity of BToM in proximity verification between tasks and association with the gold standard Sally-Anne In phase 1, content validity stage, we identified the percentages of agreement among 8 experts regarding the BToM. Afterwards (phase 2), the instrument was applied to 30 participants; from the socioeconomic class level c. Neuropsychological measures were also applied. Correction evaluators were trained to correct the instrument. Percentages of agreement between the content judges and the Intraclasses Correlation Coefficient (IC) were used to evaluate the correlation between brokers. Finally (phase 3), the responses of 44 participants, from the Non - Governmental Organization - Reaction Institute and from the Rio de Janeiro school of socioeconomic class level c. were evaluated. The results suggest that: (a) the BToM instrument, shows evidence of validity of the content, (b) the validity of the data, high correlation indices between both pairs of correction evaluators, even in more subjective tasks of the instrument as Verbalizations and (c) evidence of construct validity is identified. Some changes in the instrument are discussed; as well as enlargement of the sample with differentiated sociocultural patterns, helping to identify alternative answers and possible impact of age on the association between the tasks of the gold standard instrument
\end{abstract}

Key-words: BToM, content validity; construct validity; Sally-Anne task; reability; ASD. 


\section{1-INTRODUÇÃO}

Entende-se a Teoria da Mente (ToM) como um constructo sociocognitivo de extrema relevância no perfil neuropsicológico de transtornos do neurodesenvolvimento, tais como o Transtorno do Espectro Autista- TEA. Por conseguinte, torna-se pertinente desenvolver instrumentos acurados de avaliação (Fernandes et al., 2018).

Alguns pontos críticos são observados nos instrumentos ou em tarefas experimentais de ToM. Dentre eles, se destacam: (1) o próprio constructo de ToM: ele possui processos e habilidades diferentes em sua composição, com alcance de maior complexidade em diferentes etapas do desenvolvimento (Flavel et al., 1999); (2) relação com outros domínios cognitivos: verificam-se questionamentos quanto ao impacto no desempenho de ToM e as possíveis relações de memória de trabalho, flexibilidade cognitiva e controle inibitório (Barendsen, et al., 2018; Christ et al., 2007; Durleman \& Franck, 2015; Leung \& Zakzanis, 2014; Lind \& Bowler, 2010); (3) modelo das tarefas: uso de tarefas circunscritas, que envolvem o mesmo paradigma (falsa crença), apesar de se apresentarem de formas distintas (Altschuler et al., 2018; van Buijsen et al., 2018), que, por sua vez, não seriam suficientes para entender a manifestação dos diferentes processos e habilidades deste constructo.

A partir dessas discussões, foi desenvolvido um instrumento de avaliação de ToM, que visa a integração, em um modelo de múltiplas tarefas, de diferentes domínios do constructo. A partir de uma orientação teórica de desenvolvimento do modelo de ToM, os paradigmas do presente instrumento apresentam diferentes níveis de complexidades. Além disso, de acordo com a literatura sobre as relações com outros aspectos cognitivos, foram construídos recursos de controle cognitivo, através de tarefas controle, ou que estão inseridos nas tarefas de avaliação de ToM.

A proposta de construção teve como diretrizes: (A) um instrumento de avaliação de ToM precisa abranger diferentes aspectos do constructo; (B) o instrumento deve conter tarefas de controle de outros domínios cognitivos que possam interferir no desempenho de ToM; (C) o instrumento deve identificar 
possíveis diferenças de desempenho em ToM, considerando que clinicamente se observam variações de prejuízos. Estas variações estariam associadas às diferentes complexidades intrínsecas aos domínios de ToM.

Diante de um novo instrumento, o próximo passo é buscar evidências de validade de conteúdo e confiabilidade. De acordo com Haynes, Richard e Cubani (1995), a validade de conteúdo pode sofrer impacto de todos os elementos do instrumento, possuindo uma natureza dinâmica. Os itens a serem avaliados podem se modificar, a partir, por exemplo, de mudanças de paradigmas de observação, ou mesmo do observador. A partir desta perspectiva, o planejamento do teste tem um impacto significativo para ter uma representatividade conceitual (Raymundo, 2009). Assim, a validade de conteúdo abrange não apenas a avaliação de especialistas quanto à proximidade do instrumento em relação ao constructo definido previamente, mas também a elaboração do instrumento. A elaboração consistiria da definição dos aspectos conceituais mais importantes para a construção dos itens (Alexandre \& Coluci, 2011).

Já a confiabilidade mede a homogeneidade da medida. Ou seja, o quanto ela consegue medir aquele constructo, como, por exemplo, desempenho em ToM, sem erros de variações de resultados, em função do avaliador ou mesmo do momento em que o sujeito foi avaliado (De Bem et al., 2011). Logo, entende-se que um instrumento é confiável quando uma medida consegue reproduzir um resultado de forma consistente.

Existem formas diferentes de se medir a confiabilidade/precisão de um teste. Dentre eles, encontram-se: (a) a verificação da estabilidade, onde resultados do mesmo teste são obtidos em tempos diferentes; pode acontecer por testereteste; (b) a consistência interna, que aponta para a relação interna entre os subitens do teste, e (c) a equivalência, que pode se dar por formas paralelas de um mesmo instrumento ou pela concordância quanto aos escores do instrumento, normalmente realizada por diferentes avaliadores (Alexandre, Gallasch, Lima \& Rodrigues, 2013; Souza, et al., 2017).

No modelo de concordância entre avaliadores, uma das análises mais usadas é o coeficiente de correlação intraclasse (CI). Ele pode ser entendido da seguinte forma: caso o valor seja $<0,40$, seria interpretado como pobre; com o 
valor $0,40<\mathrm{CI}<0,75$, seria interpretado como satisfatório e, com valor $>$ ou igual 0,75 , seria interpretado como excelente. Outros autores falam de um valor de 0,70 como um ponto de corte para a interpretação e um bom coeficiente de correlação. Ou seja, os pontos de corte variam a partir da metodologia utilizada e das referências utilizadas (Matos, 2014).

Após a validade de conteúdo, que mostra a representatividade conceitual do instrumento, e a confiabilidade, que diz respeito a sua reprodutibilidade, a validade de constructo é a etapa que permite a generalização da medida. Neste momento (validade de constructo), há a verificação da proximidade entre os elementos do novo instrumento com outros instrumentos que reconhecidamente, medem o mesmo que o instrumento atual se propõe a medir (Pasquali, 2009).

No contexto de avaliação de ToM, o padrão-ouro identificado é a tarefa de falsa crença Sally-Anne (Baron-Cohen et al., 1985). A falsa crença consiste na identificação das crenças de outro, a partir de situações incongruentes, ou seja, a partir de perspectivas visuais diferentes (Flavell et al., 1999). Encontram-se modelos de falsa crença de $1^{\mathrm{a}}$ ordem e de $2^{\mathrm{a}}$ ordem. Na crença de $1^{\mathrm{a}}$ ordem, a crença de uma outra pessoa é identificada, na de $2{ }^{a}$ ordem identifica-se a crença que uma outra pessoa tem sobre um terceiro (Muris et al., 2004). A tarefa Sally-Anne é uma tarefa de $1{ }^{a}$ ordem. Nela, são apresentadas duas bonecas à criança. Uma delas tem um objeto, que ela coloca em sua cesta, e depois sai da sala. A boneca que permanece na sala muda o local do objeto (da cesta para caixa). Os sujeitos respondem onde a boneca que volta para sala, e não viu a troca, vai procurar seu objeto.

Apesar de ser considerada o padrão-ouro de avaliação em ToM no TEA, tem recebido diversas críticas (Altschuler et al., 2018). Dentre eles, seu aspecto circunscrito quando se considera os diferentes domínios de ToM, que pode alterar o real desempenho, inclusive em indivíduos com TEA (Lind \& Bowler, 2010). Caminha-se, então, para um modelo de avaliação mais complexo que envolvam tarefas de domínios diferentes, em uma tentativa de proximidade com demandas sociais ecológicas (Schaller \& Rauh, 2017).

Tomando a validade de conteúdo, confibialidade e validade de constructo como etapas iniciais e norteadoras para a validação de um novo instrumento, o objetivo do presente estudo é apresentar evidências de validade a partir da (1) elaboração do instrumento, considerando a natureza dinâmica de constructos 
psicológicos; (2) a verificação da qualidade da representação do conteúdo por avaliação de juízes especialistas; (3) verificar concordância de escores de correção entre corretores e (4) verificar a validade de constructo de BToM em um procedimento de verificação da proximidade das tarefas e associação com o padrão-ouro Sally-Anne.

O estudo compreende três fases: (1) elaboração do instrumento e avaliação dos itens do instrumento, através de juízes especialistas, (2) estudo de confiabilidade, a partir de concordância de escores de correção entre avaliadores e (3) estudo de validade de constructo, a partir de proximidade entre os elementos do instrumento e associação com padrão-ouro Sally-Anne.

\section{2-MÉTODO}

\subsection{1-ASPECTOS ÉTICOS}

Este estudo foi aprovado no Comitê de Ética em Pesquisa da Pontifícia Universidade Católica (PUC-Rio), onde foi realizado o estudo. O comitê gerou o parecer com o seguinte número: 2017-28.

\subsection{2-PARTICIPANTES:}

\subsubsection{1.-FASE 1 - Validade de Conteúdo:}

Foram selecionados oito profissionais de psicologia, com experiência em neuropsicologia ou intervenções psicoterápicas em TEA (Tabela 11), com diferentes níveis de prática clínica e titulação acadêmica. 
Tabela 11: Descrição da formação profissional dos juízes

\begin{tabular}{|c|c|c|c|}
\hline Juiz & $\begin{array}{c}\text { Nível } \\
\text { acadêmico }\end{array}$ & Especialidade & Tempo \\
\hline 1 & Mestrado & Neuropsicologia & 13 anos \\
\hline 2 & Mestrado & $\begin{array}{c}\text { Neuropsicologia e intervenção } \\
\text { cognitivo-comportamental }\end{array}$ & 5 anos \\
\hline 3 & Especialista & Intervenção TEA & 5 anos \\
\hline 4 & Especialista & Intervenção TEA & 7 anos \\
\hline 5 & Especialista & Neuropsicologia & 1 ano \\
\hline 6 & Especialista & Neuropsicologia & 8 anos \\
\hline 7 & Especialista & Neuropsicologia & 1 ano \\
\hline 8 & Graduação & Psicologia & 1 ano \\
\hline
\end{tabular}

\subsubsection{2-FASE 2 - Confiabilidade:}

O instrumento foi aplicado em 30 participantes, sem diagnóstico de TEA, de 7 a 12 anos. Eles faziam parte da Organização Não Governamental - Instituto Reação e de escola do Rio de Janeiro e uma escola particular do Rio de Janeiro de classe socioeconômica nível C. A classe foi medida, a partir de renda mensal.

As 30 crianças foram incluídas a partir dos seguintes critérios: (a) todas estavam matriculadas em escola regular; (b) ausência de reprovação escolar; (c) ausência de mediação escolar; (d) ausência de queixas sociais (dificuldades de compreensão de regras socais, isolamento social e prejuízos de interação com pares) e (e) comportamentais (ausência de comportamentos agressivos com pares, prejuízos de sustentação de atenção em atividades formais e acadêmicas).

A amostra de avaliadores de correção foi composta por quatro avaliadores com experiência em neuropsicologia e práticas de intervenção e avaliação de TEA, sendo um mestre e três especialistas. 


\subsubsection{3-FASE 3 - Validade de Constructo:}

Participaram deste estudo 44 sujeitos, sem diagnóstico de autismo, de 7 a 12 anos. Eles faziam parte da Organização Não Governamental - Instituto Reação e de escola do Rio de Janeiro e uma escola particular do Rio de Janeiro de classe socioeconômica nível c. A classe foi medida, a partir de renda mensal.

Os 44 participantes foram incluídos a partir dos seguintes critérios: (a) todas estavam matriculadas em escola regular; (b) ausência de reprovação escolar; (c) ausência de mediação escolar; (d) ausência de queixas sociais (dificuldades de compreensão de regras sociais, isolamento social e prejuízos de interação com pares), e (e) comportamentais (comportamentos agressivos com pares, prejuízos de sustentação de atenção em atividades formais e acadêmicas). As queixas foram avaliadas a partir de um questionário sociodemográfico e clínico (APÊNDICE A). Os critérios de exclusão foram: (a) índices de quociente de funcionamento cognitivo global abaixo de 85, a partir do desempenho no WASI (Wechsler, 2014).

\subsection{3-PROCEDIMENTOS}

\subsubsection{1-FASE 1- Validade de Conteúdo:}

As tarefas do instrumento foram construídas com base em uma abordagem modular e clínica acerca do constructo ToM (Flavell, 1999; Flavell et al.,1999). Inicialmente, foi realizada uma revisão bibliográfica, que descrevia um número significativo de tarefas construídas, majoritariamente, a partir de modelos clínicos de um mesmo paradigma (falsa crença). A partir desta revisão (Estudo 1; capítulo 2) e de um modelo piloto baseado em histórias em quadrinhos (Estudo 2; capítulo 3), o primeiro modelo do instrumento foi construído.

Em seguinda, os juízes foram recrutados através de uma amostra de conveniência. Estes receberam um convite via e-mail e telefone. Após o aceite, recebiam o seguinte material: 1) texto explicativo sobre o conceito de ToM e sobre o modelo de múltiplos níveis (Anexo A); 2) aula preparada e ministrada 
pelo pesquisador sobre conceitos de ToM, a ideia de funções executivas como variáveis que impactam ToM e a apresentação do instrumento (Apêndice A); 3) material construído pelos pesquisadores, onde haviam perguntas a respeito do instrumento. Este material foi utilizado para avaliação do juiz. Ele deveria responder se o item era adequado, dentro da proposta teórica apresentada anteriormente. Dentre estes questionamentos, há itens globais (adequação das ideias centrais do instrumento) e específicos (particularidades das tarefas). Além disso, os juízes foram solicitados a dar sugestões, se necessário, para melhorar a adequação dos itens que eram percebidos como inadequados.

\subsubsection{2-FASE 2 - Confiabilidade:}

O termo de consentimento foi entregue e a avaliação foi realizada após a assinatura dos mesmos. Após BToM ser aplicado em 30 participantes, sem diagnóstico de TEA, de 7 a 12 anos, foram escolhidos quatro avaliadores de correção. Os avaliadores foram treinados com material explicativo sobre o conceito de ToM, seus domínios e múltiplos níveis (ANEXO A). Foi ministrada uma aula sobre o instrumento, suas tarefas e correção preparada pelo pesquisador (APÊNDICE D).

Primeiramente, os 30 testes aplicados foram e corrigidos pelo pesquisador. Neste momento, foram inseridas respostas alternativas em alguns itens em função da frequência de respostas. Após esta primeira análise das respostas, foi finalizada a folha de resposta para os avaliadores de correção.

A folha de resposta final (APÊNDICE E) contém as instruções e o local indicado para a correção. Na aula de correção ministrada aos avaliadores, foi mostrado como realizar a pontuação alternativa, o somatório de acertos e o cálculo da porcentagem de acertos em cada tarefa (acerto/escore total).

Uma cópia da folha de respostas foi preparada para os avaliadores. Estas folhas de respostas não tinham qualquer identificação dos sujeitos, como nome, idade, escolaridade, origem da coleta, nem correções prévias. Eram cópias preparadas apenas para os avaliadores da precisão, elas continham apenas as 
respostas dadas pelos participantes da ONG e o modelo de correção final (já com a inserção de respostas alternativas a resposta originalmente mais adequada).

Em seguida, os avaliadores de correção, após treinamento, foram acessados para realizar as correções. Eles foram divididos em pares (dois pares com dois profissionais). Eles foram agrupados da seguinte forma: (a) em cada par tinha um profissional de neuropsicologia sem experiência em TEA e um profissional com experiência em TEA, podendo ser neuropsicólogo ou não; (b) em cada par havia um profissional considerado sênior e um profissional com menor tempo de experiência clínica.

Cada par ficou responsável por 15 participantes. Cada avaliador corrigiu, de forma independente, as mesmas crianças. Eles utilizavam as fichas preparadas das folhas de respostas, contudo as suas correções eram feitas em material independente e só o pesquisador tinha acesso, para que a correção de um não interferisse na do outro. Após as correções de um dos avaliadores, eram trocados os sujeitos entre eles. Em seguida as pontuações de cada um foram avaliadas.

\subsubsection{3-FASE 3 - Validade de Constructo:}

Após a assinatura do termo de consentimento, os instruntos foram aplicados em 44 participantes, foram corrigidos e planilhados. Em seguida foram realizadas as análises pertinentes.

\subsection{4- INSTRUMENTOS:}

\subsubsection{1-FASE 1- Validade de Conteúdo:}

Material apresentado para avaliação dos juízes, com perguntas acerca do instrumento foi a ficha de avaliação dos juízes, que será apresentada a seguir.

A escala apresentada aos juízes quanto à adequação do instrumento continha os seguintes itens globais sobre o conteúdo do instrumento: 
Quadro 1: Itens avaliados pelos especialistas

\begin{tabular}{|c|c|}
\hline Itens Globais & $\begin{array}{l}\text { O instrumento mede Teoria da Mente, entendida como } \\
\text { capacidade de inferir estados mentais internos de outros? } \\
\text { O instrumento mede Teoria da Mente em múltiplos domínios? } \\
\text { O instrumento consegue avaliar domínio de reconhecimento de } \\
\text { emoções em faces? } \\
\text { O instrumento consegue medir o domínio de inferência de estado } \\
\text { mental, a partir de falsas crenças? } \\
\text { O instrumento consegue avaliar inferências sociais a partir de } \\
\text { pistas contextuais e visuoespaciais? } \\
\text { O instrumento apresenta características de demanda gradual } \\
\text { quanto ao nível de inferência de estados mentais? } \\
\text { O instrumento apresenta como característica a redução de } \\
\text { demanda de memória de trabalho? } \\
\text { O instrumento apresenta tarefas de controle de variáveis: } \\
\text { nomeação; controle inibitório, memória de trabalho, coerência } \\
\text { central? } \\
\text { Pode auxiliar no diagnóstico diferencial do TEA? }\end{array}$ \\
\hline Itens específicos & $\begin{array}{l}\text { As perguntas realizadas nas tarefas remetem a domínios de ToM: } \\
\text { (1) Gostaria que respondesse às questões sobre a tarefa } \\
\text { "Nomeação e gradação de emoções simples" (Exemplo 1); } \\
\text { (2) Gostaria que respondesse as questões sobre a "tarefa de } \\
\text { identificação de estados mentais (EM)" (Exemplo 2); } \\
\text { (3) Gostaria que respondesse às questões sobre a tarefa de } \\
\text { organização lógica complexa OLc (Codificação de verbalizações) } \\
\text { (Exemplo 3) } \\
\text { As emoções estão adequadas visualmente } \\
\text { Sugestões de alterações nas histórias e desenhos }\end{array}$ \\
\hline
\end{tabular}

Você reconhece esta emoção como feliz?
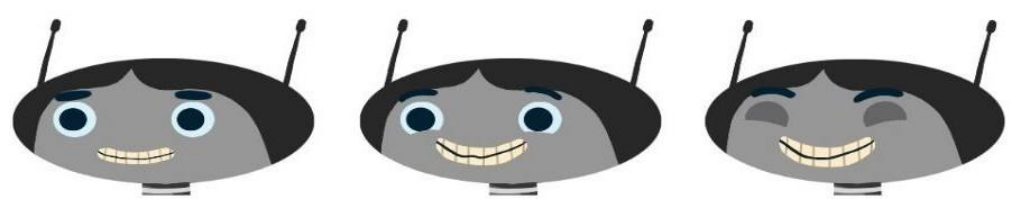

alegria

\section{Exemplo 1}


Na história 2, a pergunta e o modelo da história avaliam a etapa de falsa crença BaronCohen de conteúdo inesperado

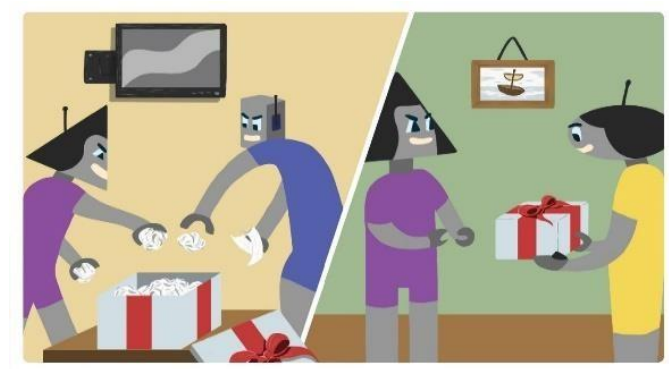

- A Flor (Apontar) A flor pensa que tem o que na caixa?

\section{Exemplo 2}

Abaixo serão apresentados os níveis de diferentes estados mentais, considerados por Baron-D Cohen, que podem ser narrados na cena 1, além da inferência central da cena. Você concorda com os níveis destacados?

Na cena 1
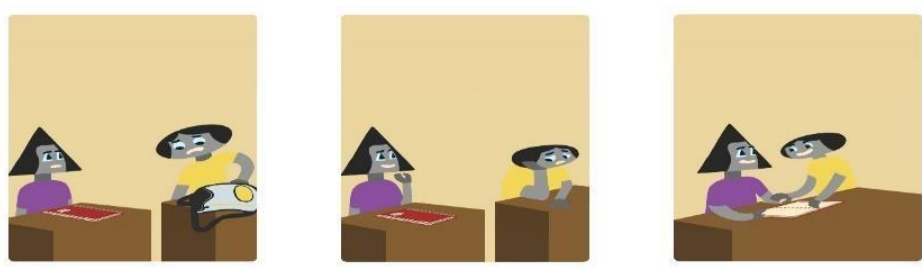

\begin{tabular}{|l|l|l|l|}
\hline CENA & MIG & SIM & NÃO \\
\hline Nível & Respostas esperadas & & \\
\hline $\begin{array}{l}\text { Entendimento } \\
\text { de emoção- } \\
\text { Nível 1 }\end{array}$ & $\begin{array}{l}\text { Identificação de emoção por reconhecimento de faces } \\
\text { (Quando a Flor fica triste -FACE); }\end{array}$ & & \\
\hline $\begin{array}{l}\text { Entendimento } \\
\text { de emoção } \\
\text { Nível 3 }\end{array}$ & $\begin{array}{l}\text { Identificação de emoção baseada na situação (Flor fica } \\
\text { triste porque esqueceu o caderno); }\end{array}$ & & \\
\hline $\begin{array}{l}\text { Entendimento } \\
\text { de emoção } \\
\text { Nível 4 }\end{array}$ & Crença verdadeira/antecipação de comportamento (A & & \\
\hline $\begin{array}{l}\text { Identificação } \\
\text { de inferência } \\
\text { principal da dela esqueceu o livro" ou "precisa de ajuda") } \\
\text { história }\end{array}$ & $\begin{array}{l}\text { Conceito Geral: } \\
\text { Empatia e Comportamentos pró-sociais: }\end{array}$ & & \\
Ela quis ajudar a amiga & Ela sentiu compaixão da colega & & \\
\hline
\end{tabular}

Exemplo 3 


\subsubsection{2--FASE 2 - Confiabilidade:}

\subsubsection{1-Questionário sociodemográfico e clínico:}

É composto por informações tais como: idade, escolaridade, escolaridade dos pais, história de desenvolvimento linguístico e motor, diagnósticos prévios e histórico familiar (APÊNDICE B)

\subsubsection{2- Termo de Consentimento Livre e Esclarecido}

O termo de consentimento foi apresentado aos pais e o termo de assentimento, às crianças (APÊNDICE C).

\subsubsection{3- Bateria de Teoria da Mente (BToM).}

Este instrumento é constituído por 8 tarefas, sendo 5 de ToM, 3 tarefas controles pareadas: Tarefa 1: Nomeação de objetos; Tarefa 2: Nomeação de Emoções(NEs); Tarefa 3: Gradação de emoções simples (GEs); Tarefa 4: Tarefa Go no-Go; Tarefa 5: Identificação de estados mentais (EM), Tarefa 6: Organização Lógica simples (OLs); Tarefa 7: Organização Lógica complexa (OLc); Tarefa 8: Vervalizações.

\subsubsection{3--FASE 3 - Validade de Constructo:}

\subsubsection{1-Questionário sociodemográfico e clínico:}

É composto por informações tais como: idade, escolaridade, escolaridade dos pais, história de desenvolvimento linguístico e motor, diagnósticos prévios e histórico familiar (APÊNDICE B)

\subsubsection{2- Termo de Consentimento Livre e Esclarecido}

O termo de consentimento foi apresentado aos pais e o termo de assentimento, às crianças (APÊNDICE C). 


\subsubsection{3- Bateria de Teoria da Mente (BToM).}

Este instrumento é constituído por 8 tarefas, sendo 5 de ToM, 3 tarefas controles pareadas: Tarefa 1: Nomeação de objetos; Tarefa 2: Nomeação de Emoções(NEs); Tarefa 3: Gradação de emoções simples (GEs); Tarefa 4: Tarefa Go no-Go; Tarefa 5: Identificação de estados mentais (EM), Tarefa 6: Organização Lógica simples (OLs); Tarefa 7: Organização Lógica complexa (OLc); Tarefa 8: Vervalizações.

\subsubsection{4- Bateria neuropsicológica breve:}

A-WASI (Wechsler, 2014): Instrumento breve de avaliação da inteligência, aplicável a crianças de 6 anos a idosos de 89 anos de idade. Fornece informações sobre os QIs Total, de Execução e Verbal a partir de quatro subtestes (Vocabulário, Cubos, Semelhanças e Raciocínio Matricial).

B-Paradigma Stroop-Vitória (Oliveira et al., 2016; Spreen e Strauss (1998)): Avalia a susceptibilidade à interferência. $\mathrm{O}$ teste consiste em três condições. $\mathrm{Na}$ parte 1, o indivíduo deve nomear o mais rápido possível 24 quadrados pintados com as cores azul, verde, vermelho e amarelo. Na parte 2, o indivíduo deve nomear o mais rápido possível as cores, só que agora em forma de palavras comuns. Na parte 3, o procedimento é semelhante ao das partes anteriores, só que as palavras formam os nomes das cores pintadas de cores incongruentes.

C-Rey Auditory Verbal Learning Test - Ravlt (Oliveira et al., 2016; Spreen e Strauss, 1998): Avalia a memória episódica anterógrada verbal. O teste consiste na leitura pelo examinador de 12 palavras por 4 tentativas consecutivas. Cada tentativa é seguida por uma evocação livre. Após 20 minutos de intervalo, os indivíduos são solicitados a evocar livremente a lista de palavras. Posteriormente, é realizada uma tarefa de reconhecimento.

D-Fluência verbal (Oliveira et al., 2016; Spreen e Strauss, 1998): Avalia memória semântica e flexibilidade cognitiva. O procedimento é solicitar que o indivíduo produza oralmente o maior número possível de palavras iniciando com as letras "F”, “A", "M", um minuto para cada. Não são consideradas palavras corretas: nomes próprios e derivações de gênero, número e grau. Além disso, será aplicado o teste de fluência de animais (associação semântica). 
E-Cópia da figura de Rey (Oliveira \& Rigoni, 2010; Spreen e Strauss, 1998): Avalia a habilidade visuoespacial/construtiva (planejamento, organização, estratégias de resolução de problemas, funções visuais e motoras) e memória episódica visual. O procedimento consiste em solicitar a copiar a figura complexa de Rey em uma folha de papel em branco (cópia) e, após 20 minutos, de forma incidental, solicitar que a reproduza de memória (recordação).

\subsubsection{5- Tarefa Sally-Anne (Baron-Cohen, et al., 1985):}

Tarefa clássica de ToM. Nesta tarefa duas bonecas são apresentadas. Uma delas coloca uma bola de gude dentro de uma cesta e sai da sala. A que fica na sala tira a bola de gude da cesta e esconde em uma caixa. Os sujeitos respondem onde a boneca vai procurar a bola de gude quando ela voltar para a sala.

\section{3-ANÁLISE ESTATÍSTICA}

\subsection{1-FASE 1 - Validade de Conteúdo:}

Os dados foram inseridos em uma planilha eletrônica. Verificaram-se a concordância dos especialistas, por meio da porcentagem de concordância entre os juízes, calculado a partir da divisão do número de juízes que julgaram o item como adequado pelo número total de especialistas. Este índice é calculado a partir da seguinte fórmula: \% = (número de participantes que concordaram/número total de participantes x 100). Ao usar esse método, deve-se considerar aceitável uma taxa de concordância de $90 \%$ entre os observadores.

\subsection{2-FASE 2 - Confiabilidade:}

As medidas de concordância utilizaram coeficientes de correlação. A análise estatística foi realizada com o pacote estatístico SPSS v.18. Foi utilizado o Coeficiente de Correlação Intraclasses (IC), two-way mixed model. Two-way, pois os dois fatores (sujeitos controle e avaliadores de precisão) são sujeitos e mixed, pois os avaliadores foram escolhidos pelo pesquisador. Como método, foi 
usado absolute agreement entre avaliadores. Foi calculada a concordância inter (2 avaliadores) para cada tarefa do instrumento. Para verificar o nível de coeficiente de correlação, adotou-se a seguinte pontuação: IC $<0,40$ - concordância fraca, IC $<0,75$ - concordância moderada e IC >0,75 alta concordância.

\subsection{3-FASE 3 - Validade de Constructo:}

Foi realizada uma análise de cluster hierárquico, a fim de verificar como os itens do instrumento se aproximavam ou se distanciavam, visto que ele foi construído para abranger, por um lado, tarefas que representam diferentes aspectos de um mesmo constructo (ToM) e, por outro, tarefas controle, que avaliam outras variáveis cognitivas ou aspectos de dissociação de uma variável cognitiva. Foi realizada a análise com método de correlação de Pearson em uma amostra de 30 controles. Os escores foram padronizados por porcentagem. Foram verificadas as correlações e o dendograma por aproximação das variáveis.

Por fim, foi verificada a relação entre o instrumento e uma tarefa clássica (padrão-ouro de avaliação de ToM) da literatura de tarefas de ToM. Foi utilizado o teste não paramétrico de associação de Qui-quadrado

\section{4-RESULTADOS}

\subsection{1- FASE 1: Validade de Conteúdo: Elaboracão do instrumento e análise} de juízes.

Teoricamente, foram consideradas os diferentes domínios do constructo ToM (Flavell et al., 1987; Flavell et al., 1981; Flavell, 1999); o impacto de outras variáveis cognitivas em ToM, como memória de trabalho, controle inibitório (inibição comportamental e aspectos da inibição cognitiva) (Barendse et al., 2018; Christ et al., 2007; Schimitt et al., 2018); bem como de variáveis intervenientes, como a relação com objeto x relação com a mente (Baron-Cohen et al., 1986).

Além disso, foram inseridas as variações de desenvolvimento em domínios de reconhecimento de emoções e de falsas crenças. No caso de falsa crença, a tomada de perspectiva visual, os níveis de representação da perspectiva 
visual aumentam até alcançar a falsa crença (Flavel et al., 1981). Já o reconhecimento de emoções e o uso de linguagem emocional descritiva, que surgem com 2 anos de idade, iniciando pela ideia de felicidade, seguida por tristeza, raiva, medo/surpresa (Flavell, 1999; Golan, Gordon, Fichman \& Keilan, 2018), apresentam, segundo a literatura, variações de desempenho em TEA, por exemplo. Algumas variações se dão devido ao impacto de emoções da valência negativa, em outros casos pela intensidade da emoção (Bal et al., 2010; Jones et al., 2011).

A partir disto, foi construído um instrumento de ToM com múltiplas tarefas, para ampliar o nível de problemas sociais a serem resolvidos e permitir avaliação de múltiplos domínios de ToM, com controle de variáveis intervenientes (outros domínios cognitivos e variações de complexidade dentro do próprio domínio de ToM).

a) Os domínios escolhidos foram: 1) reconhecimento de emoções, considerado um precursor de teoria da mente para alguns autores (Flavell, 1999); 2) domínio de falsa crença considerado padrão-ouro (Baron-Cohen et al., 1985); 3) um domínio de análise das relações causais de contexto social, a partir de pistas visuais, considerado um aspecto mais avançado de ToM (Klin, 2000).

b) Diferentes níveis de complexidade dentro dos domínios de ToM.

c) Controle de variáveis de outros domínios cognitivos: nomeação de objetos; controle inibitório (inibição comportamental), memória de trabalho (fonológica e visuoespacial), relação causal mecânica, ou seja, do mundo físico. Esse controle foi feito internamente na tarefa (ou seja, em sua estrutura, como na quantidade de quadros, ou através de perguntas de compreensão); ou com tarefas pareadas (1tarefas similares, que recrutam algum domínio cognitivo necessário ao bom desempenho na tarefa experimental, mas que não recrutam ToM; 2- tarefas que recrutam outros domínios cognitivos).

d) Controle de variáveis provenientes da mudança de complexidade de ToM: nomeação de emoção mais explícita antes de se realizar a gradação de sutilezas da mesma emoção e aumento da complexidade de perspectiva visual simples até a falsa crença. 
As tarefas definidas para avaliação de diferentes domínios de ToM foram: (1) identificação de emoções básicas em faces e (2) gradação de emoções; (3) identificação de falsas crenças em cenas; (4) organização lógica de histórias com inferências sociais. Além dos domínios, as tarefas foram pensadas de forma a ter controle de variáveis cognitivas: dentro da própria tarefa, ou com tarefas controle, pareadas às tarefas (Tabela 3 ). $\mathrm{O}$ instrumento final compreende 8 tarefas, sendo 5 de ToM, 3 tarefas controles pareadas: Tarefa 1: Nomeação de objetos; Tarefa 2: Nomeação (NEs); Tarefa 3: gradação de emoções simples (GEs); Tarefa 4: Tarefa Go no-Go; Tarefa 5: Identificação de estados mentais (EM); Tarefa 6: Organização Lógica simples (OLs); Tarefa 7: Organização Lógica complexa (OLc); Tarefa 8: Verbalizações. Os controles de cada tarefa foram descritoas na tabela 2.

Tabela 12: Tarefas ToM X tarefas controle de variáveis cognitivas

\begin{tabular}{|c|c|c|c|}
\hline Tarefa ToM & $\begin{array}{l}\text { Controle de } \\
\text { outro domínio } \\
\text { cognitivo com } \\
\text { tarefa pareada }\end{array}$ & $\begin{array}{l}\text { Controle de } \\
\text { complexidade } \\
\text { dentro do domínio } \\
\text { ou com tarefa } \\
\text { pareada } \\
\end{array}$ & $\begin{array}{c}\text { Controle de outro domínio cognitivo na } \\
\text { estrutura da tarefa }\end{array}$ \\
\hline $\begin{array}{l}\text { Nomeação de } \\
\text { emoções-NEs }\end{array}$ & $\begin{array}{l}\text { Nomeação de } \\
\text { objetos }\end{array}$ & $\mathrm{X}$ & $\begin{array}{l}\text { Número de elementos reduzidos, apenas } \\
\text { uma imagem mostrada por vez. }\end{array}$ \\
\hline $\begin{array}{l}\text { Gradação de } \\
\text { emoções } \\
\text { simples-GEs } \\
\end{array}$ & $\mathrm{X}$ & NEs & $\mathrm{X}$ \\
\hline $\begin{array}{l}\text { Identificação de } \\
\text { estados mentais } \\
(\mathrm{EM})\end{array}$ & $\begin{array}{l}\text { Tarefa go no-go } \\
\text { - controle } \\
\text { inibitório- } \\
\text { inibição } \\
\text { comportamental }\end{array}$ & $\begin{array}{l}\text { Perguntas quanto à } \\
\text { tomada de } \\
\text { perspectiva simples } \\
\text { Modelo de falsa } \\
\text { crença-tomada de } \\
\text { perspectiva } 2^{\circ} \text { nível }\end{array}$ & $\begin{array}{l}\text { 1- Perguntas controle, que avaliam a } \\
\text { compreensão da cena, no que diz respeito } \\
\text { às relações entre as ações das personagens } \\
\text { (relaçôes lógicas do mundo físico|) } \\
\text { 2- Aumento da quantidade de ações } \\
\text { 3- Não uso de recursos verbais para } \\
\text { interação entre as personagens }\end{array}$ \\
\hline $\begin{array}{c}\text { Organização } \\
\text { Lógica } \\
\text { complexa (OLc) }\end{array}$ & $\begin{array}{c}\text { Organização } \\
\text { lógica simples- } \\
\text { mecânica-com } \\
\text { relações causais } \\
\text { do mundo } \\
\text { físico, sem } \\
\text { inferências } \\
\text { mentais }\end{array}$ & $\mathrm{X}$ & $\begin{array}{l}\text { 1-Aumento da complexidade das histórias, } \\
\text { no que diz respeito à quantidade de } \\
\text { quadros e de complexidade das intenções. } \\
\text { 2- Não uso de recursos verbais para } \\
\text { interação entre as personagens }\end{array}$ \\
\hline Verbalizações & $\mathrm{X}$ & OLc & X \\
\hline
\end{tabular}

Após a definição da ideia geral do instrumento, as personagens foram

idealizadas para ser um grupo de amigos, que estariam presentes em todas as 
tarefas que compõem o instrumento. A ideia foi tornar o instrumento familiar e lúdico. Também foram definidas características de personalidade para cada um. Elas foram construídas em forma de desenho animado: Quatro personagens robôs, com características específicas de personalidade (tabela 3) e cenários: escola, casa, local onde brincam.

Tabela 13: Características principais e nomes das personagens

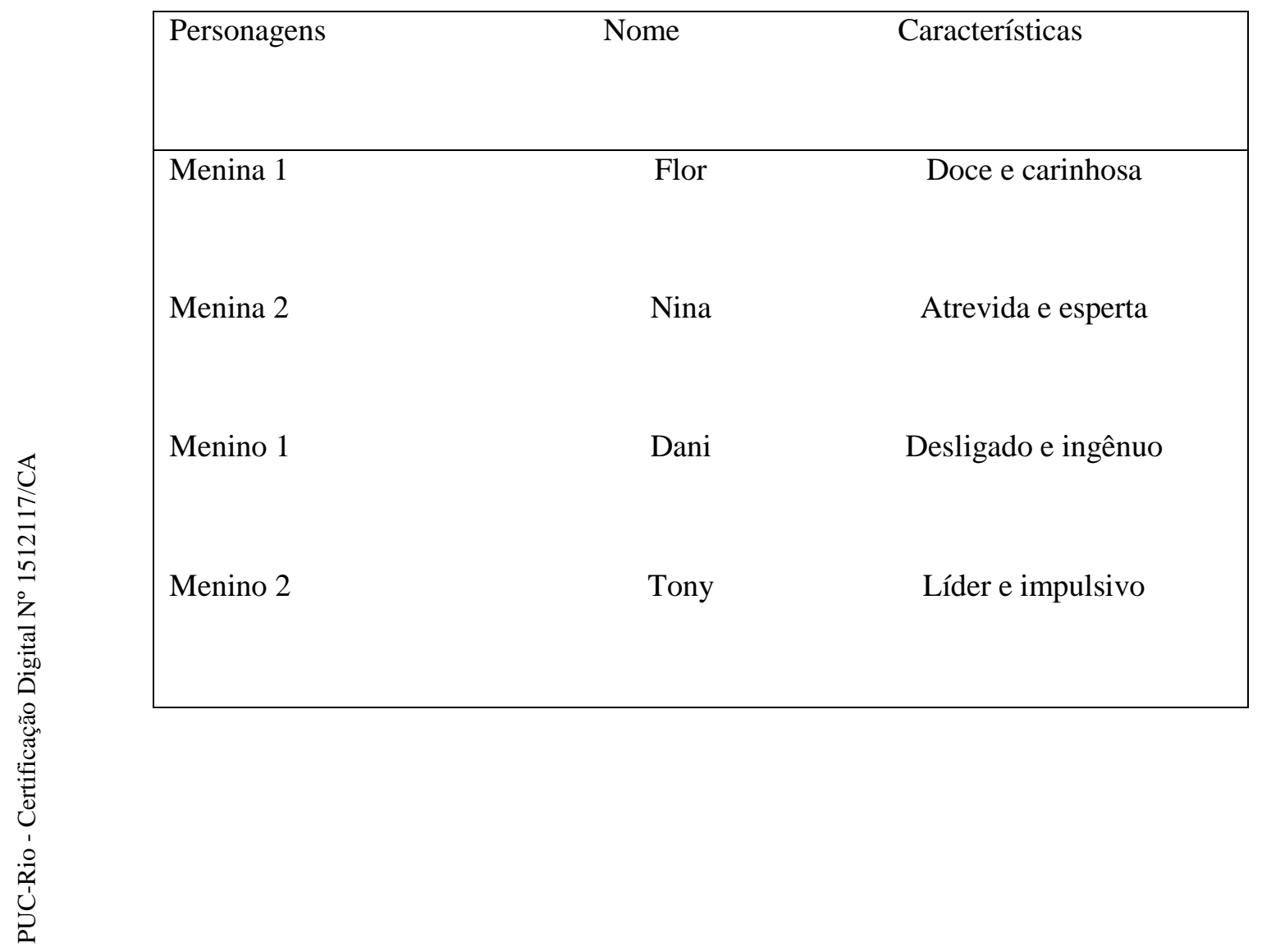



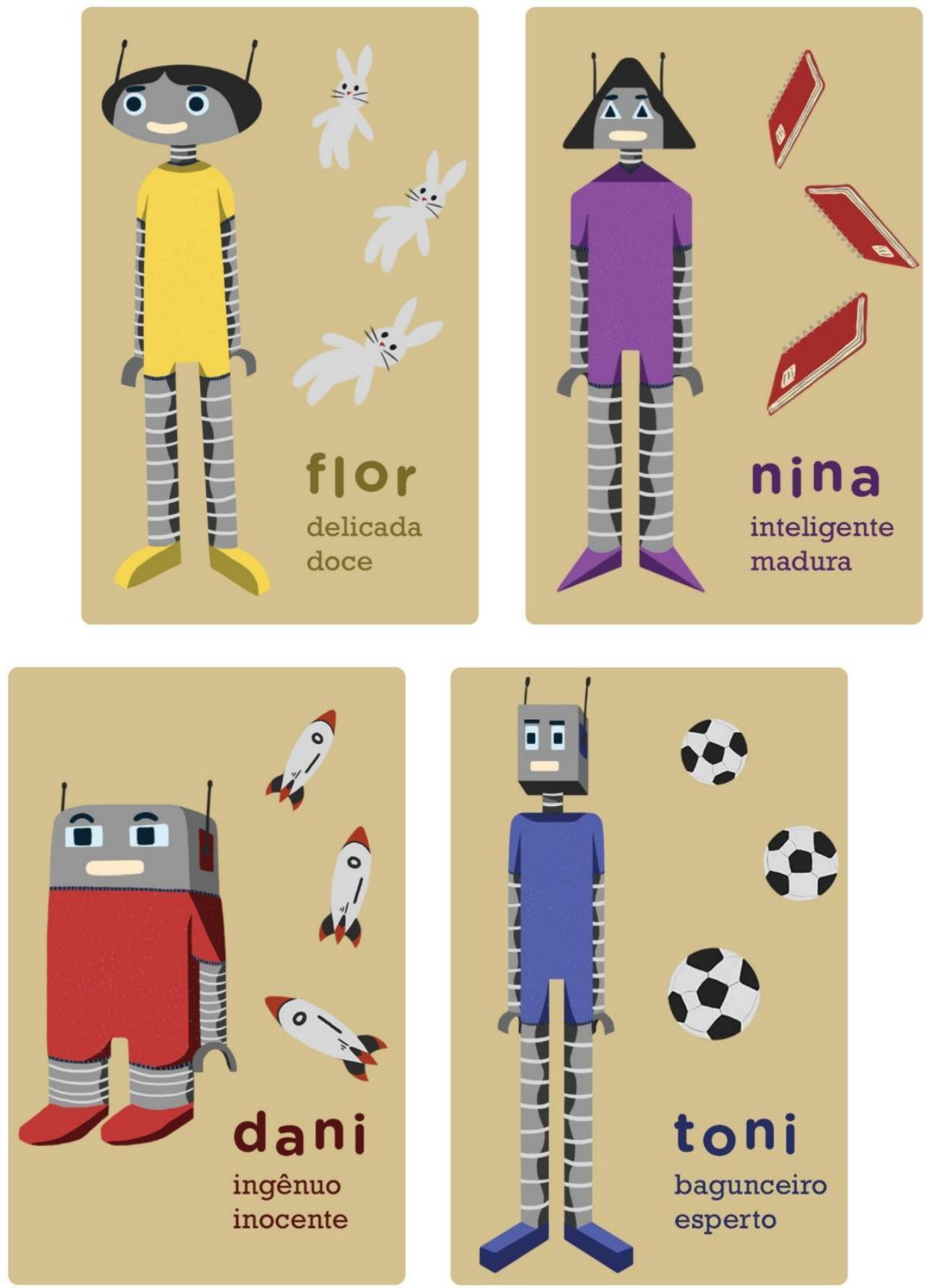

Os itens do instrumento envolviam tarefas com reconhecimento de emoções em faces, interações entre personagens em histórias simples e organização lógica de histórias. As ideias centrais das histórias foram definidas, de forma que não fosse necessário o uso do recurso verbal de interação entre as personagens. O objetivo era criar histórias que pudessem ser compreendidas apenas através dos desenhos. Isso foi conversado com o desenhista antes de elas serem roteirizadas. 
As tarefas foram roteirizadas. Era especificado quadro a quadro como cada personagem e os objetos iriam se posicionar, que objetos estariam presentes, que emoções estariam presentes e quantos quadros comporiam a história. As personagens que participam das histórias foram escolhidas para compor a ideia principal, em função também de suas características de personalidade, escolhidas previamente.

Todas as etapas foram revisadas com o desenhista durante a produção. Modificações foram realizadas no processo, em função de alguns entraves como: (a) deixar clara a emoção (intensidade - como muito feliz tinha todos os detalhes, ou tipo medo x raiva); (b) ou a posição do objeto (p. ex., se estava claro que o objeto estava sendo retirado ou colocado); (c) o direcionamento do olhar; (d) a clareza do desenho (p. ex., se o papel amassado não ia parecer pipoca, ou se a televisão não parecia um tablet). Após a visualização da história, modificações também foram realizadas, como a realização de ajustes a ser definido pelos pesquisadores quando não se alcançou o objetivo da história, ou quando aspectos das emoções estavam pouco definidos.

$\mathrm{O}$ instrumento-piloto foi apresentado a um especialista em ToM e TEA, a fim de verificar a relação dos itens do instrumento com o constructo de ToM e a forma dos itens. Foram considerados os seguintes comentários do especialista para realizar ajustes nos itens do instrumento:

(a) Organização lógica: histórias mais adequadas utilizavam destaques de objetos para favorecer a compreensão;

(b) Emoções em faces - a inadequação da expressão de medo e da expressão ardilosa;

(c) Modelo de avaliação de um dos itens: inserção de análise de narrativa nas histórias lógicas de OLc

O instrumento foi denominado Bateria de Teoria da Mente (BToM) para a identificação de desempenho em diferentes níveis de ToM, controlando variáveis cognitivas. O público-alvo são crianças com TEA de 7-12 anos de idade. A seguir, será apresentada a descrição detalhada de cada tarefa ToM e controle. 


\section{Tarefa 1: Nomeação de objetos}

Esta tarefa é controle, devido à dissociação existente entre nomeação de emoções e objetos, observada na literatura. Foram definidos 24 objetos isolados (Exemplo 1), que faziam parte dos roteiros das histórias. O procedimento compreende apresentar cada objeto separadamente e solicitar que o sujeito o nomeie. A apresentação é sempre na mesma ordem, e a ordem de apresentação foi definida previamente por sorteio.

Instrução: "Diga o nome desta figura"
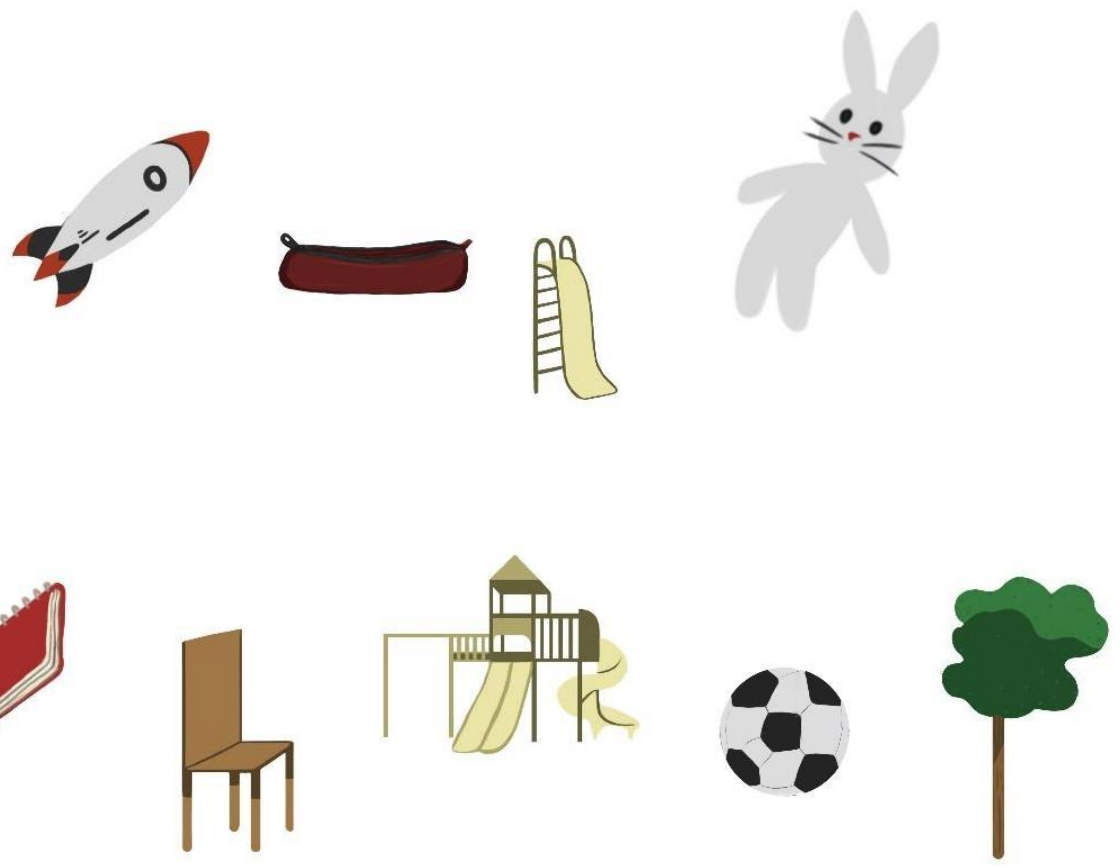

\section{Exemplo 1}

A correção desta tarefa se dá a partir da listagem de acertos quanto à nomeação das imagens apresentadas. Em seguida, é calculado o percentual de acertos.

\section{Tarefa 2: Nomeação de emoções simples (NEs)}

Esta tarefa engloba domínio de precursores de ToM, quanto à identificação de estados mentais, ou seja, reconhecimento de emoções (Flavell et al., 1999). 
Nesta tarefa foram utilizadas 4 emoções básicas (Felicidade, Tristeza, Medo e Raiva). As imagens foram trabalhadas para que todas as faces estivessem na mesma posição. A imagem de uma das personagens (Flor) foi trabalhada dentro dessas referências. Os sinais de expressão emocional foram retirados da descrição feita por Ekman (2003).

O procedimento é apresentar as emoções de conteúdo mais explícito separadamente e solicitar a nomeação. Caso haja erro, a emoção é nomeada para a criança.

\section{Instruções:}

1- Apresentar a carta do rosto feliz (número 3) e dizer:

\section{1- Instrução: "Qual o nome dessa}

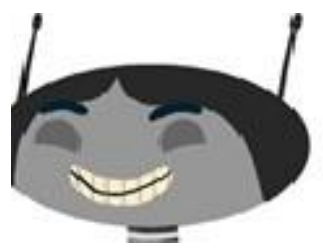

2- Apresentar a carta do rosto triste (número 3) e dizer:

2- Instrução: “Qual o nome dessa

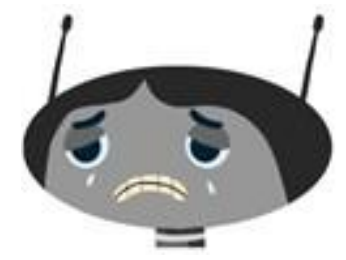

3- Apresentar a carta do rosto medo (número 3) e dizer:

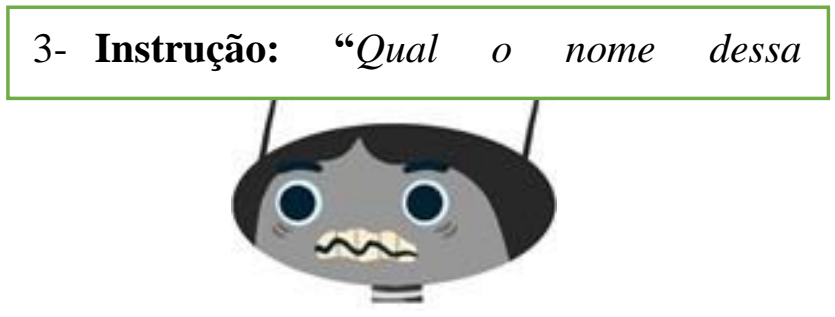

4- Apresentar a carta do rosto raiva (número 3) e dizer:

4- Instrução: “Qual o nome dessa




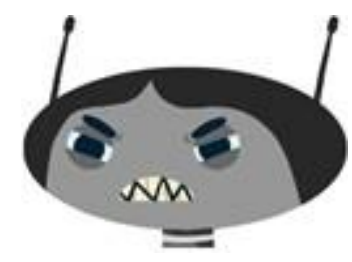

A correção desta tarefa se dá a partir da listagem de acertos quanto à nomeação das emoções. Em seguida, é calculado o percentual de acertos. O controle da tarefa é pareado e interno, através da nomeação de objetos e com número reduzido de estímulos.

\section{Tarefa 3: Gradação de emoções simples (GEs)}

Nesta etapa, há uma gradação de emoções. Neste momento, cada grupo contém 3 faces em níveis diferentes, que variam do mais sutil até o mais intenso da emoção, representado por sinais de expressão não verbal, tais como: sorriso mais sutil (linha da boca menos curva) ou mais intenso (linha da boca mais curva, bochechas levantadas); olhos mais sutis (menos estreitos), ou em nível mais intenso de emoção (pele da pálpebra para cima). Estes sinais foram retirados da descrição feita por Ekman (2003).

O procedimento é apresentar as emoções da mesma qualidade fora de ordem (essa ordem foi definida por sorteio) e solicitar que sejam organizadas da menos sutil para a mais explícita, como, por exemplo, pouco feliz, médio feliz e muito feliz.

1-Dar as 3 cartas da emoção FELIZ, NA ORDEM ESPECIFICADA NO

VERSO DA CARTA e solicitar:

Instrução: "Coloque da menos para a mais, ou seja, da menos

feliz para a mais feliz" 

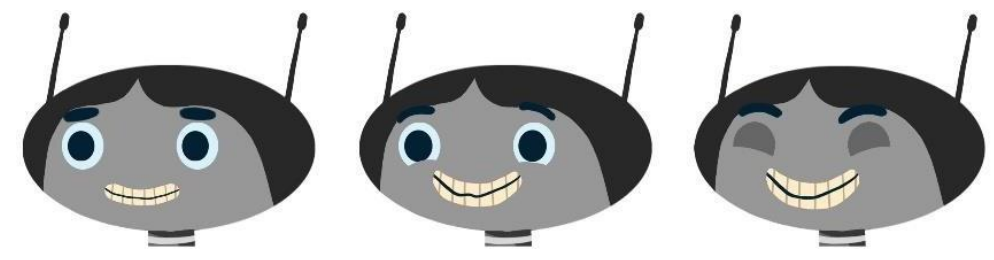

\section{alegria}

2- Dar as 3 cartas da emoção TRISTE, NA ORDEM ESPECIFICADA NO VERSO DA CARTA e solicitar:

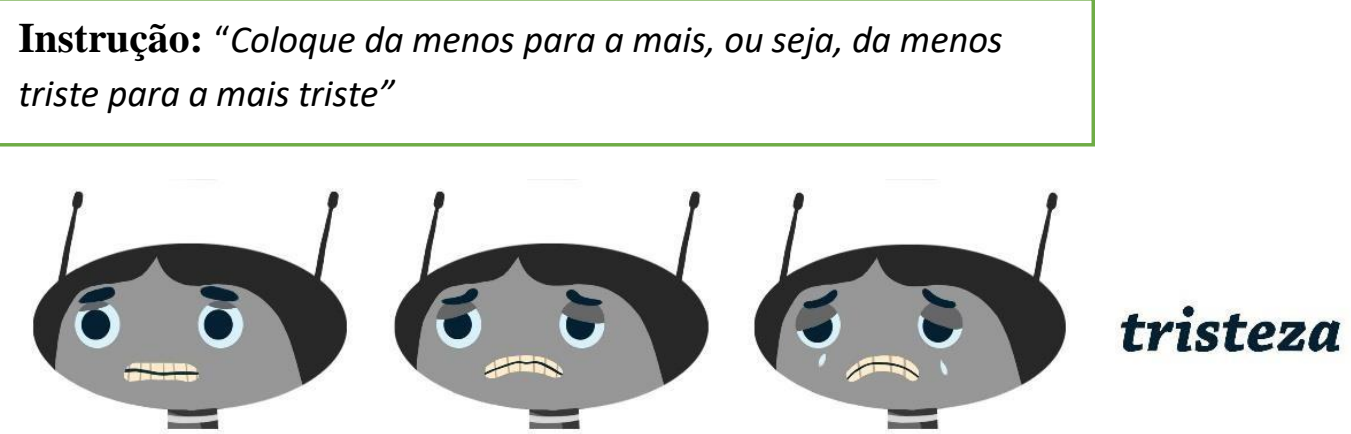

3- Dar as 3 cartas da emoção MEDO, NA ORDEM ESPECIFICADA NO VERSO DA CARTA e solicitar:

Instrução: "Coloque da menos para a mais, ou seja, da menos medo para a mais medo"
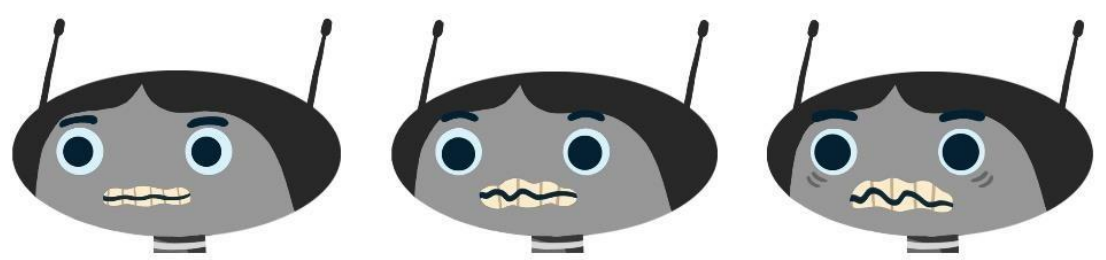

medo

4- Dar as 3 cartas da emoção RAIVA, NA ORDEM ESPECIFICADA NO VERSO DA CARTA e solicitar

Instrução: "Coloque da menos para a mais, ou seja, da menos raiva para a mais raiva" 

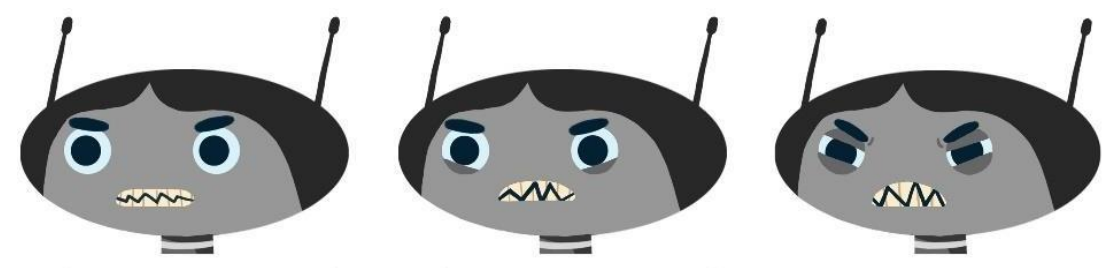

raiva

O controle da tarefa é pareado, realizado a partir da apresentação de emoções básicas, não complexas e da apresentação individual na primeira etapa (NEs). A correção desta tarefa se dá a partir da listagem de acertos quanto à sequência da gradação. Em seguida, é calculado o percentual de acertos.

\section{Tarefa 4: Tarefa Go no-Go}

A tarefa 2 é uma tarefa controle, baseada no processo de controle inibitório, inserido no constructo de funções executivas. Ela é uma tarefa controle pareada da tarefa seguinte de identificação de estados mentais, pois se acredita que prejuízos em inibição podem gerar respostas não corretas (Austin et al., 2014; Schimtt et al., 2018).

É realizada com os 4 personagens do instrumento. Eles foram colocados em uma mesma ordem. Esta ordem foi definida por sorteio, para ser aleatória. O procedimento é bater com a mão na mesa a cada vez que as personagens Tony, Flor e Nina aparecerem (Go). Quando a personagem Dani aparecer, ela deve inibir o movimento da mão (NO-GO). A seguinte instrução é dada:

Instrução: Vou te mostrar várias vezes as personagens, bata na mesa toda vez que as personagens aparecerem, mas não bata na mesa quando o Dani (CARTÃO VERMELHO) aparecer" (MOSTRAR O CARTÃO PARA A CRIANÇA). "Mantenha a mão perto do ombro e, depois que você bater, retorne com ela para o ombro". 

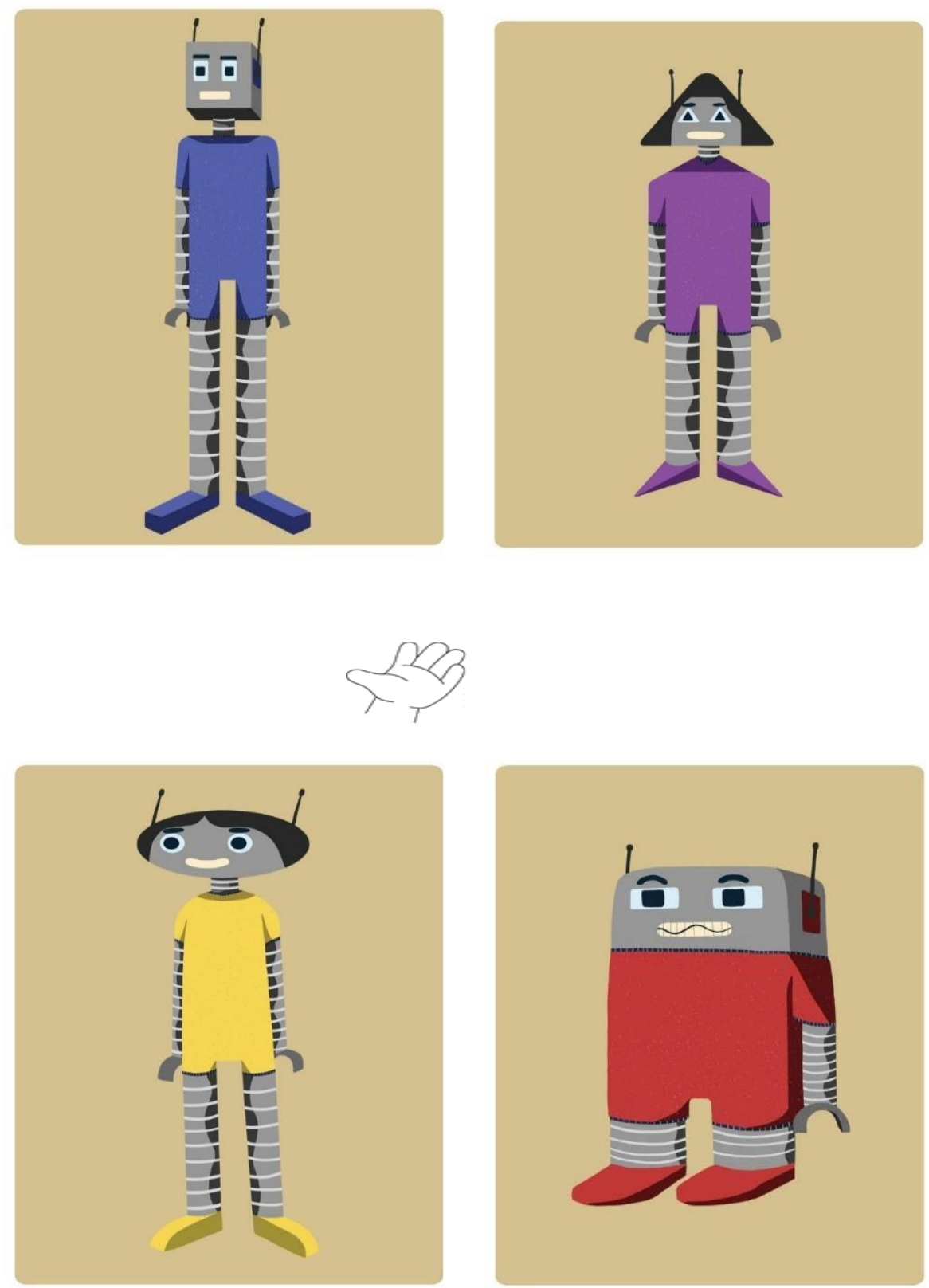

A correção desta tarefa se dá a partir da listagem de acertos (go e no-go). Em seguida, é calculado o percentual de acertos.

\section{Tarefa 5: Identificação de estados mentais (EM)}

Foram construídas 3 cenas. Elas têm apenas um quadro, mas foram aumentando em complexidade de divisões, de inferência e de falsa crença. O 
aumento da divisão de quadros e inferência é uma tentativa de controle de memória de trabalho fonológica (perguntas) e visuoespacial (quadros). O controle interno da tarefa (complexidade) é feito a partir da complexificação das perguntas de ToM, avaliando aspectos diferentes dos domínios (perguntas de tomada de perspectiva simples e complexa - falsa crença). O controle de outros domínios cognitivos internos é feito através de perguntas controle, que avaliam a compreensão da cena, no que diz respeito às relações entre as ações das personagens - as relações lógicas do mundo físico; o aumento da quantidade de ações; o não uso de recursos verbais para interação entre as personagens, para controle de memória de trabalho e de relações lógicas do mundo físico. O controle pareado de outros domínios cognitivos é feito através da tarefa Go no-Go.

Cena 1: Um quadro - um dos meninos está olhando para as meninas que estão fazendo um piquenique. Elas sentadas no parque, com uma cesta de frutas, sanduíches, embalagem de suco. Ele, mais distante, olhando com uma expressão de que queria participar. Mas uma delas não está olhando para ele, e a outra está de frente para a personagem Dani. Nesta etapa são realizadas sempre uma pergunta controle de compreensão e, em seguida, as perguntas relacionadas à falsa crença.

Na cena 1, a pergunta de ToM refere-se à etapa see-know (uma etapa prévia e mais simples de falsa crença):

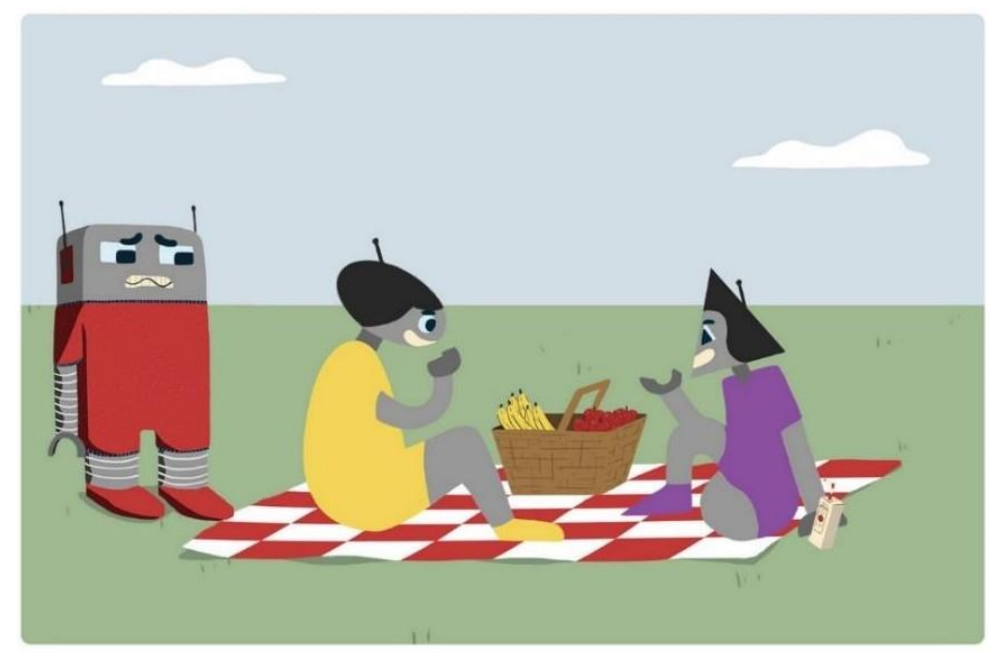

O procedimento consiste em apresentar e fazer a pergunta controle:

Instrução: "Para onde o Dani (Apontar) está olhando?" 
Em caso de erro na pergunta controle, dar a resposta correta. Em seguida, perguntar:

Instrução: “A Flor (Apontar) sabe que o Dani está olhando pra elas?” "A Nina (Apontar) sabe que o Dani está olhando para elas?"

Cena 2: Um quadro dividido em dois: 2 personagens enchem uma caixa de presente de papel, com uma expressão "maldosa”. No outro quadro, um dos personagens entrega a caixa de presente para o outro, considerando uma falsa crença de conteúdo inesperado:

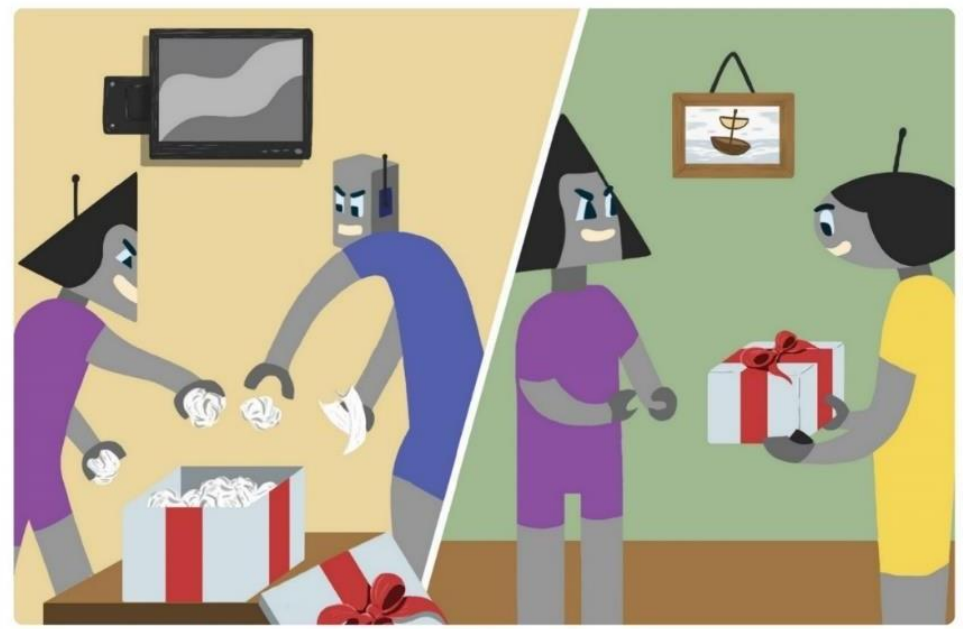

O procedimento consiste em apresentar e fazer a perguntar controle:

Instrução: "O que estão colocando na caixa?”

Em caso de erro na pergunta controle, dar a resposta correta. Em seguida, perguntar:

Instrução: “O que a Flor (Apontar) pensa que tem na caixa?”

Cena 3: Um quadro divido em 3, onde um menino que está no recreio pega o sanduiche que está na mochila de um dos meninos e coloca na mochila de um terceiro. No primeiro quadro, ele tira de uma mochila; no segundo quadro, ele coloca em outra; no terceiro quadro, os 2 personagens que tiveram os sanduíches trocados estão juntos. É realizada uma pergunta controle de compreensão. Em seguida, são realizadas as perguntas de falsa crença de mudança de localização: 


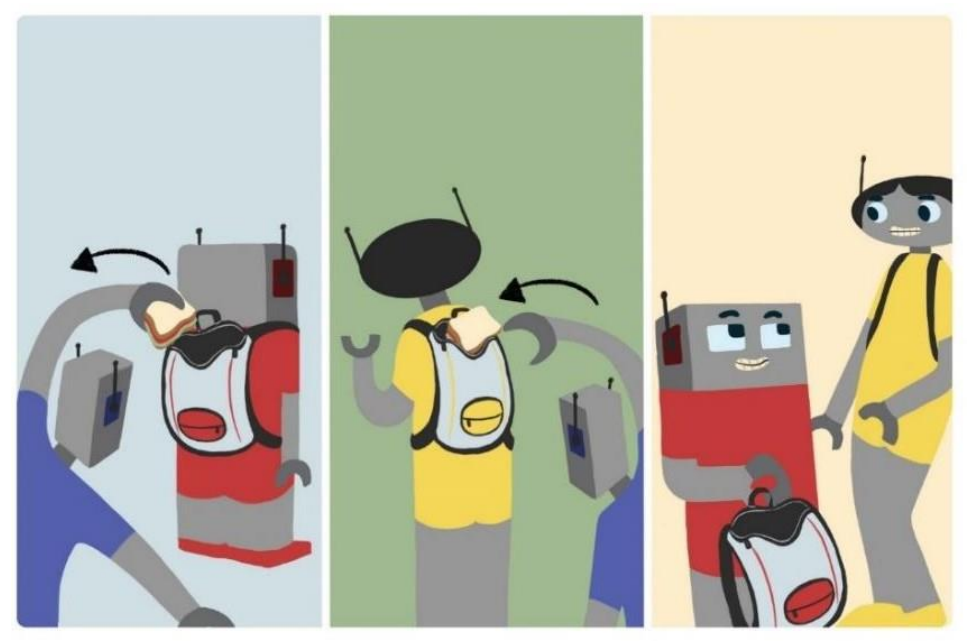

O procedimento consiste em apresentar e fazer as perguntas controle:

Instrução: “O que Tony está fazendo nessa cena” (apontar para o Tony na primeira etapa da cena)?

“O que Tony está fazendo nessa cena" (apontar para o Tony na primeira etapa da cena)?

Em caso de erro na pergunta controle, dar a resposta correta. Em seguida, perguntar:

Instrução: "Onde o Dani vai procurar o sanduíche pra lanchar?”

"A flor sabe que o sanduíche está na mochila dela?"

perguntas com conteúdo de falsa crença. Em seguida, é calculada a porcentagem de acertos.

\section{Tarefa 6: Organização Lógica Simples (OLs):}

Esta tarefa é uma tarefa controle da tarefa de organização lógica complexa, pois avalia a relação causal do mundo físico. São 5 histórias mecânicas, apenas com uma sequência visual do acontecimento, e cada história utiliza apenas uma personagem, para controlar o impacto de uma interação social entre elas. 
Elas aumentam em quantidade de quadros, de 3 a 5 quadros, baseados em span de memória de trabalho, outro processo inserido no constructo de funções executivas e que tem impacto significativo na compreensão de cenas sociais, o que seria o controle interno da tarefa. O roteiro das histórias encontra-se na Tabela 14.

Tabela 14: Roteiro das cenas de OLs

\begin{tabular}{|c|c|}
\hline Cenas & Roteiro \\
\hline Cena 1 & $\begin{array}{l}\text { Quadro 1: Personagem sonolento no parque. } \\
\text { Quadro 2: Está fechando o olho. } \\
\text { Quadro 3: Fecha completamente. }\end{array}$ \\
\hline Cena 2 & $\begin{array}{l}\text { Quadro 1: uma personagem olha para o caderno em cima da mesa } \\
\text { Quadro 2: Abre o caderno. } \\
\text { Quadro 3: Escreve nele. }\end{array}$ \\
\hline Cena 3 & $\begin{array}{l}\text { Quadro 1:Personagem na lanchonete. } \\
\text { Quadro 2: Pega um doce. } \\
\text { Quadro 3: Doce reduzindo. } \\
\text { Quadro 3: Sem o doce na mão (como se já tivesse comido) }\end{array}$ \\
\hline Cena 4 & $\begin{array}{l}\text { Quadro 1: Personagem olha o lápis. } \\
\text { Quadro 2: Personagem pega o lápis. } \\
\text { Quadro 3: Ele vai levando o lápis até o estojo. } \\
\text { Quadro 4: Coloca o lápis dentro do estojo. }\end{array}$ \\
\hline Cena 5 & $\begin{array}{l}\text { Quadro 1: Personagem vê um brinquedo preso numa árvore no parque. } \\
\text { Quadro 2: Pega algo para subir. } \\
\text { Quadro 3: Está subindo. } \\
\text { Quadro 4: Está pegando o brinquedo. } \\
\text { Quadro 5: Está descendo. }\end{array}$ \\
\hline \multicolumn{2}{|c|}{$\begin{array}{l}\text { O procedimento consiste em apresentar cada história seguindo a ordem } \\
\text { NUMÉRICA, no verso da carta. Anotar cada resposta seguindo a ordem de } \\
\text { LETRAS. Solicitar, após apresentar as histórias em ordem numérica da esquerda } \\
\text { para a direita (posição do avaliando): }\end{array}$} \\
\hline
\end{tabular}

Instrução: "Agora coloque na ordem certa." 

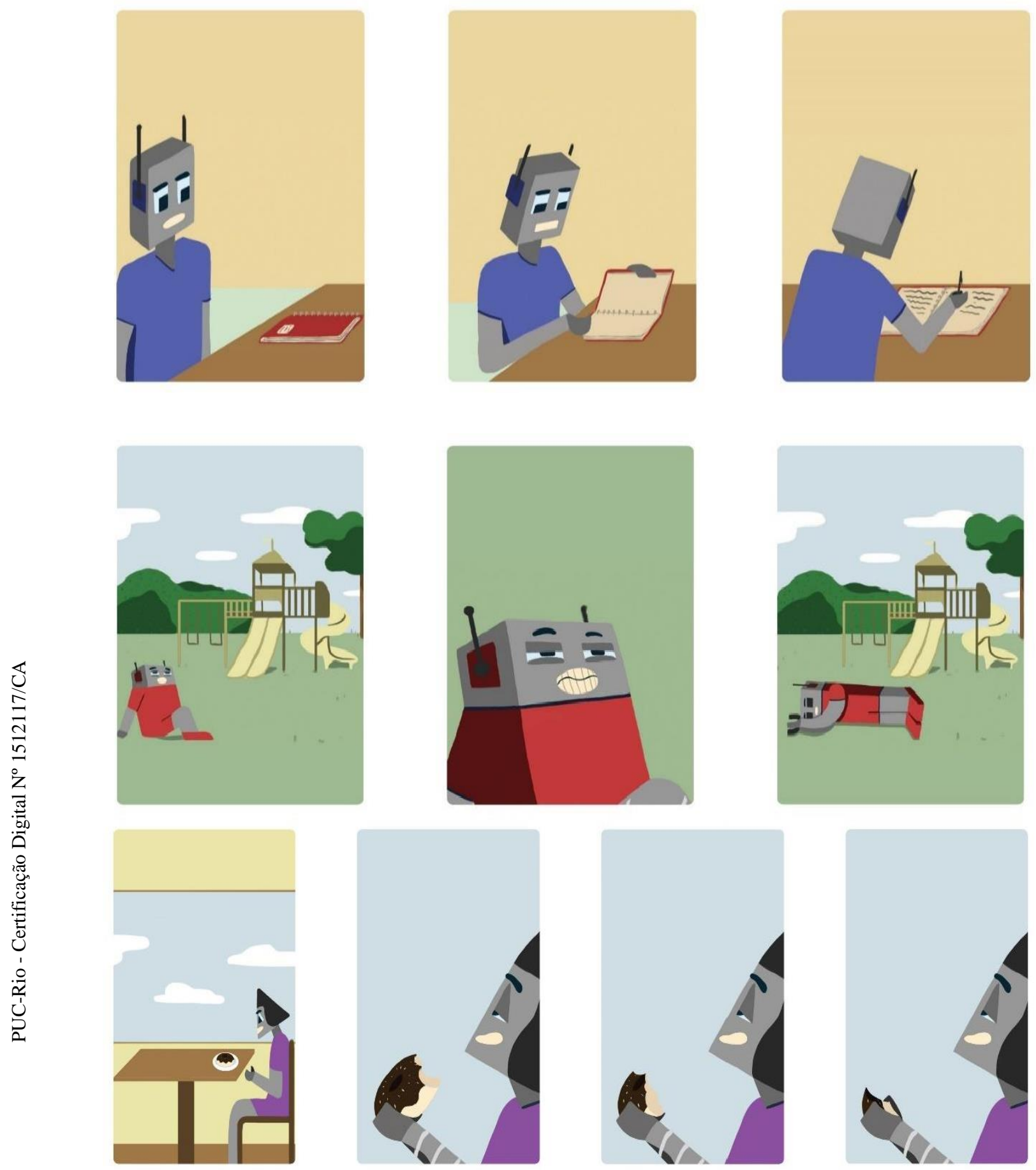

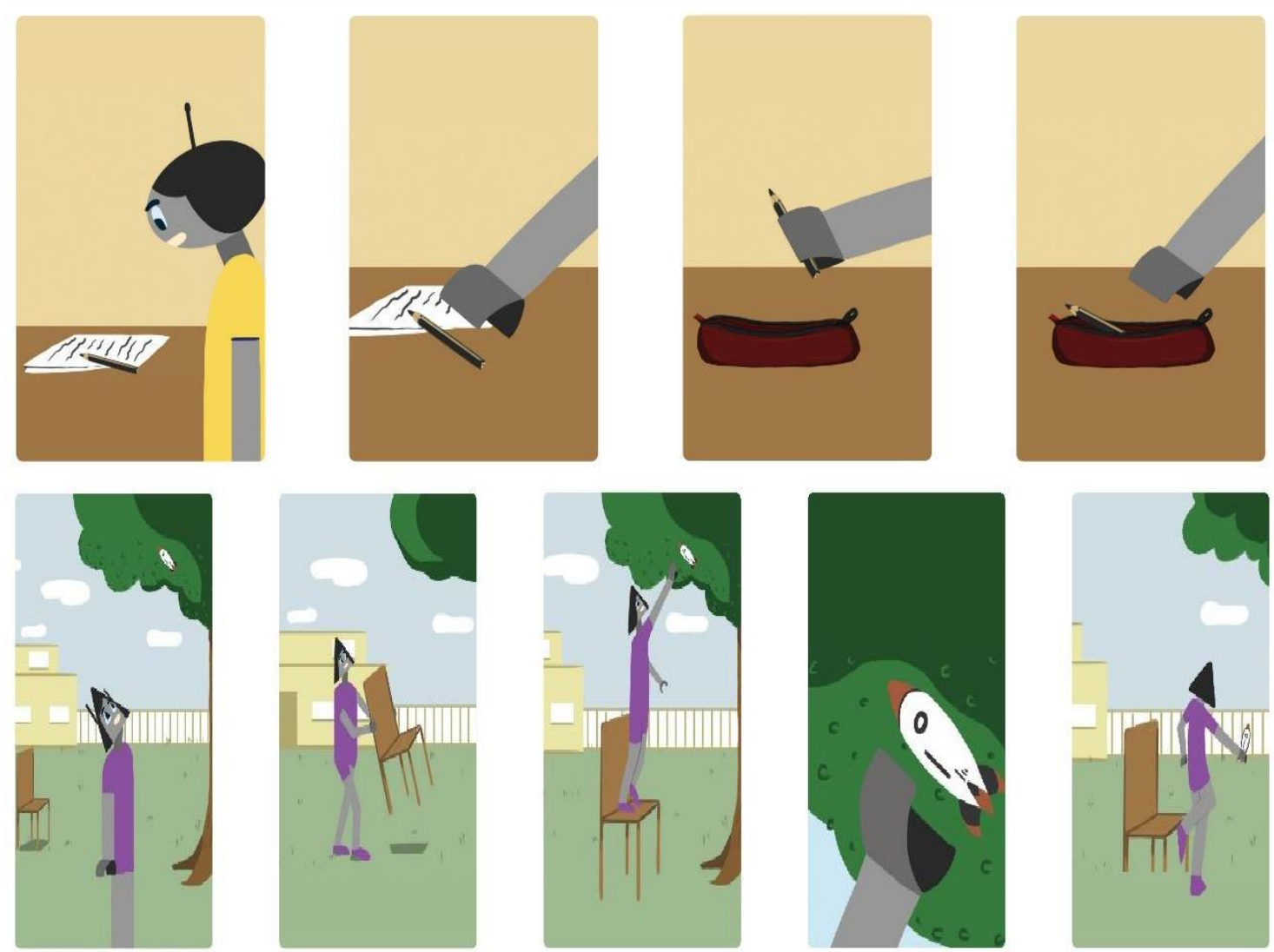

Tarefa 7: Organização Lógica Complexa (OLc)

Esta tarefa de ToM compreende 5 histórias com interação entre personagens, para gerar análise de relações causais em contextos sociais. Elas aumentam em quantidade de quadros, de 3 a 5 quadros, baseados em span de memória de trabalho, da mesma forma que foi utilizado na tarefa anterior (Tabela 4). O controle interno é feito com aumento gradual da demanda de memória de trabalho (aumentando a quantidade de quadros de forma gradativa) e da complexidade das intenções. O controle pareado de outros domínios cognitivos é feito pela OLC, que avalia relações causais do mundo físico. 
Tabela 4: Roteiro das cenas de OLc

\begin{tabular}{|c|c|}
\hline Cenas & Roteiro \\
\hline Cena 1 & $\begin{array}{l}\text { Quadro 1: Na sala, uma das meninas olhou para a amiga (estava } \\
\text { nervosa/preocupada). } \\
\text { Quadro 2: Ela viu que ela não estava conseguindo encontrar seu livro e } \\
\text { estava triste. } \\
\text { Quadro 3: A amiga compartilha o livro, e a amiga fica feliz. }\end{array}$ \\
\hline Cena 2 & $\begin{array}{l}\text { Quadro 1: Um dos meninos e uma das meninas estão indo em um dos } \\
\text { brinquedos (parque), correndo para chegar. O brinquedo deve estar no } \\
\text { mesmo quadro, na direção do olhar deles. } \\
\text { Quadro 2: O menino passa à frente dela e entra no brinquedo. } \\
\text { Quadro 3: Ela aparece bem irritada olhando para ele no brinquedo. }\end{array}$ \\
\hline Cena 3 & $\begin{array}{l}\text { Quadro 1: A personagem mais impulsiva pega o lápis que o outro } \\
\text { personagem (mais ingênuo) ia usar. (colocar uma expressão meio } \\
\text { ardilosa). } \\
\text { Quadro 2: A personagem mais ingênua está olhando para outra coisa ou } \\
\text { pessoa e não percebe. } \\
\text { Quadro 3: Quando busca o lápis, fica surpresa por não estar ali } \\
\text { Quadro 4: A que pegou faz uma expressão de quem fez algo errado. }\end{array}$ \\
\hline Cena 4 & $\begin{array}{l}\text { Quadro 1: Uma das meninas (a mais doce) está procurando algo que } \\
\text { perdeu no parque. } \\
\text { Quadro 2: Um dos meninos (impulsivo) passa e olha para ela procurando } \\
\text { Quadro3: Começa a procurar e acha o objeto dela. } \\
\text { Quadro 4: Eles se abraçam, e ela está feliz com o objeto. }\end{array}$ \\
\hline Cena 5 & $\begin{array}{l}\text { Quadro 1: No recreio, os } 2 \text { meninos estão brincando } \\
\text { Quadro 2: As } 2 \text { meninas se aproximam com uma expressão de que } \\
\text { querem brincar } \\
\text { Quadro 3: Eles ficam com uma expressão de tédio, pois não querem. } \\
\text { Quadro 4: Elas insistem e entram na brincadeira. } \\
\text { Quadro 5: Eles ficam com expressão de irritados. }\end{array}$ \\
\hline
\end{tabular}

O procedimento é apresentar cada história seguindo a ordem NUMÉRICA, no verso da carta. Anotar cada resposta seguindo a ordem de LETRAS. Solicitar, após apresentar as histórias em ordem numérica da esquerda para a direita (posição do avaliando):

Instrução: “Agora coloque na ordem certa." 

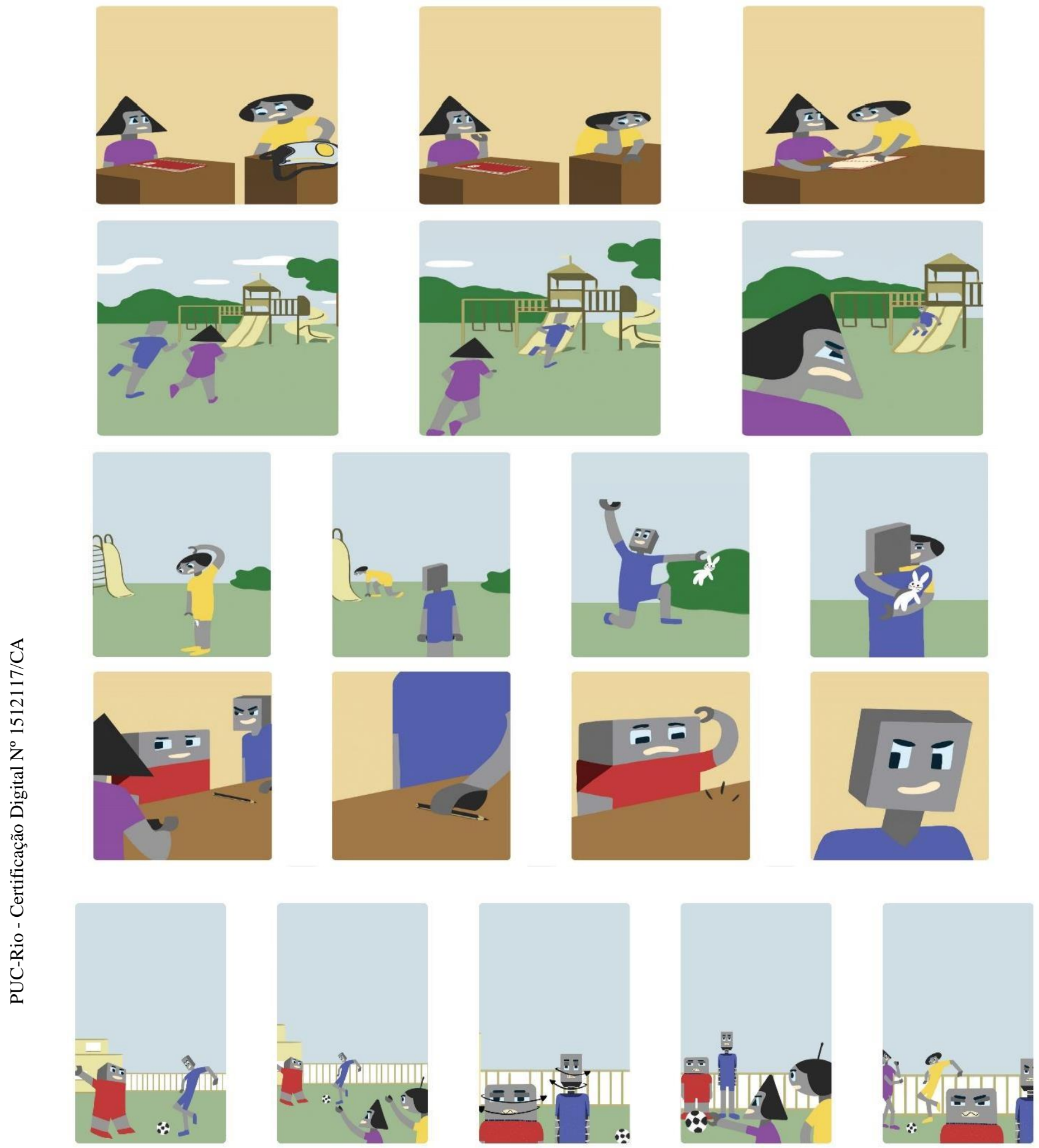

A correção se dá, em um primeiro momento, considerando-se os acertos na ordenação das histórias. 


\section{Tarefa 8: Verbalizações}

Esta tarefa compreende a narrativa, realizada pela criança, posterior à organização lógica dos cartões da tarefa 7. O controle pareado é feito pela própria OLc, pois a criança tem acesso visual às imagens para contar a hitória. $\mathrm{O}$ procedimento é o seguinte:

Após a criança colocar na ordem certa, solicitar:

Instrução: "Agora me conte essa história."

\section{(ANOTAR EXATAMENTE COMO A CRIANÇA CONTA)}

Essa narrativa é corrigida baseada na presença de verbalizações de estados mentais, que foram categorizados, segundo o modelo de Howlin et al. (2006). As histórias foram previamente pré-categorizadas e a pontuação é categórica, ou seja, se há ou não presença das verbalizações esperadas para cada história. Em seguida, é feito o somatório da presença de verbalizações. Em ambas são calculadas as porcentagens do escore final.

\subsection{2.- FASE 1 - Análise de Conteúdo por procedimento sistematizado a juízes}

Participaram do estudo oito juízes, diferentes dos pesquisadores que criaram os itens, todos psicólogos, com experiência em intervenção em TEA e/ou em neuropsicologia e com o público infantojuvenil, sendo 2 mestres em Neuropsicologia, 3 especialistas em Neuropsicologia, 2 especialistas em intervenções comportamentais em TEA, 1 psicóloga, com experiência profissional variando de 1 ano a 13 anos $(M=5,1$ e desvio padrão, $\mathrm{DP}=4,2)$. As respostas dadas pelos juízes foram avaliadas quanto à concordância, por meio da porcentagem de concordância entre os juízes. Foram encontrados os seguintes resultados para cada item da avaliação global do instrumento: 
Tabela 15: Concordância quanto aos itens globais do instrumento:

\begin{tabular}{|c|c|}
\hline Item & $\begin{array}{c}\text { Porcentagem } \\
\text { de } \\
\text { concordância }\end{array}$ \\
\hline $\begin{array}{l}\text { O instrumento mede a Teoria da Mente entendida como capacidade de inferir } \\
\text { estados mentais internos de outros? }\end{array}$ & $100 \%$ \\
\hline O instrumento mede Teoria da Mente em múltiplos domínios? & $100 \%$ \\
\hline $\begin{array}{l}\text { O instrumento consegue avaliar domínio de reconhecimento de emoções em } \\
\text { faces? }\end{array}$ & $100 \%$ \\
\hline $\begin{array}{l}\text { O instrumento consegue medir o domínio de inferência de estado mental, a partir } \\
\text { de falsas crenças? }\end{array}$ & $100 \%$ \\
\hline $\begin{array}{l}\text { O instrumento consegue avaliar inferências sociais a partir de pistas contextuais } \\
\text { e visuoespaciais? }\end{array}$ & $100 \%$ \\
\hline $\begin{array}{l}\text { O instrumento apresenta características de demanda gradual quanto nível de } \\
\text { inferência de estados mentais? }\end{array}$ & $100 \%$ \\
\hline $\begin{array}{l}\text { O instrumento apresenta como característica a redução de demanda de memória } \\
\text { de trabalho? }\end{array}$ & $75 \%$ \\
\hline Pode auxiliar no diagnóstico diferencial do autismo? & $100 \%$ \\
\hline $\begin{array}{l}\text { O instrumento mede Teoria da Mente, entendida como capacidade de inferir } \\
\text { estados mentais internos de outros? }\end{array}$ & $100 \%$ \\
\hline O instrumento mede Teoria da Mente em múltiplos domínios? & $100 \%$ \\
\hline
\end{tabular}

Quanto aos itens específicos sobre ToM (adequação de emoções, adequação de perguntas que avaliam falsa crença, codificação de verbalizações de estados mentais), as seguintes porcentagens de concordância foram encontradas (Tabela 16) 
Tabela 16: Concordância em itens específicos de ToM

\begin{tabular}{|c|c|}
\hline Item & $\begin{array}{c}\text { Porcentagem } \\
\text { de } \\
\text { concordância }\end{array}$ \\
\hline Você reconhece esta emoção como feliz? & $100 \%$ \\
\hline Você reconhece esta emoção como triste? & $100 \%$ \\
\hline Você reconhece esta emoção como medo? & $87,5 \%$ \\
\hline Você reconhece esta emoção como raiva? & $100 \%$ \\
\hline As perguntas avaliam tomada de perspectiva do Baron-Cohen? & $100 \%$ \\
\hline A pergunta avalia falsa crença Baron-Cohen de conteúdo inesperado? & $100 \%$ \\
\hline As perguntas avaliam falsa crença Baron-Cohen de mudança de localização? & $100 \%$ \\
\hline OLc1- Identificação de emoção por reconhecimento de faces & $100 \%$ \\
\hline Identificação de emoção baseada na situação & $100 \%$ \\
\hline Crença verdadeira/antecipação de comportamento & $87,5 \%$ \\
\hline Conceito Geral: Empatia e Comportamentos pró-sociais & $100 \%$ \\
\hline OLc2- Identificação de emoção por reconhecimento de faces & $100 \%$ \\
\hline Identificação de emoção baseada na situação & $100 \%$ \\
\hline Identificação baseada no desejo & $100 \%$ \\
\hline Conceito Geral: Havia uma disputa & $100 \%$ \\
\hline OLc3- Identificação de emoção por reconhecimento de faces & $100 \%$ \\
\hline Identificação de emoção baseada na situação & $100 \%$ \\
\hline Tomada de perspectiva complexa & $100 \%$ \\
\hline Crença verdadeira/antecipação de comportamento & $100 \%$ \\
\hline Conceito Geral: Atitude pró-social (altruísta) & $100 \%$ \\
\hline OLc4- Identificação de emoção por reconhecimento de faces & $75 \%$ \\
\hline Identificação de emoção por reconhecimento de faces & $100 \%$ \\
\hline Emoções baseadas nas crenças & $100 \%$ \\
\hline Crença verdadeira/antecipação de comportamento & $100 \%$ \\
\hline Falsa crença (predizer a ação da pensão em função daquilo que ela falsamente & $100 \%$ \\
\hline Estabilização da habilidade de fingir & $100 \%$ \\
\hline Conceito geral: fazer uma brincadeira com terceiro & $100 \%$ \\
\hline OLc5- Identificação de emoção por reconhecimento de faces & $100 \%$ \\
\hline \multicolumn{2}{|l|}{ Identificação de emoção por reconhecimento de faces } \\
\hline Identificação de emoção baseada na situação & $100 \%$ \\
\hline Identificação de emoção baseada na situação & $100 \%$ \\
\hline \multicolumn{2}{|l|}{ Tomada de perspectiva complexa - como aparece para eles } \\
\hline Conceito Geral 1: Elas queriam brincar com eles. Conceito 2: Eles não queriam & $100 \%$ \\
\hline
\end{tabular}




\subsubsection{FASE 2 - Confiabilidade: Análise de precisão por correlação de}

\section{correcões de diferentes avaliadores de correcão}

Foram calculadas as correlações entre os dois pares de avaliadores separadamente. Foram encontrados os seguintes resultados para o primeiro par de avaliadores (tabela 17 e 18).

Tabela 17: Coeficiente de correlação intraclasse (ICC)-Par 1

\begin{tabular}{llll}
\hline Itens & N & IC & P \\
\hline NO & 15 &, 918 &, $000^{* *}$ \\
NGEs-Identificação & 15 &, 739 &, $001^{*}$ \\
NGEs-Gradação & 15 &, 963 &, $000^{* *}$ \\
GO NO GO & 15 & 1,00 &, $000^{* *}$ \\
EM & 15 &, 925 &, $000^{* *}$ \\
OLs & 15 &, 974 &, $000^{* *}$ \\
OLc & 15 &, 996 &, $000^{* *}$ \\
Verbalizações na narrativa & 15 &, 604 &, $005^{*}$ \\
\hline
\end{tabular}

$\mathrm{N}=$ participantes; IC=correlação intraclasse; *p $<0,05 ; * * \mathrm{p}<0,001$

Tabela 18: Coeficiente de correlação intraclasse (ICC)-Par 2

\begin{tabular}{llll}
\hline Itens & $\mathrm{N}$ & $\mathrm{IC}$ & $\mathrm{P}$ \\
\hline NO & 15 &, 962 &, $000^{* *}$ \\
NEs-Identificação & 15 &, 921 &, $000^{* *}$ \\
GEs-Gradação & 15 &, 983 &, $000^{* *}$ \\
GO NO GO & 15 &, 940 &, $000^{* *}$ \\
EM & 15 &, 957 &, $000^{* *}$ \\
OLs & 15 &, 958 &, $000^{* *}$ \\
OLc & 15 &, 964 &, $000^{* *}$ \\
Verbalizações na narrativa & 15 &, 755 &, $001^{*}$ \\
\hline
\end{tabular}




\subsection{3.-FASE 3 - Validade de constructo: Análise de cluster entre as tarefas e associacão com padrão-ouro Sally Anne.}

\subsubsection{1-Análise de Cluster entre as tarefas de BToM}

Os resultados da análise de cluster apontam para o seguinte dendograma:

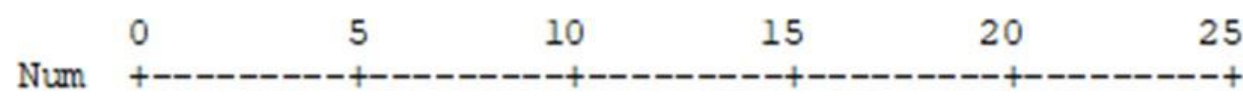

Go no Go

OLc

Verbalização

EM

Nomeação

OLs

NEs

GEs

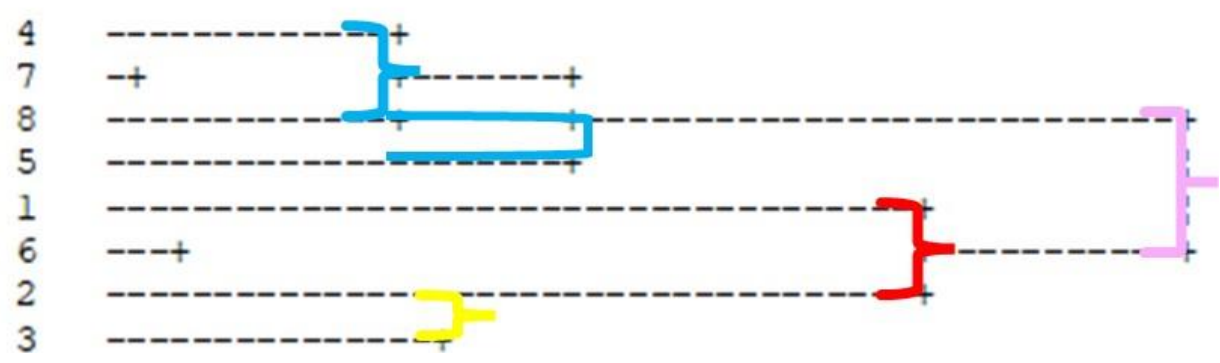

Grupo 1: tarefa controle go no-go se aproxima de OLc e com as verbalizações da narrativa. Esse grupo se une a seguir a partir das verbalizações com a tarefa de EM.

Grupo 2: Mais distanciados encontram-se a nomeação de objetos, que se aproxima de OLs e se une ao grupo de nomeação de emoções.

Grupo 3: No extremo oposto ao grupo 1, encontra-se um grupo formado por nomeação de emoções e gradação e emoções.

No nível hierárquico 25, o grupo 1 se une com grupo 2, mas ainda mantém o afastamento maior do grupo 3.

\subsubsection{Análise de associação entre as tarefas do instrumento e o padrão-ouro}

\section{Sally-Anne.}

Foi realizado o teste de Qui-quadrado para verificar as relações entre as tarefas que avaliam ToM do instrumento e o padrão-ouro Sally-Anne. Observamse associações entre o padrão-ouro e as tarefas GEs e EM. Resultados podem ser vistos em tabela 19. 
Tbela 19- Associações entre as tarefas BToM e Sally-Anne

\begin{tabular}{ccc}
\hline & Qui-quadrado & $\mathrm{p}$ \\
\hline NEs & 6,967 & 0,31 \\
GEs & 19,51 & $0,00^{* *}$ \\
EM & 18,3 & $0,00^{* *}$ \\
OLc & 14,23 & 0,22 \\
Verbalizações & 28,10 & 0,10 \\
\hline P=valor de significância ${ }^{* *} \mathrm{p}<0,05$ & &
\end{tabular}

\section{5-DISCUSSÃO}

\subsection{1- FASE 1- Evidências de Validade de Conteúdo do Instrumento BToM} (Elaboracão e concordância entre juízes)

Este artigo propõe a primeira versão da BToM. Ela compreende 7 tarefas, sendo 4 de ToM propriamente dita e 3 tarefas de controle de variáveis cognitivas. A estrutura conceitual do instrumento é baseada em dados encontrados na literatura. Esses aspectos englobam a ideia da existência de diferentes domínios que compõem a ToM em uma perspectiva de desenvolvimento (Flavell, et al., 1999).

Esse constructo englobaria domínios, com diferentes habilidades cognitivas e com níveis de complexidade diferentes. Esses domínios podem surgir mais cedo no desenvolvimento, como o reconhecimento da emoção, distinção entre aparência e realidade e tomadas de perspectiva visuais simples, sendo observados aspectos mais complexos mais tardiamente, como a tomada de perspectiva visuais complexas, a linguagem emocional descritiva, a compreensão das intenções e das relações causais entre informações sociais e afetivas, a partir de organização visuoespacial (Flavell, 1999; Flavell et al., 1987; Flavell et al., 1981; Baron-Cohen et al., 1986).

A proposta do instrumento não abarca todos os domínios de ToM. No entanto, ele é composto de múltiplas tarefas, recrutando domínios, baseados na 
cronologia deste desenvolvimento. Logo, ele é formado por reconhecimento de emoções básicas/gradação, seguido por identificação de perspectivas visuais (diferentes níveis), e, por fim, organizações causais de informações que requerem entendimento de intenções e análise de relações lógicas de pistas visuoespaciais para gerar inferências sociais. Segundo Flavell (1999), o reconhecimento e a nomeação de emoções iniciariam por volta de dois anos de idade, enquanto que a identificação de percepção visual de nível 1 e 2, bem como falsas crenças, começariam no primeiro período pré-escolar. Por volta de cinco anos, as crianças conseguem distinguir intenções de desejos e compreendem bem a diferença entre estados psicológicos, do mundo físico/mecânico.

Além de o instrumento compreender um modelo de multitarefas, com domínios retirados do constructo ToM, em diferentes momentos de seu desenvolvimento, ele tem como objetivo controlar aspectos cognitivos, em especial aspectos de autorregulação: controle inibitório e memória de trabalho, vistos na literatura como sendo de grande importância para o desempenho de ToM (Kouklaria et al., 2018). Além disso, busca controlar variáveis cognitivas, que são entendidas como variáveis intervenientes da tarefa experimental de ToM, como o acesso semântico de objetos do mundo físico e não afetivo e a organização causal de ações físicas (Baroh-Cohen et al., 1986).

A elaboração do instrumento apresenta, portanto, coerência com aspectos conceituais da ToM, com a necessidade de se pensar em outras variáveis cognitivas associadas a ToM, bem como de utilizar uma perspectiva de desenvolvimento cognitivo (Tonietto, 2011), visto que impactam tanto seu desenvolvimento quanto seu desempenho.

No que diz respeito à análise realizada pelos juízes, foram observados altos níveis de concordância na maior parte dos itens globais e específicos. Ressalta-se que a metodologia respeitou os parâmetros utilizados na composição de juízes e na análise estatística utilizada (Alexandre \& Coluci, 2011). O item que obteve menor concordância entre os itens globais $(75 \%)$ foi o questionamento quanto à redução de demanda de memória de trabalho nas tarefas. É possível que não tenha ficado claro que a quantidade de informações presentes nas tarefas (como estímulos), a mudança da complexidade dentro do próprio constructo e de seus domínios (tomada de perspectiva simples até falsa crença), e o não uso de 
recursos verbais para interação entre personagens, foi a perspectiva escolhida pelos autores como o índice de redução de memória de trabalho.

Além disso, hipotetiza-se que a forma como a pergunta foi realizada no material de respostas dos juízes pode não ter sido ideal. A pergunta utilizada foi: “O instrumento apresenta como característica a redução de demanda de memória de trabalho?". A forma da questão pode ter confundido os juízes. A proposta é que existam tarefas com redução de demanda de trabalho para entender as diferenças de desempenho de ToM, porém, no instrumento, as tarefas sempre começam de um modelo mais fácil para o mais difícil, ocorrendo, na verdade, um aumento gradual da demanda. Acredita-se que a forma da pergunta pode ter influenciado o entendimento dos juízes.

Quanto aos itens específicos do instrumento, foram observadas concordância igualmente significativas na tarefa 1 e 2 (NEs e GEs) entre as emoções feliz, triste, raiva (100\%). A emoção medo apresentou menor concordância entre os juízes, com 87,5\% (6 juízes em 8). Esta emoção apresenta características complexas de serem representadas em desenhos, como pregas abaixo do olho e a abertura do olhar; além disso, apresenta semelhanças com outra emoção de valência negativa: raiva (Biehl et al., 1997)

$\mathrm{Na}$ literatura de reconhecimento de emoções, também se observa inconsistências. Alguns estudos apontam menor concordância para reconhecimento de medo, nojo e raiva, do que para felicidade e tristeza, por exemplo. Lee, Kim, Yeon, Kim e Chae (2013), discutem algumas possibilidades. Uma delas seria que emoções como nojo, medo e raiva suscitariam atitudes mais negativas dos observadores do que a emoção tristeza, também negativa, o que poderia gerar mais confusão. Também discutem quanto ao impacto cultural e a complexidade de componentes faciais envolvidos nas emoções. Em um estudo transcultural foi observada maior universalidade para rotulagem de emoções de felicidade do que para emoções de valência negativa. Entretanto, salienta-se diferenças culturais, para idianos o mais baixo nível de consistência foi para medo e raiva, equanto que para holandeses foi para nojo (Mishra, Ray \& Srinivasan, 2018).

Na tarefa 2 (EM), houve índice de concordância de 100\% quanto às perguntas de identificação de estados mentais, que envolvem de forma mais 
circunscrita a perspectiva visual, tanto em nível de tomada de perspectiva de $1^{\circ}$ nível (see-know), quanto em $2^{\circ}$ nível, como falsa crença em mudança de conteúdo e de localização nas 3 cenas. Esta tarefa é a que mais se aproxima de tarefas clássicas de ToM, que normalmente usam o paradigma de falsa crença. Foi possível, a partir do modelo de complexificação gradual de demandas, avaliar e separar diferentes aspectos da perspectiva visual (Flavell et al., 1981), tornando a tarefa de fácil compreensão.

$\mathrm{Na}$ tarefa 3 (OLc), a maior parte dos itens específicos sobre a categorização da narrativa das histórias foi classificada com 100\% de concordância. Quatro itens obtiveram concordâncias abaixo de 100\%, respectivamente: antecipação do comportamento na história 1-75\% (ela esqueceu o livro e vai precisar de ajuda); Identificação de emoção por reconhecimento de faces na história 4-75\%, (o tony estava de deboche); item de identificação de emoções em faces na história 5-75\% (O dani ficou bravo); tomada de perspectiva complexa na história 5-75\% (Elas estavam olhando para a bola para brincar). Verifica-se que as discordâncias se concentram em itens de identificação de emoções ou na história 5. Esta última história apresentou questões quanto à sua intepretação; ela foi mantida em função da qualidade das inferências sociais existentes. Entretanto, durante a elaboração, ela passou por mais alterações, quando comparada a outras histórias, em função da dificuldade em representar o roteiro planejado, em especial no que diz respeito à insatisfação das personagens masculinas e às intenções das personagens femininas. Acredita-se que as falhas iniciais da história se refletiram na análise dos juízes.

No caso da história 4, os juízes que discordaram relatam que ele não estaria com o rosto de deboche e sim com cara de "mau". Mais uma vez, destacase que as emoções são aspectos difíceis de serem representados em desenho, por conta dos traços complexos da face humana, o que pode sugerir a necessidade de aprimoramento de algumas representações de emoções no desenho (Lee et al., 2013).

Os altos níveis de concordância sugerem que o instrumento apresenta características condizentes com os aspectos conceituais do constructo de ToM. Além disso, sugerem que os demais aspectos teóricos discutidos pelos autores, como a proposta de controle de memória de trabalho, controle inibitório, relações 
lógicas causais, foram contemplados pelas tarefas apresentadas. Os itens com menor concordância indicam aprimoramento dos desenhos, que representam emoções de valência negativa, e a modificação da história mais complexa da organização lógica.

\subsection{2- FASE 2- Evidências de confiabilidade do Instrumento BToM}

A partir dos resultados, verifica-se que os dois pares de juízes alcançam concordância moderada a alta (Matos, 2014). As correlações mais altas são as dos itens NO, NEs, GEs, GO no GO, EM, OLs, OLc. No subitem de verbalizações de narrativas, existem variações, que ainda assim são adequadas.

Os itens NO, NEs, GEs, GO no GO, EM, OLs, OLc apresentam um modelo de correção objetivo, que pode ser compreendido facilmente por avaliadores diferentes. As ligeiras diferenças de correção podem ser atribuídas a falhas atencionais de correção do avaliador. Além disso, na tarefa de nomeação de emoções, ocorreram interpretações, devido à subjetividade dos avaliadores. Foram aceitas nomenclaturas de emoções diferentes de feliz, triste, medo e raiva. Apesar de ter sido explicado previamente quanto à não utilização de respostas alternativas, é possível que algumas respostas, por se aproximarem muito do uso cotidiano, como alegre no lugar de feliz, assustado no lugar de medo, ou bravo no lugar de raiva, foram consideradas pelo avaliador, em função do viés de subjetividade. Neste primeiro modelo não foram aceitas respostas alternativas; entretanto, não é descartada a possibilidade de inserção futuramente, caso seja avaliada alta frequência de respostas desse tipo.

Diferente dos itens mais objetivos do instrumento, o subitem de verbalizaçõess de narrativas (OLc), mostra-se como um item mais subjetivo, pois se refere a tentativa de categorização de narrativas, por meio de um modelo préexistente (Howlin et al.,2006). Ele apresenta concordância menos elevada, quando comparado as outras tarefas do instrumento.

No primeiro par de avaliadores foram obtidos resultados altos de correlação (acima de 0,75). O segundo par de avaliadores obteve correlação moderada (acima de 0,60). Neste segundo par de avaliadores, houve dois pontos importantes a serem discutidos: (1) um dos avaliadores mostrou maior exigência 
em todas as análises de respostas, pois a sua pontuação teve uma tendência a ser mais baixa em todas as histórias de todos os sujeitos; (2) alguns sujeitos obtiveram pontuações muito discrepantes.

A interferência da subjetividade deste subitem já era esperada. Buscou-se controlar, por meio do treinamento dos avaliadores de correção, o uso de um modelo estruturado de categorização pré-existente (Howlin et al., 2006). Ainda assim, há efeito da subjetividade, porém as concordâncias se mantiveram entre moderada e alta. Logo, entende-se que essas variações não desqualificam a precisão da tarefa. Contudo, nos leva a pensar sobre possibilidades de ajustes. Dentre esses ajustes, podemos citar:

Na história 1, a nomeação das emoções é algo a ser destacado no entendimento de nível 1 (Identificação de emoção por reconhecimento de faces (Flor fica triste). Por vezes, as crianças usam "chateado" para representar a tristeza e isso é comum nas narrativas. Logo, poderiam ser inseridas nomenclaturas diferentes para expressar a tristeza entre os exemplos apresentados aos aplicadores. Da mesma forma, mais exemplos poderiam ser incluídos na identificação das inferências ("Ela quis ajudar a amiga". "Ela sentiu compaixão pela colega/amiga", como: "ela quis dividir", ou "ela dividiu", "elas fizeram juntas", "ela emprestou o caderno").
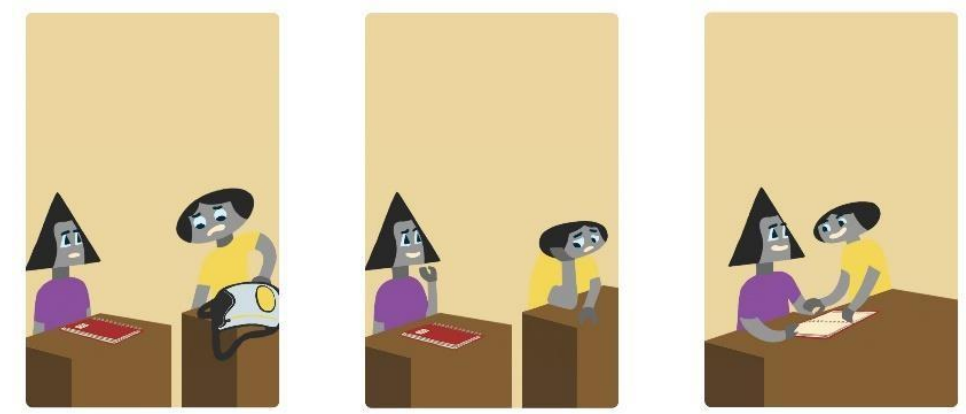

Na história 3, observa-se na identificação da inferência principal Conceito Geral: Atitude pró-social (altruísta): "Ele viu que ela estava procurando o coelhinho e foi ajudar"; "Ele ajudou a procurar o coelhinho" a possibilidade de outras respostas serem aceitas, como "ele achou para ela"; "ele encontrou o coelhinho e deu para ela". 
Na história 4, foram observadas as seguintes questões a serem melhoradas: Entendimento de emoção - Nível 1 (Identificação de emoção por reconhecimento de faces $\mathrm{O}$ tony estava de deboche); Estabilização da identificação da habilidade de fingir (Tony pegou o lápis para fingir que ele tinha sumido).
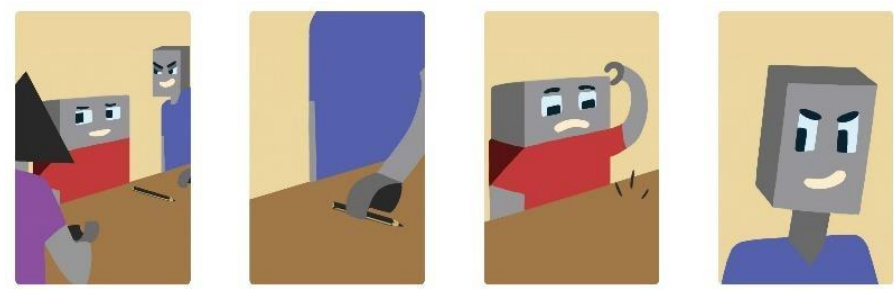

Há dúvidas sobre a expressão “deboche”, logo poderiam ser acrescentadas, como foi sugerido pelos avaliadores, "cara de mau”, por exemplo. Além disso, poderia ser identificado de forma mais clara, em qual parte da cena se espera a cara de mau ou de deboche, no quadro 1 ou 4, por exemplo. Quanto à estabilização da habilidade de fingir, poderia ser incluído como exemplo "ele escondeu o lápis do amigo/dani/outro")

Na história 5, 2 itens são colocados para descrever o Entendimento de emoção -Nível 1 (Identificação de emoção por reconhecimento de faces), um para o Tony e um para o Dani. Em algumas histórias, as crianças reconhecem, mas não falam sobre cada um em separado, o que pode ter alterado a pontuação para alguns juízes. Uma modificação que poderia deixar mais claro é transformar os dois itens em 1 e ampliar a nomenclatura da emoção (eles ficaram com raiva/bravos/chateados); além disso, seria possível indicar o momento em que se espera esta narrativa por parte do sujeito, ou seja, em qual quadro da história)

\subsection{3- FASE 3-Evidências de Validade de Constructo do Instrumento BToM}

Ao se verificar a relação de proximidade entre os itens do instrumento, através da análise de cluster, o dendrograma mostra relações de proximidade entre as tarefas. No grupo 1, encontram-se tarefa controle go no-go mais próxima de OLs e com as verbalizações da narrativa. Isso pode ser justificado pelo fato de a tarefa go no-go ser um paradigma de controle inibitório e tarefas de organização lógica exigirem análise da informação, para que haja a compreensão correta da ordem entre os elementos, em especial quando aumenta a quantidade de itens. Já a 
verbalização é uma subtarefa da organização lógica complexa. A narrativa da história também depende da boa análise da informação, para que a construção do discurso se complexifique. Logo, quando se pensa em análise da informação, é importante que haja inibição de interferência e da própria ação impulsiva para buscar identificar os elementos principais da história e as relações de nexo causal.

Este primeiro grupo se une, a partir das verbalizações, com a tarefa de EM, onde se exige a compreensão de relações entre os objetos (troca de posição, de conteúdo), mas também entre as personagens (direção do olhar, o que vai achar). Do mesmo modo, isso é exigido da tarefa de verbalizações (é necessário identificar relações entre objetos e personagens para narrar a história).

O grupo 2 se encontra mais distanciado. A nomeação de objetos se aproxima de OLc e se une ao grupo de nomeação de emoções. A nomeação remete ao acesso à rede semântica; logo, tanto conteúdos do mundo físico quanto emocionais, em algum nível, são estados organizados em categorias semânticas. Da mesma forma, a organização lógica, envolve acesso semântico, como por exemplo é necessário entender significados das ações para sequenciá-las.

No nível hierárquico 25, o grupo 1 se une com grupo 2; logo, os grupos apresentam relações de proximidade entre si a partir das verbalizações da narrativa, englobando estados mentais, nomeação de objetos, até a organização logica complexa. Ainda assim, o grupo 3 se encontra no extremo oposto ao grupo 1, ou seja, se mantém fora deste grupo maior. $O$ aspecto da emoção, cronologicamente no desenvolvimento, é o primeiro a se desenvolver, o que justificaria menos dependência de variáveis executivas, de relações lógicas ou mesmo de perspectiva visual (Falvell et al., 1981; Flavell et al., 1987).

Quanto à avaliação a partir de um padrão-ouro do constructo de ToM, a análise apresenta baixos índices de correlação entre a tarefa Sally-Anne e a tarefa de NEs, verbalizações e OLc. Contudo, há uma boa associação entre as tarefas GEs e EM. Isso se justifica, pois, as tarefas do instrumento representam características diferentes de um mesmo constructo, que inclusive se desenvolvem em momentos diferentes do desenvolvimento infantil (Flavell, 2004; Flavell, et al., 1987; Flavell et al., 1981; Flavell, 1999). Ao contrário, a tarefa Sally-Anne fica circunscrita ao paradigma de falsa crença, sendo justamente esta a grande crítica ao modelo, pois, além de ser uma tarefa experimental, ela é limitada a um 
domínio do constructo, sendo uma provável causa de nem sempre ser verificada correspondência entre o desempenho em falsa crença e os prejuízos observados no cotidiano (Altschuler et al., 2018; Baron-Cohen, 1989; Klin, 2000; Muris et al., 1999). Além disso, é possível que ela seja impactada por alguns domínios cognitivos, mas não por outros (Austin, et al., 2014).

\section{6-CONSIDERAÇÕES FINAIS}

De modo geral, verificam-se concordâncias significativas entres os juízes na análise dos itens do instrumento. As discordâncias encontram-se em torno de falhas (1) na forma das perguntas realizadas nas fichas apresentadas aos juízes; (2) na compreensão de alguns aspectos da teoria de outros domínios cognitivos, como memória de trabalho, e (3) nas representações dos desenhos. Mas não, necessariamente, na análise conceitual dos itens.

O presente artigo também mostra correções adequadas, com correlações entre os avaliadores altas entre os itens objetivos. No item subjetivo, variam de moderada a alta. Dentre os aspectos que merecem maior atenção para futuras modificações e discussões, encontram-se o uso da nomenclatura emocional e as verbalizações de estados mentais nas narrativas.

$\mathrm{O}$ uso da nomenclatura emocional pode requerer maior flexibilidade na consideração de respostas, em função de sinônimos utilizados no cotidiano. Devem-se levar em conta, ainda, questões socioculturais, que podem influenciar o uso de vocabulário, tornando este mais rico ou mais empobrecido. O modelo sociocultural também pode ajudar a entender se o padrão da linguagem é pertinente e/ou funcional dentro do grupo social avaliado.

Quanto às narrativas, a existência de avaliadores mais exigentes foi fundamental para identificar falhas e/ou a necessidade de se ampliar a forma de categorizar as respostas. Avaliadores mais exigentes podem apresentar dificuldades em flexibilizar alguns padrões. Nesse sentido, é importante ter uma quantidade maior de exemplos de respostas de narrativas para suprir as necessidades dos avaliadores ou mesmo diferenças socioculturais ou cognitivas, que podem influenciar o vocabulário emocional, necessário para narrativas. 
Hipotetiza-se que isso reduziria as possibilidades de discordância e correções incoerentes.

Quanto a validade de constructo, o dendrograma sugere outras formas de se conectar essas tarefas, em função da natureza da tarefa e mesmo de como essas tarefas podem ir funcionalmente interagindo entre si, a partir do desenvolvimento cronológico dos domínios de ToM, bem como a partir das relações com outros domínios cognitivos, como inibição, construção de nexo causal e acesso semântico.

A partir da análise do Qui-quadrado, verificam-se associações entre apenas duas tarefas. Entretanto, o padrão-ouro da literatura é limitado em termos de avaliação de outros domínios de ToM. A tarefa Sally-Anne avalia apenas o paradigma de falsa crença. Por consequência, sua associação se dá com a tarefa EM, construída para avaliar este paradigma. Estes resultados indicam que o instrumento possui evidências de validade de constructo. Os resultados apontam, inclusive, para corroborar críticas quanto à limitação de modelos muito circunscritos como o Sally-Anne.

Algumas possibilidades de alteração do instrumento foram discutidas no presente artigo. Além disso, é possível realizar uma ampliação da amostra, em diferentes grupos socioeconômicos, com futura reanálise das respostas dos sujeitos, para identificar respostas pertinentes e frequentes. Isso poderia auxiliar no desenvolvimento de novos exemplos e respostas alternativas. 


\section{5- MARCADORES SOCIOCOGNITIVOS nO TEA COM HABILIDADE VERBAL PRESERVADA: UM ESTUDO DE VALIDADE DE CRITÉRIO DA BTOM}

Resumo

Déficits sociocomportamentais, oriundos de prejuízos em ToM, estão associados a algumas patologias, dentre elas o Transtorno do Espectro Autista (TEA). O instrumento Bateria de Teoria da Mente (BToM) foi desenvolvido com intuito de avaliar diferentes aspectos do ToM e controlar varáveis cognitivas intervenientes ao seu desempenho. Levando em conta as diferenças cognitivas e sociocognitivas entre crianças com e sem diagnóstico de TEA, este estudo tem como objetivos: (1) verificar perfil sociocognitivo em crianças com diagnóstico de TEA mais preservados; (2) verificar a acurácia diagnóstica do instrumento BToM e (3) identificar marcadores sociocognitivos no diagnóstico de TEA de altas habilidades. Este estudo foi registrado e aprovado pelo Comitê de Ética da Pontificia Universidade Católica do Rio de Janeiro-PUC-Rio. A amostra foi constituída por 59 crianças, de 7 a 12 anos, sendo 44 participantes do grupo controle e 15 participantes com diagnóstico de TEA. Os instrumentos utilizados foram: questionário sócio-demográfico e clínico, bateria neuropsicológica breve, instrumento BToM. Foram realizadas a análise descritiva dos dados, o teste U de Mann-Withney para comparar o desempenho do grupo controle e clínico (TEA) nas tarefas de BToM e para a caracterização neuropsicológica dos grupos. Por fim, a análise de curva ROC verificou a acurácia de cada tarefa BToM. Os resultados apontam para diferenças neuropsicológicas em: índice gloval, índice verbal, memória de trabalho, flexibilidade cognitiva, mas não para controle inibitório. Verifica-se diferenças significativas entre os grupos em 6/8 tarefas de BToM. Quanto a acurácia diagnóstica, as tarefas de Estados Mentais e Verbalizações emergem como possíveis marcadores sociocognitivos de fenótipos mais preservados de TEA.

Palavras-chave: BToM; acurácia diagnóstica; marcadores sociocognitivos; memória de trabalho; flexibilidade cognitiva; controle inibitório; TEA.

\section{Abstract}

Sociocomportmental deficits due to impairment in ToM, are associated with Autism Spectrum Disorder (ASD). The Instrument Battery of assessment of Theory of Mind (BToM) was developed with the purpose of evaluating different aspects in ToM and controlling the cognitive variables involved in its performance. Taking into account the cognitive and sociocognitive differences between children with and without ASD diagnosis, this study aims to: (1) to verify 
sociocognitive profile in children diagnosed with ASD; (2) to verify the diagnostic accuracy of the BToM instrument and (3) to identify sociocognitive markers in the diagnosis of high-ability ASD. This study was registered and approved by the Ethics Committee of the Pontifical Catholic University of Rio de Janeiro-PUCRio. The sample consisted of 59 children, from 7 to 12 years old, 44 participants control group and 15 participants with ASD diagnosis. The instruments used were: socio-demographic and clinical questionnaire, short neuropsychological battery, BToM instrument. Descriptive data analysis, Mann-Whitney U test to compare the performance BToM tasks and neuropsychological characterization were performed. Finally, the ROC curve analysis verified the accuracy of each BToM task. The results point to neuropsychological differences in global index, verbal index, working memory, cognitive flexibility, but not for inhibitory control. There are significant differences between groups in 6/8 BToM tasks. As for the diagnostic accuracy, the tasks of Mental States and Verbalizations emerge as possible sociocognitive markers of light TEA phenotypes.

Key-Words: BToM; accuracy; sociocognitive markers; working memory; cognitive flexibility; inhibitory control; ASD.

\section{1- INTRODUÇÃO}


Teoria da mente (ToM) é uma habilidade sociocognitiva concernente à compreensão de estados mentais de terceiros. Ela auxilia na identificação e antecipação de comportamentos durante a dinâmica social (O’Connor \& Evans, 2019; Sanvicente-Vieira et al., 2012). Desse modo, impacta diretamente a competência social, o interesse social e a integração entre pares (Carlson et al., 2013; Smogorzewska et al., 2018).

Déficits sociocomportamentais, oriundos de prejuízos em ToM, estão associados a algumas patologias, dentre elas o Transtorno do Espectro Autista (TEA) (Smogorzewska et al., 2018; Zainal \& Newman, 2018; Zakai-Mashiach, Ziv \& Dromi, 2017). Pessoas com TEA mostram inabilidades em atribuir estados mentais como descrever emoções e pensamentos em diferentes personagens ou em situações do cotidiano (Fitzpatrick et al., 2018). Ao contrário, crianças típicas já demonstram essas habilidades em fases pré-escolares (Zakai-Mashiach, et al., 2017).

O comprometimento em tarefas de falsas crenças em indivíduos com TEA é amplamente discutido na literatura (Austin et al., 2014; Baron-Cohen et al., 1985; Buitelaar et al., 1999; Scheeren et al., 2013; Kimhi et al., 2014). Entretanto, para alguns autores, níveis mais leves do espectro, como os antigos diagnósticos de Síndrome de Asperger, conseguiriam ter melhor desempenho, em função do teor explícito da tarefa. (Schneider, Slaughter, Bayliss \& Dux, 2013). Também relacionam melhor desempenho de falsa crença com melhor habilidade verbal (Scheeren et al., 2013).

Além dos prejuízos e peculiaridades de ToM em TEA, as tarefas utilizadas para a avaliação deste constructo também sofrem questionamentos. As críticas observadas na literatura remetem à utilização de tarefas que não compreendem a diversidade do constructo, o que pode ser um obstáculo para a acurácia da análise do desempenho (Altschuler et al., 2018; Flavell, 1999; Pedreño et al., 2017). Outra característica desses questionamentos se refere à variabilidade do diagnóstico de TEA, em particular quando se consideram os diferentes níveis, como aqueles com habilidade verbal preservada (Schneider et al., 2013), bem como o impacto de outras funções cognitivas, como memória de trabalho, deslocamento atencional e outros domínios (Austin et al., 2014; Kimhi et al., 2014). 
A interface com outros domínios cognitivos, verificados no desempenho de tarefas de ToM, estaria associada ao perfil cognitivo do espectro. Verificam-se prejuízos e discussões importantes quanto à influência de funções executivas no perfil neuropsicológico de TEA. Dentre os dados trazidos pela literatura, há maior robustez de resultados quanto à memória de trabalho e inconsistências quanto à flexibilidade cognitiva e ao controle inibitório (Christ et al., 2011; Miller et al., 2015).

O instrumento Bateria de Teoria da Mente (BToM) foi desenvolvido neste cenário. Ele pretende avaliar diferentes aspectos do ToM e controlar varáveis cognitivas intervenientes ao seu desempenho, compreendendo tarefas de ToM propriamente ditas (quatro tarefas) e tarefas controle de outros domínios cognitivos (três tarefas). As tarefas do instrumento são baseadas em modelos encontrados na literatura (Pedreño et al., 2017; Altschuler et al., 2018, Durrleman \& Franck, 2015; Lind e Bowler, 2010), seguindo uma perspectiva teórica de desenvolvimento cognitivo (Flavell et al., 1999).

Por ser um instrumento diagnóstico, entende-se como uma etapa crucial a validade de critério. A validade de critério é entendida como a eficácia que o instrumento tem em predizer um desempenho específico do sujeito, e este desempenho torna-se o critério a ser avaliado (Pasquali, 2009). Optou-se por realizá-la através das diferenças de desempenho em ToM em crianças com e sem TEA.

Levando em conta as diferenças cognitivas quanto ao desempenho de ToM, bem como outros domínios da cognição de crianças com e sem diagnóstico de TEA, este estudo aborda os seguintes objetivos: (1) verificar perfil sociocognitivo em crianças com diagnóstico de TEA de altas habilidades, a partir das diferenças no desempenho do instrumento BToM e outras medidas neuropsicológicas; (2) verificar a acurácia diagnóstica do instrumento BToM, a partir da presença do diagnóstico de TEA e (3) identificar marcadores sociocognitivos no diagnóstico de TEA classificados como médio a moderado.

\section{2-MÉTODO}




\subsection{1- PARTICIPANTES:}

A amostra foi constituída por 59 crianças, de 7 a 12 anos, sendo 44 participantes do grupo controle e 15 participantes com diagnóstico de TEA. A amostra é oriunda das seguintes instituições: (1) Organização Não Governamental - ONG do Instituto Reação; (2) Escola particular do Rio de Janeiro, (3) Serviço de Psicologia aplicada da Pontifícia Universidade Católica, Puc-Rio.

Grupo controle (GC): As crianças foram incluídas a partir dos seguintes critérios: (a) todas estavam matriculadas em escola regular; (b) ausência de reprovação escolar; (c) ausência de mediação escolar; (d) ausência de queixas sociais (dificuldades de compreensão de regras socais, isolamento social e prejuízos de interação com pares) e (e) comportamentais (comportamentos agressivos com pares, prejuízos de sustentação de atenção em atividades formais e acadêmicas). As queixas foram avaliadas a partir de um questionário sociodemográfico e clínico (Apêndice A). Além disso, foi realizada avaliação neuropsicológica para a caracterização dos grupos.

Grupo Clínico TEA (GTEA): Os participantes do grupo clínico foram incluídos a partir de: (a) diagnóstico psiquiátrico clínico. Os critérios de exclusão envolvem ausência de doença neurológica, déficits visuais e auditivos. Além disso, foi realizada avaliação neuropsicológica para a caracterização dos grupos. A avaliação psiquiátrica foi construída partir dos critérios do DSM-5 (APA, 2013). Foi realizada entrevista clínica com os pais e a observação da criança. $\mathrm{Na}$ entrevista realizada com os pais, foi dada ênfase ao desenvolvimento motor, social, cognitivo e afetivo. Foi dada atenção especial a informações sobre atraso, alterações ou ausência da fala, desinteresse nas relações pessoais, ausência da atenção compartilhada, rigidez cognitiva, dificuldade em realizar e/ou manter contato visual, alterações sensoriais, uso atípico de brinquedos e/ou objetos, deficiência nas brincadeiras simbólicas (faz de conta), estereotipias. Para a observação da criança na sala de atendimento, foi usado o instrumento de avaliação da gravidade do Autismo: CARS - Childhood Autism Rating Scale (Schopler Reichler, Renner, 1988). Os participantes tem um perfil de TEA com 
habilidades verbais presentes e com grau de gravidade do espectro variando de médio à moderado do espectro.

\subsection{2- INSTRUMENTOS}

A) Questionário sociodemográfico e clínico que será composto por informações tais como: idade, escolaridade, escolaridade dos pais, história de desenvolvimento linguístico e motor, diagnósticos prévios e histórico familiar (Apêndice A).

B) Bateria neuropsicológica breve:

1-WASI (Wechsler, 2014): Instrumento breve de avaliação da inteligência, aplicável a crianças de 6 anos a idosos de 89 anos de idade. Fornece informações sobre os QIs Total, de Execução e Verbal a partir de quatro subtestes (Vocabulário, Cubos, Semelhanças e Raciocínio Matricial).

2-Paradigma Stroop-Vitória (Oliveira et al., 2016; Spreen e Strauss, 1998): Avalia a susceptibilidade à interferência. O teste consiste em três condições. Na parte 1, o indivíduo deve nomear o mais rápido possível 24 quadrados pintados com as cores azul, verde, vermelho e amarelo. Na parte 2, o indivíduo deve nomear o mais rápido possível as cores só que agora em forma de palavras comuns. $\mathrm{Na}$ parte 3, o procedimento é semelhante ao das partes anteriores, só que as palavras formam os nomes das cores pintadas de cores incongruentes.

3-Fluência verbal (Oliveira et al., 2016; Spreen e Strauss, 1998): Avalia memória semântica e flexibilidade cognitiva. O procedimento é solicitar que o indivíduo produza oralmente o maior número possível de palavras iniciando com as letras "F", “A", "M", um minuto para cada. Não são consideradas palavras corretas: nomes próprios e derivações de gênero, número e grau. Além disso, será aplicado o teste de fluência de animais (associação semântica).

4-Índice de Memória de trabalho da Escala Weschler de Inteligência-WISC IV (Wechsler, 2013): Avalia, através dos subtestes com dígitos e sequência de números e letras, o índice de memória de trabalho (armazenamento e processamento da informação). Subteste dígitos: consiste de aplicação de sequências de números. Ele é aplicado em duas etapas (ordem direta e ordem inversa). Na ordem direta, o avaliando deve repetir as sequências na ordem em que são ditas pelo aplicador. Na sequência inversa, o avaliando deve repetir a 
sequência na ordem inversa à que o avaliador está repetindo. Cada item do subteste é composto por duas tentativas. A cada item, a quantidade de números na sequência aumenta. As tentativas não podem ser repetidas pelo avaliador. Este subteste avalia memória de trabalho fonológica, atenção sustentada e flexibilidade cognitiva. Subteste com sequência números e letras: consiste de aplicação de sequências de números e letras, onde o avaliando deve colocar em ordem, iniciando por números e depois por letras. Os números devem estar em ordem crescente e as letras, em ordem alfabética.

C) Bateria de Teoria da Mente (BToM). Este instrumento é constituído por 8 tarefas, sendo 5 de ToM, 3 tarefas controles pareadas: Tarefa 1: Nomeação de objetos; Tarefa 2: Nomeação de Emoções(NEs); Tarefa 3: Gradação de emoções simples (GEs); Tarefa 4: Tarefa Go no-Go; Tarefa 5: Identificação de estados mentais (EM), Tarefa 6: Organização Lógica simples (OLs); Tarefa 7: Organização Lógica complexa (OLc); Tarefa 8: Vervalizações.

1-Tarefa controle - Nomeação de Objetos (NO): Avalia acesso semântico. O procedimento é apresentar 24 objetos isolados e solicitar a nomeação do objeto. A correção desta tarefa se dá a partir do percentual de acertos.

2-Tarefa ToM- Nomeação de emoções simples (NEs): Avalia etapa inicial de ToM, referente ao reconhecimento de emoções. São apresentados os níveis mais explícitos de 4 emoções básicas: Feliz, Triste, Medo e Raiva. O procedimento é mostrar essas emoções separadamente e solicitar a nomeação. Em seguida, é calculado o percentual de acertos.

3-Tarefa ToM- gradação de emoções simples (GEs): Avalia reconhecimento de nuances de emoções. Os diferentes níveis de cada emoção são apresentados fora de ordem. Solicita-se que o avaliando gradue do nível mais sutil para o nível mais explícito, dentro da qualidade da emoção. É calculado o percentual de acertos.

4-Tarefa controle - go no-go: Avalia controle inibitório (inibição comportamental), com a apresentação das personagens, onde três são go e uma no-go. Em seguida, é calculado o percentual de acertos. 
5-Tarefa ToM- Identificação de estados mentais (EM) - Avalia o domínio de falsa crença em ToM. O procedimento é apresentar as cenas e realizar perguntas de falsa crença. Na primeira cena, há pergunta sobre see-know. Na segunda cena é realizada uma pergunta de falsa crença de conteúdo inesperado e na terceira cena é realizada uma pergunta de falsa crença de mudança de localização. Em seguida, é calculado o percentual de acertos.

6-Tarefa controle- Organização Lógica Simples (OLs): Avalia relação causal no mundo físico. O procedimento é apresentar os quadros de cada história fora de ordem. Solicita-se que o avaliando coloque na ordem correta de acontecimentos. Em seguida, é calculado o percentual de acertos

7-Tarefa ToM - Organização Lógica complexa (OLc): Avalia a relação causal em contexto social, a partir de pistas visuais. O procedimento é apresentar os quadros de cada história fora de ordem. Solicita-se que o avaliando coloque na ordem correta de acontecimentos. A correção é feita a partir da ordenação de histórias. É calculado o percentual do escore final de acertos.

8-Tarefa ToM-Verbalizações de narrativa - As narrativas são provenientes das tarefas OLc. Essa narrativa é corrigida, baseada na presença de verbalizações de estados mentais. A correção se a partir somatório da presença de verbalizações. É calculado o percentual do escore final de acertos.

\subsection{3-PROCEDIMENTOS E ASPECTOS ÉTICOS:}

Este estudo foi registrado e aprovado pelo Comitê de Ética da Pontificia Universidade Católica do Rio de Janeiro-PUC-Rio. O comitê gerou o parecer com o seguinte número: 2017-28. O estudo não apresentou risco para a saúde dos participantes. A participação foi voluntária, de modo que os sujeitos não receberam qualquer tipo de pagamento. Os voluntários puderam desistir da participação a qualquer momento.

A aplicação do instrumento BToM e os demais testes de avaliação foram realizados após a assinatura do Termo de Consentimento Livre e Esclarecido - 
TCLE (Apêndice C) e do Termo de assentimento (Apêndice C). As avaliações foram realizadas por neuropsicólogos e estagiários de neuropsicologia treinados.

\subsection{4- ANÁLISE ESTATÍSTICA}

Foram realizadas a análise descritiva dos dados, com informações sobre média de idade, frequência de gênero e média de escolaridade. Além disso, o teste U de Mann-Withney foi utilizado para comparar o desempenho do grupo controle e clínico (TEA) nas tarefas de BToM. Da mesma forma, ele foi utilizado para a caracterização neuropsicológica dos grupos. Ele é considerado uma versão não paramétrica do Teste t. Por fim, a análise de curva ROC verificou a acurácia de cada tarefa BToM, considerando o critério presença ou não de TEA da amostra. Foram identificadas a área sob a curva para todas as tarefas de BToM. Em seguida, foram definidos os pontos de corte e os índices de sensibilidade para as tarefas que tiveram área acima de 0,80 .

\section{3-RESULTADOS}

Este estudo foi composto por 59 sujeitos, sendo o grupo controle formado por $44(74,6 \%)$ indivíduos e o grupo com diagnóstico de TEA por 15 sujeitos $(25,4 \%)$. A idade variou de 7 a 12 anos e a escolaridade, do $1^{\circ}$ ao $7^{\circ}$ ano do ensino fundamental. Observa-se um maior número de indivíduos do sexo masculino no GTEA. As Tabelas 19 e 20 mostram a caracterização da amostra em termos de idade, escolaridade e sexo.

Tabela 19. Dados sociodemográficos GC e GTEA

\begin{tabular}{|c|c|c|c|c|c|c|}
\hline & \multicolumn{2}{|c|}{ GTEA } & \multicolumn{2}{|c|}{ GC } & \multirow{2}{*}{$\begin{array}{l}\text { Teste U de } \\
\text { Mann- } \\
\text { Whitney (Z) }\end{array}$} & \multirow[b]{2}{*}{$\mathrm{p}$} \\
\hline & $\mathrm{n}$ & M (DP) & $\mathrm{n}$ & M (DP) & & \\
\hline Idade & 15 & $8,4(1,4)$ & 44 & $9,5(1,6)$ & $-1,7$ & 0,08 \\
\hline Escolaridade & 15 & $2,9(1,4)$ & 44 & $3,7(1,7)$ & $-1,7$ & 0,08 \\
\hline
\end{tabular}




\begin{tabular}{lllll}
\hline & $\mathrm{n}$ & Porcentagem & $\mathrm{n}$ & Porcentagem \\
\hline Gênero (F) & 1 & $6,7 \%$ & 29 & $65,9 \%$ \\
& 14 & $93,3 \%$ & 15 & $34,1 \%$ \\
\hline Gênero(M) & 14 &
\end{tabular}

Em seguida, foi realizado o Teste $U$ de Mann Whitney para a caracterização neuropsicológica entre o GC e GTEA. Foram definidos o Índice de Funcionamento Global (FG), Índice de Execução (IE), Índice Verbal (IV), Índice de memória de trabalho (IMT), uma medida de flexibilidade (FAM) e atenção (Stroop). Essas variáveis foram definidas em função da literatura neuropsicológica acerca das diferenças entre crianças com e sem diagnóstico de TEA. Verificam-se diferenças significativas entre os grupos em FG, IV, IMT, FAM e condição 1 (C1) e 2 (C2), mas não na condição 3 (C3) do STROOP.

Tabela 20: Comparação de perfis neuropsicológicos GC e GTEA.

\begin{tabular}{|c|c|c|c|c|c|c|}
\hline & \multicolumn{2}{|r|}{ GC } & \multicolumn{2}{|r|}{ GTEA } & \multicolumn{2}{|c|}{ Teste U de Mann-Whitney } \\
\hline & $\mathrm{n}$ & Média (DP) & $\mathrm{N}$ & Média (DP) & (Z) & $\mathrm{P}$ \\
\hline FG & 44 & $94,7(12,2)$ & 14 & $81,5(14,9)$ & $-2,8$ & $0,01 *$ \\
\hline IV & 44 & $96,8(15,5)$ & 14 & $78,9(19,8)$ & $-2,7$ & $0,01 *$ \\
\hline $\mathrm{IE}$ & 44 & $93,9(12,6)$ & 14 & $88,1(13,6)$ & $-1,6$ & 0,10 \\
\hline IMT & 44 & $95,2(11,1)$ & 12 & $70,2(18,4)$ & $-4,1$ & $0,00^{* * *}$ \\
\hline \multicolumn{7}{|c|}{ FAM } \\
\hline $\mathrm{F}$ & 40 & $6,0(3,6)$ & 13 & $3,5(3,4)$ & $-2,1$ & $0,04 *$ \\
\hline A & 40 & $6,2(3,2)$ & 13 & $2,8(2,9)$ & $-3,5$ & $0,00 * *$ \\
\hline $\mathrm{M}$ & 40 & $6,6(3,7)$ & 13 & $3,0(2,2)$ & $-3,3$ & $0,00 * *$ \\
\hline \multicolumn{7}{|c|}{ STROOP } \\
\hline $\mathrm{C} 1$ & 42 & $24,3(7,5)$ & 13 & $28,3(9,1)$ & $-2,2$ & $0,03^{*}$ \\
\hline $\mathrm{C} 2$ & 42 & $31,3(11,3)$ & 13 & $36,6(11,7)$ & $-1,6$ & 0,11 \\
\hline $\mathrm{C} 3$ & 42 & $42,3(16,7)$ & 13 & $52,0(27,1)$ & $-0,8$ & 0,39 \\
\hline
\end{tabular}

GC: grupo controle; GTEA: grupo TEA; n: número de sujeitos; Z: Escore Z; p: nível de significância. $* \mathrm{p}<0,05 * * \mathrm{p}<0,01$

Foi realizado Teste U de Mann Whitney para comparar os grupos quanto ao desempenho em BToM. Os resultados mostraram diferenças significativas entre os grupos para as tarefas: go no-go, EM, OLs, OLc e verbalizações. O mesmo não foi observado para as tarefas nomeação de objetos, NEs e GEs, como mostrado na Tabela 21. 
Tabela 21:Comparação entre GC e GTEA nas tarefas de BToM

\begin{tabular}{ccccccc}
\hline & \multicolumn{2}{c}{ GC } & \multicolumn{2}{c}{ GTEA } & \multicolumn{2}{c}{ Teste U de Mann-Whitney } \\
\hline & $\mathrm{N}$ & Média (DP) & $\mathrm{n}$ & Média (DP) & $\mathbf{( Z )}$ & $\mathrm{p}$ \\
\hline Nomeação & 44 & $0,93(0,03)$ & 15 & $0,92(0,81)$ & $-0,2$ & 0,85 \\
NEs & 44 & $0,82(0,18)$ & 15 & $0,75(0,16)$ & $-1,5$ & 0,14 \\
GEs & 44 & $0,90(0,18)$ & 15 & $0,76(0,29)$ & $-2,2$ & $0,03^{*}$ \\
GO no GO & 44 & $0,98(0,03)$ & 15 & $0,94(0,06)$ & $-3,3$ & $0,00^{* *}$ \\
EM & 44 & $0,87(0,14)$ & 15 & $0,55(0,26)$ & $-4,5$ & $0,00^{* *}$ \\
OLs & 44 & $0,63(0,16)$ & 15 & $0,40(0,23)$ & $-3,5$ & $0,00^{* *}$ \\
OLc & 44 & $0,85(1,27)$ & 15 & $0,42(0,23)$ & $-3,2$ & $0,00^{* *}$ \\
Verbalizações & 44 & $0,42(0,15)$ & 15 & $0,18(0,07)$ & $-5,0$ & $0,00^{* *}$
\end{tabular}

GC: grupo controle; GTEA: grupo TEA; NEs: Nomeação de emoções; GEs: Gradação de emoções; EM: Estados Mentais; OLs: Organização Lógica Simples; OLc: Organização Lógica Complexa. n: número de sujeitos; Z: Escore Z; p: nível de significância.

$* \mathrm{p}<0,05 ; * * \mathrm{p}<0,01$

A análise de curva ROC foi realizada para identificar a acurácia de cada tarefa de BToM. As áreas abaixo da curva de todas as tarefas são apresentadas na Tabela22

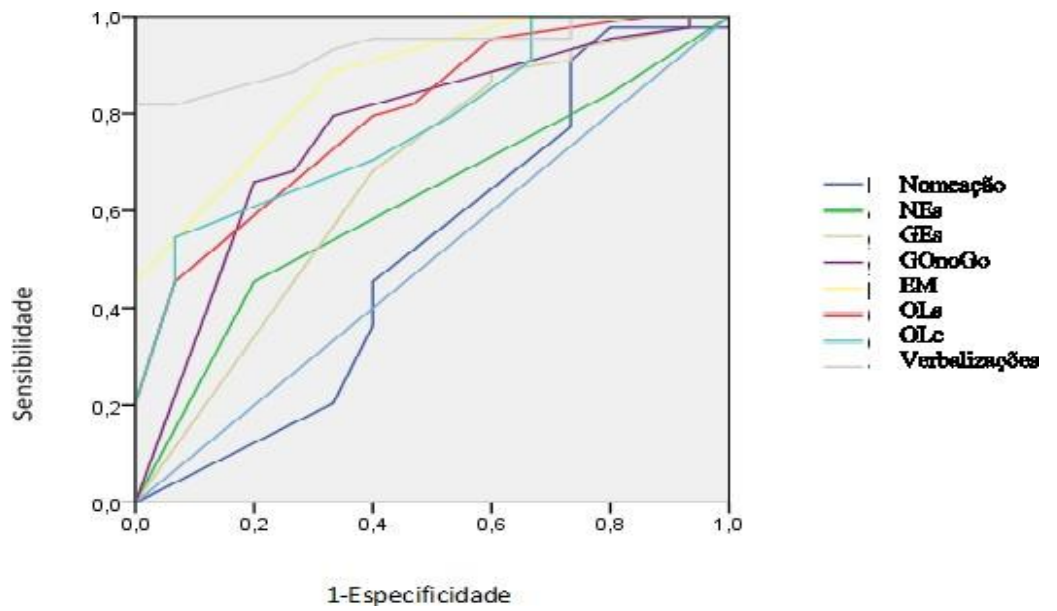

NEs: Nomeação de emoções; GEs: Gradação de emoções; EM: Estados Mentais; OLs: Organização Lógica Simples; OLc: Organização Lógica Complexa 
Tabela 22: Área sob a curva tarefas BToM

\begin{tabular}{lcc}
\hline & Área da Curva & $Z$ \\
\hline Nomeação & 0,516 & 1,8 \\
\hline NEs & 0,618 & 0,9 \\
\hline GEs & 0,668 & 0,5 \\
\hline Go no-Go & 0,764 & 1,2 \\
\hline EM & 0,871 & $8,2^{*}$ \\
\hline OLs & 0,796 & 4,8 \\
\hline OLc & 0,777 & 4,3 \\
\hline Verbalizações & 0,933 & $11,1^{*}$ \\
\hline
\end{tabular}

Para as tarefas que apresentaram área sob a curva acima de 0,80, discrimina-se o diagnóstico de TEA. Para essas tarefas de BToM, foram calculados pontos de corte, sensibilidade e especificidade (tabela 23).

Tabela 23-Pontos de corte de Estados Mentais e Verbalizações

\begin{tabular}{lcc}
\hline & Estados Mentais & Verbalizações \\
\hline Área da Curva & 0,871 & 0,933 \\
\hline $\mathrm{Z}$ & 8,2 & 11,1 \\
\hline Ponto de Corte & $<=50$ & $<=14.5$ \\
\hline Sensibilidade & 100 & 95.5 \\
\hline Especididade & 66.7 & 73.3 \\
\hline
\end{tabular}

\section{4-Discussão}

O presente trabalho buscou identificar marcadores sociocognitivos de crianças com TEA de altas habilidades, a partir de evidências de validade de critério do instrumento BToM. Em um primeiro momento, foram identificadas diferenças dos perfis sociocognitivos de crianças com e sem o diagnóstico de TEA, no que diz respeito a ToM e a outros domínios cognitivos. Em seguida, 
foram realizadas análises de curva ROC para identificar a acurácia das tarefas de BToM.

Os grupos foram comparados quanto a medidas de domínios cognitivos mais gerais e de domínios de ToM. Quanto às medidas de domínios cognitivos mais gerais, os resultados mostraram diferenças no perfil de funções executivas em medidas de memória de trabalho, flexibilidade cognitiva, mas não em medidas de controle de interferência (C3-Stroop). Além disso, foram encontradas diferenças significativas para FG e IV, mas não para IE, o que aponta para similaridades entre os grupos, no que diz respeito a tarefas que recrutam habilidades visuoconstrutivas e identificação de categorias por pareamento visual. As análises de ToM, destacam diferenças entre as tarefas de BToM. Os grupos se diferenciam nas tarefas: GEs, GO no-Go, EM, OLs, OLc e verbalizações. Não são observadas diferenças em NEs, considerada a tarefa mais simples no desenvolvimento de ToM.

No que se refere à acurácia diagnóstica, apenas as tarefas EM e as verbalizações discriminam o grupo com e sem diagnóstico de TEA, sugerindo possíveis marcadores sociocognitivos. Elas mostram ótima acurácia do instrumento para identificar crianças com TEA. O mesmo não é observado para as demais tarefas de ToM propriamente ditas: NEs, GEs, OLc.

A literatura aponta diferenças no desempenho neuropsicológico (cognitivos, como funções executivas; e sociocognitivos, como ToM) de indivíduos diagnosticados com TEA e crianças sem o diagnóstico. Indivíduos sem diagnóstico de TEA apresentariam melhor desempenho do que os diagnosticados (Barendse et al., 2018; Berenguer, Miranda, Colomer, Baixauli \& Roselló, 2017; Christ et al., 2017; Christ et al., 2011; Schmitt, et al., 2018). Os resultados do presente artigo encontraram diferenças significativas entre os grupos GC e GTEA em componentes de funções cognitivas, assim como em componentes do instrumento BToM. Além disso, mostraram acurácia do instrumento para o diagnóstico de TEA. 


\subsection{1- Perfil Neuropsicológico GC e GTEA}

Os grupos GC e GTEA apresentam diferenças nas seguintes variáveis cognitivas: IMT, IE, FG, fluência verbal (FAM), C1 do Stroop. Não se observam diferenças na tarefa C2 e C3 do Stroop e em IE. Os resultados quanto a funções executivas estão condizentes com a literatura, que destaca os três componentes no TEA: flexibilidade cognitiva, memória de trabalho (MT) e controle inibitório (CI). A literatura mais atual encontra resultados mais consistentes para o impacto de MT em TEA do que CI, mesmo quando se pensa nesses dois processos atuando na flexibilidade cognitiva.

Miller et al. (2015), por exemplo, acreditam que as diferenças observadas em tarefas de flexibilidade se relacionam com prejuízos na sustentação de uma nova regra. Para os autores, a sustentação redirecionaria o comportamento e não a inibição de pensamentos. A sustentação da regra faz parte do conceito de MT.

Outros estudos também sugerem que MT faz parte do processamento de informação afetiva e do mundo social. Segundo Mammarella et al. (2014), a percepção de cenas visuais por detalhes e não como um todo integrado, também estaria no campo de MT. Esses aspectos são pontos críticos em TEA, logo MT se destacaria neste perfil cognitivo (Barendse et al., 2018) ao se conectar com outros aspectos da cognição social de TEA, como a coerência central (Losh, et al., 2009), e ser um aspecto essencial no processamento das informações.

No que diz respeito ao paradigma de controle inibitório, os resultados mostram diferenças na tarefa de velocidade de processamento $(\mathrm{C} 1$ e $\mathrm{C} 2)$, mas não na tarefa de controle inibitório (C3). Christ et al. (2007) também não encontraram diferenças entre TEA e típicos no paradigma stroop, mas verificaram prejuízos na resistência a distratores visuais e tarefas go no-go. Assim como esse estudo de 2007, Christ et al. (2011) e Schmitt et al. (2018) mostraram que o grupo com TEA teria mais impacto na inibição de interferências visuais quando estas aparecem ao mesmo tempo, ou seja, em situações de escolha e de incerteza. Por outro lado, em situações claras, onde entendem como e onde precisam inibir, eles conseguiriam ter melhor desempenho, como observado no modelo Stroop. Considerando que o constructo de controle inibitório também se mostra múltiplo, com diferentes modelos de controle de interferência, é possível que no TEA haja prejuízos em 
aspectos diferentes de controle inibitório daquele que é avaliado pelo paradigma utilizado neste estudo.

Além disso, as situações de incerteza com estímulos visuais podem sofrer impacto da MT (onde se exigem sustentação e análise para escolha), que tem se mostrado um domínio cognitivo importante na literatura e nos resultados do presente artigo. Mas é possível que o controle inibitório no TEA sofra interferências do deslocamento atencional, ou o desengajamento de uma situação de interesse. $O$ desengajamento atencional é parte do processo da atenção compartilhada, de extrema relevância no modelo de desenvolvimento cognitivo de TEA (Schietecatte, Roeyers \& Warreyn, 2012). Jaworski e Eigsti (2017) mostram relação de atenção compartilhada com baixos níveis de atenção visual, em especial no deslocamento visual (desengajamento ou shift) e sugerem que as bases de atenção executiva teriam como fundamento esses fatores. Dessa forma, os prejuízos observados em controle inibitório podem ser secundários a processos anteriores na cronologia do desenvolvimento, considerando este outro aspecto o desenvolvimento sociocognitivo atípico deste diagnóstico

A flexibilidade é a característica cognitiva que mais se assemelha conceitualmente aos critérios comportamentais e nosológicos presentes no TEA, mas ela também mostra algumas inconsistências de resultados na literatura. Por vezes, é mais clara a identificação em termos comportamentais do que em critérios mais objetivos, como testes cognitivos (Leung e Zakzanis, 2014). Este estudo utilizou como medida de flexibilidade a fluência verbal fonológica, visto que ela demanda mais alternância de estratégias para favorecer a maior geração de palavras. Foram observadas diferenças significativas entre os grupos GC e GTEA.

Neste cenário, os diferentes modelos de tarefas podem recrutar mais um processo do que o outro, por exemplo. Da mesma forma que em controle inibitório, há uma relação de flexibilidade com o deslocamento visual da atenção. O deslocamento atencional pode apresentar suas origens na atenção compartilhada. Da mesma forma que as tarefas podem variar em termos de processos de MT e CI, podem recrutar menor ou maior demanda de deslocamento atencional (Jaworski \& Eigsti, 2017).

Dentre os resultados encontrados, observam-se, ainda, prejuízos em componente verbal (IV) e funcionamento cognitivo global (FG), mas não em 
componente de execução (IE). Os subtestes que compõem IV têm um modelo semântico, eles recrutam formação de conceitos e identificação de categorias. Por outro lado, o IE é formado por subtestes de visuoconstrução (relações lógicas de objetos físicos) e categorização de informações visuais. O material semântico apresenta maior fragilidade no TEA, tanto que os sujeitos demonstram maior dificuldade em construção de nexo causal do mundo social (Baroh-Cohen et al, 1986), sendo mais hábeis em identificar relações causais de objetos e do mundo físico (Singman \& Ungerer, 1981).

Os resultados estão condizentes com a literatura. Eles trazem à tona pontos importantes sobre o perfil neuropsicológico do TEA e as relações com o modelo de desenvolvimento de funções cognitivas. Discutem-se as relações funcionais existentes entre MT, CI, flexibilidade, deslocamento atencional e atenção compartilhada, além do uso de informações semânticas e de relação causal do mundo físico e perceptual no processo de desenvolvimento atípico.

\subsection{2- Diferenças entre os grupos e acurácia diagnóstica do instrumento BToM}

ToM seria um marcador importante do TEA (Fernandes, et al., 2018; Losh, 2009), tendo o paradigma de falsa crença como o modelo de avaliação mais difundido na literatura (Altschuler et al., 2018). Isso tem sido criticado na literatura, devido à circunscrição deste paradigma diante da complexidade do constructo de ToM (Pedreño et al., 2017; Oktay-Gür et al., 2018).

Seguindo esta linha, o instrumento BToM é composto por múltiplas tarefas que envolvem reconhecimento de expressões emocionais em faces (NEs e GEs), a identificação de diferentes tomadas de perspectivas (EM), incluindo a falsa crença, a compreensão de relações lógicas do mundo social (OLc) e as verbalizações de estados mentais. Também inclui tarefas de controle cognitivo, como acesso semântico (nomeação), controle inibitório (GO no-GO), organização de relações causais do mundo físico (OLs), além de controles de compreensão das cenas sociais e memória de trabalho.

Os resultados mostraram diferenças significativas entre o GC e GTEA, conforme descrito na literatura (Fitzpatrick et al., 2018; Zakai-Mashiach, et al., 
2017), mas não em todas as tarefas de ToM. Foram observadas diferenças em verbalizações, EM, OLc e GE, mas não para NEs.

Analisando o modelo das tarefas, EM reproduz o padrão-ouro encontrado na literatura (Baron-Cohen et al., 1985). Logo, é pertinente com os prejuízos em falsas crenças em TEA. Já as tarefas OLc e as verbalizações são tarefas que acessam aspectos de ToM mais complexos, como relações causais, baseadas em detecção de pistas sociais (OLc) e construção de narrativas espontâneas, com conteúdo de inferências de estados mentais (verbalizações). A tarefa GEs avalia a identificação de nuances de emoções, também consideradas um aspecto mais complexo de ToM. Contudo, o reconhecimento de emoções tem suas particularidades. Ele é um dos aspectos mais estudados no TEA (Luckhardt et al., 2017) e pode sofrer impacto da qualidade e da intensidade da emoção (Bal et al., 2010). Tanto é que os mesmos resultados não foram encontrados para tarefa NEs.

Ressalta-se que a tarefa NEs encontra-se em um nível menos complexo de reconhecimento de emoções em faces. Ela utiliza apenas quatro emoções básicas, o que pode ser um facilitador para o desempenho. Também pode ser influenciado pela demanda de contexto, ou por características como idade e funcionamento intelectual (Beeger, 2008; Golan, et al., 2018). Como o reconhecimento de emoções básicas em faces é cronologicamente uma das fases precursoras no desenvolvimento de ToM, é possível que em crianças mais velhas, ou com menos prejuízo intelectual e/ou maior aprendizagem de situações sociais, podem ter compensado parte de suas dificuldades por aprendizagem explícita. Esses resultados mostram que outros modelos de avaliação de ToM, que não apenas o paradigma de falsas crenças, são pertinentes na diferenciação entre grupos com e sem diagnóstico de TEA.

Dentre as tarefas controle, foram observadas diferenças para tarefa Go noGo e OLs, mas não para a nomeação. O instrumento foi criado para ter tarefas controle, assumindo a hipótese de que TEA não teria prejuízos significativos nestas tarefas, devido ao seu perfil cognitivo, como no caso de nomeação de objetos e OLs, onde apresentam melhor desempenho em relação a objetos físicos. A tarefa go no-go foi criada para controlar impacto excessivo de aspectos inibitórios nas respostas sociais. 
Considerando, a própria estrutura do BToM, já se esperava que algumas tarefas não mostrassem diferenças de desempenho entre os grupos. Assim, os resultados de nomeação encontram-se dentro do esperado. Quanto à tarefa OLs, acredita-se que as diferenças são pertinentes às demandas da tarefa. Apesar de ser uma organização lógica, que busca não acessar inferências sociais, ela recruta análise da informação e detecção de detalhes para a organização do todo, logo depende de outros domínios da cognição, como rastreamento e deslocamento atencional, visual e memória de trabalho para conexão das partes no todo, aspectos cognitivos prejudicados em ToM (Jaworski \& Eigsti,2017; Mammarella et al., 2014).

Já a tarefa Go no-Go aponta para resultados de diferenças clínicas esperadas. Ela é uma tarefa de controle inibitório, com um modelo diferente do paradigma stroop. A literatura que aborda controle inibitório em crianças com TEA mostra que paradigmas como go no-go podem ser mais sensíveis na identificação de falhas em controle inibitório em TEA (Christ et al., 2011).

Quando se avalia a acurácia de BToM, os resultados mostram que as tarefas de verbalizações e EM discriminam os grupos com e sem diagnóstico de TEA. Isso sugere que as tarefas que envolvem construção de narrativas e avaliação da capacidade de diferentes tomadas de perspectiva e falsa crença apresentam melhor poder de discriminação diagnóstica nesta amostra. Neste cenário, elas emergem como possíveis marcadores sociocognitivos do TEA mais preservado cognitivamente

Acredita-se que tarefas de reconhecimento de emoções sejam menos consistentes devido ao seu desenvolvimento precoce no constructo de ToM e às influências do meio e da qualidade da emoção (Flavell, 1999; Golan et al., 2018). Algumas tarefas poderiam se tornar muito simples, mesmo para indivíduos com TEA ou, talvez, este grupo de TEA verbal já tenha desenvolvido esses domínios fundamentais de ToM.

Um estudo de Luckhardt et al. (2017) verificou em sujeitos com TEA e típicos, com aproximadamente 12 anos de idade, com uma medida de eventrelated-potentials, diferenças no reconhecimento mais implícito das emoções quando comparado a reconhecimentos explícitos. Ou seja, quando são explicitamente instruídos a considerar o conteúdo emocional, eles apresentam 
melhor desempenho. Esta ideia está em concordância com o modelo de ToM implícito e explicito (Oktay-Gür, et al., 2018). Ainda nesta linha teórica, a tarefa de OLc também é mais explicita e, apesar de recrutar relações de nexo causal social (Baron-Cohen, et al., 1986), ela pode ser compensada por outros recursos cognitivos.

A tarefa de verbalizações, por outro lado, é complexa quanto ao recrutamento de recursos cognitivos; contudo, ela seria apresentada como a tarefa mais implícita do instrumento. Na instrução de narrativa, não há qualquer comando explícito de verbalizações de estados mentais, o que pode ter lhe conferido maior poder de discriminação diagnóstica dentre todas elas.

Outra hipótese, não excludente da primeira, é que esta amostra é constituída por um perfil de TEA com habilidades verbais presentes e com funcionamento cognitivo não compatível com perfis mais comprometidos do espectro, como pouca ou nenhuma habilidade verbal, pouca ou nenhuma funcionalidade social. As diferenças dos fenótipos, claramente apontam para diferenças cognitivas e em ToM. O perfil desta amostra pode não ter prejuízos em domínios mais simples de ToM, não apenas por compensação, mas por diversidade do perfil de desenvolvimento de ToM (Scheeren et al., 2013; Schneider et al., 2013). Ou seja, é possível que existam perfis diferentes de prejuízos em ToM, o que permitiria diferentes caminhos de desenvolvimento no espectro para um nível mais ou menos preservado em outros domínios cognitivos.

\subsection{CONSIDERAÇÕES FINAIS}

Os resultados mostram diferenças no perfil neuropsicológico entre crianças com e sem diagnóstico de TEA, tanto para domínios de funções executivas, habilidades verbais, inteligência geral, como para domínio de ToM. Além disso, identificam marcadores sociocognitivos nas tarefas de verbalizações e EM. Elas apresentam maior poder diagnóstico para este grupo de TEA verbal e com habilidades de domínio geral mais preservadas.

Este perfil clínico de TEA é onde se encontra a maior dificuldade diagnóstica, visto que seu perfil se assemelha a outros diagnósticos do 
neurodesenvolvimento, com habilidades verbais em nível funcional, habilidades visuoconstrutivas e visuoperceptuais preservadas e funcionamento global dentro de uma faixa esperada para a idade. Em função das proximidades cognitivas e comportamentais de outros modelos diagnósticos, a avaliação sociocogitiva (ToM) mostra-se de grande importância para o diagnóstico de TEA, o que gera a necessidade de se desenvolverem instrumentos com capacidade diagnóstica acurada para este tipo de perfil, onde os prejuízos não são notórios.

Os resultados também sugerem pontos interessantes na discussão quanto ao perfil sociocognitivo do TEA, como: estudo de relações primárias e secundárias entre processos mais frios da cognição e sociocognitivos, visto que, cronologicamente, os processos sociocognitivos têm marcos anteriores ao desenvolvimento de CI, MT e FC, por exemplo. Contudo, este estudo apresenta limitações, dentre elas: (1) amostra de TEA reduzida em comparação com o grupo controle; (2) características do instrumento que podem ser melhoradas, como tarefas de domínio de reconhecimento de emoções, e (3) amostra composta apenas por escolares, o que impede a comparação das tarefas em termos de desenvolvimento de ToM. Estudos futuros poderiam incluir uma amostra préescolar, ampliar a amostra atual e identificar o padrão de ToM em outros transtornos de neurodesenvolvimento em comparação com TEA. 


\section{6-CONCLUSÕES}

A Teoria da Mente se apresenta como um constructo multifacetado, com interfaces com diferentes domínios cognitivos. Desta forma, entedê-la no contexto de diagnósticos do neurodesenvolvimento, como o Transtorno do Espectro Autista-TEA, requer instrumentos multitarefas e que viabilizem controle de variáveis intervenientes ao seu desempenho. O presente trabalho teve como objetivo apresentar o desenvolvimento e evidências de validação de uma Bateria de Avaliação em Teoria da Mente, o BToM.

O instrumento foi construído considerando duas perspectivas teóricas: visão modular de ToM; e uma orientação neuropsicológica do desenvolvimento infantil. Para isto foi proposta uma revisão das tarefas de ToM. $\mathrm{O}$ artigo 1 contribuiu com a organização de informações quanto aos modelos de avaliação de ToM, as críticas aos modelos mais utilizados e as novas tendências. A construção de um piloto foi apresentada no artigo 2. Neste momento, o piloto foi testado em dois diagnósticos de neurodesenvolvimento, em seguida foram realizadas modificações nas tarefas a partir das observações de desempenho e nos procedimentos de aplicação. Nos artigos seguintes foram desenvolvidas as evidências de qualidade do instrumento. Foram explicitados os resultados quanto a validade de conteúdo, confiabilidade e valiade de constructo (artigo 3), e a comparação entre grupos de TEA, com crianças sem o diagnóstico de TEA, foi mostrada no artigo 4, com intuito de identificar a validade clínica do instrumento, considerando como critério o diagnóstico de TEA.

Nas etapas de validação, os resultados mostram evidências de validade de conteúdo, de constructo, e confiabilidade do instrumento. Por fim, foram encontrados dados significativos quanto sua acurácia diganóstica, em tarefas de Estados Mentais e Verbalizações. Além disso, foram identificados outros domínios cognitivos que se diferenciam mais consistentemente, como: memória de trabalho, flexibilidade cognitiva e índices verbais e globais do funcionamento. Ressalta-se que estes resultados são circunscritos a amostra avaliada neste estudo, que tem características de TEA verbal, com relativa preservação do funcionamento cognitivo (apenas dois participantes autistas apresentaram índice de funcionamento global abaixo da classificação limítrofe). Destaca-se, ainda que 
este perfil é um considerado de mais difícil diagnóstico, pois se confunde com outros diagnósticos como a deficiência intelectual e outros padrões atípicos do neurodesenvolvimento, o que torna a acurácia diagnóstica, identificada nos marcadores sociocognitivos do instrumento, bem como as diferenças cognitivas, em especial em memória de trabalho, flexibilidade e controle inibitório, relevante no âmbito clínico e acadêmico.

Ao longo do desenvolvimento do trabalho, observa-se algumas limitações. Dentre elas: (1) o tamanho da amostra clínica, pois o perfil de TEA deste estudo requeria um padrão mais preservado do desenvolvimento cognitivo, o que torna a amostra mais rara; (2) em função de variabilidades no perfil cognitivo e social, nem todas as crianças puderam completar etapas da avaliação neuropsicológica proposta inicialmente (devido a alfabetização, traços comportamentais, como rigidez comportamental, que impediram a aplicação de alguns testes); (3) dificuldades inerentes ao processo de validação do instrumento, como: modificações em imagens e histórias que podem ser realizadas.

Considerando as discussões levantadas durante a construção dos artigos e as limitações identificadas pelos pesquisadores envolvidos, algumas propostas de estudos são consideradas, para o aprimoramento do instrumento e consolidação de resultados e discussões teóricas, tais como: (A) ampliação da amostra com idade entre 7-12 anos; permitindo estudos com controle e comparação entre diferentes perfis de funcionamento global no TEA (B) ampliação da amostra para idades préescolares, o que poderia auxiliar em estudos de desenvolvimento de ToM; (C) estudos com outros perfis clínicos em comparação com TEA; (D) estudos que aprimorassem a etapa do reconhecimento de emoções, com inserção de medidas neurofisiológicas, que poderiam neutralizar viés de aprendizagem na nomeação de emoções. 


\section{7- REFERÊNCIAS}

Alexandre, N. M. C. \& Coluci, M. Z. O. (2011). Validade de conteúdo nos processos de construção e adaptação de instrumentos de medidas. Ciência \& Saúde Coletiva, 16(7), 3061-3068. https://doi.org/10.1590/S1413-81232011000800006.

Alexandre, N. M. C., Gallasch, C. H., Lima, M. H. M. \& Rodrigues, R. C. M. (2013). A confiabilidade no desenvolvimento e avaliação de instrumentos de medida na área da saúde. Revista Eletrônica de Enfermagem, 15(3), 800-807.https://doi.org/10.5216/ree.v15i3.20776.

Alloway, T. P., Seed, T. \& Tewolde, F. (2016). An investigation of cognitive overlap in working memory profiles in children with developmental disorders. International Journal of Educational Research, 75, 1-6. doi: 10.1016/j.ijer.2015.09.009.

Altschuler, M., Sideridis, G., Kala, S. et al. J Autism Dev Disord (2018) 48: 3945. https://doiorg.ez370.periodicos.capes.gov.br/10.1007/s10803-018-3663-1.

American Psychiatry Association. (2013). Diagnostic and Statistical Manual of Mental disorders - DSM-5. 5th.ed. Washington: American Psychiatric Association.

Astington, J. W. (1998). Theory of mind goes to school. Educational Leadership, 56(3), 46-48.

Austin, G., Groppe, K. \& Elsner, B. (2014). The reciprocal relationship between executive function and theory of mind in middle childhood: a 1-year longitudinal perspective. Frontiers in psychology, 5, 655. doi:10.3389/fpsyg.2014.00655

Baddeley A. Working memory: theories, models, and controversies. Annu Rev Psychol. 2012;63:1-29. doi: 10.1146/annurev-psych-120710-100422. [PubMed] [CrossRef].

Bal, E., Harden, E., Lamb, D., Van Hecke, A. V., Denver, J. W., \& Porges, S. W. (2010). Emotion recognition in children with Autism spectrum disorders: 
Relations to eye gaze and autonomic state. Journal of Autism and Developmental Disorders, 40, 3, 358-370.

Baron-Cohen, S. (1989). Are autistic children behaviourists? An examination of their mental-physical and appearance-reality distinctions. Journal of Autism and Developmental Disorders, 19, 579-600. doi:10.1007/BF02212859.

Baron-Cohen, S., Leslie, A. \& Frith, U. (1986). Mechanical, behavioural and Intentional understanding of picture stories in autistic children (Vol. 4). https://doi.org/10.1111/j.2044-835X.1986.tb01003.X.

Baron-Cohen, S., Leslie, A. M., Frith, U. (1985) Does the autistic child have a “'theory of mind'? Cognition,.21, 1, 37-46.

Barendse, E. M., Hendriks, M. P., Jansen, J. F., Backes, W. H., Hofman, P. A., Thoonen, G., Aldenkamp, A. P. (2013). Working memory deficits in high-functioning adolescents with autism spectrum disorders: neuropsychological and neuroimaging correlates. Journal of $\begin{array}{lll}\text { Neurodevelopmental } & \text { Disorders, } & 5(1),\end{array}$ https://doi.org/10.1186/1866-1955-5-14.

Barendse, E. M., Schreuder, L. J., Thoonen, G., Hendriks, M. P., Kessels, R. P., Backes, W. H., Aldenkamp, A. P. \& Jansen, J. F. (2018). Working memory network alterations in high-functioning adolescents with an autism spectrum disorder. Psychiatry Clinical Neuroscience, 72, 7383. doi: $10.1111 / \mathrm{pen} .12602$.

Baron-Cohen, S., Leslie, A. M. \& Frith, U. (1985) Does the autistic child have a “'theory of mind'? Cognition, 21 (1), 37-46. doi: 0010-0277/85.

Begeer, S., Bernstein, D.M., Aßfalg, A., Azdad, H., Glasbergen, T., Wierda, M. \& Koot, H.M. (2016). Reprint of: Equal egocentric bias in school-aged children with and without autism spectrum disorders. Journal Experimental Child Psychology, 149, 134-145. doi: 10.1016/j.jecp.2016.05.017.

Berenguer, C., Miranda, A., Colomer, C. et al. J Autism Dev Disord (2018) 48: 430. https://doi-org.ez370.periodicos.capes.gov.br/10.1007/s10803017-3349-0. 
Bexkens, A., Ruzzano, L, Collot D' Escury-Koenigs, A.M., Van der Molen, M.W. \& Huizenga, H.M. (2014). Inhibition deficits in individuals with intellectual disability: a meta-regression analysis. Journal Intellectual Disabilyty Research., 58 (1), 3-16. doi: 10.1111/jir.12068.

Biehl, M., Matsumoto D., Ekman P., Hearn V., Heider, K., Kudoh, T., et al. (1997). Matsumoto and Ekman's Japanese and Caucasian Facial Expressions of Emotion (JACFEE): reliability data and crossnational differences. Journal Nonverbal Behavioral, 21, 3-21.

Birch, S. A., Li, V., Haddock, T., Ghrear, S.E., Brosseau-Liard, P., Baimel, A. \& Whyte, M. (2017). Perspectives on perspective taking: How children think about the minds of others. Advances Child Development and Behavior, 52, 185-226. doi: 10.1016/bs.acdb.2016.10.005.

Booth, R. D. L. \& Happé, F. G. E.(2018). Evidence of Reduced Global Processing in Autism Spectrum Disorder. Journal of Autism Developmental Disorder, $\quad 48, \quad 1397 . \quad$ https://doiorg.ez370.periodicos.capes.gov.br/10.1007/s10803-016-2724-6.

Bosco, F.M., Gabattore, I. \& Tirassa, M. (2014). A broad assessment of theory of mind in adolescence: The complexity of mindreading. Consciousness and Cognition, 24, 84-97. doi: 10.1016.

Brasil (2013) Ministério da saúde. Diretrizes de Atenção à Reabilitação da pessoa com transtornos do espectro do autismo (TEA). Brasília/DF.

Brown, M. M., Thibodeau, R.B., Pierucci, J. M. \& Gilpin, A. T. (2017). Supporting the development of empathy: The role of theory of mind and fantasy orientation. Social Development, 26(4), 951-964.

Bühler, E., Bachmann, C., Goyert, H., Heinzel-Gutenbrunner, M. \& KampBecker, I.(2011). Differential Diagnosis of Autism Spectrum Disorder and Attention Deficit Hyperactivity Disorder by Means of Inhibitory Control and 'Theory of Mind'. Journal of Autism Developmental Disorder, 41, 1718. doi:10.1007/s10803-011-1205-1.

Buitelaar, J. K., Swaab, H. \& van der Wees, M. (1996). Neuropsychological impairments and deficits in theory of mind and emotion recognition in a non-autistic boy. European Child \& Adolescent Psychiatry, 5, 44-51. doi:10.1007/BF00708214. 
Buitelaar, J. K. \& van der Wees, M. (1997). Are deficits in the decoding of affective cues and in mentalizing abilities independent? Journal of Autism and Developmental Disorders, 27 (5), 539-556. doi:10.1023/A:1025878026569

Buitelaar, J. K., van der Wees, M., Swaab-Barneveld, J. T. \& van der Gaag, R. J. (1999). Theory of mind and emotion recognition functioning in autistic spectrum disorders and in psychiatric control and normal children. Development and Psychopathology, 11, 39-58. doi: 10.1017/S0954579499001947.

Buitelaar, J. K, van der Wees, M., Swaab-Barneveld, H. \& van der Gaag, R. J. (1999). Verbal memory and performance IQ predict theory of mind and emotion recognition ability in children with autistic spectrum disorders and in psychiatric control children. Journal of Child Psychology and Psychiatry, 40 (6), 869-881. doi: 10.1111/14697610.00505 .

Carlson, S.M., Koenig, A. \& Harms, M.B. (2013). Theory of mind. WIREs Cognitive Science, 4, 391-402. doi: 10.1002/wcs.1232.

Constantino, J. N. \& Charman T. (2016). Diagnosis of Autism Spectrum Disorder: reconciling the syndrome, its diverse origins, and variation-inexpression. The Lancet Neurology, 15, 3, 279-91. doi:10.1016/S14744422(15)00151-9.

Crestani, A. H., Moraes, A. B. de \& Souza, A. P. R. de. (2017). Validação de conteúdo: clareza/pertinência, fidedignidade e consistência interna de sinais enunciativos de aquisição da linguagem. CoDAS, 29(4). https://doi.org/10.1590/2317-1782/201720160180.

Christ, S.E., Holt, D.D., White, D.A. et al. J Autism Dev Disord (2007) 37: 1155. https://doi.org/10.1007/s10803-006-0259-y.

Christ, S. E., Kester, L. E., Bodner, K. E. \& Miles, J. H. (2011). Evidence of selective inhibitory impairment in individuals with autism spectrum disorder. Neuropsychology, 25(6), 690-701.

Dekker, M. C., Ziermans, T. B. \& Swaab, H. (2016). The impact of behavioural executive functioning and intelligence on math abilities in children 
with intellectual disabilities. Journal Intellectual Disability Research., 60 (11), 1086-1096. doi: 10.1111/jir.12276.

De Bem, A. B., Lanzer, E. A., Tambosi Filho, E., Sanchez, O. P. \& Bernardi Junior, P. (2011). Validade e confiabilidade de instrumento de avaliação da docência sob a ótica dos modelos de equação estrutural. Avaliação: Revista da Avaliação da Educação Superior (Campinas), 16(2), 375-401. https://doi.org/10.1590/S1414-40772011000200008.

Demetriou, E. A., Lampit, A., Quintana, D. S., Naismith, S. L., Song, Y. J. C., Pye, J. E., Guastella, A. J. (2018). Autism spectrum disorders: a metaanalysis of executive function. Molecular Psychiatry, 23(5), 11981204. https://doi.org/10.1038/mp.

Devine, R.T., White, N., Ensor, R. \& Hughes, C. (2016). Theory of mind in middle childhood: Longitudinal associations with executive function and social competence. Developmental Psychology, 52 (5), 758-771. doi: 10.1037/dev0000105.

Diamond, A. (2013). Executive Functions. Annual Review of Psychology, 64, 135-168. http://dx.doi.org/10.1146/annurev-psych-113011-143750.

Djuric-Zdravkovic, A., Japundza-Milisavljevic, M. \& Macesic-Petrovic, D. (2010) Attention in children with intellectual disabilities. Procedia Social and Behavioral Sciences, 5, 1601-1606._doi: 10.1016/j.sbspro.2010.07.332.

Durrleman, S. \& Franck, J. (2015) Exploring links between language and cognition in autism spectrum disorders: Complement sentences, false belief, and executive functioning. Journal of Communication Disorders, 54 15-31. doi: 10.1016/j.jcomdis.2014.12.001.

Ekman, P. \& Friesen, W. V. (2003). Unmasking the face. A guide to recognizing emotions from facial clues. Cambridge: Malor Books.

Faja, S. \& Dawson, G. (2014). Performance on the dimensional change card sort and backward digit span by young children with autism without intellectual disability. Child Neuropsychology: A Journal On Normal And Abnormal Development In Childhood And Adolescence, 20(6), 692-699. doi:10.1080/09297049.2013.856395. 
Fisher, N. \& Happé, F. (2005). A Training Study of Theory of Mind and Executive Function in Children with Autistic Spectrum Disorders. Journal of Autism and Developmental Disorders, 35, 6, DOI 10.1007/s10803-005-0022-9.

Flavell, J. H. (2004). "Theory-of-Mind Development: Retrospect and Prospect." Merrill-Palmer Quarterly, 50 (3), 274-290. Project MUSE, doi:10.1353/mpq.2004.0018.

Flavell, J. H., Miller, H. P. \& Miller, S. A. (1999). Desenvolvimento cognitivo (Trad. Claudia Dornelles). Porto Alegre: Artmed.

Flavell, J. H. (1999). Cognitive Development: Children's Knowledge About the Mind. Annu. Rev. Psychol., 50,21-45.

Flavell, J. H., Flavell, E. R. \& Green, F. L. (1987). Young Children's Knowledge About the Apparent-Real and Pretend-Real Distinctions. Developmental Psychology, 23(6), 816-822.

Flavell, J. H., Everett, B. A., Croft, K. \& Flavell, E. R. (1981). Young ChIldren's Knowledge about Visual Perception: Further EvIdence for the Level 1 - Level 2 DIstInctIon. Developmental Psychology, 17, 99103. http://dx.doI.org/10.1037/0012-1649.17.1.99.

Fisher, N. \& Happé, F. (2005). A training study of theory of mind and executive function in children with autistic spectrum disorders. Journal of Autism and Developmental Disorders, 35 (6), 757-771. doi: 10.1007/s10803-005-0022-9.

Fitzpatric, P., Frazier, J.A. \& Cochran, D.E. (2018). Relationship Between Theory of Mind, Emotion Recognition, and Social Synchrony in Adolescents With and Without Autism . Frontiers in Psychology, 9, 1337. doi: 10.3389/fpsyg.2018.01337.

Golan, O., Gordon, I, Fichman, K \& Keinan, G. (2018). Specific Patterns of Emotion Recognition from Faces in Children with ASD: Results of a Cross-Modal Matching Paradigm. Autism and Developmental Disorders, 48, 844-852. https://doi.org/10.1007/s10803-017-3389-5. 
Grosse Wiesmann, C., Friederici, A.D., Singer, T. \& Steinbeis, N. (2016). Implicit and explicit false belief development in preschool children. Developmental Science. 20 (5), e12445. doi: 10.1111/desc.12445,

Hadwin J., Baron-Cohen, S., Howlin P. \& Hill, K. (1996) Can we teach children with autism to understand emotions, belief, or pretence? Developmental Psychopathology, 8, 345-365.

Haynes, S. N., Richard, D. C. S. \& Kubany, E. S. (1995). Content validity in psychological assessment: A functional approach to concepts and methods. Psychological Assessment, 7, 238-247. doi:10.1037/10403590.7.3.238.

Hale, C. M. \& Tager-Flusberg, H. (2005). Social communication in children with autism. The relationship between theory of mind and discourse development. SAGE Publications and The National Autistic Society, 9 (2), 157-178. doi: 10.1177/1362361305051395.

Happé, F. (1994). An advanced test of Theory of Mind: Understanding of story characters' thoughts and feelings by able autistic, mentally handicapped, and normal children and adults. Journal of Autism and Developmental Disorders, 24(2), 129-154. doi: 10.1007/BF02172093.

Henderson, H. A., Ono, K. E., McMahon, C., Schwartz, C. B., Usher, L. V. \& Mundy, P. C. (2015). The costs and benefits of self-monitoring for higher functioning children and adolescents with autism. Journal of Autism and Developmental Disorders, 45 (2), 548-559. doi: 10.1007/s10803-013-1968-7.

Howlin, P., Baron-Cohen, S. \& Hadwin, J. A. (2006). Teaching Children with Autism to Mind-Read: A Practical Guide for Teachers and Parents. Wiley.

Hutchins, T. L., Prelock, P. A. \& Chace, W. (2008). Test-Retest Reliability of a Theory of Mind Task Battery for Children With Autism Spectrum Disorders. Focus on Autism and Other Developmental Disabilities, 23,4, 195-206. https://doi.org/10.1177/1088357608322998 
Iwanaga, R., Tanaka, G., Nakane, H., Honda, S., Imamura, A. \& Ozawa, H. (2013). Usefulness of near-infrared spectroscopy to detect brain dysfunction in children with autism spectrum disorder when inferring the mental state of others. Psychiatry Clinical Neuroscience 67 (4), 203-209. doi: 10.1111/pcn.12052.

Kaland, N., Møller-Nielsen, A., Callesen, K. \& Smith, L. (2002). A new 'advanced' test of theory of mind: evidence from children and adolescents with Asperger syndrome. Journal of Child Psychology and Psychiatry, 43(4), 517-528. doi: 10.1111/1469-7610.00042.

Kaland, N., Callesen, K., Møller-Nielsen, A. Mortensen, E. L. \& Smith, L. (2008). Performance of children and adolescents with asperger syndrome or high-functioning autism on advanced theory of mind tasks. Journal of Autism Development Disorders, 38, 1112-1123. doi: 10.1007/s10803007-0496-8 .

Kaland, N., Smith, L. \& Mortensen, E. L. (2007). Response times of children and adolescents with asperger syndrome on an 'advanced' test of theory of mind. Journal of Autism and Developmental Disorders, 37, 197-209. doi: 10.1007/s10803-006-0152-8.

Kimhi, Y., Shoam-Kugelmas, D., Ben-Artzi, G. A., Ben-Moshe, I. \& BaumingerZviely, N. (2014). Theory of mind and executive function in preschoolers with typical development versus intellectually able preschoolers with autism spectrum disorder. Journal of Autism Developmental Disorders, 44, 2341. doi:10.1007/s10803-014-2104$\mathrm{z}$.

Klin, A. (2000). Attributing social meaning to ambiguos visual stimuli in higherfunctioning autism and asperger syndrome: The social attribution task. Journal Child Psychoogy and Psychiatry. 41 (7), 831-846. doi: 10.1111/1469-7610.00671.

Korkiakangas, T., Dindar, K., Laitila, A. \& Kärnä, E. (2016). The Sally-Anne test: An interactional analysis of a dyadic assessment (Vol. 51). https://doi.org/10.1111/1460-6984.12240.

Kouklari, E.-C., Tsermentseli, S. \& Auyeung, B. (2018). Executive function predicts theory of mind but not social verbal communication in 
school-aged children with autism spectrum disorder. Research in Developmental Disabilities, $\quad 76, \quad 12-24$. https://doi.org/10.1016/j.ridd.2018.02.015.

Jaworski, J.L.B. \& Eigst,i I-M. (2017). Low-level visual attention and its relation to joint attention in autism spectrum disorder. Child Neuropsychology. 23(3), 316-331. doi:10.1080/09297049.2015.1104293.

Lee, K. U., Kim, J., Yeon, B., Kim, S. H., \& Chae, J. H. (2013). Development and Standardization of Extended ChaeLee Korean Facial Expressions of Emotions. Psychiatry investigation, 10(2), 155-63.

Leung, R., C. \& Zakzanis, K., K. (2014). Brief Report: Cognitive Flexibility in Autism Spectrum Disorders: A Quantitative Review. Journal of Autism and Developmental Disorders, 44 (10), 2628-2645. doi: 10.1007/s10803-014-2136-4.

Lind, S. E. \& Bowler, D. M. (2010). Impaired performance on see-know tasks amongst children with autism: Evidence of specific difficulties with theory of mind or domain-general task factors? Journal of Autism Development Disorders, 40, 479-484. doi: 10.1007/s10803-009-0889.

Losh, M., Adolphs, R., Poe, M.D., Couture, S., Penn, D., Baranek, G.T. \& Piven, J. (2009) Neuropsychological profile of autism and the broad autism phenotype. Archives Gen Psychiatry. 66 (5), 518-26. doi: 10.1001/archgenpsychiatry.2009.34.

Machado, A. C. \& Bello, S. F. (2015). Habilidades sociocomunicativas e de atenção compartilhada em bebês típicos da primeira infância. Revista Psicopedagogia, 32,98, 150-7.

Matos, D. A. S. (2014). Confiabilidade e Concordância entre juízes: aplicações na área educacional. Est. Aval. Educ., 25, 59, 298-324.

Miller, H. L., Ragozzino, M. E., Cook, E. H., Sweeney, J., A. \& Mosconi, M. W (2015). Cognitive Set Shifting Deficits and Their Relationship to Repetitive Behaviors in Autism Spectrum Disorder. Journal of Autism Developmental Disorder, 45,805-815. doi: 10.1007/s10803-0142244-1.

Miller, S. A. (2009). Children's Understanding of Second-Order Mental States. Psychological Bulletin, 135 (5), 749-773. doi: 10.1037/a0016854. 
Mishra, M.V., Ray, S.B. \& Srinivasan, N (2018). Cross-cultural emotion recognition and evaluation of Radboud faces database with an Indian sample. PLoS One, 13,10, e0203959 (ISSN: 1932-6203).

Miyake, A., Friedman, N. P., Emerson, M. J., Witzki, A. H., Howerter, A. \& Wager, T. D. (2000). The Unity and Diversity of Executive Functions and Their Contributions to Complex "Frontal Lobe" Tasks: A Latent Variable Analysis. Cognitive Psychology, 41(1), 49-100. https://doi.org/10.1006/cogp.1999.0734.

Muris, P., Steerneman, P., Meesters, C., Merckelbach, H., Horselenberg, R., van den Hogen, T., van Dongen, L. (1999). The TOM test: A new instrument for assessing theory of mind in normal children and Children with pervasive developmental disorders. Journal of Autism and Developmental Disorders, 29 (1), 67-80. doi: 10.1023/A:1025922717020.

Nigg, J. T. (2000). On inhibition/disinhibition in developmental psychopathology: Views from cognitive and personality psychology and a working inhibition taxonomy. Psychological Bulletin, 126(2), 220. https://doi.org/10.1037/0033-2909.126.2.220.

O'Connor, A. M. \& Evans, A. D. (2019). The role of theory of mind and social skills in predicting children's cheating. Journal of Experimental Child Psychology, 179, 337-347. https://doi.org/10.1016/j.jecp.2018.11.018

Oliveira, R,. M. \& Charchat-Fichman, H. (2008). Brazilian children performance on Rey's Auditory verbal learning paradigm. Arquivos de NeuroPsiquiatria, 66, 40-44. doi: 10.1590/S0004-282X2008000100010.

Oliveira, R., M., Mograbi, D.,C., Gabrig, I.,A. \& Charchat-Fichman, H. (2016). Normative data and evidence of validity for the Rey Auditory Verbal Learning Test, Verbal Fluency Test, and Stroop Test with Brazilian children. Psychology \& Neuroscience, 9(1), 54-67. doi: 10.1037/pne0000041.

Oliveira, M.S.: Rigoni, M.S. (2010). Figuras Complexas de Rey: Teste de Cópia e de Reprodução de Memória de Figuras Geométricas Complexas. São Paulo: Casa do Psicólogo. 
Osterhaus, C., Koerber, S., Sodian, B. (2016). Scaling of Advanced Theory-ofMind Tasks. Child Development, 87(6), 1971-1991. doi: 10.1111/cdev.12566.

Oktay-Gür, N., Schulz, A. \& Rakoczy, H. (2018). Children exhibit different performance patterns in explicit and implicit theory of mind tasks. Cognition, 173, 60-74.

Pasquali, Luiz. (2009). Psicometria. Revista da Escola de Enfermagem da USP, 43(spe), 992-999. $\quad$ https://dx.doi.org/10.1590/S0080$\underline{62342009000500002 .}$

Pedersen, A. L., Pettygrove, S., Lu, Z., Andrews, J., Meaney, F. J., KurziusSpencer, M., Cunniff, C. (2016). DSM Criteria that Best Differentiate Intellectual Disability from Autism Spectrum Disorder. Child Psychiatry and Human Development, 1-9. doi: 10.1007/s10578-0160681-0.

Pedreño, C., Pousa, E., Navarro, J. B. et al. J Autism Dev Disord (2017) 47: 2401.https://doi-rg.ez370.periodicos.capes.gov.br/10.1007/s10803017-3156-7.

Pemer, J., Frith, U., Leslie, A. M. \& Leekam, S. (1989). Exploration of the autistic child's theory of mind: Knowledge, belief, and communication. Child Development, 60 (3), 688-700. DOI INEXISTENTE

Peterson, C. C. (2002). Drawing Insight from Pictures: The development of concepts of false drawing and false belief in children with deafness, normal hearing, and autism. Child Development, 73 (5), 1442-1459. doi:10.1111/j.1467-9450.2009.00750.x

Pilowsky, T., Yirmiya, N., Arbelle, S. \& Mozes, T. (2000). Theory of mind abilities of children with schizophrenia, children with autism, and normally developing children. Schizophrenia Research, 42, 145-155. doi: 10.1016/S0920-9964(99)00101-2.

Polyak, A., Kubina, R. M. \& Girirajan, S. (2015). Comorbidity of Intellectual Disability Confounds Ascertainment of Autism: Implications for Genetic Diagnosis. American Journal of Medicine Genetic, Part B 168B, 600-608. doi: 10.1002/ajmg.b.32338. 
Premack, D. \& Woodruff, G. (1978). The chimpanzee have a theory of mind? The Behavioral and Brain Sciences, 4, 515-526.

Prior, M., Leekam, S., Ong, B., Eisenmajer, R., Wing, L., Gould, J. \& Dowe, D. (1998). Are There Subgroups within the Autistic Spectrum? A Cluster Analysis of a Group of Children with Autistic Spectrum Disorders. Journal of Child Psychology and Psychiatry, 39(6), 893-902. doi: $\underline{10.1111 / 1469-7610.00389 .}$

Pruett, J. R., Kandala, S., Petersen, S. E. \& Povinelli, D. J. (2015). Brief Report: Theory of Mind, Relational Reasoning, and Social Responsiveness in Children With and Without Autism: Demonstration of Feasibility for a Larger-Scale Study. Journal of autism and developmental disorders, 45(7), 2243-51.

Raymundo, V.P. (2009). Construção e validação de instrumentos: um desafio para psicolinguística. Letras de Hoje, 44(3), 86-93.

Roazzi, A. \& Santana, S. M. (2008). Teoria da mente e estados mentais de primeira e segunda ordem. Psicologia: Reflexão e Crítica, 21 (3), 437 445. doi: 10.1590/S0102-79722008000300012.

Salgueiro, E., Nunes, L., Barros, A., Maroco, J., Salgueiro, A. I. \& dos Santos, M. E. (2012). Effects of a dolphin interaction program on children with autism spectrum disorders - an exploratory research. BMC Research Notes, 5, 199. doi: 10.1186/1756-0500-5-199.

Sanvicente-Vieira, B., Brietzke, E. \& Grassi-Oliveira, R. (2012). Translation and adaptation of Theory of Mind tasks into Brazilian Portuguese. Trends in Psychiatry and Psychotherapy, 34, 4, 178-185.

Schaller, M. \& Rauh, U., (2017). What difference does it make? Implicit, explicit and complex social cognition in autism spectrum disorders. Journal of Autism and Developmental Disorders, 47(4), 961-979. doi: 10.1007/s 10803-016-3008-x.

Scheeren, A. M., de Rosnay, M., Koot, H.M. \& Begeer, S. (2013). Rethinking theory of mind in high-functioning autism spectrum disorder. Journal of Child Psychology and Psychiatry, 54 (6), 628-635. doi: 10.1111/jcpp.12007. 
Schmitt, L. M., White, S. P., Cook, E. H., Sweeney, J. A. \& Mosconi, M. W. (2018). Cognitive mechanisms of inhibitory control deficits in autism spectrum disorder. Journal of Child Psychology Psychiatry, 59, 586595. doi: $\underline{10.1111 / j c p p .12837 .}$

Schneider, D., Slaughter, V. P., Bayliss, A. P. \& Dux, P. E. (2013). A temporally sustained implicit theory of mind deficit in autism spectrum disorders. Cognition, $129(2)$, $410-417$ https://doi.org/10.1016/j.cognition.2013.08.004

Schuchardt, K., Gebhardt, M. \& Mäehler, C. (2010). Working memory functions in children with different degrees of intellectual disability. Journal of Intellectual Disability Research, 54(4), 346-53. doi: 10.1111/j.13652788.2010.01265.x.

Silliman, E. R., Diehl, S. F., Bahr, R. H., Hnath-Chisolm, T., Zenko, C. B. \& Friedman, S. A. (2003). A new look at performance on theory-of-mind tasks by adolescents with Autism Spectrum Disorder. Language, Speech, and Hearing Services in Schools, 34, 236-252.

Simms, M. D. (2017). When Autistic Behavior Suggests a Disease Other than Classic Autism Pediatric Clinics of North America 64, 127-138 doi: 10.1016/j.pcl.2016.08.009.

Smogorzewska, J. Szumski, G. \& Grygiel, P. (2018). Same or different? Theory of mind among children with and without disabilities. PLOS ONE 13 (10), e0202553. https://doi.org/10.1371/journal. pone.0202553.

Solomon, M., McCauleya, J. B., Iosife, Ana-Maria, Carter, C. S. \& Ragland, J. D. (2016). Cognitive control and episodic memory in adolescents with autism spectrum disorders. Neuropsychologia, 89, 31-41. doi:10.1016/j.neuropsychologia.2016.05.013.

Souza, A. C de, Alexandre, N. M. C. \& Guirardello, E. de B. (2017). Propriedades psicométricas na avaliação de instrumentos: avaliação da confiabilidade e da validade. Epidemiologia e Serviços de Saúde, 26(3), 649-659. https://dx.doi.org/10.5123/s167949742017000300022. 
Schietecatte, I., Roeyers, H. \& Warreyn, P. J. (2012). Exploring the nature of joint attention impairments in young children with autism spectrum disorder: associated social and cognitive skills. Autism Devopmental $\quad$ Disorder, $\quad$ 42(1). org.ez370.periodicos.capes.gov.br/10.1007/s10803-011-1209-X

Spreen, O. \& Strauss, E. (1998). Compendium of Neuropsychological Tests, Administration, Norms and Commentary. Oxford: Oxford University Press.

Stuss, D. T. \& Alexander, M. P. (2005). Does Damage to the Frontal Lobes Produce Impairment in Memory? Current Directions in Psychological Science, 14(2), 84-88. doi: 10.1111/j.0963-7214.2005.00340.x.

Steerneman, P. (1994). Theory-of-mind screening-schaal [Theory-of-Mind Screening-Scale]. Leuven/Apeldoorn: Garant.

van Buijsen, M., Hendriks, A., Ketelaars, M. \& Verhoeven, L. (2011). Assessment of theory of mind in children with communication disorders: Role of presentation mode. Research in Developmental Disabilities, 32(3), 10381045.http://dx.doi.org/10.1016/j.ridd.2011.01.036.

Tager-Flusberg, H. \& Sullivan, K. (1994). A second look at second-order belief attribution in Autism. Journal of Autism and Developmental Disorders, 24 (5), 577-586. doi: 10.1007/BF02172139.

Tomasello, M. (2003). Constructing a language: a usage-based theory of language acquisition. Cambridge, MA: Harvard University Press.

Tonietto, L., Wagner, G. P., Trentini, C. M., Sperb, T. M. \& Parente, M. A. de M. P. (2011). Interfaces entre funções executivas, linguagem e intencionalidade. Paidéia (Ribeirão Preto), 21(49), 247-255. doi: 10.1590/s0103-863x2011000200012.

Trammell, B., Wilczynski, S. M., Dale, B. \& McIntosh, D. E. (2013). Assessment and differential diagnosis of comorbid conditions in adolescents and adults with autism spectrum disorders. Psychology in the Schools, 50, 936-946. doi: 10.1002/pits.21720. 
Wechsler, D. (2014). Escala Wechsler abreviada de Inteligência (WASI). São Paulo: Casa do Psicólogo. ISBN: 978-85-8040-375-6.

Wechsler, D. (2013). Escala Wechsler de Inteligência para Crianças - Quarta Edição (WISC IV). São Paulo: Casa do Psicólogo.

Wellman, H. M. \& Liu, D. (2004). Scaling of theory-of mind tasks. Child Development, 75 (2), 523-541. doi: 10.1111/j.1467$\underline{8624.2004 .00691 . x}$

Wimmer, H. \& Pemer, J. (1983). Beliefs about beliefs: Representation and constraining function of wrong beliefs in young children's understanding of deception. Cognition, 13, 103-128. doi: 10.1016/0010-0277(83)90004-5.

White, S. J., Frith, U., Relleck, J., Al-Noor, Z. \& Gilbert, S. J. (2014). Autistic adolescents show atypical activation of the brain's mentalizing system even without a prior history of mentalizing problems. Neuropsychologia, 56, 17-25. doi: 10.1016/ j.neuropsychologia.2013.12.013.

Yates, K. \& Le Couteur, A. (2016). Diagnosing autism/autism spectrum disorders. Paediatrics And Child Health, 26, $12 . \quad \underline{\text { doi: }}$ 10.1016/j.paed.2016.08.004

Yat-Fan-Siu, N. \& Jiaying LE, J (2015). A Review of the Verbal Memory Profile of Individuals with Autism Spectrum Disorder. Journal Psychology Clinical Psychiatry 2 (1), 00050. doi: 10.15406/jpcpy.2015.02.00050.

Yang, J., Zhou, S., Yao, S., Su, L. \& McWhinnie, C. (2009). The Relationship Between Theory of Mindand Executive Function in a Sample of Childrenfrom Mainland China. Child Psychiatry and Human Development, 40(2), 169-182.https://doi.org/10.1007/s10578-008-

$\underline{0119-4}$

Yeh, Z.T., Tsai, M.C., Tsai, M.D., Lo, C.Y. \& Wang, K.C. (2016). The relationship between theory of mind and the executive functions: Evidence from patients with frontal lobe damage. Applied Neuropsychology Adult, 9, 1-8. doi: 10.1080/23279095.2016.1185425.

Yirmiya, N. \& Shulman, C. (1996). Seriation, Conservation, and Theory of Mind Abilities in Individuals with Autism, Individuals with Mental 
Retardation, and Normally Developing Children. Child Development, 67, 2045-2059. doi: 10.1111/j.1467-8624.1996.tb01842.x

Zainal, N. H \& Newman, M.G (2018). Worry amplifies theory-of-mind reasoning for negatively valenced social stimuli in generalized anxiety disorder. Journal of Affective Disorders 227, 824-833.

Zakai-Mashiach, M., Ziv, M. \& Dromi, E. (2017) Preschoolers' social interest toward a child with ASD and their Theory of Mind abilities, European Early Childhood Education Research Journal, 25(4), 561-574, DOI: $\underline{10.1080 / 1350293 X .2017 .1331073 .}$ 


\section{APÊNDICE A- Aula para treinamento dos juízes que validaram o conteúdo}

\section{Teoria da Mente}

A teoria da mente (ToM) (Baron-Cohen et al.,1985; Premack \& Woodruff, 1978), seria definida como a habilidade de inferir estados mentais internos de outras pessoas, como

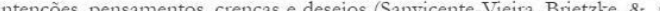
2012).

Significa ter acesso aos pensamentos, desejos e emoções próprios e de outras pessoas (Durrleman, \& Franck, 2015; Miller, 2009).

- Ela vem sendo discutida em larga escala no autismo. Verifica-se um consenso do prejuízo neste diagnóstico (Baron-Cohenet al.,, 1985; Leslie \& Frith, 1987; Premack \&-Woodruff, 1978; Wimmer \& Perner, 1983)

Teoria da Mente

Flavell, Miller e Miller (1999) e Baron Cohen, ToM consiste de diferentes niveis ou módulos.

- Têm relações com outras funções cognitivas, uma vez que a atenç̃̃o conjunta e a orientação do olhar, por exemplo, estão relacionadas a aspectos de pragmática e intencionalidade (Tomasello, 2003) e ao conceito de funções executivas (Tonietto et al. 2011).

Assim, a Teoria da Mente teria um alto desempenho pontual, mas exigiria uma progressão de estágios para alcançá-lo, bem como participação de áreas mais gerais de funcionamento cognitivo, como funções executivas (memória de trabalho, controle inibitório). 
Domínios identificados em revisão de artigos

- (a) precursores de teoria da mente, onde se enquadram tarefas de identificação de conceitos de estados mentais, distinção entre estados fisicos e mentais e reconhecimento de emoções (Flavell et al., 1999);

- (b) falsas crenças, que envolvem tarefas de conteúdo incoerente para verificação de crenças das personagens (Howlin, Baron-Cohen \& Hadwin , 2006)

- (c) identificação contexto social, a partir de pistas visuais, que envolvem tarefas de compreensão de cenas sociais, a partir de rastreio de pistas visuais no ambiente (Klin, 2000)

Validação de Bateria de Teoria da Mente para diagnóstico de TEA

Instrumento composto por tarefas de teoria da mente e tarefas controle (controle cognitivo)

- Tarefa 1-(Controle) Nomeação de Objetos

- Tarefa 2- (ToM)-Nomeação de emoções

- Tarefa 3-(ToM)-Gradação de emoções

- Tarefa 4- (Controle)-Go NO Go (controle inibitório)

- Tarefa 5-(ToM)- Identificacão de estados mentais

- Tarefa 6- (controle)- Organização Lógica (sequência visual)

- Tarefa 7- (ToM)- Organização Lógica com Inferência

Tarefa 1-Nomeação

- Instrução: "Diga o nome destas figuras"- apresentar uma figura por vez.
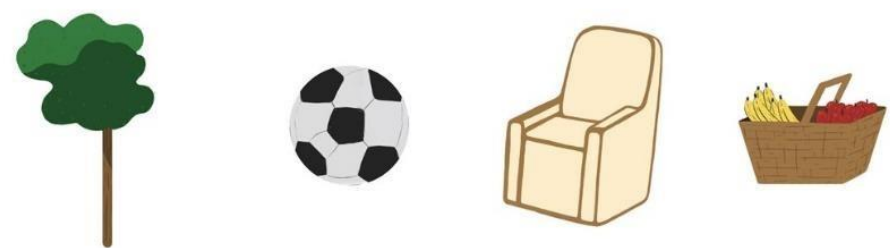
Tarefa 2-Nomeação de emoções

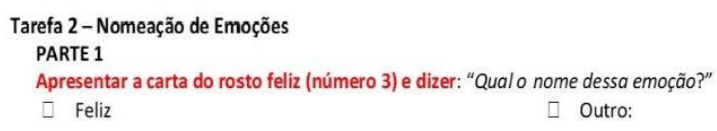

Apresentar a carta do rosto feliz (número 3) e dizer: "Qual o nome dessa emoção?" ¿ Feliz ㄱ Outro:

Apresentar a carta do rosto triste (número 3) e dizer: "Qual o nome dessa emoção?" [. Triste (1) Outro:

Apresentar a carta do rosto com medo (número 3) e dizer: "Qual o nome dessa emoção?" ¿ Medo $\square$ Outro:

Apresentar a carta do rosto com raiva e (número 3) e dizer: "Qual o nome dessa emoção?" (- Outro: (1) Raiva

Tarefa 2-gradação de emoções

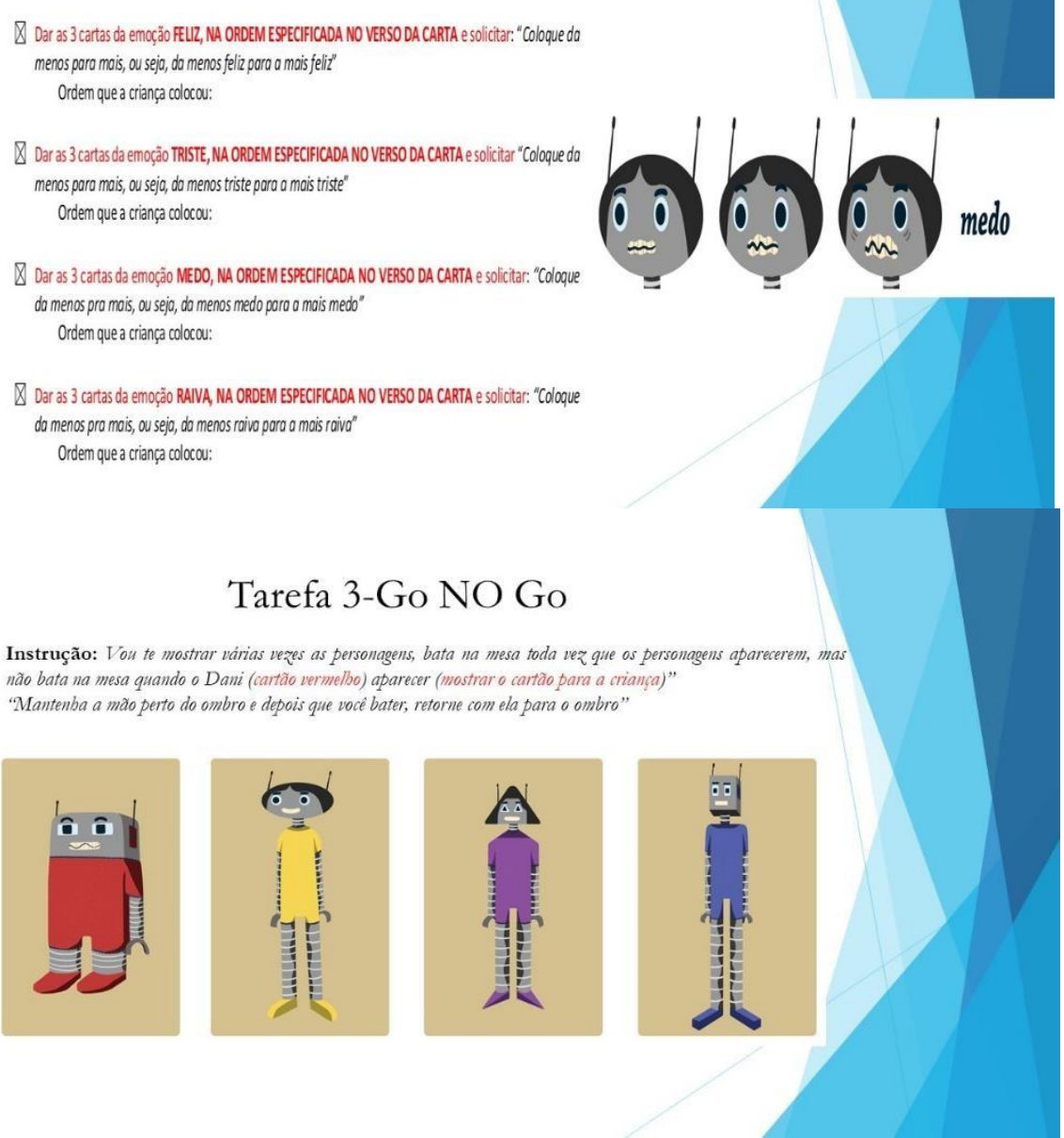


Tarefa 4- Identificação de Estados Mentais Apresentar e perguntar:

Em caso de erro na pergunta controle: dar a resposta correta

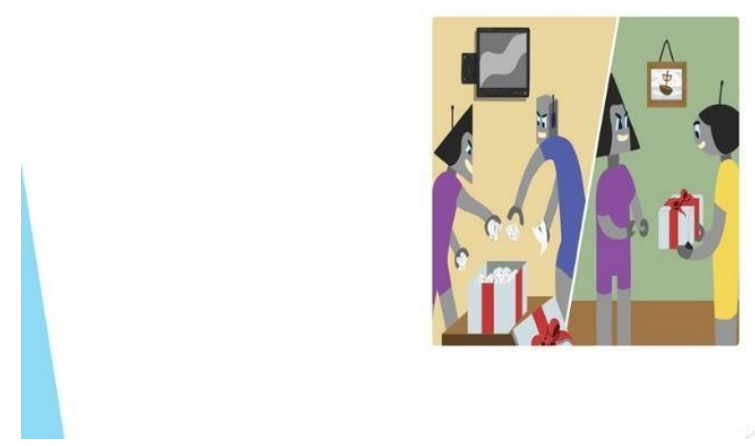

Tarefa 5- Organização Lógica Simples

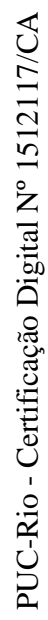

Apresentar cada história seguindo a ordem NUMÉRICA, no verso da carta. Anotar cada resposta seguindo a ordem de LETRAS

- Solicitar, após apresentar as histórias em ordem numérica da esquerda para direita (posição do avaliando): "Agora coloque na ordem certa"
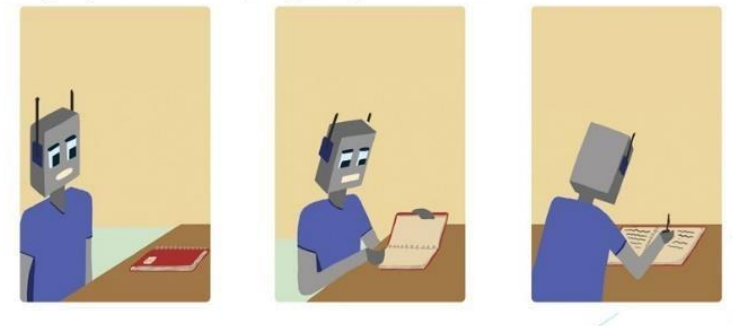

Tarefa 6-Organização Lógica Complexa

Apresentar cada história seguindo a ordem NUMÉRICA, no verso da carta. Anotar cada resposta seguindo a ordem de LETRAS.

aṕs apresentar as histórias em ordem numérica da esquerda para direita (posição do avaliando): "Agora coloque na ordem certa"

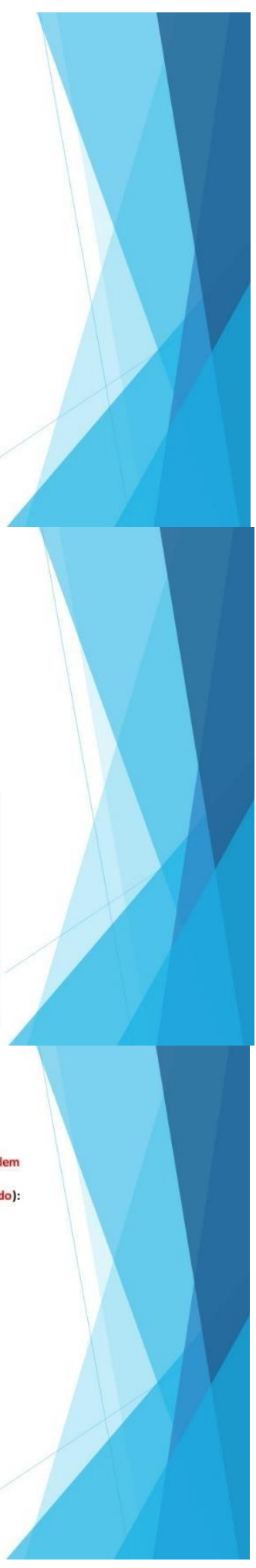


APÊNDICE B- Questionário sóciodemográfico e clínico

Grupo de Pesquisa

PUC-Rio

Doutoranda: Conceição Fernandes Orientadora: Helenice Charchat Fichman

Questionário sócio-demográfico

e clínico

Nome da criança

Código:

Data de Nascimento da criança: Idade:

Nome

dos

responsáveis:

Escolaridade dos responsáveis:

Renda Familiar:

Escolaridade da criança:

Escola:

Telefones para contato:

Data de preenchimento:

Sobre o parto. Nasceu de quantas semanas? Houve algum problema durante parto ou gestação?

Qual idade começou a falar? Se considera que houve atraso ou dificuldade, explique brevemente: 
Qual idade começou andar? Se considera que houve atraso ou dificuldade, explique brevemente: 
Quanto tempo costuma ficar com seu filho ao longo do dia (por exemplo: brincar, fazer dever, levar a escola.)

Seu filho apresenta problemas auditivos ou de visão?

Seu filho apresenta dificuldades de aprendizagem na escola?

( ) Reprovação

( ) Notas baixas. Quanto em média?

( ) Dificuldades para realizar deveres de casa (precisa de muita ajuda, se perde, ou se confunde?)

( ) Dificuldades com cópia de matéria durante a aula

( ) Trocas ou esquecimento de letras na leitura e/ou escrita.

( ) Dificuldade na leitura ou interpretação de textos

( ) Outro :

Seu filho apresenta queixas de comportamento?

( ) Não respeita comandos em casa e/ou na escola (ordens dos pais e professores)

( ) Não respeita as regras de rotina da casa e/ou da escola, como respeitar horários deveres, tomar banho, se arrumar para escola, parar de jogar ou brincar, dormir.

( ) Conversa muito ou brinca na escola durante as aulas

( ) Recebe queixas dos professores frequentemente. Se sim, quais

( ) Brinca muito a ponto de incomodar os amigos

( ) Demonstra agitação (corre muito, fala muito, parece estar sempre muito "ligado") 
( ) Outro

Seu filho apresenta queixas sociais?

( ) Bate ou morde os colegas

( ) Não brinca com outras crianças da mesma idade

( ) Brinca com outras crianças, mas parece não entender as regras ou parece estar apenas próximo

( ) prefere brincar sozinho ou ficar em casa a fazer atividades externas ou com outras pessoas.

( )Fala pouco

( ) Não consegue contar sobre como foi o dia

( ) Se esconde das pessoas

( ) Corre ao redor de objetos ou lugares, ao invés de brincar

( ) Parece nãos e interessar por conversar ou brincar com crianças de sua idade

( ) Parece não ouvir quando é chamado

( ) outro

Seu filho já foi a um Neurologista, Psiquiatra, Psicólogo ou Fonoaudiólogo?

$$
(\quad) \operatorname{Sim} \quad(\quad) \text { Não }
$$

Caso sua resposta tenha sido sim, explique brevemente o motivo: 
$\longrightarrow$

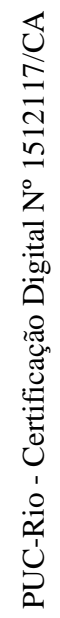


APÊNDICE C- Termos de Consentimento Livre e Esclarecido

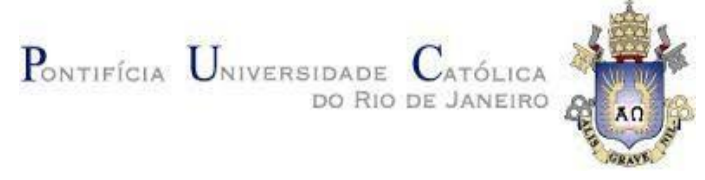

\section{TERMO DE CONSENTIMENTO LIVRE E ESCLARECIDO}

Projeto de Pesquisa: Desenvolvimento e Evidências de Validade de uma Nova Bateria Infanto-juvenil de avaliação de Teoria da Mente para diagnóstico de autismo.

Doutoranda: Conceição Santos Fernandes; Professora Orientadora: Helenice Charchat Fichman (PUC-RIO)

Prezado, venho por meio deste, convidá-lo a participar desta pesquisa. O objetivo é desenvolver um instrumento que favoreça maior precisão de avaliação de Teoria da Mente para diagnóstico de autismo. Para colaborar com este estudo, o participante participará de três sessões, com duração de aproximadamente 1 hora. Serão coletados dados, através da aplicação de testes, paradigmas, tarefas e escalas, que serão usados apenas com finalidade científica. Os horários serão estipulados pelas instituições e acordados com os participantes.

Você tem toda a liberdade para não querer participar da pesquisa, ou mesmo para mudar de ideia, caso tenha concordado em participar. Caso sinta necessidade de solicitar maiores esclarecimentos sobre a pesquisa, poderá entrar em contato a doutoranda e orientadora responsáveis, através dos telefones (21) 99557-3102, (21) 992191293, através do departamento de Psicologia: Rua Marquês de São Vicente, 225, Sala 201L - Gávea - CEP: 22543-900, Rio de Janeiro - RJ - Tel. (021) 3527-1001 / 3527-2286, ou pelos e-mails: conceicaosf@yahoo.com.br e hcharchat@uol.com.br.

A participação nesta pesquisa envolve riscos mínimos, como cansaço devido ao tempo gasto na aplicação. Se isto ocorrer você poderá interromper a qualquer momento, e retomá-los posteriormente, se assim o desejar. Caso isto, assim como nenhum beneficio direto, embora, como mencionado acima, os resultados deste estudo gerarão benefícios a população infanto-juvenil. Todas as informações coletadas neste estudo são estritamente confidenciais. Apenas os membros do grupo de pesquisa terão conhecimento dos dados individuais. Os dados obtidos serão para uso exclusivo desta pesquisa e apenas os resultados gerais poderão ser publicados em periódicos científicos e apresentados e discutidos em eventos científicos. Você não terá nenhum tipo de despesa ou receberá pagamento por participar deste estudo.

Ao aceitar participar da pesquisa, receberá uma cópia assinada do termo de consentimento, enquanto a outra permanecerá com os membros da pesquisa. Tendo em vista as informações apresentadas, de forma livre e esclarecida, aceito participar desta pesquisa:

Eu, concordo com a participação do meu filho neste estudo.

Telefone de contato:

Assinatura:

Assinatura (pesquisador)

Local e data 


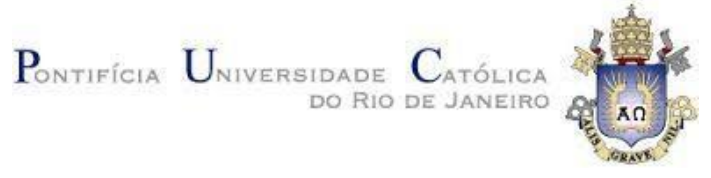

\section{Termo de assentimento do menor}

Olá, meu nome é Conceição Fernandes, você está sendo convidado para participar da pesquisa: Desenvolvimento e Evidências de Validade de uma Nova Bateria Infanto-juvenil de avaliação de Teoria da Mente para diagnóstico de autismo. Querermos entender como as crianças entendem as situações sociais. Nesta pesquisa, as crianças irão realizar algumas tarefas, algumas semelhantes as que você realiza na escola e outras onde terá que interpretar algumas situações sociais, em 3 dias diferentes. As crianças que irão participar têm idade próxima a sua (6 a 12 anos de idade). Não tem nenhum risco, mas também nenhum beneficio direto, mas os resultados irão ajudar outras crianças. Você não precisa participar, se não quiser, é um direito seu e não terá nenhum problema se desistir. Ninguém saberá que você está participando da pesquisa, não falaremos a outras pessoas. Os resultados da pesquisa vão ser publicados, mas sem identificar seu nome. Quando terminarmos a pesquisa, nós iremos fornecer a você e seus pais os resultados obtidos.

Se você tiver alguma dúvida, você pode me perguntar. Caso tenha alguma dúvida depois, você me telefonar (21995573102), ou também para minha orientadora (21992191293).

$\mathrm{Eu}$ aceito participar da pesquisa Desenvolvimento e Evidências de Validade de uma Nova Bateria Infanto-juvenil de avaliação de Teoria da Mente para diagnóstico de autismo. Entendi que posso dizer "sim" e participar, mas que, a qualquer momento, posso dizer "não" e desistir que ninguém vai ficar furioso. Os pesquisadores tiraram minhas dúvidas e conversaram com os meus responsáveis.

Você receberá uma cópia assinada deste termo de assentimento e eu ficarei com outra. Li e concordo em participar da pesquisa.

Rio de Janeiro, de de

Assinatura do menor

Assinatura do responsável

Assinatura pesquisador 


\section{APÊNDICE D- Aula para treinamento dos juízes de precisão do instrumento BToM}

\section{Teoria da Mente}

A teoria da mente (ToM) (Baron-Cohen et al 1985; Premack \& Woodruff, 1978), seria definida como a habilidade de inferir estados mentais internos de outras pessoas, como intenções, pensamentos, crenças e desejos (Sanvicente-Vieira, Brietzke, \& Grassi-Oliveira, 2012).

- Significa ter acesso aos pensamentos, desejos e emoções próprios e de outras pessoas (Durrleman, \& Franck, 2015; Miller, 2009).

Ela vem sendo discutida em larga escala no autismo. Verifica-se um consenso do prejuízo neste diagnóstico (Baron-Cohenet al.,, 1985; Leslie \& Frith, 1987; Premack \&lWoodruff, 1978; Wimmer \& Perner, 1983).

\section{Teoria da Mente}

Flavell, Miller e Miller (1999) e Baron Cohen, ToM consiste de diferentes níveis ou módulos.

- Têm relações com outras funções cognitivas, uma vez que a atenção conjunta e a orientacão do olhar, por exemplo, estão relacionadas a aspectos de pragmática e intencionalidade (Tomasello, 2003) e ao conceito de funções executivas (Tonietto et al., 2011).

- Assim, a Teoria da Mente teria um alto desempenho pontual, mas exigiria uma progressão de estágios para alcançá-lo, bem como participação de áreas mais gerais de funcionamento cognitivo, como funções executivas (memória de trabalho, controle inibitório). 


\section{Domínios identificados em revisão de artigos}

(a) precursores de teoria da mente, onde se enquadram tarefas de identificação de conceitos de estados mentais, distinção entre estados físicos e mentais e reconhecimento de emoções (Flavell et al., 1999);

(b) falsas crenças, que envolvem tarefas de conteúdo incoerente para verificação de crenças das personagens (Howlin, Baron-Cohen \& Hadwin, 2006)

(c) identificação contexto social, a partir de pistas visuais, que envolvem tarefas de compreensão de cenas sociais, a partir de rastreio de pistas visuais no ambiente (Klin, 2000).

Validação de Bateria de Teoria da Mente para diagnóstico de TEA

Instrumento composto por tarefas de teoria da mente e tarefas controle (controle cognitivo)

Tarefa 1-(Controle) Nomeação de Objetos

> Tarefa 2-(ToM)-Nomeação de emoções

- Tarefa 3-(ToM)- Gradação de emoções

- Tarefa 4- (Controle)-Go NO Go (controle inibitório)

> Tarefa 5-(ToM)-Identificação de estados mentais

> Tarefa 6- (controle)- Organização Lógica (sequência visual)

> Tarefa 7-(ToM)- Organização Lógica com Inferência 


\section{Tarefa 1-Nomeação}

> Instrução: "Diga o nome destas figuras" - apresentar uma figura por vez.
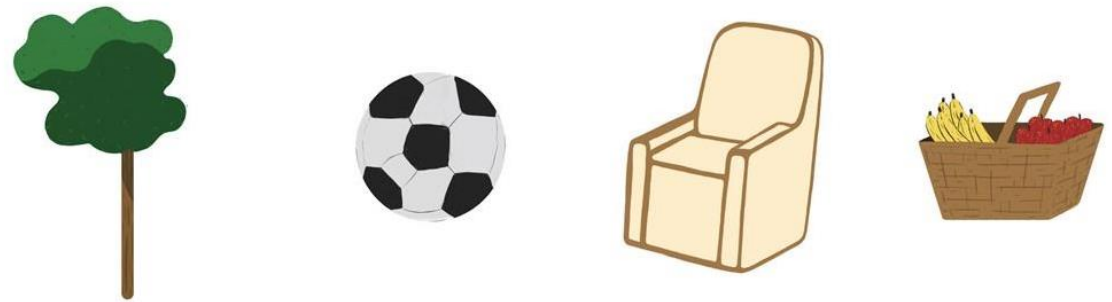

\section{Correção}

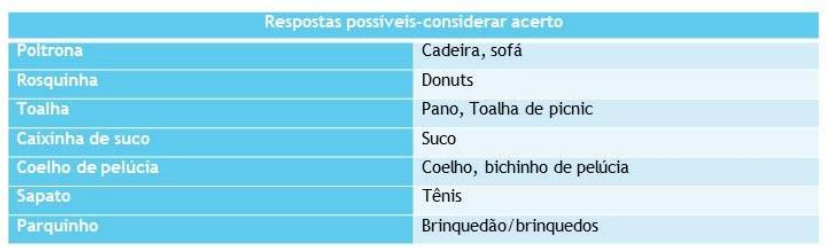

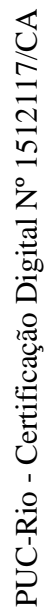
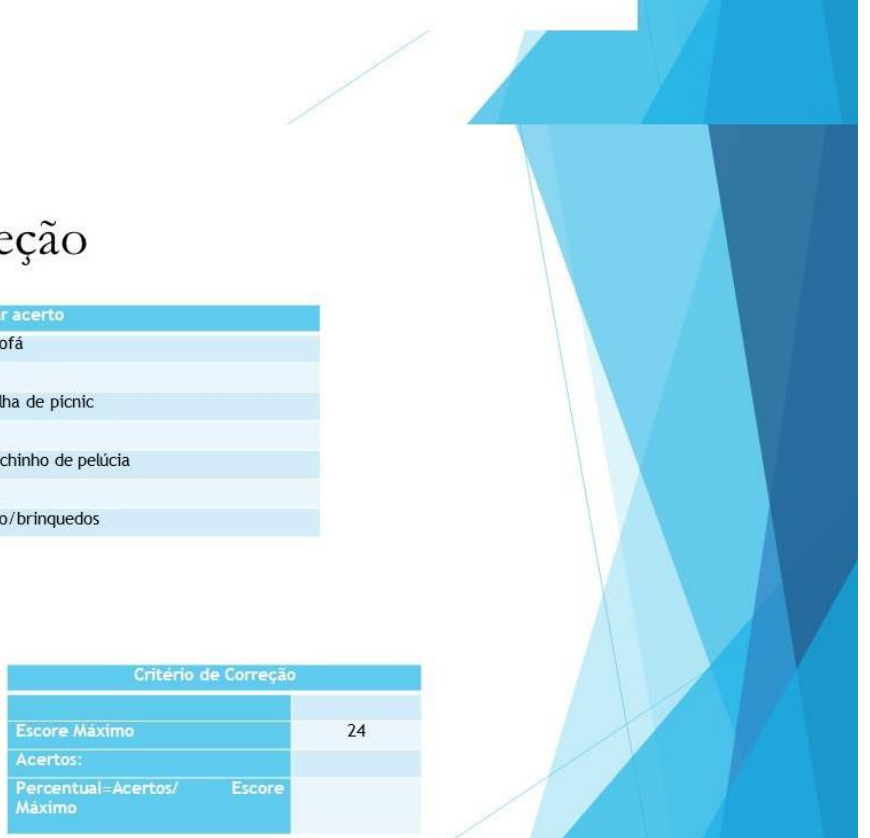
Tarefa 2-Nomeação de emoções

\section{Tarefa 2 - Nomeação de Emoções}

PARTE 1

Apresentar a carta do rosto feliz (número 3) e dizer: "Qual o nome dessa emoção?"

$\square$ Feliz

¿ Outro:

Apresentar a carta do rosto triste (número 3) e dizer: "Qual o nome dessa emoção?"

$\square$ Triste

- Outro:

Apresentar a carta do rosto com medo (número 3) e dizer: "Qual o nome dessa emoção?" ¿ Medo

$\square$ Outro:

Apresentar a carta do rosto com raiva e (número 3) e dizer: "Qual o nome dessa emoção?"

$\square$ Outro:

$$
\square \text { Raiva }
$$

\section{Correção}

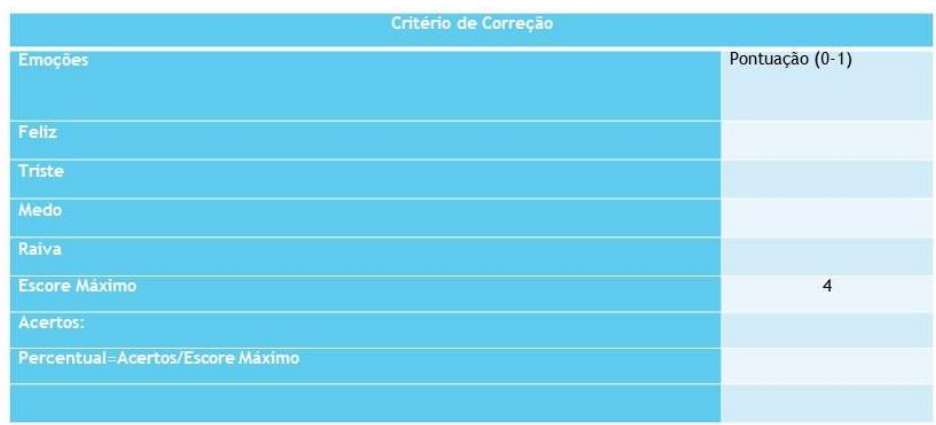


Tarefa 2-gradação de emoções

$\triangle$ Dar as 3 cartas da emoção FELIZ, NA ORDEM ESPECIFICADA NO VERSO DA CARTA e solicitar: "Coloque da menos para mais, ou seja, da menos feliz para a mais feliz" Ordem quea criança colocou:

$\triangle$ Dar as 3 cartas da emoção TRISTE, NA ORDEM ESPECIFICADA NO VERSO DA CARTA e solicitar "Coloque do menos para mais, ou seja, da menos triste para a mais triste" Ordem quea criança colocou:

\Dar as 3 cartas da emoção MEDO, NA ORDEM ESPECCFICADA NO VERSO DA CARTA e solictar: "COloque da menos pra mais, ou seja, da menos medo para a mais medo" Ordem quea criança colocou:

Q Dar as 3 cartas da emoção RAVI, NA ORDEM ESPECCFICADA NO VERSO DA CARTA e solictar: "COloque da menos pra mais, ou seja, da menos raiva para a mais raiva" Ordem que a criança colocou:

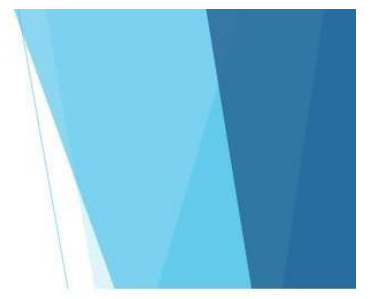

\section{Correção}

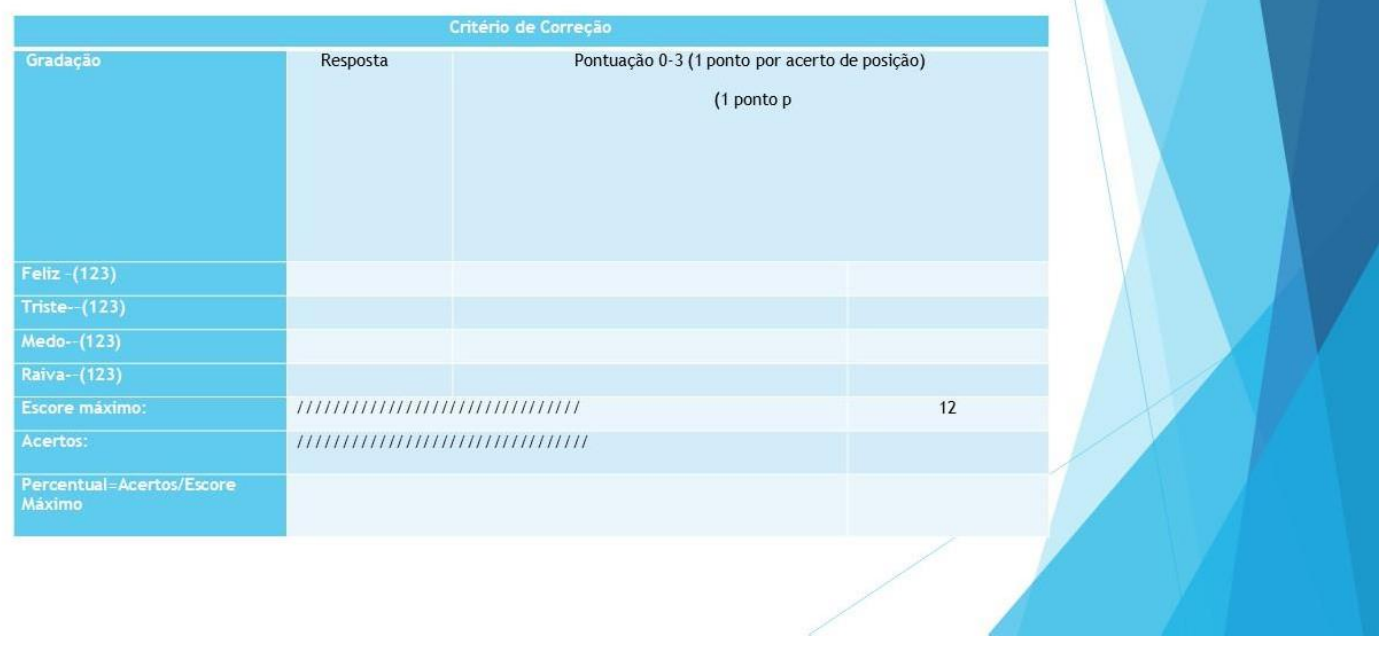




\section{Tarefa 3-Go NO Go}

Instrução: Vou te mostrar várias vezes as personagens, bata na mesa toda vez que os personagens aparecerem, mas não bata na mesa quando o Dani (cartão vermelho) aparecer (mostrar o cartão para a criança)"

"Mantenha a mão perto do ombro e depois que você bater, retorne com ela para o ombro"
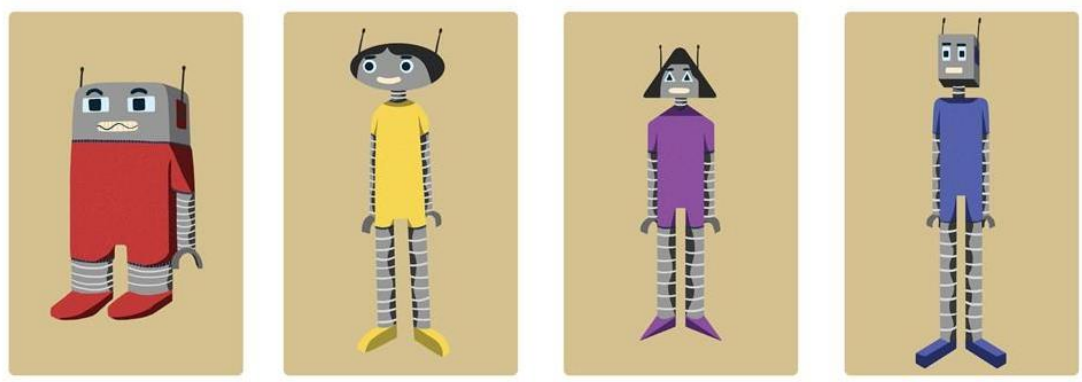

Tarefa 4- Identificação de Estados Mentais Apresentar e perguntar:

Em caso de erro na pergunta controle: dar a resposta correta

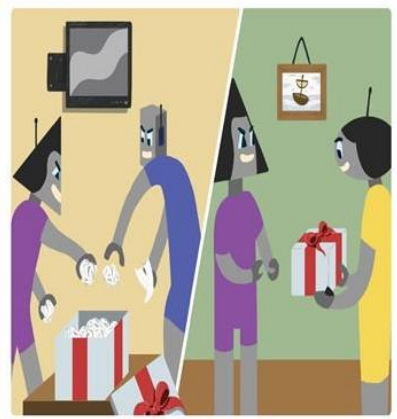

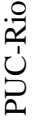


Tarefa 4-Critério de Correção

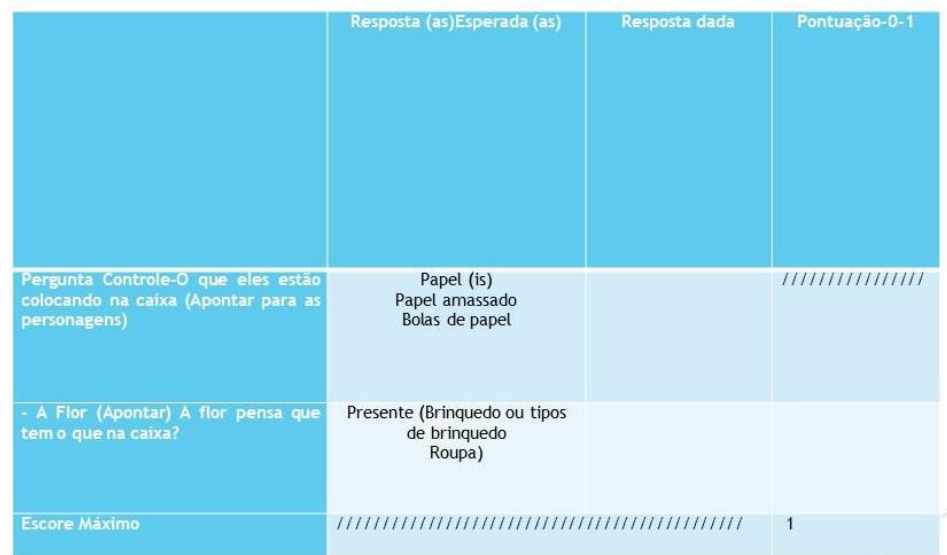

Tarefa 5- Organização Lógica Simples

U

- Apresentar cada história seguindo a ordem NUMÉRICA, no verso da carta. Anotar cada resposta seguindo a ordem de LETRAS.

- Solicitar, após apresentar as histórias em ordem numérica da esquerda para direita (posição do avaliando): “Agora coloque na ordem certa"
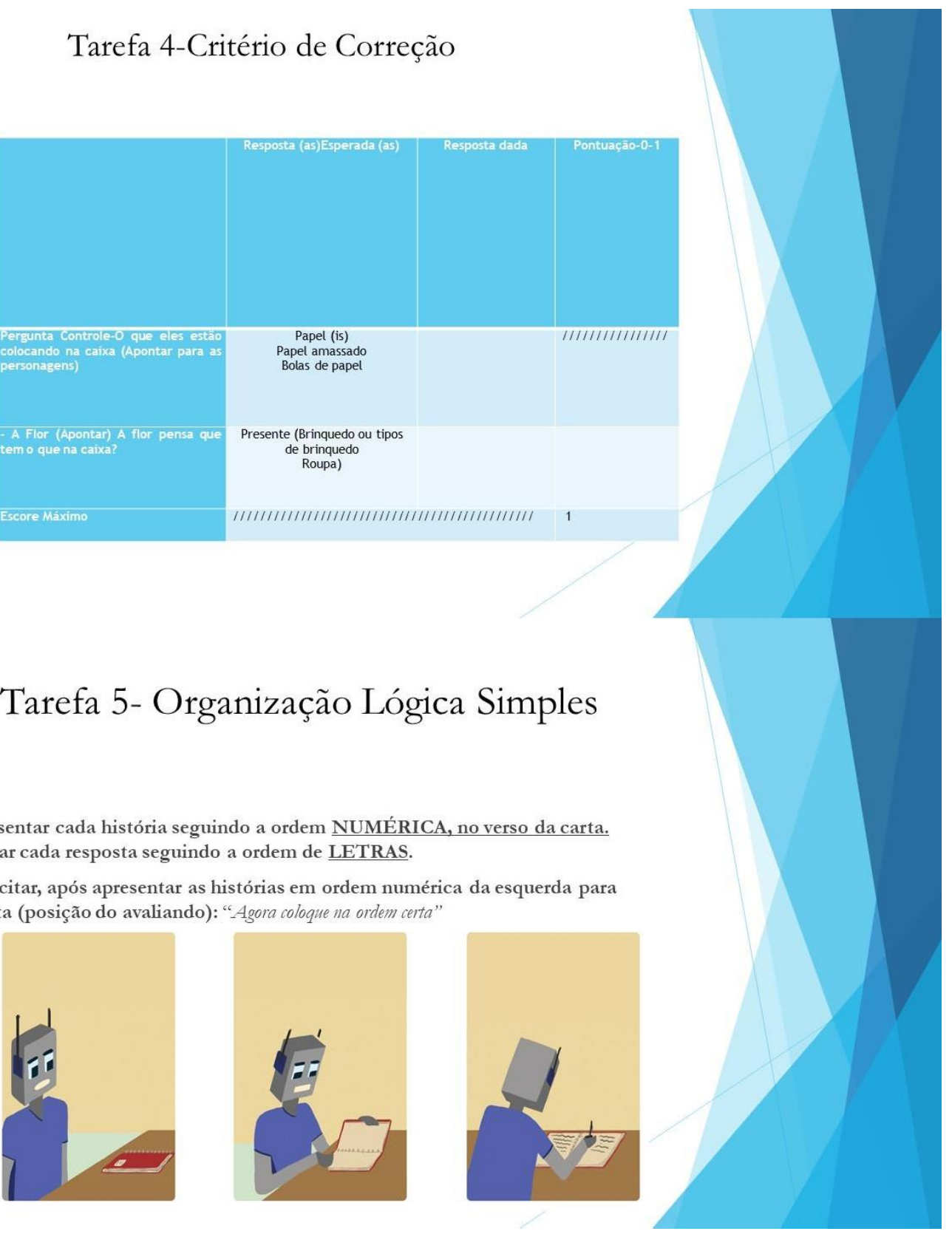


\section{Correção}

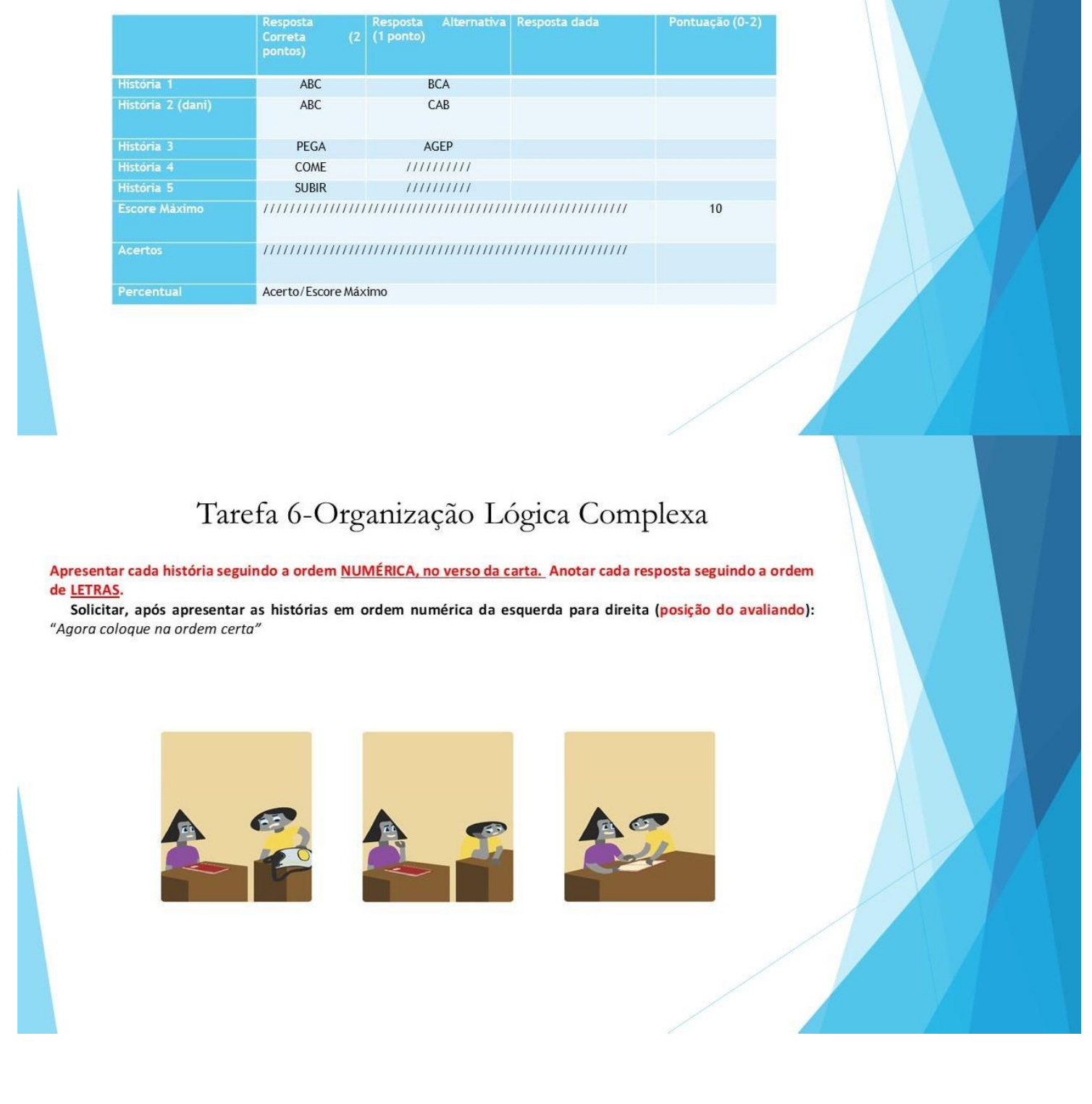




\section{Correção}

\begin{tabular}{|c|c|c|c|c|}
\hline & \begin{tabular}{|l|} 
Resposta \\
Correta \\
pontos)
\end{tabular} & $\begin{array}{l}\text { Resposta Alternativa } \\
\text { (1 ponto) }\end{array}$ & Resposta dada & Pontuaça $(0-2)$ \\
\hline Histöria 1 & MIG & IMG & & \\
\hline Histónia 2 & RUN & & & \\
\hline Histónia 3 & AJUD & & & \\
\hline História 4 & JOKE & EJOK & & \\
\hline História 5 & RAIVA & RAVAIA/ RAIAV & & \\
\hline Escore Máximo & \multicolumn{3}{|c|}{ 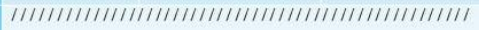 } & 10 \\
\hline Acertos & \multicolumn{3}{|c|}{ 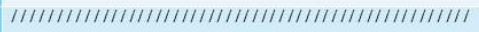 } & \\
\hline Percentual & \multicolumn{3}{|c|}{ Acerto/Escore Máximo } & \\
\hline
\end{tabular}

\section{Correção Narrativa}

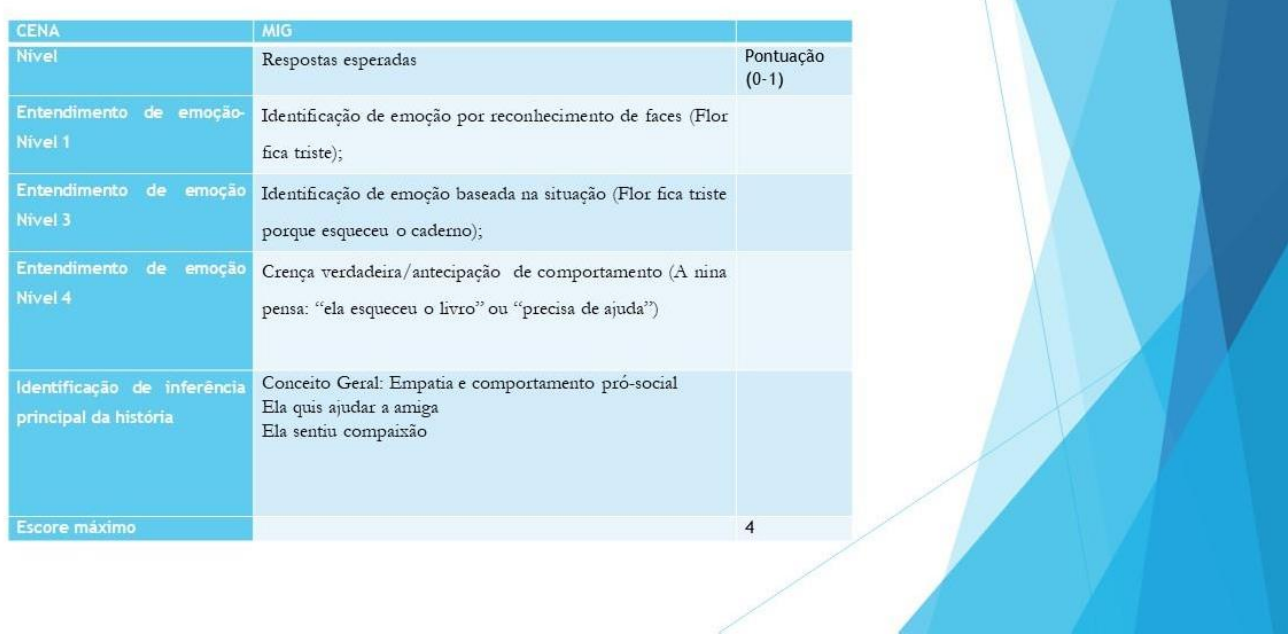


Nome:

APÊNDICE E- Folha de Registro e apuração de BToM

Idade:

Data de Nascimento:

Instituição:

Data de Aplicação:

Apresentar os personagens:

Instrução: "Temos 4 personagens. Eles são robôs e se chamam Dani, Tony, Nina e Flor. O Dani é meio ingênuo, um pouco desligado. O Tony é o líder da turma, às vezes faz muita bagunça. A Nina é a mais esperta das meninas e gosta de estar sempre com os meninos. A Flor é meiga e carinhosa. Eles frequentam juntos a escola, e o parquinho pra brincar".

\section{Tarefa 1 - Nomeação de Objetos.}

Instrução: "Diga o nome destas figuras" - apresentar uma figura por vez.

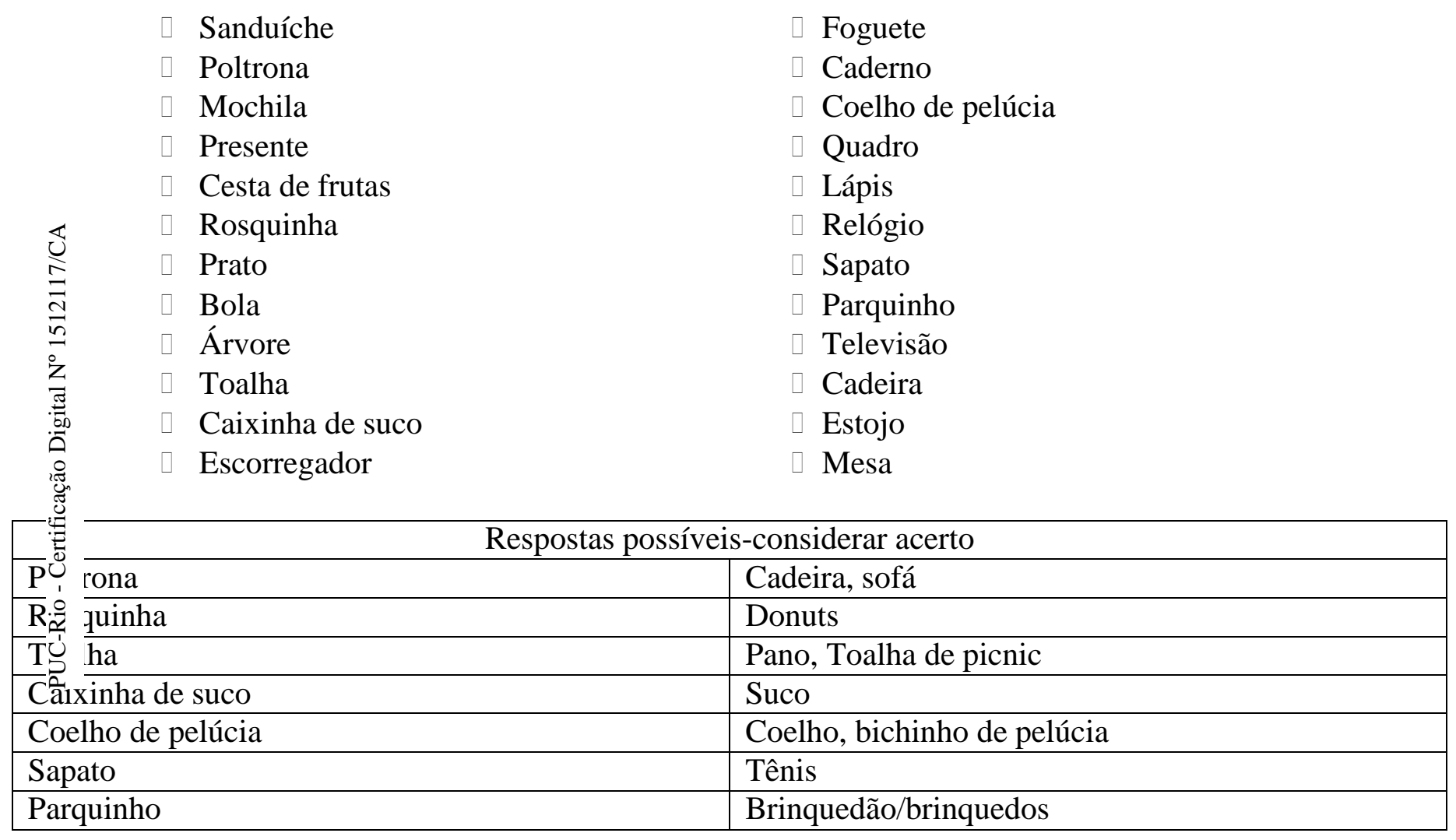

\begin{tabular}{|l|c|}
\hline \multicolumn{2}{|c|}{ Critério de Correção } \\
\hline \multicolumn{2}{|c|}{} \\
\hline Escore Máximo & 24 \\
\hline Acertos: \\
\hline $\begin{array}{l}\text { Percentual=Acertos/ Escore } \\
\text { Máximo }\end{array}$ \\
\hline
\end{tabular}


Tarefa 2 - Nomeação de Emoções

PARTE 1

Apresentar a carta do rosto feliz (número 3) e dizer: "Qual o nome dessa emoção?"

$\Upsilon$ Feliz

Outro:

Apresentar a carta do rosto triste (número 3) e dizer: "Qual o nome dessa emoção?"
$\Upsilon$ Triste
Outro:

Apresentar a carta do rosto com medo (número 3) e dizer: "Qual o nome dessa emoção?"

$\Upsilon$ Medo

Outro:

Apresentar a carta do rosto com raiva e (número 3) e dizer: "Qual o nome dessa emoção?"

$\Upsilon$ Raiva

Outro:

\begin{tabular}{|l|c|}
\hline \multicolumn{2}{|c|}{ Critério de Correção } \\
\hline Emoções & Pontuação (0-1) \\
\hline Feliz & \\
\hline Triste & \\
\hline Medo & \\
\hline Raiva & 4 \\
\hline Escore Máximo & \\
\hline Acertos: & \\
\hline Percentual=Acertos/Escore Máximo & \\
\hline & \\
\hline
\end{tabular}

P蛋 RTE 2-Gradação de Emoções

$\rightarrow$ Dar as 3 cartas da emoção FELIZ, NA ORDEM ESPECIFICADA NO VERSO DA CARTA e solicitar: "Coloque da menos para mais, ou seja, da menos feliz para a mais feliz"

Ordem que a criança colocou:

$\rightarrow \quad$ Dar as 3 cartas da emoção TRISTE, NA ORDEM ESPECIFICADA NO VERSO DA CARTA e solicitar "Coloque da menos para mais, ou seja, da menos triste para a mais triste"

Ordem que a criança colocou:

$\rightarrow$ Dar as 3 cartas da emoção MEDO, NA ORDEM ESPECIFICADA NO VERSO DA CARTA e solicitar: "Coloque da menos pra mais, ou seja, da menos medo para a mais medo"

Ordem que a criança colocou:

$\rightarrow$ Dar as 3 cartas da emoção RAIVA, NA ORDEM ESPECIFICADA NO VERSO DA CARTA e solicitar: "Coloque da menos pra mais, ou seja, da menos raiva para a mais raiva"

Ordem que a criança colocou:

Gradação

Feliz - (123)

\section{Critério de Correção}

Resposta Pontuação 0-3 (1 ponto por acerto de posição) 
Triste--(123)

Medo--(123)

Raiva--(123)

Escore máximo:

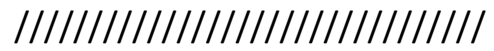

Acertos:

Percentual=Acertos/Escore

\section{Tarefa 3 - Go/No-go}

Instrução: Vou te mostrar várias vezes as personagens, bata na mesa toda vez que os personagens aparecerem, mas não bata na mesa quando o Dani (cartão vermelho) aparecer (mostrar o cartão para a criança)"

"Mantenha a mão perto do ombro e depois que você bater, retorne com ela para o ombro"

Quantidade de erros:

Tipo de erro:

\section{Critério de Correção}

Escore Máximo

Acertos (Total acertos):

Percentual=Acertos/ Escore

Máximo

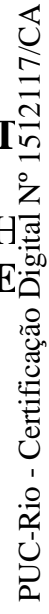

efa 4 - Identificação de estados mentais

TÓRIA 1: Apresentar e perguntar:

$\mathrm{E}_{\tilde{\theta}}^{. \overline{0}}$ caso de erro na pergunta controle: dar a resposta correta

\begin{tabular}{|c|c|c|c|}
\hline & \begin{tabular}{|r} 
Resposta \\
(as)Esperada (as)
\end{tabular} & Resposta dada & $\begin{array}{l}\text { Pontuação-O- } \\
1\end{array}$ \\
\hline $\begin{array}{l}\text { Pergunta Controle-Para } \\
\text { onde o Dani tá olhando? } \\
\text { (Apontar o Dani) }\end{array}$ & $\begin{array}{c}\text { Para a comida } \\
\text { Para as meninas no } \\
\text { picnic }\end{array}$ & & |/IIIIIIIIIIIIIII \\
\hline $\begin{array}{l}\text { - A Flor (Apontar) sabe que } \\
\text { o Dani está olhando pra } \\
\text { elas? }\end{array}$ & Não & & \\
\hline $\begin{array}{l}\text { - A Nina (Apontar) sabe que } \\
\text { o Dani está olhando para } \\
\text { elas? }\end{array}$ & Sim & & \\
\hline Escore Máximo & \multicolumn{2}{|c|}{ 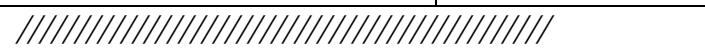 } & 2 \\
\hline
\end{tabular}

HISTÓRIA 2: Apresentar e perguntar:

Em caso de erro na pergunta controle: dar a resposta correta 


\begin{tabular}{|l|c|c|c|}
\hline & $\begin{array}{c}\text { Resposta(as)Esperada } \\
\text { (as) }\end{array}$ & Resposta dada & $\begin{array}{c}\text { Pontuação-0- } \\
\text { I }\end{array}$ \\
\hline $\begin{array}{l}\text { Pergunta controle-o que eles } \\
\text { estão colocando na caixa } \\
\text { (Apontar para as } \\
\text { personagens) }\end{array}$ & $\begin{array}{c}\text { Papel (is) } \\
\text { Papel amassado }\end{array}$ & & Bolas de papel \\
\hline $\begin{array}{l}\text { - A Flor (Apontar) A flor } \\
\text { pensa que tem o que na } \\
\text { caixa? }\end{array}$ & $\begin{array}{c}\text { Presente (Brinquedo ou } \\
\text { tipos de brinquedo } \\
\text { Roupa) }\end{array}$ & & \\
\hline Escore Máximo & & & \\
\hline
\end{tabular}

HISTÓRIA 3: Apresentar e perguntar:

Em caso de erro na pergunta controle: dar a resposta correta (Esta cena tem 2 perguntas controle-2 etapas)

\begin{tabular}{|c|c|c|c|}
\hline & $\begin{array}{c}\text { Resposta (as)Esperada } \\
(\text { as })\end{array}$ & Resposta dada & $\begin{array}{l}\text { Pontuação- } \\
0-1\end{array}$ \\
\hline $\begin{array}{l}\text { Perguntas Controles- } \\
\text { 1-O que Tony está fazendo } \\
\text { nessa cena (apontar para o } \\
\text { Tony na primeira etapa da } \\
\text { cena) } \\
2-O \text { que Tony está fazendo } \\
\text { nessa cena (apontar para o } \\
\text { Tony na primeira etapa da } \\
\text { cena) }\end{array}$ & $\begin{array}{l}\text { 1-Está tirando o } \\
\text { sanduíche da mochila } \\
\text { (Do Dani) } \\
\text { 2-Está colocando na } \\
\text { outra mochila (Flor) }\end{array}$ & & |||||||||||||||||| \\
\hline $\begin{array}{l}\text { Onde o Dani vai procurar o } \\
\text { sanduiche pra lanchar? }\end{array}$ & Na mochila dele & & \\
\hline $\begin{array}{l}\text { A flor sabe que o sanduíche } \\
\text { está na mochila dela? }\end{array}$ & Não & & \\
\hline Escore Máximo & "IIIIIIIIIIIIIIIIIIIIIIIIIIIIIIIIIIIIIII & & 2 \\
\hline
\end{tabular}

\begin{tabular}{|l|c|}
\hline \multicolumn{2}{|c|}{ Critério de Correção } \\
\hline Escore Máximo & 5 \\
\hline Acertos: & \\
\hline $\begin{array}{l}\text { Percentual=Acertos/ Escore } \\
\text { Máximo }\end{array}$ & \\
\hline
\end{tabular}

Tarefa 5 - Organização Lógica simples

Apresentar cada história seguindo a ordem NUMÉRICA, no verso da carta. Anotar cada resposta seguindo a ordem de LETRAS. 
Solicitar, após apresentar as histórias em ordem numérica da esquerda para direita (posição do avaliando): "Agora coloque na ordem certa"

\begin{tabular}{|c|c|c|c|c|}
\hline & $\begin{array}{l}\text { Resposta } \\
\text { Correta ( } 2 \\
\text { pontos) }\end{array}$ & $\begin{array}{l}\text { Resposta } \\
\text { Alternativa } \\
\text { ponto) }\end{array}$ & Resposta dada & $\begin{array}{c}\text { Pontuação } \\
(0-2)\end{array}$ \\
\hline História 1 & $\mathrm{ABC}$ & $\mathrm{BCA}$ & & \\
\hline $\begin{array}{l}\text { História } \\
\text { (dani) }\end{array}$ & $\mathrm{ABC}$ & $\mathrm{CAB}$ & & \\
\hline História 3 & PEGA & AGEP & & \\
\hline História 4 & COME & ////////// & & \\
\hline História 5 & SUBIR & $\mid / / / / / / / / /$ & & \\
\hline $\begin{array}{l}\text { Escore } \\
\text { Máximo }\end{array}$ & \multicolumn{3}{|c|}{ 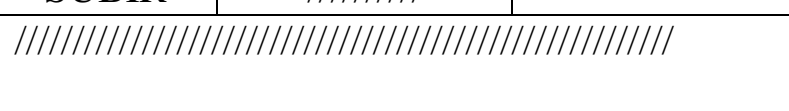 } & 10 \\
\hline Acertos & \multicolumn{3}{|c|}{ 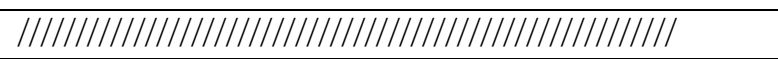 } & \\
\hline Percentual & \multicolumn{3}{|c|}{ Acerto/Escore Máximo } & \\
\hline
\end{tabular}

\section{Tarefa 6 - Organização Lógica Complexa}

Apresentar cada história seguindo a ordem NUMÉRICA, no verso da carta. Anotar cada resposta sr lindo a ordem de LETRAS.

$\varangle$ olicitar, após apresentar as histórias em ordem numérica da esquerda para direita (posição do

a iando): "Agora coloque na ordem certa"

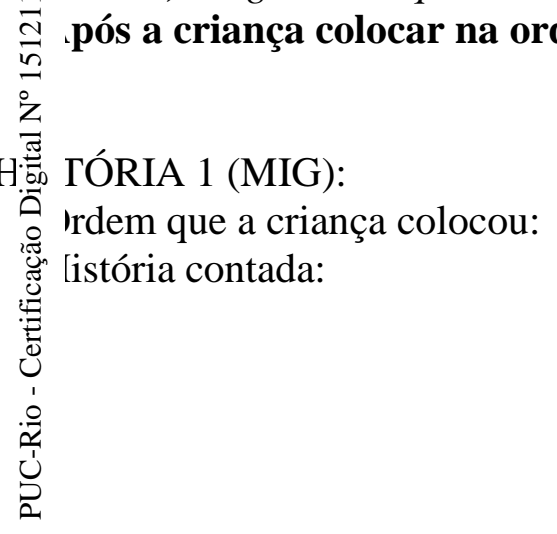

\section{HISTÓRIA 2 ( RUN ):}

Ordem que a criança colocou:

História contada:

HISTÓRIA 3 ( AJUD):

Ordem que a criança colocou:

História contada: 
HISTÓRIA 4 (JOKE):

Ordem que a criança colocou:

História contada:

HISTÓRIA 5 (RAIVA):

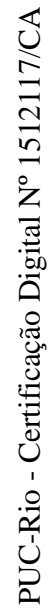


Ordem que a criança colocou:

História contada:

\section{Pontuação da etapa 1-Organização Lógica}

\begin{tabular}{|c|c|c|c|c|}
\hline & $\begin{array}{l}\text { Resposta } \\
\text { Correta ( } 2 \\
\text { pontos) }\end{array}$ & $\begin{array}{l}\text { Resposta } \\
\text { Alternativa } \\
\text { ponto) }\end{array}$ & Resposta dada & $\begin{array}{c}\text { Pontuação } \\
(0-2)\end{array}$ \\
\hline História 1 & MIG & IMG & & \\
\hline História 2 & RUN & & & \\
\hline História 3 & AJUD & & & \\
\hline História 4 & JOKE & EJOK & & \\
\hline História 5 & RAIVA & $\begin{array}{l}\text { RAVAIA/ } \\
\text { RAIAV }\end{array}$ & & \\
\hline $\begin{array}{l}\text { Escore } \\
\text { Máximo }\end{array}$ & \multicolumn{3}{|c|}{ 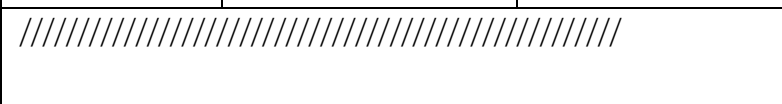 } & 10 \\
\hline Acertos & \multicolumn{3}{|c|}{ I/IIIIIIIIIIIIIIIIIIIIIIIIIIIIIIIIIIIIIIIIIIIIIIIIIIIII } & \\
\hline Percentual & \multicolumn{3}{|c|}{ Acerto/Escore Máximo } & \\
\hline
\end{tabular}

\section{Gabarito de respostas-Verbalizações}

\begin{tabular}{|c|c|c|}
\hline CENA & MIG & \\
\hline Nível & Respostas esperadas & $\begin{array}{l}\text { Pontuação } \\
(0-1)\end{array}$ \\
\hline $\begin{array}{l}\text { Entendimento } \quad \text { de } \\
\text { emoção-Nível } 1\end{array}$ & $\begin{array}{l}\text { Identificação de emoção por reconhecimento de } \\
\text { faces (Flor fica triste); }\end{array}$ & \\
\hline $\begin{array}{l}\text { Entendimento } \quad \text { de } \\
\text { emoção Nível } 3\end{array}$ & $\begin{array}{l}\text { Identificação de emoção baseada na situação } \\
\text { (Flor fica triste porque esqueceu o caderno); }\end{array}$ & \\
\hline $\begin{array}{l}\text { Entendimento } \quad \text { de } \\
\text { emoção Nível } 4\end{array}$ & $\begin{array}{l}\text { Crença verdadeira/antecipação } \\
\text { comportamento (A nina pensa: "ela esqueceu o } \\
\text { livro" ou "precisa de ajuda") }\end{array}$ & \\
\hline $\begin{array}{ll}\text { Identificação } & \text { de } \\
\text { inferência principal } & \text { da }\end{array}$ & $\begin{array}{l}\text { Conceito Geral: empatia, comportamento pró- } \\
\text { social: }\end{array}$ & \\
\hline
\end{tabular}




\begin{tabular}{|l|l|l|}
\hline história & $\begin{array}{l}\text { Ela quis ajudar a amiga. } \\
\text { Ela sentiu compaixão pela colega/amiga }\end{array}$ & \\
\hline Escore máximo & & 4 \\
\hline
\end{tabular}

\begin{tabular}{|c|c|c|}
\hline CENA & RUN & \\
\hline Nível & Respostas esperadas & $\begin{array}{l}\text { Pontuação } \\
(0-1)\end{array}$ \\
\hline $\begin{array}{ll}\text { Entendimento } & \text { de } \\
\text { emoção-Nível } 1 & \end{array}$ & $\begin{array}{l}\text { Identificação de emoção por reconhecimento de } \\
\text { faces } \quad \text { (Nina } \quad \text { (ELA) fica com } \\
\text { raiva/brava/chateada); }\end{array}$ & \\
\hline $\begin{array}{ll}\text { Entendimento } & \text { de } \\
\text { emoção Nível } 3 & \end{array}$ & $\begin{array}{l}\text { Identificação de emoção baseada na situação } \\
\text { (Nina (ELA) fica brava porque ele chegou na } \\
\text { frente dela ou Nina (ELA) fica com raiva dele } \\
\text { porque ele chegou primeiro) ou ela ficou com } \\
\text { raiva por que ele chegou; ela ficou brava porque } \\
\text { perdeu) }\end{array}$ & \\
\hline $\begin{array}{ll}\text { Entendimento } & \text { de } \\
\text { emoção Nível } 4 & \end{array}$ & $\begin{array}{l}\text { Identificação baseada no desejo } \\
\text { Ela ficou com raiva porque queria ganhar }\end{array}$ & \\
\hline $\begin{array}{ll}\text { Identificação } & \text { de } \\
\text { inferência principal } & \text { da } \\
\text { história } & \end{array}$ & $\begin{array}{l}\text { Conceito Geral: Havia uma disputa } \\
\text { Eles estavam apostando corrida } \\
\text { Estavam correndo para ver quem chega primeito } \\
\text { Estavam competindo }\end{array}$ & \\
\hline Escore máximo & & 4 \\
\hline
\end{tabular}




\begin{tabular}{|c|c|c|}
\hline CENA & AJUD & \\
\hline Nível & Respostas esperadas & $\begin{array}{l}\text { Pontuação } \\
(0-1)\end{array}$ \\
\hline $\begin{array}{ll}\text { Entendimento } & \text { de } \\
\text { emoção-Nível 1 } & \end{array}$ & $\begin{array}{l}\text { Identificação de emoção por reconhecimento de } \\
\text { faces (Flor (ELA) ficou feliz); }\end{array}$ & \\
\hline $\begin{array}{l}\text { Entendimento } \quad \text { de } \\
\text { emoção Nível } 3\end{array}$ & $\begin{array}{l}\text { Identificação de emoção baseada na situação } \\
\text { (Flor (ELA) ficou feliz porque ele achou o } \\
\text { coelhinho, Flor (ELA) ficou feliz porque ele deu } \\
\text { o coelhinho pata ela) } \\
\text { Entendimento de crença-Nível } 4 \\
\text { Crença verdadeira/antecipação de } \\
\text { comportamento (ela não está achando, vai } \\
\text { precisar de ajuda) }\end{array}$ & \\
\hline $\begin{array}{l}\text { Entendimento } \\
\text { crença-Nível } 2\end{array}$ & $\begin{array}{l}\text { Tomada de perspectiva complexa (ele viu que ela } \\
\text { estava procurando um objeto e precisando de } \\
\text { ajuda) }\end{array}$ & \\
\hline $\begin{array}{ll}\text { Identificação } & \text { de } \\
\text { inferência principal } & \text { da } \\
\text { história } & \end{array}$ & $\begin{array}{l}\text { Conceito Geral: Atitude prossocial (altruísta) } \\
\text { Ele viu que ela estava procurando o coelhinho e } \\
\text { foi ajuda } \\
\text { Ele ajudou a procurar o coelhinho }\end{array}$ & \\
\hline Escore máximo & & 4 \\
\hline
\end{tabular}

\begin{tabular}{|c|c|c|}
\hline CENA & JOKE & \\
\hline Nível & Respostas esperadas & $\begin{array}{c}\text { Pontuação } \\
(0-1)\end{array}$ \\
\hline
\end{tabular}




\begin{tabular}{|c|c|}
\hline $\begin{array}{l}\text { Entendimento } \\
\text { de emoção- } \\
\text { Nível } 1\end{array}$ & $\begin{array}{l}\text { Identificação de emoção por reconhecimento de faces } \\
\text { O tony estava de deboche }\end{array}$ \\
\hline $\begin{array}{l}\text { Entendimento } \\
\text { de emoção- } \\
\text { Nível } 1\end{array}$ & $\begin{array}{l}\text { Identificação de emoção por reconhecimento de faces } \\
\text { O dani ficou confuso }\end{array}$ \\
\hline $\begin{array}{l}\text { Entendimento } \\
\text { de emoção- } \\
\text { Nível } 5\end{array}$ & $\begin{array}{c}\text { Emoções baseadas nas crenças } \\
\text { O Tony estava (Ele) estava com uma cara de } \\
\text { mal/estranha/de deboche porque teve uma ideia } \\
\text { O Tony (Ele) estava com uma cara de mal/estranha/de } \\
\text { deboche porque pensou em pegar o lápis } \\
\text { O Tony (Ele) estava com uma cara de mal/estranha/de } \\
\text { deboche porque pensou em enganar o amigo/dani/o de } \\
\text { vermelho }\end{array}$ \\
\hline $\begin{array}{l}\text { Entendimento } \\
\text { de crença } \\
\text { nível } 4\end{array}$ & $\begin{array}{l}\text { Crença verdadeira/antecipação de comportamento (O } \\
\text { tony vai fazer algo; ele está pensando em pegar o lápis; } \\
\text { ele está querendo enganar o amigo) }\end{array}$ \\
\hline $\begin{array}{l}\text { Entendimento } \\
\text { de crença- } \\
\text { Nível } 5\end{array}$ & $\begin{array}{c}\text { Falsa crença (predizer a ação da pensão em função } \\
\text { daquilo que ela falsamente acredita) } \\
\text { Ele vai procurar e cadê? } \\
\text { Ele foi procurar e não entendeu onde estava o lápis } \\
\text { Quando ele foi pegar o lápis na mesa, não viu o lápis } \\
\text { Ele olhou para mesa, mas achou que não estava } \\
\text { enxergando muito bem }\end{array}$ \\
\hline $\begin{array}{l}\text { Estabilização } \\
\text { da } \\
\text { identificação } \\
\text { da habilidade } \\
\text { de fingir }\end{array}$ & Tony pegou o lápis para fingir que ele tinha sumido \\
\hline $\begin{array}{l}\text { Identificação } \\
\text { de inferência }\end{array}$ & $\begin{array}{c}\text { Conceito Geral: Fazer uma brincadeira com um terceiro, } \\
\text { que envolve mudança de local do objeto }\end{array}$ \\
\hline
\end{tabular}




\begin{tabular}{|c|c|c|}
\hline $\begin{array}{c}\text { principal da } \\
\text { história }\end{array}$ & Eles queriam esconder o lápis dele & \\
& $\begin{array}{c}\text { Ele queria fazer bagunça, porque ele é muito levado } \\
\text { Ele queria enganar o amigo dele (Dani) }\end{array}$ & \\
\hline $\begin{array}{c}\text { Escore } \\
\text { máximo }\end{array}$ & & 8 \\
\hline
\end{tabular}

\begin{tabular}{|c|c|c|}
\hline CENA & Raiva & \\
\hline Nível & Respostas esperadas & $\begin{array}{l}\text { Pontuação } \\
(0-1)\end{array}$ \\
\hline $\begin{array}{l}\text { Entendimento de } \\
\text { emoção-Nível } 1\end{array}$ & $\begin{array}{l}\text { Identificação de emoção por reconhecimento de } \\
\text { faces (TONY (ele) ficou bravo); }\end{array}$ & \\
\hline $\begin{array}{l}\text { Entendimento de } \\
\text { emoção-Nível } 1\end{array}$ & $\begin{array}{l}\text { Identificação de emoção por reconhecimento de } \\
\text { faces (dani (ele) ficou bravo); }\end{array}$ & \\
\hline $\begin{array}{ll}\text { Entendimento } & \text { de } \\
\text { emoção Nível } 3 & \end{array}$ & $\begin{array}{l}\text { Identificação de emoção baseada na situação (eles } \\
\text { ficaram com raiva, porque elas pegaram a bola } \\
\text { deles) }\end{array}$ & \\
\hline $\begin{array}{l}\text { Entendimento } \\
\text { emoção Nível } 3\end{array}$ & $\begin{array}{l}\text { Identificação de emoção baseada na situação (eles } \\
\text { não gostaram de ficar sem jogar; eles ficaram } \\
\text { entendiados ao verem elas jogando) }\end{array}$ & \\
\hline $\begin{array}{l}\text { Entendimento de } \\
\text { crença-Nível } 2\end{array}$ & $\begin{array}{l}\text { Tomada de perspectiva complexa- como aparece } \\
\text { para eles (elas estavam olhando para bola para } \\
\text { brincar; elas estavam querendo brincar com a bola } \\
\text { deles; elas queriam brincar com a bola }\end{array}$ & \\
\hline $\begin{array}{l}\text { Identificação de } \\
\text { inferência principal } \\
\text { da história }\end{array}$ & $\begin{array}{l}\text { Conceito Geral 1: Elas queriam brincar com eles. } \\
\text { (1) } \\
\text { Elas pediram para brincar com eles } \\
\text { Elas queriam brincar com a bola deles } \\
\text { Conceito 2: Eles não queriam brincar com elas, elas }\end{array}$ & \\
\hline
\end{tabular}




\begin{tabular}{|l|l|l|}
\hline & não aceitaram. (2) & \\
Elas pegaram a bola deles para brincar & Elas tomaram a bola deles & \\
\hline Escore máximo & & 7 \\
\hline
\end{tabular}

\section{Total de acertos:}

\section{Tarefa 7 - Sally e Annie}

Resposta: 


\section{THE NORMAL \\ CHILD AS A MIND- \\ READER}

A "theory of mind" is defined as the ability to infer other people's mental states (their thoughts, beliefs, desires, intentions, etc), and the ability to use this information to interpret what they say, make sense of their behaviour and predict what they will do next. By the time toddlers start to speak it is clear that they talk about actions in terms of mental states. From as early as 18-30 months, normal children refer to

\section{THE NORMAL CHILD AS A MIND-READER}

a range of mental states: emotions, desires, beliefs, thoughts, dreams, pretence etc. ${ }^{11.12}$ By the age of 3-4 years, as experimental studies show, the child's theory of mind is well developed. Recent debates have, however, questioned whether this type of understanding is properly called a "theory". We do not discuss this issue here, but instead use the more neutral term of "mind-reading".

Dennett ${ }^{13}$ proposed that the "acid test" of whether a child is able to mind-reac arises in situations involving false belief. Thus, if the child knows the money is in the old china vase, but that Burglar Bill thinks it's in the desk drawer, if asked where Burglar Bill will look for the money the child should judge that he will look in the wrong place - the desk drawer. Using a false belief task, Wimmer and Perner ${ }^{14}$ showed that children of around 4 years of age were able to pass such a test. An adaptation of their procedure ${ }^{15}$ is illustrated in Figure 1.1.

As can be seen, the test involves appreciating that since Sally was absent when her marble was moved from its original location, she didn't see it being moved and so she won't know it was moved, and therefore must still believe it is in its original position. When asked: "Where will Sally look for her marble?" (i.e. a Belief Question) the vast majority of 4 year old children are able to answer correctly.

The ability to understand false beliefs is a complex one, because the child has to take into account Sally's belief in order to make the correct prediction about her behaviour. However, even at a much earlier stage normal children appear to be well aware that people have information in their heads - that is that they have informational states. An early sign of such understanding is seen in their ability to pass tests of visual perspective-taking. Two levels of visual perspective-taking can be identified. The first is called Level 1 - the abilify to infer what another person can see. This appears to be present even by 2 years of age. ${ }^{16}$ Thus, 2 year olds can put things out of or bring things into sight, when requested to do so. Level 2 visual perspective-taking is the ability to infer how the object appears to another person. This seems to take longer to develop. In fact it is not until 3-4 years of age that children reliably pass Level 2 tasks. For example, when shown a picture of a turtle which appears either right-side up or upside-down (depending on which side

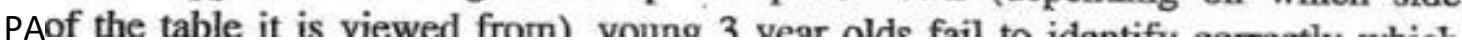


of these two perspectives the experimenter would have, when his or her perspective differs from that of the child.

A related achievement in the development of mind-reading is in children's understanding of the principle that "seeing-leads-to-knowing". For example, 3 year olds are easily able to indicate which of two people will know what is in a container, if one of them has looked into the container whilst the other has simply touched it. ${ }^{17}$ Such an ability demonstrates that even at this young age, children are aware of the importance of access to information in acquiring knowledge.

So much for tests of children's understanding of informational states. What about their understanding of desire and emotion? Desire is often thought to be the other key mental state, next to belief, in understanding others' behaviour. With beliefs and desires, all kinds of behaviour become interpretable. For example, in watching a movie and trying to understand why the protagonist tiptoes into his empty flat, we

\section{THE FIVE LEVELS OF EMOTIONAL UNDERSTANDING}

\section{Level 1. Recognition of facial expression from photographs}

This is the ability to recognise, from photographs, facial expressions such as happy, sad, angry, and afraid.

\section{Level 2. Recognition of emotion from schematic drawings}

This is scored if the child is able to identify the correct face from four facial cartoons: happy, sad, angry, and afraid, in the same way as above.

\section{Level 3. Identification of situation-based emotions}

These are emotions triggered by situations (e.g. fear when an accident is about to occur). At this level the child should be able to predict how a character will feel, given the obvious emotional content of the picture.

\section{Level 4. Desire-based emotions}

These are emotions caused by a person's desire being fulfilled or unfulfilled. At this level the child should be able to identify a character's feelings (either happy or sad) according to whether his or her wishes are fulfilled or not.

\section{Level 5. Belief-based emotions}

These are emotions caused by what someone thinks is the çase, even if what they think conflicts with reality. The child is required to follow a sequence of three pictures and to interpret the feeling that cartoon characters will experience according to whether they believe their desires have been satisfied or not.

The following sections describe how to assess and teach at each of these levels. 


\section{THE FIVE LEVELS OF INFORMATIONAL STATE UNDERSTANDING}

\section{Level 1. Simple visual perspective taking}

This is the understanding that different people can see different things. At this level the child can judge what you (the teacher) can see or not see.

\section{Level 2. Complex visual perspective taking}

This involves understanding not only what people see but how it appears to them. This level requires the child to judge both what another person can see and HOW it appears to that person.

\section{Level 3. Understanding the principle that "seeing leads to knowing"}

This is the ability to understand that people only know things that they have experienced (directly or indirectly). In this teaching programme, we simplify this level by only assessing the link between SEEING and KNOWING, though of course there are also links between HEARING or FEELING and KNOWING.

\section{Level 4. Predicting actions on the basis of a person's knowledge}

This tests the child's understanding of True Belief. Here, children are required to predict a person's actions on the basis of where that person believes an object to be.

\section{Level 5. Understanding false beliefs}

This level assesses the child's ability to understand False Belief, the standard approach to theory of mind reasoning. Here children are required to predict a person's actions on the basis of where that person falsely believes an object to be. 